\title{
Fisheries escape, temperature, and infectious agents: multiple stressors impacting wild sockeye salmon spawning migrations
}

\author{
by \\ Laura K. Elmer \\ B.Sc., University of Manchester, 2016
}

A thesis submitted to the Faculty of Graduate and Post Doctoral Affairs in partial fulfillment of the requirements for the degree of

\author{
DOCTOR OF PHILOSOPHY \\ in \\ Biology \\ CARLETON UNIVERSITY \\ Ottawa, Ontario
}

(c) 2020

Laura K. Elmer 


\section{Abstract}

Across the globe animals that engage in migration are exposed to many threats. This is exemplified by the decline of Pacific salmon populations. Understanding causes behind declines of migratory Pacific salmon populations will help mitigate the threats these fish face during their iconic migrations. Spawning migrations return adult salmon from ocean feeding grounds to natal freshwater habitats to spawn and complete their lifecycle. These spawning migrations are naturally challenging, but due to human activity salmon are now also forced to navigate a gauntlet of fishing gears and dams, all while water temperatures are rising. This thesis aims to investigate how fishing gear escape, water temperature, and infectious agents affect a population of Fraser River sockeye salmon (Oncorhynchus nerka) during their spawning migration.

Approximately half of all fish that experienced a simulated gillnet entanglement were capable of volitional escape, suggesting gear escape is a frequent event for in-river fisheries. Despite finding no impact of fisheries escape on migration or spawning success, I did find novel evidence of behavioural thermoregulation following escape. High water temperatures confounded results of fisheries interactions due to exceptionally high mortality. During a year of warm river temperatures, fish showed increased expression of thermal stress biomarkers, dramatically reduced survival, and differences in infectious agent profiles compared with a cooler year. Infectious agent profiles were also analyzed in fish that perished below a dam, and differences in certain infectious agent prevalence and loads were found when compared with live fish, suggesting a possible involvement of infectious agents in en-route mortality. Behavioural thermoregulation was also observed in fish with higher overall infectious agent burden.

This thesis adds further evidence demonstrating the severe consequences of high water temperatures for Pacific salmon. In an era of warming waters, thermal selection may be an increasingly important behaviour to improve survival and spawning success. I also demonstrate that escape from fishing gear can be a common occurrence that is currently unaccounted for in escapement estimates. Fisheries managers should consider incorporating gear escape consequences in escapement estimate models, and protecting thermal refuges along migration corridors, to help protect Pacific salmon populations. 


\section{Acknowledgements}

I have so many people to acknowledge and to thank, and for that itself I am incredibly grateful. First and foremost, to my supervisors, Dr Steven Cooke and Dr Scott Hinch, for their exceptional guidance, advice, and support. I am very fortunate to have been supervised by two accomplished researchers at the forefront of Pacific salmon and fisheries research. I am also incredibly fortunate to be supported by two dynamic and talented groups, both the Fish Ecology and Conservation Physiology Lab (FECPL) and the Pacific Salmon Ecology and Conservation (PSEC) lab. Thanks to Vivian Nguyen, Jacqueline Chapman, Lisa Kelly, and Andrea Reid from FECPL. Thanks to David Moulton, Steve Johnstone, Bill Harrower, Byron Hendricks, Adam Kanigan, Nolan Bett, Amy Teffer, and, of course, Andrew Lotto from the PSEC lab. Finally, big thanks to Art Bass for so much help with study design, statistical analyses, and analyzing results!

This work was made possible thanks to the help of Fisheries and Oceans Canada. From DFO eWatch I have David Patterson, Kendra Robinson, and Steve Healy, to thank for their help in the field and with sample collection. From Stock Assessment I have John Bylenga, Dennis Klassen, Brian Leaf, and Tim Pankratz to thank for their help collecting carcasses and tags at Gates Creek. I also had the incredible privilege of joining Dr Kristi Miller and her team at the Molecular Genetics Lab, Pacific Biological Station. This lab performs incredibly valuable research and has developed such impressive technology and laboratory procedures. I have Karia Kaukinen, Angela Shulze, Shaorong Li, Tobi Ming, Amy Tabata, Arash Akbarzadeh, and Aimee-Lee Houde to thank for the time, teaching, and patience with all my questions.

Special thanks and recognition go to St'át'imc First Nation and N'Quatqua First Nation. Thank you to St'át'imc EcoResources - this work would not be possible without you. In particular, Bonnie Adolph, Avaleen Adolph, Roxx Ledoux, Rebecca Riley, and Wes Payne, who all worked tirelessly and taught me so much about the land and the salmon where I was privileged to work. From the N'Quatqua Fisheries I would also like to acknowledge and thank Harry O'Donaghey, Leo O'Donaghey, Lance O'Donaghey, and Chris Fletcher, for their help with carcass and tag retrieval at Gates Creek spawning channel. 
And to all the other organisations that helped along the way! InStream Fisheries Research helped so much with the supply and installation of PIT receivers - thanks to Caroline Melville, LJ Wilson, Carson White, Mike Chung, and Dani Ramos-Espinoza. Thanks to BC Hydro for all their help with Seton Dam operations, especially Matt Casselman and Riley Hall. Thanks also go to Splitrock Environmental for assistance in the field, to Red Barn Campground for access to receiver sites and a place to live, and thanks to Steve Hall and his son for supply, delivery, and installation of the fish fence.

I thank my family and my friends for all the behind-the-scenes emotional support and encouragement. To my parents and grandparents thank you! To Nick Elcheson, who was there every step of the way, you helped me in more ways that you know.

To everyone - I am truly grateful.

And finally, to the fish - thank you. This was all for you, and I hope you reap the benefits of this work. 


\section{Table of Contents}

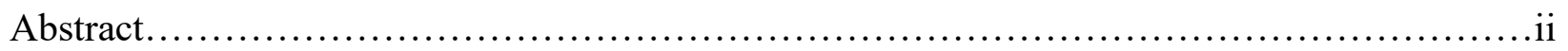

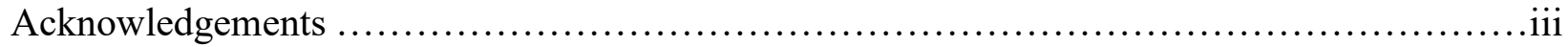

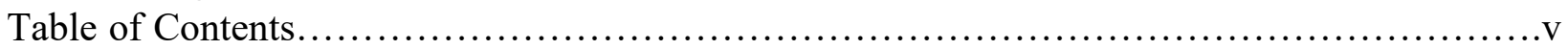

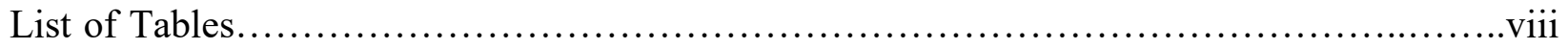

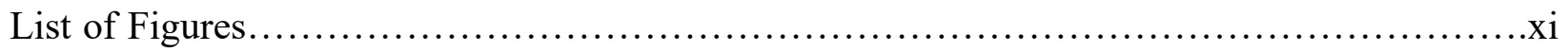

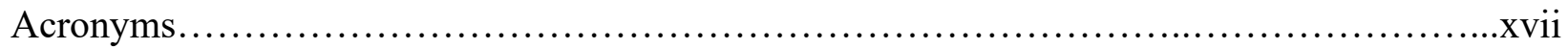

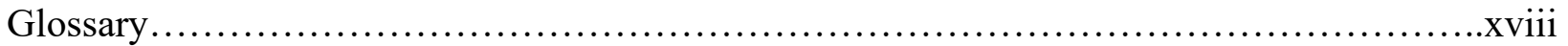

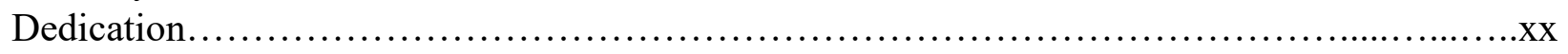

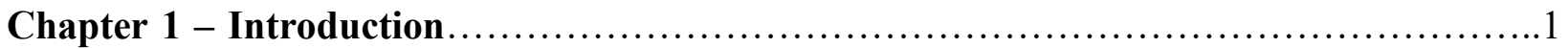

1.1 Animal migrations in the Anthropocene.........................................

1.2 Pacific salmon spawning migrations ............................................

1.3 Fisheries interactions and their impacts for Pacific salmon.........................5

1.4 Infectious agents of wild Pacific salmon.......................................... 12

1.5 Warming water temperatures and thermal refuge ................................ 15

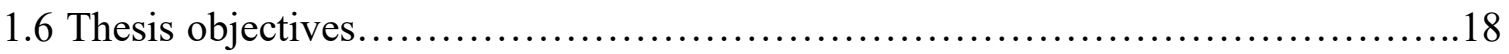

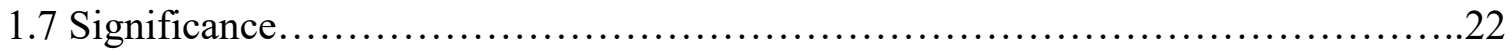

Chapter 2 - Thermal selection and delayed migration following escape from simulated inriver fisheries capture for adult sockeye salmon (Oncorhynchus nerka) ....................24

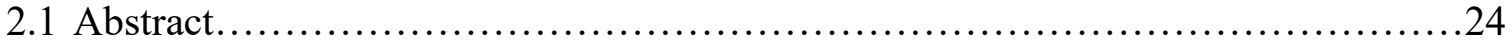

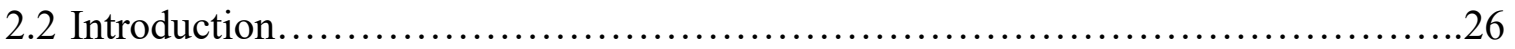

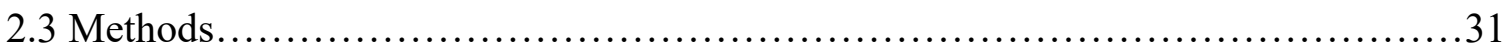

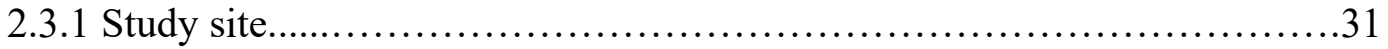

2.3.2 Fish collection, gear simulation, and tagging ............................ 31



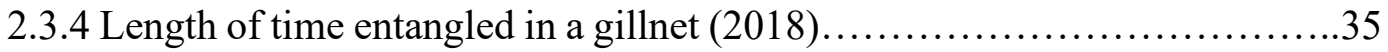

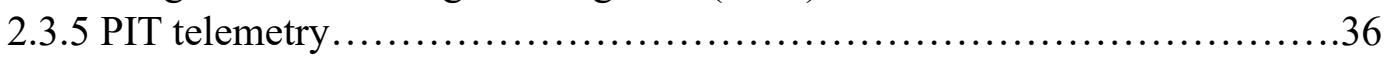

2.3.6 Recovery of carcasses..................................................... 37

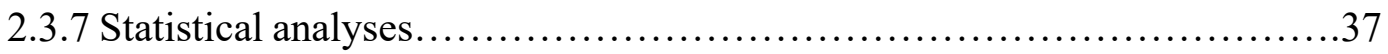

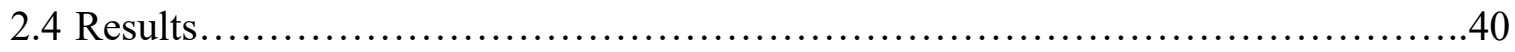

2.4.1 Consequences of gear escape simulations (2017) .......................40

2.4.2 Thermal selection during lake migration................................44

2.4.3 Female spawning success following gear escape........................44

2.4.4 Initial estimate on proportion of fish that can escape from a gillnet (2018)...46

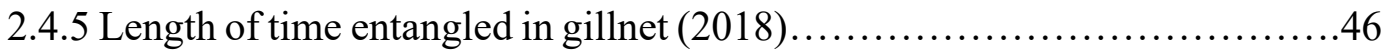

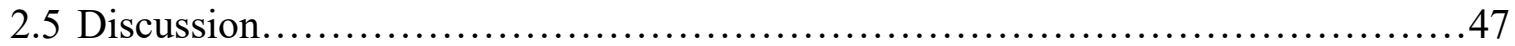

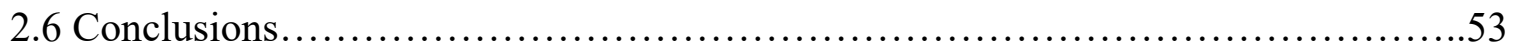


Chapter 3 - Changes in biomarker expression and infectious agent profiles during spawning migrations and following experimental fisheries interactions of wild sockeye salmon

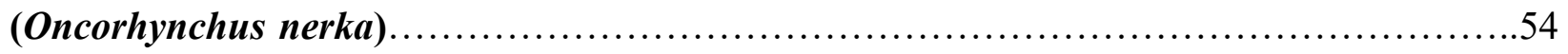

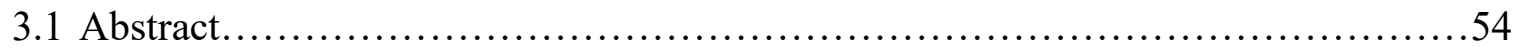

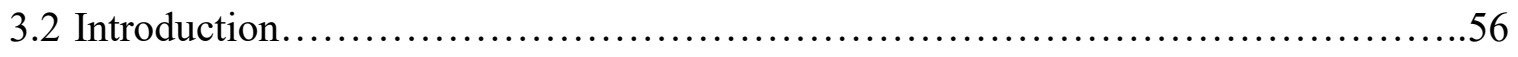

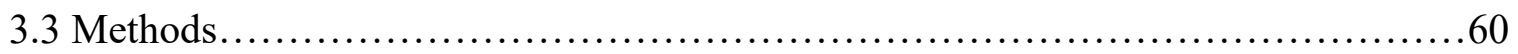

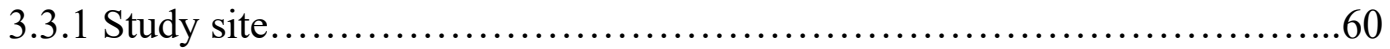

3.3.2 Fish collection, biopsy, and tagging at Seton River fish fence..............61

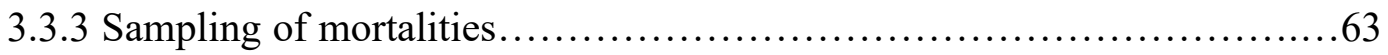

3.3.4 PIT telemetry............................................................

3.3.5 Recapture of tagged fish at spawning grounds........................64

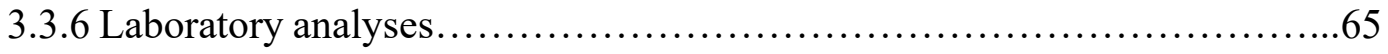

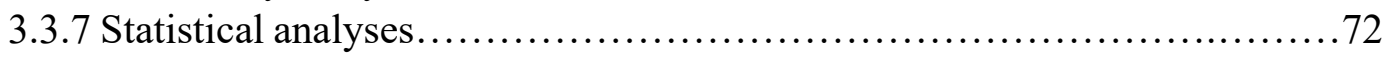

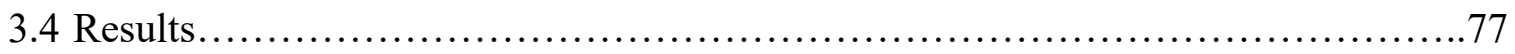

3.4.1 Changes in infectious agent load and prevalence.........................77

3.4.2 Infectious agent burden and thermal selection............................80

3.4.3 Changes in gene expression over migration............................ 81

3.4.4 Biomarker expression changes following gear escape.....................83

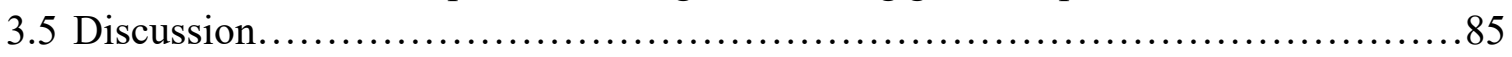

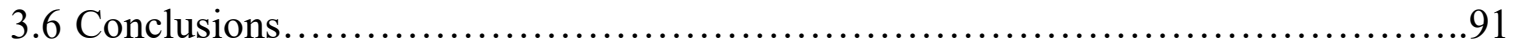

Chapter 4 - Survival, biomarker expression, and infectious agents of wild sockeye salmon (Oncorhynchus nerka) in a year of high Fraser River water temperatures...................92

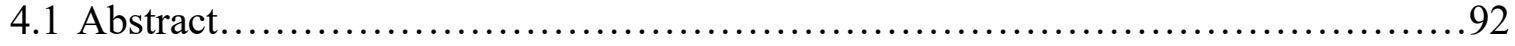

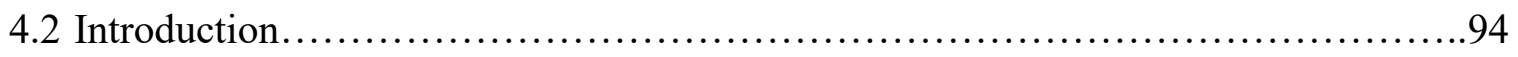

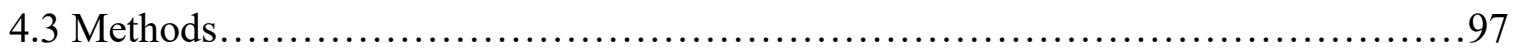

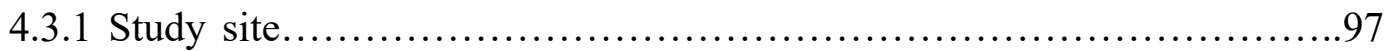

4.3.2 Fish collection, biopsy, and tagging .................................. 98

4.3.3 PIT telemetry .................................................... 100

4.3.4 Characterizing thermal experience during Fraser River migration..........100

4.3.5 Laboratory analyses............................................... 102

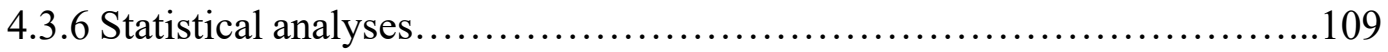

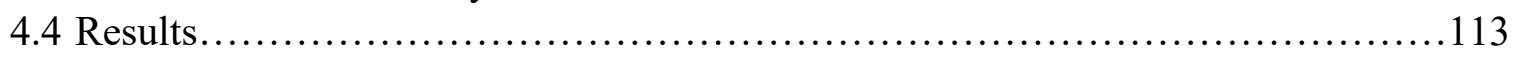

4.4.1 Characterizing thermal migration experience in the Fraser River...........113

4.4.2 Migration success................................................. 116

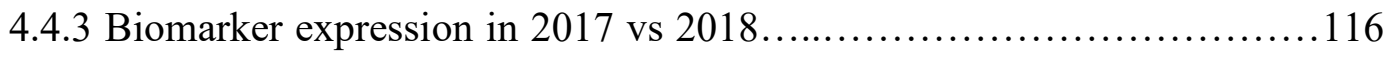

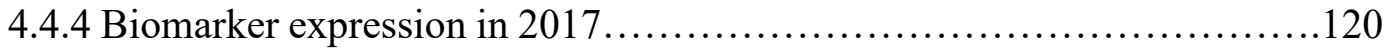

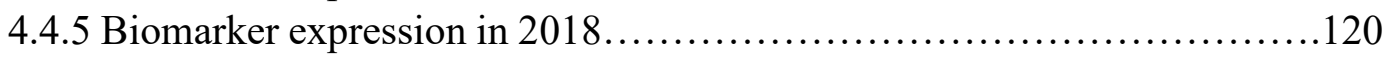

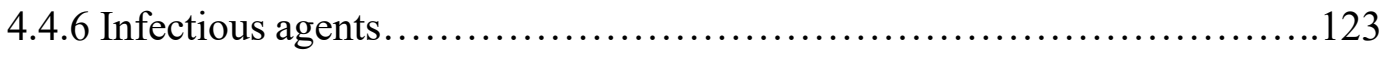

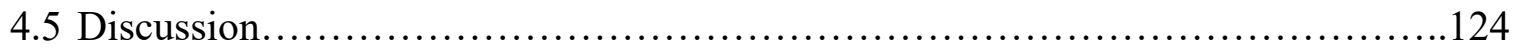

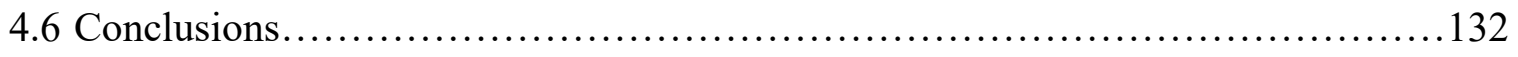


Chapter 5 - Comparing the prevalence, load, and diversity of infectious agents in live sockeye salmon (Oncorhynchus nerka) and those that died during their final segment of freshwater

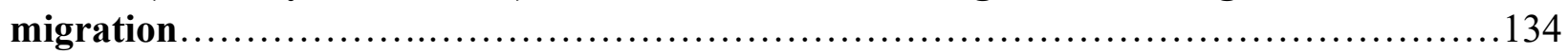

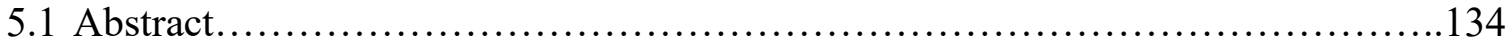

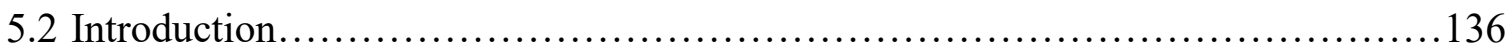

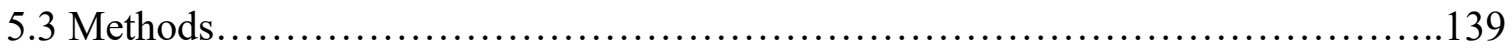

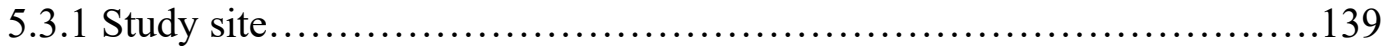

5.3.2 Collection and sampling of mortalities.............................. 139

5.3.3 Characterizing thermal experience during Fraser River migration..........141

5.3 .4 Laboratory analyses..............................................

5.3 .5 Statistical analyses................................................ 150

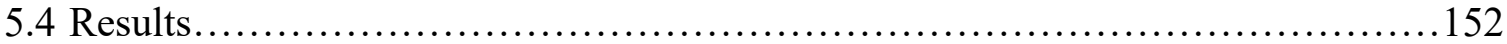

5.4.1 Fraser River temperature experience..............................152

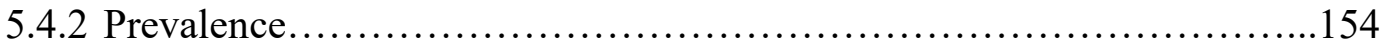

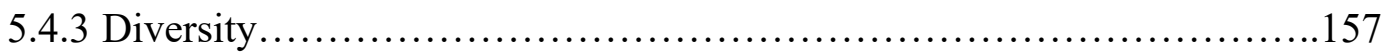

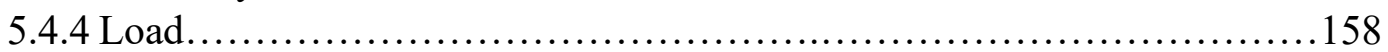

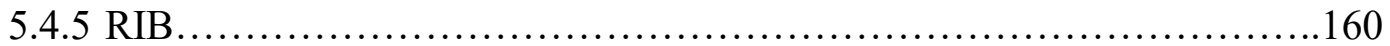

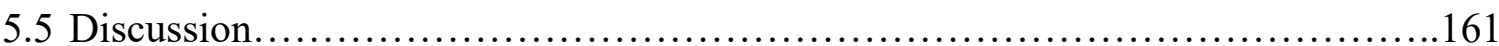

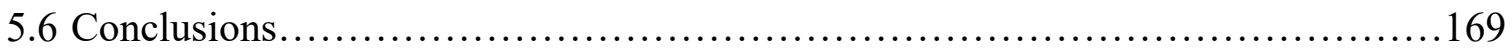

Chapter 6 - Conclusion......................................................... 172

6.1 Consequences of fisheries escape for Pacific salmon........................... 174

6.2 High water temperature is a critical environmental factor during Pacific salmon spawning migrations.................................................... 177

6.3 Infectious agents contributing to en-route mortality of Pacific salmon..............179

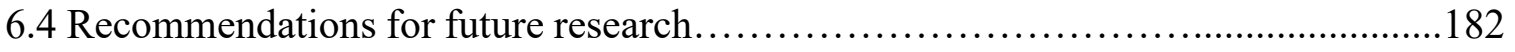

6.5 Management implications................................................. 185

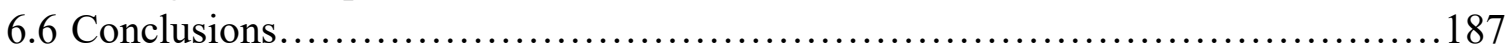

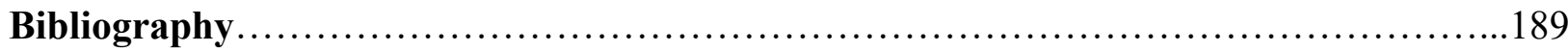




\section{List of Tables}

Table 2.1. Model results for logistic and linear regression models testing the effects of treatment, and sex on various response variables related to migration success, time, and temperature. Significant findings $(\mathrm{p}<0.05)$ are boldened

Table 2.2. Summary of migration success and migration time of fish to both Seton Dam fishway exit and Gates Creek spawning grounds across all gear escape treatment groups $(\mathrm{C}=$ control, $\mathrm{G}=$ gillnet escape, $\mathrm{S}=$ seine net escape, $\mathrm{T}=$ tangle net escape) and for both males (M) and females (F). The average migration temperatures of fish through both Seton and Anderson Lakes is also shown.

Table 3.1. Sockeye salmon host biomarkers evaluated using qPCR. A total of 25 biomarkers were assayed, including 3 house-keeping genes (HKG). Biomarkers are categorized as genes involved with viral disease development (VDD), morality-related signatures (MRS), thermal stress, immune response, or general stress. Forward (F) and reverse (R) primer sequences and probe $(\mathrm{P})$ sequences are given.

Table 3.2. Infectious agents assayed in sockeye salmon during this study. A total of 18 infectious agents were evaluated through qPCR. Forward primer $(\mathrm{F})$, reverse prime $(\mathrm{R})$ and probe $(\mathrm{P})$ sequences are given .70

Table 3.3. Model results for linear mixed effects models testing the effects of sex, treatment (gillnet and seine net escape simulations), and location (Seton fence vs Gates Creek) on infectious agent loads (RNA copy numbers). $\mathrm{G}=$ gillnet escape simulation, $\mathrm{S}=$ seine net escape simulation. Significant findings $(\mathrm{p}<0.05)$ are boldened..............................78 
Table 3.4. Model results for logistic regression models testing the effects of sex, treatment (control vs gillnet and seine net escape simulations), and location (Seton fence vs Gates Creek) on infectious agent prevalence (presence or absence of each infectious agent in a fish). $G=$ gillnet escape simulation, $\mathrm{S}=$ seine net escape simulation. Significant findings $(\mathrm{p}<0.05)$ are boldened. .79

Table 4.1. Migration time estimated for Gates Creek sockeye salmon for various intervals from the Fraser River mouth to Gates Creek spawning grounds 101

Table 4.2. Sockeye salmon host biomarkers evaluated using qPCR. A total of 25 biomarkers were assayed, including 3 house-keeping genes (HKG). Biomarkers are categorized as genes involved with viral disease development (VDD), morality-related signatures (MRS), thermal stress, immune response, or general stress. Forward (F) and reverse (R) primer sequences and probe $(\mathrm{P})$ sequences are given. 104

Table 4.3. Infectious agents assayed in sockeye salmon. A total of 18 infectious agents were evaluated through qPCR. Forward primer $(\mathrm{F})$, reverse primer $(\mathrm{R})$, and probe $(\mathrm{P})$ sequences are given.

Table 4.4. Average, minimum, and maximum temperatures $\left({ }^{\circ} \mathrm{C}\right)$ estimated to be experienced by sampled Gates Creek sockeye salmon at 3 temperature loggers along their migration route to spawning grounds.

Table 5.1. Migration time estimated for Gates Creek sockeye salmon for various intervals from the Fraser River mouth to Gates Creek spawning grounds 
Table 5.2. Infectious agents assayed in sockeye salmon during this study. A total of 47 infectious agents, and one host reference gene, were evaluated through qPCR. Forward primer (F), reverse primer $(\mathrm{R})$ and probe $(\mathrm{P})$ sequences are given............................... 144

Table 5.3. Average, minimum, and maximum temperatures $\left({ }^{\circ} \mathrm{C}\right)$ estimated to be experienced by Gates Creek sockeye salmon sampled as part of this study in 2015, 2017, and 2018. Temperatures are estimated at two temperature loggers placed in the Fraser River...........153

Table 5.4. MANOVA results comparing infectious agent prevalence and load (RNA copy numbers) between live and dead fish (condition) and among years. Significant findings ( $\mathrm{p}<$

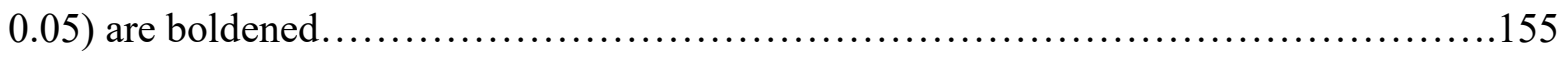




\section{List of Figures}

Figure 1.1. Conceptual figure illustrating the cumulative and interactive effects of three major factors influencing Pacific salmon spawning migrations: water temperature, infectious agents, and fisheries interactions. Cumulative (or combined) effects are symbolized by red arrows, and here represent when fish experience both stressors at the same time, usually resulting in increased mortality. Interactive effects are symbolized by blue arrows, and here represents how one factor can subsequently affect another by altering fish behaviour or physiology

Figure 2.1. Map of the Seton system in British Columbia, Canada. The location of the Seton Dam and the fish fence are shown, and locations of PIT receivers on the Seton Dam fishway and at Gates Creek mouth are indicated by a yellow star. Map of the Fraser River is shown in the lower right-hand corner. The location of the Seton system is outlined by a red box on this

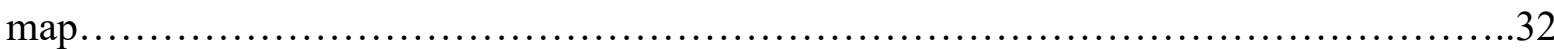

Figure 2.2. River-spanning fishing fence on the Seton River. .34

Figure 2.3. Photos of the experimental gear escape simulations performed in this study. (A) Gillnet entanglement simulation. Here a 5.25 -inch $(13.25 \mathrm{~cm})$ mesh gillnet $(60 \mathrm{~cm} \times 60 \mathrm{~cm})$ was strung tightly across a wooden frame. As fish swam through the net they typically become entangled around their operculum, as shown. (B) Tangle net simulation. A 5.25-inch mesh gillnet was loosely strung between two floats. As fish swam through the loosely hung netting they typically became entangled in multiple places from their operculum to their caudal fin. (C) Seine net entrapment simulation. Fish were corralled into a shallow section of the 
riverbank and escape was simulated by dragging the lead line over the fish, as shown. (D) A tagged fish following gillnet escape simulation, displaying typical markings resulting from gillnet entanglement around the operculum. (E) Typical markings resulting from tangle net escape simulation 36

Figure 2.4. (A) Migration time to pass Seton Dam (as defined by time of release following tagging to final detection at dam fishway exit PIT receiver) across all treatment groups. Fish that experience gill net and seine net escape simulation take significantly longer to pass Seton Dam compared to control fish. (B) Migration time to Gates Creek spawning grounds (defined as time of release following tagging to first detection at PIT receiver located at the mouth of Gates Creek). Fish that experience gill net and seine net escape simulation take significantly longer to migrate to Gates Creek compared to control fish. For each boxplot, the centre black line of the box indicates the median, the upper and lower box limits represent the first and third quartiles, the whiskers represent 1.5 times the inter-quartile range, and the points represent outliers

Figure 2.5. Temperature of migration through both Seton and Anderson lakes. Fish that experienced gillnet or seine net escapement migrated at significantly cooler temperatures through Seton Lake compared with control fish that did not encounter any fishing gear. There was no significant difference between treatment groups in Anderson Lake. For each boxplot, the centre black line of the box indicates the median, the upper and lower box limits represent the first and third quartiles, the whiskers represent 1.5 times the inter-quartile range, and the points represent outliers.

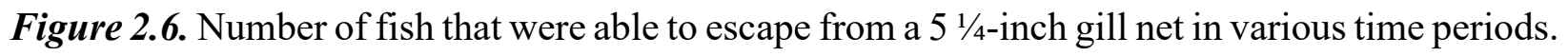
The greatest proportion of fish (46.5\%) were able to escape in less than 10 seconds...........46 
Figure 3.1. Barplots and Beanplots showing the prevalence and load, respectively, of infectious agents detected at Seton Fence and Gates Creek sockeye in 2017. Small hash marks represent individual fish and the larger horizontal line represents the group mean at either Seton fence or Gates Creek locations. Data from Seton fence is shown on the left-hand side of the plots (red). Data from Gates Creek is shown on the right-hand side (blue) 80

Figure 3.2. Relationship between relative infection burden (RIB) and the average migration temperature through both Seton and Anderson lakes. The red line represents the mean response, and the shaded area represents the $95 \%$ confidence level interval for predictions from the linear model.

Figure 3.3. (A) NMDS plot comparing samples taken from fish at Seton fence (red points) to samples taken from those same fish at Gates Creek (blue points). Host biomarkers scores were calculated as weighted averages and plot on the ordination space. (B) Correlation of individual biomarkers with NMDS1. Biomarkers are categorized based on their function: thermal stress, viral disease development (VDD), mortality-related signature (MRS), immune response, and general stress. .82

Figure 3.4. NMDS ordination plot comparing biomarker expression of fish at Seton fence and Gates Creek for each treatment group (control, gillnet escape, seine net escape). Numbers correspond to each treatment group mean at either Seton fence or Gates Creek locations. Ellipses represent $95 \%$ confidence intervals for each group at each location. Host biomarkers scores were calculated as weighted averages and plot on the ordination space.....

Figure 4.1. (A) Map of the Seton System in British Columbia, Canada. The locations of the Seton Dam and the fish fence used to capture fish for this study are shown on the map. Locations of 
PIT receivers are indicated by yellow stars. (B) Map of the Fraser River watershed. The Seton System is outlined by a red box on the map. Locations of temperature loggers at Hope, Texas Creek, and Seton fish fence, are indicated by red points. Steveston and Gates Creek are indicated by yellow and green points, respectively

Figure 4.2. Average daily water temperature recorded by thermal loggers placed in the Fraser River at Hope (A) and at Texas Creek (B) in 2017 and 2018. The time period displayed in each figure shows only relevant dates that fish sampled at the fish fence in Gates Creek were estimated to be at these thermal logger sites in both years. Due to largely invariant temperatures along the lower Fraser River migration corridor, temperatures recorded at these thermal loggers are sufficient for extrapolating the thermal experience along the Fraser River migration route for Gates Creek sockeye salmon in this study.

Figure 4.3. (A) NMDS plot of host biomarker expression of Gates Creek sockeye salmon sampled in both 2017 and 2018. The colour of points corresponds to the year each individual was sampled; red in 2018 (warmer water temperature year) and blue in 2017 (cooler water temperature year). Confidence ellipses (95\%) are also shown for each year. Circular points correspond to fish that did not successfully migrate to spawning grounds, and triangular points correspond to fish that did successfully migrate to spawning grounds. (B) Correlation of individual biomarkers with NMDS2. Biomarkers are categorized based on their function: thermal stress, viral disease development (VDD), mortality-related signature (MRS), immune response, and general stress.

Figure 4.4. Boxplots comparing the relative expression of six thermal biomarkers. Expression of all thermal biomarkers was significantly higher in 2018 compared with 2017. For each plot, * indicates $\mathrm{p}<0.01, * *$ indicates $\mathrm{p}<0.001$, and $* * *$ indicates $\mathrm{p}<0.0001$. For each boxplot, the xiv 
thicker black line indicates the median, the upper and lower box limits represent the first and third quartiles, the whiskers represent 1.5 times the inter-quartile range, and the circles represent outliers

Figure 4.5. NMDS plot of host biomarker expression of Gates Creek sockeye salmon sampled in 2017. Biomarkers (shown in grey) are referenced in Table 4.2. The colour of points corresponds to whether each individual went on to successfully migrate to Gates Creek spawning grounds following sampling and tagging. Red points are individuals that did not successfully migrate to Gates Creek, blue points are those that were successfully detected at Gates Creek. Circular points correspond to females and triangular points correspond to males. Confidence ellipses (95\%) are also shown for each year. Vectors represent extrinsic variables fit onto the ordination. These extrinsic variables included the relative loads of Parvicapsula minibicornis (mpa_min), Ceratomyxa shasta (mce_sha), and Candidatus Branchiomonas cisticola (mc_b_cys), fork length, and Seton River water temperature at the time of tagging.....

Figure 4.6. NMDS plot of host biomarker expression of Gates Creek sockeye salmon sampled in 2018. Biomarkers (shown in grey) are referenced in Table 4.2. The colour of points corresponds to whether each individual went on to successfully migrate to Gates Creek spawning grounds following sampling and tagging. Red points are individuals that did not successfully migrate to Gates Creek, blue points are those that were successfully detected at Gates Creek. Circular points correspond to females and triangular points correspond to males. Confidence ellipses (95\%) are also shown for each year. Vectors represent extrinsic variables fit into the ordination. These extrinsic variables included the relative loads of Parvicapsula minibicornis (mpa_min), Ceratomyxa shasta (mce_sha), and Candidatus Branchiomonas 
cisticola (mc_b_cys), fork length, and Seton River water temperature at the time of tagging...

Figure 4.7. Comparison of infectious agent prevalence and loads in 2017 (red) and 2018 (blue). Bars represent prevalence of each infectious agent ( $\%$ of fish sampled that were positive for each infectious agent). Beans represent infectious agent load (RNA copy number). Small lines represent the RNA copy number in individual fish. The longer, boldened line represents the group average.

Figure 5.1. Infectious agent prevalence ( $\%$ of total fish sampled that tested positive for each infectious agent) during each study year. Prevalence of each infectious agent in both dead (red bars) and live (blue bars) sampled fish. 156

Figure 5.2. RNA copy numbers of (A) Ceratomyxa shasta, (B) Flavobacterium psychrophilum and (C) Parvicapsula minibicornis. RNA copy numbers are compared between live and dead sampled fish in each year. For each boxplot, the thicker black line indicates the median, the upper and lower box limits represent the first and third quartiles, the whiskers represent 1.5 times the inter-quartile range, and the points represent outliers.

Figure 5.3. Relative infection burden (RIB) compared between live and dead sampled fish over three years. RIB was significantly higher in fish during $2018(\mathrm{p}=0.048)$. RIB also differed significantly between live and dead fish in 2018 only; dead fish had significantly higher RIB compared with live fish $(\mathrm{p}=0.027)$. For each boxplot, the thicker black line indicates the median, the upper and lower box limits represent the first and third quartiles, the whiskers represent 1.5 times the inter-quartile range, and the points represent outliers 160 


\section{Acronyms}

ANOVA Analysis of Variance

DFO Department of Fisheries and Ocean Canada

FRIM Fishing-Related Incidental Mortality

GLM Generalized Linear Model

HT-qPCR High-Throughput Quantitative Polymerase Chain Reaction

MRS Mortality-Related Signature

NMDS Non-Metric Multidimensional Scaling

PCA Principal Component Analysis

PERMANOVA Permutational Multivariate Analysis of Variance

PIT Passive Integrated Transponder

PRV Piscine Orthoreovirus

RIB Relative Infection Burden

VDD Viral Disease Development 


\section{Glossary}

Aerobic scope the difference between routine and maximum oxygen consumption during aerobic activity

Behavioural thermoregulation seeking and holding in thermally optimal habitat

Biomarker a gene for which increased expression is indicative of a specific stressor or physiological response.

By-catch non-target species captured by a fishery that are subsequently released

Carrier state the presence of an infectious agent without any clinical indications of disease for the host

En-route mortality fish that die during spawning migrations before reaching spawning areas

Escapee fish (can be target- or non-target species) that are captured by a fishery but manage to free themselves before human intervention

Escapement the number of fish that reach spawning grounds after avoiding, escaping, or being intentionally released from fisheries

Fisheries interaction when a fish makes contact with fishing gear

Fisheries escape when a fish frees itself from capture by a fishery before human intervention.

Fishing gear any equipment directly used to capture fish

Infectious agents viruses, bacterium, microparasites, and fungi with potential of causing disease

Infectious agent load the number of RNA copies of that infectious agent detected in a biopsy sample 
Non-retention encompasses any fish that are captured by a fishery, but are not harvested by that fishery (includes both by-catch and escapees)

Pre-spawn mortality fish that die on spawning grounds before spawning

Relative infection burden (RIB) a calculated metric that represents the overall burden (loads) of all infectious agents on an individual 


\section{Dedication}

To my Dad, Les Elmer 


\section{CHAPTER 1}

\section{Introduction}

\subsection{Animal migrations in the Anthropocene}

Animal migrations can be vast and spectacular, sometimes spanning entire continents and continuing over many months. Migration is widespread across the animal kingdom and is observed in both vertebrate and invertebrate species (Dingle, 1996). The breeding migrations of gray whales (Eschrichtius gibbosus; Pike, 1962), overwintering migrations of monarch butterflies (Danaus p. plexippus L.; Urquhart and Urquhart, 1978), and spawning migrations of Pacific salmon (Oncorhynchus spp.; Groot and Margolis, 1991) represent a few of the most iconic animal migrations, but unfortunately these species are also under threat from population declines. Migration can be defined as the adaptive, and often pre-emptive, movement of animals between critical habitats to complete their lifecycle (Dingle and Drake, 2007). There are many drivers of migration, including spatially distributed, or temporally fluctuating, food and resources (Southwood, 1962, 1977; Dingle and Drake, 2007), avoidance of predators (Hebbelwhite and Merril, 2009; McKinnon et al., 2010), seeking of suitable habitat for different life stages, and mating (Zampatti et al., 2010). Migratory syndrome is a term coined to encompass the suite of behavioural, physiological, and morphological traits allowing migratory movements for an animal, and the underlying genomic changes behind these traits (Dingle, 1996, 2006). Such 
changes can include the suppression of station-keeping behaviour, orientation, fat deposition, hormonal regulation, sexual maturation, and changes in body morphology (Dingle, 2006).

In an era of increasing Anthropogenic activity, we are concurrently seeing declines in many animal migrations across the globe (Wilcove, 2008; Wilcove and Wikelski, 2008). The major threats to migrants include habitat destruction, construction of barriers or obstacles in migration routes (e.g. dams, walls, fences), overexploitation, and climate change (Wilcove and Wikelski, 2008), and these stressors have further been suggested to alter host-pathogen dynamics and potentially increase infectious disease risk (Altizer et al., 2011). For some migrants, and in particular for species of freshwater fish, individuals are often pressured by all of these factors, and across the globe migrating freshwater fish have declined by an estimated $76 \%$ since 1970 (Deinet et al., 2020). Migrations are naturally challenging and energetically demanding for animals, and individual variation in fitness is often more pronounced during large-scale migrations where some succeed while other fail. Anthropogenic activity can increase the rate of migration failure by greatly increasing the challenge of migration, meaning greater fitness is required and thus fewer individuals may survive. For migrant species, conservationists are focusing not only on the prevention of extinction, but also protecting the abundance of populations. Many migrations are famous for the immense numbers of migrants that move together, and such drastic declines in migrant populations may have a number of negative impacts for the ecosystems they travel through, however these consequences are largely unknown. 


\subsection{Pacific salmon spawning migrations}

Although there are many organisms that undertake migrations, one of the most enigmatic and remarkable is the Pacific salmon (Oncorhynchus spp.). The unique life history of Pacific salmon begins in freshwater streams and takes them on remarkable out-migrations to ocean feeding areas before ultimately returning to the natal streams from which they were once spawned. Following emergence from gravel nests, juvenile salmon will eventually leave freshwater habitats for rich ocean feeding grounds. Marine residence varies between salmon species and populations (ranging from just months up to five years) and represents the period of most rapid growth for all species (Groot and Margolis, 1991). Spawning migrations return adults to natal spawning grounds with incredible fidelity and timing, which allow eggs to develop in optimal environmental conditions, and maximize survival of offspring (Keefer et al., 2004; Hinch et al., 2006). Pacific salmon are semelparous breeders, meaning they reproduce only once and then expire soon after. Lifetime fitness is therefore determined by ultimate spawning success. For a more detailed and complete review of Pacific salmon life history see Groot and Margolis (1991).

Spawning migrations are naturally challenging and physiologically demanding for adult salmon. Migration distances vary between species and populations but can range from as low as $10 \mathrm{~km}$ to over $3000 \mathrm{~km}$ (Eiler et al., 2014). Adult salmon cease feeding during spawning migrations and thus rely on endogenous energy reserves to fuel upstream migrations (Rand and Hinch, 1998; Kiessling et al., 2004). The transition from marine- to freshwater environments is also physiologically demanding and requires a suite of ionoregulatory changes that allow the fish to adapt to the differences in salinity between these environments (Shrimpton et al., 2005). Migration routes can also require fish to pass challenging sections of high flows and turbulent 
water, which represent natural hydrological obstacles that can delay migration and require burst swimming and high energic costs to pass (Fenkes et al., 2016). As fish migrate, energy reserves become further depleted and they undergo a suite of morphological and maturation changes that prepare them for spawning. Upon arriving at spawning grounds fish again undergo major physiological changes to prepare for spawning and death, such as decreases in plasma osmolality, increases in lactate and cortisol, and further decreases in gross somatic energy (Hruska et al., 2010).

In the current Anthropogenic era, salmon are now faced with many additional challenges resulting from increased human activity. Habitat destruction, fisheries capture, water pollution, and warming waters are all novel stressors now faced by freshwater fish and have contributed to declines in salmon populations (Hinch et al., 2012). Declines of many Pacific salmon species and populations continue, with species such as sockeye (Oncorhynchus nerka; Peterman and Dorner, 2012; Grant et al., 2016), chinook (Oncorhynchus tshawytscha; Riddell et al., 2013) and coho (Oncorhynchus kisutch; Bradford and Irvine, 2000) receiving particular attention. Several authors have noted that chum (Oncorhynchus keta) and pink salmon (Oncorhynchus gorbuscha), as well as river-type sockeye and chinook populations, are typically not exhibiting such declines, an interesting observation when considering these species and populations have comparatively shorter periods of adult freshwater residence (Irvine and Fukuwaka, 2011; Miller et al., 2014; Grant et al., 2019). This observation suggests that mortality during spawning migrations may be one of the more substantial factors contributing to overall population declines. Although declines in Pacific salmon populations are likely a consequence of increased mortality in all life stages, this thesis will just focus on stressors during adult spawning migrations. 
For effective and sustainable management of salmon populations in an era of continued declines, fisheries managers and decision-makers must fully understand the impacts that various stressors, environmental conditions, and fisheries practices have on survival and spawning success. Fisheries managers are tasked with determining escapement targets for salmon populations (defined as the number of fish that successfully return to spawning habitats) that will prevent collapse and allow sustainable populations. Commercial, recreational, and Indigenous fisheries are then regulated to allow escapement targets to be met. In order to achieve these escapement targets, the number of fish caught in marine and riverine fisheries is considered, as well as the fate of by-catch species that are released (Patterson et al., 2017b; DFO, 2019). However, estimating escapement is notoriously difficult. Salmon are often faced with multiple, cumulative stressors which can have varying effects on salmon survival and spawning success. An accurate understanding of the fate of salmon when faced with cumulative stressors is needed, however this is often very difficult to predict (Johnson et al., 2012; Patterson et al., 2017b).

\subsection{Fisheries interactions and their impacts for Pacific salmon}

Pacific salmon are of great nutritional value and are therefore culturally and economically important to many (Lichatowich, 2013; Gislason et al., 2017). Salmon are therefore targeted by commercial, recreational, and First Nations fisheries in both marine and riverine environments. In addition to fish that are harvested by each fishery, there are also many fish that interact with the fishing gear and are either released or escape (collectively known as non-retention fish). Fish may be intentionally released as by-catch (non-target species unintentionally caught in the fishing gear) or as practiced by recreational catch-and release anglers. In the marine environment, by-catch has been estimated between 10-40 \% of total catch (Davies et al., 2009; 
Pauly and Zeller, 2016; Zeller et al., 2018), and thus collectively represent a notable proportion of the total catch. By-catch is also a frequent occurrence in freshwater fisheries and has received increasing research attention in the last two decades (Raby et al., 2011; Raby et al., 2015; Patterson et al., 2017a).

Salmon are targeted in rivers using a variety of gear types including, but not limited to, gillnets, tangle nets, rod-and-reel, and seine nets. The frequency and fate of non-retention fish is important for accurately calculating escapement estimates for salmon populations (Patterson et al., 2017a, 2017b). Riverine fisheries are managed according to escapement targets, and both the harvest take and survival of by-catch following release from various fishing gears are incorporated into current escapement estimate models (DFO, 2019). However, there are currently no estimates on the frequency or survival of fish that escape from fishing gears prior to landing (Patterson et al., 2017a). The consequences of escape from fishing gears are largely presumed to be similar to that of by-catch, however little is known. In the following sections I will discuss what is currently known about the impacts for by-catch species released from common river fishing gears before discussing the important knowledge gaps with respect to gear escape.

When fish encounter fishing gear, a stress response is initiated. This stress response consists of primary, secondary, and tertiary responses that are intended to aid the fish in escaping from the stressor (Wendelaar Bonga, 1997; Barton, 2002). Primary stress responses include the release and synthesis of catecholamines (e.g. adrenaline) and corticosteroid hormones (e.g. cortisol). Secondary responses are considered as the resulting effects of these hormone releases including, but not limited to, immunological, metabolic, and osmoregulatory changes, as well as modulation of cardiovascular and respiratory function to maximize oxygen delivery to muscles (Reid et al., 1998) and mobilizing glucose energy stores (Barton and Iwama, 1991). Tertiary 
responses are the ultimate organism-level changes and can include behaviour such as burst swimming activity to escape the stressor, regained homeostasis (recovery from the stressor), changes in growth (Wedemeyer et al., 1990), impaired immune function (Tort, 2011; Mateus et al., 2017), or supressed maturation (Baker et al., 2013). Although the stress response primarily aids in fish escape and recovery from stressors, impaired immune function resulting from chronic stress can allow for infection and disease, and thus may be a strong contributing factor to delayed mortality following fisheries interactions (Pickering and Pottinger, 1989).

For non-retention fish, the consequences of fisheries interactions can be severe. Fishingrelated incidental mortality (FRIM) is a term coined to represent the mortality of non-retention fish following a fisheries interaction (Patterson et al., 2017a). Mortality can occur while the fish is captured, prior to landing or release ('immediate' mortality), and this is likely associated with asphyxiation or cardiac collapse (Kojima et al., 2004). Short-term mortality can occur within 24 hrs following release and is thought to be due to injury (Chopin and Arimoto, 1995) or an inability to recover from the stress of the capture event (Muoneke and Childress, 1994). Mortality can also occur days to weeks following the capture event ('delayed' mortality), and this is thought to be due to stress-induced immunosuppression (Pickering and Pottinger, 1989; Mateus et al., 2017), injury, and possible infection development (Svendsen and Bøgwald, 1997). It is important for fisheries managers to accurately account for all types of FRIM, otherwise escapement estimates will likely be over-inflated and escapement targets may not be achieved.

Estimating FRIM is very difficult as there are many factors that influence the outcome of a fisheries interaction. For Pacific salmon, the impacts of fisheries interactions can vary depending on intrinsic factors such as the population (Donaldson et al., 2010; Donaldson et al., 2012), sex (Donaldson et al., 2014; Raby et al., 2015), size (Neilson et al., 1989), and maturity 
(Raby et al., 2013; Bass et al., 2018b) of the fish. To add to this complexity, environmental factors can also impact the outcome of a fisheries interaction. Extrinsic factors such as water temperature (Gale et al., 2013), dissolved oxygen levels (Suski et al., 2006), salinity (Broadhurst et al., 2008), and even the presence of near-by predators (Ryer, 2002; Raby et al., 2014b) have all been shown to affect the outcome of fisheries interactions. Finally, different gear types and fishing practices can have varying impacts for non-retention fish, and this is accounted for in current escapement estimate models.

Gillnets are a common gear type employed in riverine fisheries for Pacific salmon. Gillnets are a length of fine mesh netting (typically nylon) that is hung vertically in the water column between a floating line at the water surface and a weighted lead line. Gillnets can vary in mesh sizing (depending on the target species), the length and depth of the net, hang ratio (defined as the length of the mesh web divided by the length of the float line or lead line), and the time the net is left in the water ('soak time'). For capture of Pacific salmon, gillnets are hung in the river at appropriate locations to intercept migrating fish. As salmon migrate upstream into the net, they become entangled, typically around the operculum. The size of the fish may determine where a fish is entangled; larger fish may be unable to fit in the mesh and instead become entangled by their teeth and snout, whereas smaller fish may be able to pass further through the meshing becoming entangled around their dorsal fin, or even able to pass through the gillnet completely. Fish that become entangled in a gillnet can experience sometimes severe lacerations from the fine meshing material, suffocation if they are tightly constricted around the gills, exhaustion as they struggle to free themselves, removal of mucus, and potentially increased susceptibility to disease (Kojima et al., 2004; Baker and Schindler, 2009). For sockeye salmon by-catch in gillnet fisheries, the Department of Fisheries and Oceans Canada (DFO) currently estimates post-release 
survival to spawning grounds to be $40 \%$ (DFO, 2019). There are now a number of studies researching the impacts of gillnet capture for Pacific salmon by-catch, and researchers have found extrinsic factors such as increased temperature (Gale et al., 2013) and entanglement duration (Teffer et al., 2017) to increase post-release mortality.

Seine nets are another commonly employed gear type for targeting Pacific salmon during spawning migrations. Seine nets, like gillnets, are also a mesh net suspended between a floating line and a weighted lead line. However, seine net meshing is typically much smaller and thicker that that of a gillnet. The basic concept of seine netting is to encircle and entrap fish by the net. This is typically done using a motorized boat to quickly encircle a school of fish within the net. The net is then used to tightly corral fish in a shallow section of water where they can be processed; target fish are harvested from this fishery whereas non-target by-catch species are released back to the river. The smaller, thicker meshing used for seine nets typically prevents fish becoming entangled within the net itself, however it is possible for smaller fish to become entangled in the seine net meshing (comparable to a fish entangled in a gillnet). Seine netting is considered a less harmful fishing practice for non-retention fish, with the most severe consequences considered as mucus removal and oxygen depletion in high density nets (Raby et al., 2014a). DFO currently estimates survival to spawning grounds of by-catch following seine capture to be as high as $95 \%$ for sockeye salmon (DFO, 2019).

Despite a growing amount of research on the consequences of fisheries interactions for by-catch, fish that escape gear before landing have rarely been considered (Patterson et al., 2017a). The fight-or-flight response initiated following fisheries capture allows some fish to successfully escape entrapment before human intervention. These fish, known as escapees or drop-outs, differ from by-catch in that they do not experience human handling, typically have 
shorter entanglement durations, and do not experience any air exposure. The frequency at which fish escape from fishing gears, and the consequences of this escape, have rarely been quantified. One study aimed to estimate the number of sockeye salmon that had escaped from commercial marine gillnet fisheries in Bristol Bay, Alaska (Baker and Schindler, 2009). In this study, sockeye salmon represented the target species of this commercial gillnet fishery. Sockeye were captured in the Wood River system, upstream of the commercial gillnetting areas, and escapees were identified as those fish that had clear markings consistent with gillnet entanglement. The authors of this study found that $11-29 \%$ of all sockeye displayed gillnet entanglement markings, and thus concluded that a substantial proportion of this population encountered and escaped from gillnets, and as a result estimates of spawning stocks may be inflated by $5-15 \%$ at a minimum (Baker and Schindler, 2009). Similar studies have also observed large numbers of Fraser River sockeye with gillnet markings over multiple years, and thus also assumed these fish escaped from gillnet fisheries (Bass et al., 2018a; Kanigan et al., 2019). Kanigan et al. (2019) found that between 2013-2016, an average of $19 \%$ of Gates Creek sockeye salmon had gillnet markings, and the number of fish with markings was correlated with gillnet fishing effort in the lower Fraser River. Bass et al. (2018) reported that 19-27 \% of sockeye salmon displayed gillnet markings between 2014-2016 and reported that these markings increased both en-route mortality and pre-spawn mortality by $16 \%$ and $19 \%$, respectively. However, major limitations of these observational studies exist in that escape is only assumed, the gillnet experience of the fish is unknown, and the number of sockeye that escape these commercial gillnets is likely higher than estimated as escapees that may have perished before reaching the sampling location are not accounted for. In an experimental study, Thompson and Hunter (1971) also aimed to quantify the number of sockeye salmon able to escape from gillnet entanglement. In this study, authors report 
that between $42-57 \%$ of fish entangled in simulated gillnet treatments were able to escape. Another study also compared the mortality of sockeye salmon escapees vs by-catch following gillnet entanglement (Thompson et al., 1971). Researchers found that escapees experienced better survival than by-catch, but still much reduced survival compared to control fish that did not experience gillnet entanglement (Thompson et al., 1971). Despite a small amount of research on gear escape, these findings highlight that the number of escapees is likely substantial and thus needs to be accounted for by fisheries managers, especially considering escapees likely experienced increased mortality.

Further research is needed to investigate the frequency and consequences of escape from fishing gears to prevent over-inflation of escapement estimates (Baker and Schindler, 2009). As with by-catch, many intrinsic and extrinsic factors likely affect the impacts of escape, and these factors also need to be well understood. Escapees can include both target- and non-target species, and the fate of non-retention target species is often ignored but needs to be considered in the context of escape (Thompson and Hunter, 1971, Thompson et al., 1971; Baker and Schindler, 2009). It is likely that non-target species may be more capable of escape from certain gears such as gillnets. Gillnets vary in mesh sizing to capture target species most effectively (size selectivity), and it is therefore more likely that non-target species that encounter these nets will escape. For example, chinook gillnets often have larger mesh sizing as chinook typically have larger bodies. Smaller bodied species, such as sockeye or coho, are therefore more likely to encounter the net but escape due to increased ability to fit through the mesh sizing. Accurate escapement rates from all gear types commonly targeting Pacific salmon, on a species-specific basis, and the resulting consequences on survival to spawning grounds and spawning success are strongly needed for more accurate escapement estimates. 


\subsection{Infectious agents of wild Pacific salmon}

Infectious agents (viruses, bacterium, microparasites, and fungi with potential of causing disease) are an inherent, natural component of ecosystems, and play an important role in the survival and evolution of most species. With continuing declines of many Pacific salmon populations, the role of infectious agents in early mortality of these fish is gaining increasing attention. The Strategic BC Salmon Health Initiative (SSHI) is a multidisciplinary research program developed to assess the role of infectious agents in wild salmon early mortality and population declines (Miller et al., 2014). This program has not only greatly increased our understanding of the infectious agents that infect salmon throughout their various life phases, but has also helped in the development of a high-throughput microfluidics platform for the rapid identification and quantification of these infectious agents (Miller et al., 2016). This platform uses high-throughput quantitative polymerase chain reaction (HT-qPCR) technology and can simultaneously detect the presence of multiple infectious agents across many host biopsy samples. This technology is therefore very powerful for the rapid, high-sensitivity detection of infectious agent presence and load in wild salmon. However, a large limitation of this approach is that the detection of an infectious agent alone does not necessarily indicate disease, and in fact most Pacific salmon are infected with infectious agents yet are free from disease (known as 'carrier state' infections). There are now over 60 potential salmonid infectious agents that have been discovered through the SSHI, with new agents being discovered every year (Mordecai et al., 2019; Mordecai et al., 2020), and likely many more still undiscovered. Following the detection of novel infectious agents, further research is needed to determine the risk imposed by the agent to their host, and the potential population-level impacts that may result. 
For teleost fish species, immune responses to infectious agents are comprised of both innate and adaptive (also known as acquired) components (Alvarez-Pellitero, 2008; Zwollo, 2017). The innate response acts as the first line of defence and is characterised by a suite of immune responses including recognition of infectious agent molecular patterns, activation of the complement cascade, immune cell migration to infected areas, and inflammation (Holland and Lambris, 2002; Alvarez-Pellitero, 2008). The adaptive immune response is driven by the presence and activity of B lymphocytes and the production of specific antibodies and antigen receptors, T lymphocytes, immunoglobulins, cytokines (e.g. interleukins, tumor necrosis factor, interferons), and major histocompatibility complexes (MHC). Adaptive immune responses are a function of immunological memory whereby previous infection with an infectious agent produces and retains specific immune cells in the organism, allowing for a faster immune response in the case of subsequent infection (Smith et al., 2019). As adult Pacific salmon migrate through freshwater rivers their immune function declines as they approach spawning grounds. Dolan et al. (2016) found that innate immune responses were dampened as Chinook salmon approached spawning areas, whereas adaptive immune responses were largely preserved. Authors also found infectious agent burden to increase as fish approached spawning grounds, but no specific agent was associated with these dampened immune responses. Results suggest that suppression of the immune system during spawning migrations of Pacific salmon is likely a natural process associated with senescence.

Many infectious agents are described as 'opportunistic', meaning they do not impact survival unless fish are in a compromised immune state (Pickering and Pottinger, 1989). As previously mentioned, the stress response can compromise immune function, and this can allow opportunistic infectious agents to invade or cause disease in fish. For example, Saprolegnia, a 
ubiquitous oomycete often visible as white patches on the body or fins of fishes, is known to invade fish that have been stressed, injured, or have compromised immune function (Bruno and Wood, 1999). Fisheries capture is a considerable stressor for by-catch and escapees, and thus may allow for infection and disease development, which may ultimately cause delayed mortality for these fish. Several studies have now reported increased FRIM due to high burden of infectious agents (Thompson and Hunter, 1971; Robertson et al., 1987; Olsen et al., 2012). Other studies have reported an increase in infection of fish from a carrier state following a stressor (Taksdal et al., 1998; Bergmann and Kempter, 2011). The presence and load of infectious agents in fish prior to fisheries interactions, as well as the presence and density of opportunistic infectious agents in the environment after a fish survives a fisheries encounter (or any stressor), may therefore both be contributing factors to delayed FRIM in Pacific salmon.

Surveys of sockeye salmon in British Columbia have detected up to 23 different infectious agents in this species (Miller et al., 2014; Bass, 2018; Thakur et al., 2019). The most prevalent agents infecting sockeye salmon include the bacteria Flavobacterium psychrophilum and Candidatus Branchiomonas cysticola, and the microparasites Parvicapsula minibicornis, Ceratomyxa shasta, Loma salmonae and Ichthyophthirius multifiliis. Some of these infectious agents are known to cause disease and compromised behaviour. F. psychrophilum can cause bacterial coldwater disease in salmon species (Starliper, 2011; Roberts, 2012), L. salmonae causes microsporidial gill disease (Speare and Lovy, 2012), and I. multifiliis is known to cause white-spot disease (Kent, 2011). Viruses are less prevalent but can include Pacific salmon parvovirus, Infectious hematopoietic necrosis virus, and Piscine reovirus (PRV). However, since these surveys, novel viruses have been discovered to infect sockeye salmon (Mordecai et al., 2019; Mordecai et al., 2020). Certain viruses have received increased attention in recent years 
due to their association with certain diseases, for example PRV has been highlighted as a potential causative factor for Heart and Skeletal Muscle Inflammation (HSMI; Di Cicco et al., 2018). Other infectious agents have been demonstrated to compromise certain behaviours, for example $P$. minibicornis infections have been associated with decreased recovery from exhaustive swimming (Wagner et al., 2005) and has been implicated in pre-spawn mortality for sockeye salmon (Bradford et al., 2010). Finally, some infectious agents are highly prevalent among salmon species, such as $\mathrm{Ca}$. B. cysticola, but are typically considered non- or less pathogenic. However, stressors or temperature changes may increase pathogenicity of certain infectious agents.

\section{Warming water temperatures and thermal refuge}

As climate change persists, both air and water temperatures continue to rise across the globe. In the Fraser River, record high temperatures and consistently observed and Pacific salmon are forced beyond their thermal tolerances (Patterson et al., 2007; Grant et al., 2019). Pacific salmon are ectothermic, and different species and populations have evolved specific thermal tolerances as a function of the historic thermal conditions encountered throughout their traditional migration routes and their migration run timing (Farrell et al., 2008; Clark et al., 2011; Eliason et al., 2011, 2013). Further, different populations and species of Pacific salmon spawn during specific time periods to maximize the survival of their offspring in the historic thermal conditions of their spawning habitat (Brannon, 1987). High temperatures are more consistently recorded in the summer months, and thus it is expected that summer-run salmon may be more vulnerable to the effects of warming waters (Martins et al., 2011). Temperature is a 
critically important environmental factor for fish (Fry, 1971), and is often considered a master factor in determining the survival of salmonids (Brett, 1971).

High water temperatures can have a number of negative effects for salmon species. Altered metabolic rate (Brett, 1995), heart rate (Prystay et al., 2017), maturation rate (Pankhurst and King, 2010), depletion of endogenous energy reserves (Hinch and Rand, 1998; Rand et al., 2006) and collapse of aerobic scope (Lee et al., 2003; Farrell et al., 2008) have all been demonstrated in adult Pacific salmon following high temperature conditions. These physiological effects can ultimately have severe and devastating consequences for survival (Crossin et al., 2008; Keefer et al., 2008; Martins et al., 2012; Hinch et al., 2012) and spawning success (West and Mason, 1987; Quinn et al., 2007). For some Late-run stocks, which historically enter the Fraser River in late-summer or early-fall, abnormal migration patterns in recent decades have been documented. These fish are entering the river 3-6 weeks earlier than normal and as a result are migrating in much warmer peak summer temperatures and survival to spawning grounds is greatly reduced, with mortality in some years exceeding $90 \%$ (Cooke et al., 2004; Hinch et al., 2012). High temperatures can also exacerbate the negative impacts and mortality from other stressors experienced by fish. It is known that high temperature reduces the ability of salmon to recover from stress and exercise (Macdonald et al., 2000), and as a result we see a great reduction in survival following stressors such as fisheries interactions in high water temperature conditions (Gale et al., 2013; Teffer et al., 2017; Teffer, 2018).

For certain Pacific salmon populations, thermal refuges are present along their migration route. Thermal refuges include lakes, reservoirs and cool water tributaries, and allow fish to 'hide' from warm river environments and mitigate the negative effects of thermal stress (Goniea et al., 2006), and this behavioural thermoregulation has been shown to increase survival to 
spawning grounds (Newell and Quinn, 2005; Mathes et al., 2010; Keefer and Caudill, 2015) and increase spawning success (Minke-Martin et al., 2018). Previous work has demonstrated behavioural thermoregulation following warm water temperatures (Goniea et al., 2006), lower levels of somatic energy (Roscoe et al., 2010), and gillnet injuries (Bass, 2018). Thermal refuges may therefore be important for improving survival following many stressors and injuries, and in an era of persistent climate change and warming water temperatures, thermal refugia may be an increasingly important behaviour for the ultimate productivity of salmon populations. However, it is important to note that only specific systems and migration routes have thermal refuges meaning not all salmon populations may be able to thermoregulate, and it is these populations that might be more vulnerable to the effects of thermal stress.

Temperature is a critical environmental factor for all organisms. Like salmon, the infectious agents that can infect these fish also have specific optimal temperature ranges and thermal tolerances. Water temperature can have many consequences for infectious agents, including altering their virulence, replication rates and development (Marcogliese, 2008), as well as affecting timing of release from intermediate hosts for certain agents (as is the case for Ceratomyxa shasta; Ray et al., 2012; Chiaramonte, 2013). For infectious agents that infect Pacific salmon, some may be negatively impacted by warming water temperatures, whereas others may benefit from warmer temperatures and as a result show increased virulence toward their host. High water temperatures can also compromise host immune function (Magnadottir et al., 1999; Dominguez et al., 2004), and thus disease progression in salmon can be affected by the impacts of temperature on both the infectious agents and on the host. Added complexity is provided by species-specific responses of infectious agents to higher water temperatures. $F$. psychrophilum, for example, shows greater virulence at lower temperatures, below $16^{\circ} \mathrm{C}$ 
(Starliper, 2011), whereas other infectious agents show increased virulence with higher temperatures, such as I. multifiliis (Noe and Dickerson, 1995), P. minibicornis (Crossin et al., 2008), Tetracapsuloides bryosalmonae (Bettge et al., 2009), and C. shasta (Chiaramonte, 2013). Thermal refuges may provide additional benefits to migrating salmon by also providing refuge from certain infectious agents (Chiaramonte et al., 2016).

\subsection{Thesis objectives}

This thesis aims to further our understanding of the consequences of fisheries escape, high water temperatures, and infectious agents in wild, adult sockeye salmon (Oncorhynchus nerka) during their spawning migrations. Specifically, I aim to investigate the consequences of these stressors, both individually and combined, on migration behaviour, survival to spawning grounds, and spawning success. Fisheries interactions, water temperature, and infectious agents are three major stressors with the potential to influence Pacific salmon productivity. Moreover, it is common for fish to be simultaneously challenged with multiple stressors (cumulative effects) in the wild (Folt et al., 1999). These three factors can also impact each other with varying consequences for the fish (interactive effects). See Figure 1 for a conceptualization of the cumulative and interactive effects between these three factors. 


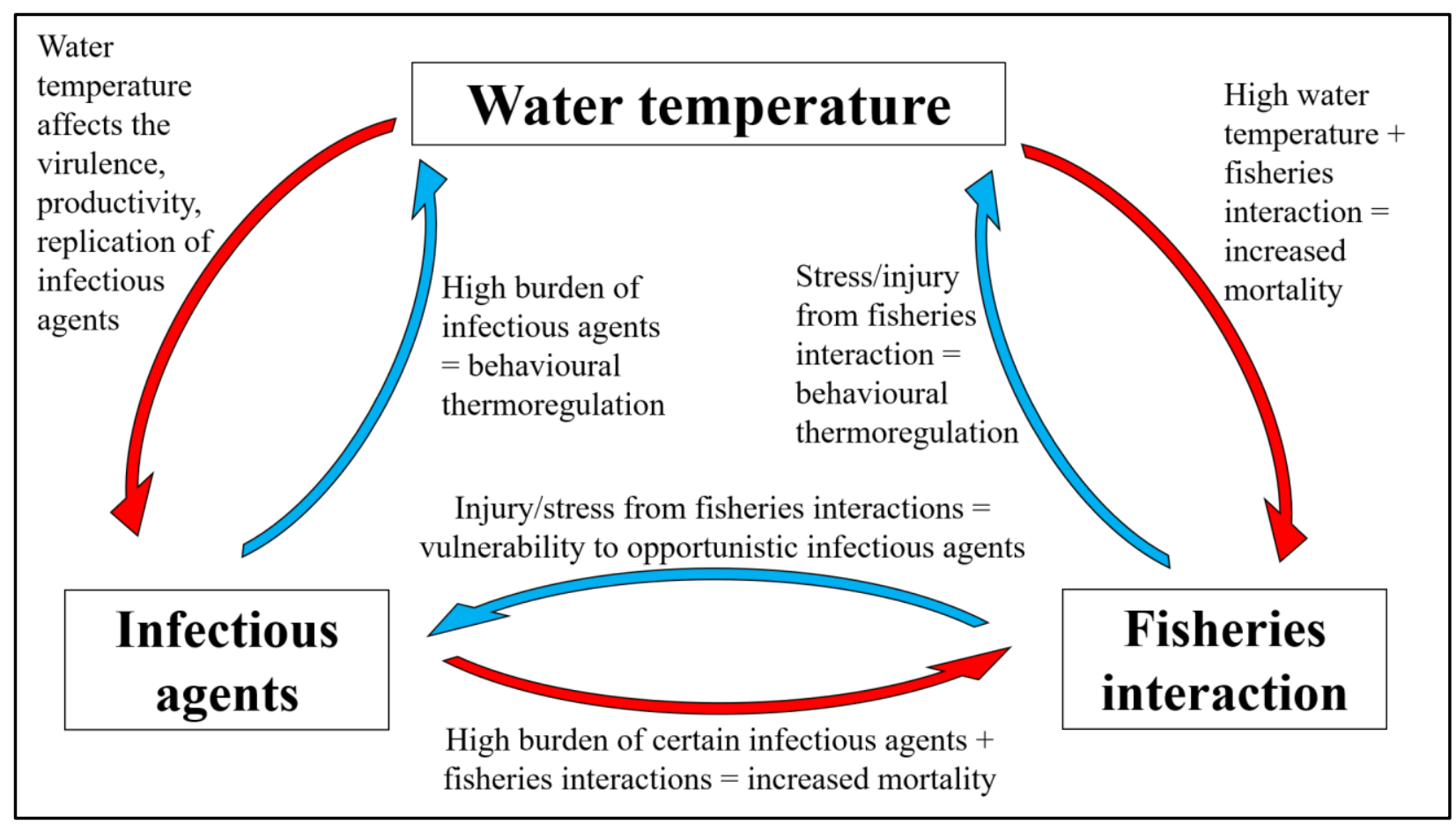

Figure 1.1. Conceptual figure illustrating the cumulative and interactive effects of three major factors influencing Pacific salmon spawning migrations: water temperature, infectious agents, and fisheries interactions. Cumulative (or combined) effects are symbolized by red arrows, and here represent when fish experience both stressors at the same time, usually resulting in increased mortality. Interactive effects are symbolized by blue arrows, and here represents how one factor can subsequently affect another by altering fish behaviour or physiology.

Research for this thesis was conducted on the Seton River, a tributary of the Fraser River approximately $360 \mathrm{~km}$ from the estuary. Gates Creek sockeye, an early summer-run population of sockeye salmon, migrate through the Seton system to ultimately spawn in Gates Creek. The Seton system provides a unique, ideal site to study the effects of fisheries escape, temperature, and infectious agents for a number of reasons: (a) the Seton River has suitable conditions for construction of a river-spanning fishing fence to capture large numbers of migrating salmon in a relatively stress- and injury-free way, (b) the Seton system contains two lakes (thermal refuges) allowing behavioural thermoregulation of migrating fish, (c) the presence of Seton Dam requires strenuous activity for fish to pass and can facilitate death in compromised fish, and (d) Gates 
Creek spawning areas are highly accessible allowing the recovery of fish carcasses to assess spawning success of females. The Seton system is therefore an excellent study site, and all experiments described in this thesis were conducted at this location.

Chapter 2: This chapter aims to increase our knowledge and understanding of the effects of gear escape (as opposed to by-catch) for Pacific salmon migration duration, behavioural thermoregulation, survival to spawning grounds, and spawning success in sockeye salmon. In this chapter I aim to (1) assess the consequences of gear escape from three major fishing gears commonly employed to target adult salmon in freshwater (gillnets, seine nets, and tangle nets), (2) assess the consequences of escape following varying durations entangled in a gillnet and (3) determine the occurrence (frequency) of escape from gillnets. I hypothesized that: (H1) Similar to by-catch, gear escape would increase migration duration and reduce survival and spawning success, (H2) Fish that experienced gear escape simulations would migrate at cooler temperatures through the lakes of the Seton system, (H3) Longer entanglement times for gillnet treatments would result in reduced survival and spawning success and increased migration duration.

Results from part (2) of Chapter 2 were confounded by high, atypical mortality of Gates Creek sockeye salmon in that year. I speculated that this mortality was likely a consequence of high water temperatures throughout the period of that study, which led to the development of Chapter 4 to further investigate these findings. 
Chapter 3: This chapter complements Chapter 2 and aimed to further our understanding of the effects of gear escape on gene expression and infectious agent prevalence and load in sockeye salmon. For this study, fish were captured and biopsied at two locations: first on the Seton River (where a subset of fish also experienced gear escape simulations) then again at Gates Creek spawning grounds. This unique dataset of repeat sampling for individual fish allowed me to investigate (1) how gene expression of specific biomarkers changes over time, and in response to fisheries escape simulations, and (2) how the prevalence and loads of infectious agents changes over time and in response to fisheries escape simulations. I hypothesized that: (H1) Gene expression would change significantly as fish migrate through the Seton system and fisheries escape would alter these gene expression changes compared with control fish. (H2) Infectious agent prevalence and load would increase as fish migrated through the Seton system, and fisheries escape would cause a greater increase in prevalence and load in these fish compared with control fish.

Results from Chapter 3 suggested that infectious agents are having negative impacts on salmon migration and spawning success, which led to the development of Chapter 5 to further investigate the role of infectious agents in early mortality of Pacific salmon.

Chapter 4: This chapter aimed to investigate the impacts of high water temperatures on survival to spawning grounds, infectious agent prevalence and load, and gene expression of sockeye salmon in the wild. This study was conducted over two years, one year of relatively 'mild' water temperatures and another of relatively 'hot' water temperatures during the Fraser River migration period of Gates Creek sockeye salmon. I hypothesized that: (H1) in the year of warmer water 
temperatures, survival would be reduced, $(\mathrm{H} 2)$ infectious agent prevalence and loads would differ between these two years, and (H3) gene expression profiles would differ between years.

Chapter 5: This chapter aims to investigate the potential role of infectious agents in reducing the fitness of Pacific salmon during spawning migrations. The fish fence constructed on the Seton River collects moribund and recently deceased fish that perish trying to pass Seton dam. This study location therefore provides a unique opportunity to assess the contribution of infectious agents in reducing the ability of these fish to navigate Seton Dam tailrace and ultimately survive. In this study I compare infectious agent profiles of fish that perish at Seton dam compared with live fish captured at Seton fish fence. Specifically, I compared the prevalence, load, and diversity of 47 infectious agents known- or suspected to infect Fraser River Pacific salmon. I hypothesized that: (H1) Infectious agent profiles would differ between live and dead fish and (H2) only select infectious agents, with more damaging or harmful impacts on their host, may be contributing to mortality of sockeye salmon in this circumstance.

\subsection{Significance}

Pacific salmon are undeniably important for their economic, cultural, and ecological value (Lichatowich 1999, 2013; Gislason et al., 2017), and there is an urgent need to understand and prevent declines in salmon populations. In the Anthropogenic era, we are seeing declines in not only Pacific salmon populations (Peterman and Dorner, 2012; Grant et al., 2016), but also in many other migrant freshwater fishes (Deinet et al., 2020) and other taxa (Wilcove, 2008; Wilcove and Wikelski, 2008) across the globe. Wilcove and Wikelski (2008) identified the major threats to migrant populations as habitat destruction, overexploitation, barriers to migration routes (such as dams and fences), and climate change. Unfortunately, Pacific salmon are 
particularly vulnerable to all of these threats because their freshwater migration often occurs at specific times in peak summer temperature months, and due to their exceptional economic and nutritional value, they are frequently targeted by many fisheries. In this thesis, I investigate three of these four major migration stressors for a population of Pacific salmon: climate change (high water temperature), overexploitation (fisheries interactions), and migration route barriers (dams). It is becoming increasingly recognized that we need to move away from assessing the consequences of stressors in isolation, and instead investigate the impacts of multiple stressors and their cumulative impacts (Cohen, 2012; Miller et al., 2014; Deinet et al., 2020). Therefore, in this thesis, I investigate the consequences of cumulative fisheries, temperature, and dam stressors for salmon migration survival and behaviour. Infectious agents are also recognized as a threat to migrant species (Altizer et al., 2011), and for Pacific salmon they can have complex cumulative and interactive effects with fisheries interactions, water temperature, and overall fitness (Miller et al., 2014), and thus their impacts on migration behaviour and success also need to be well considered (Kent, 2011; Cohen, 2012). Management strategies can be improved if we further understand the threats to migrant populations, and how cumulative stressor might interact (Folt et al., 1999). In the Anthropocene, we must strive to protect the abundance of wild, migrant animal populations through continued research, and developing improved and innovative conservation and management strategies. 


\section{CHAPTER 2}

\section{Thermal selection and delayed migration following escape from simulated in-river fisheries capture for adult sockeye salmon (Oncorhynchus nerka)}

\subsection{Abstract}

During freshwater spawning migrations, Pacific salmon are frequently targeted by commercial and Indigenous fisheries sectors that use different types of nets. In addition to fish harvested by these fisheries, a proportion of fish may be released (either to comply with regulations or on a voluntary basis), while other fish manage to escape fishing gear prior to landing. The effects of by-catch or intentional release of salmon species from common fishing gears are well-documented. The occurrence (frequency) and subsequent consequences of escape from various fishing gears is, however, currently unknown. In this study, I aim to investigate the consequences of simulated escape from three gear types on migration behaviour, migration success, and spawning success for a population of sockeye salmon (Oncorhynchus nerka). Escape from three common fishing gears (gillnet, beach seine, and tangle net) employed in riverine environments was simulated. I simulated escape, as opposed to intentional release or bycatch, by quickly cutting fish from nets after one minute of entanglement with minimal force and handling, and no air exposure. I found no effect of gear escape on migration or spawning success. However, fish that escaped fishing gear took longer to migrate to spawning grounds 
compared with fish that did not experience any gear entanglement. Fish that escaped fishing gear also demonstrated behavioural thermoregulation as they swam at cooler temperatures through a lake system compared to fish that did not experience fishing gear interactions. In a follow-up study, I investigated the frequency and time of sockeye salmon to volitionally escape from gillnet entanglement. Of 155 fish were entangled in a gillnet, $46.5 \%$ were able to escape from the net by aggressively burst swimming. Of these fish that successfully escaped, $56.9 \%$ escaped in less than 10 seconds and $72.2 \%$ escaped in less than 1 minute. Escape times ranged from 1 second to 22 minutes. Collectively, these findings highlight that the number of fish that experience gillnet entanglement may be much higher than is currently estimated when escape is not considered, and fish that escape fishing gears do exhibit behavioural changes (longer migration time and behavioural thermoregulation) that might impact overall fitness or escapement in challenging environments. 


\subsection{Introduction}

Pacific salmon (Oncorhynchus spp.) are important economically and culturally and are targeted by several different fisheries sectors in marine and freshwater environments. In riverine areas, the most common harvest approaches for commercial salmon fisheries involves targeting fish during their spawning migration using gillnets, tangle nets, beach seine nets, and rod-andreel angling. Incidental harvest and by-catch commonly occurs so many fish are released from capture, while others escape from fishing gear. The frequency and fate of fish that are released or escape, here defined as non-retention fish, is of great interest and importance for fisheries managers to estimate spawning ground escapement, and thereby effectively manage salmon populations (Ricker, 1976; Patterson et al., 2017a, 2017b). Most research to date has focused on the consequences of by-catch release from common fishing gears (reviewed in: Raby et al., 2015; Patterson et al., 2017a), and escapement models include estimates of by-catch mortality (DFO, 2019). However, much less is known about the incidence and consequences of escape, nor are escapees accounted for in current escapement models.

Different gear types cause varying injuries, levels of exhaustion and stress for nonretention fish, and may also have different ultimate spawning and survival consequences (Cooke et al., 2013; Uhlmann and Broadhurst, 2013). It is therefore important to consider the consequences of fisheries interactions for different gears. During gillnet entanglement, fish can experience exhaustion, suffocation, lacerations (sometimes extensive and severe), and removal of mucus which can act as an entry point for infectious agents (Kojima et al., 2004; Baker and Schindler, 2009). A number of studies that have investigated migration survival of sockeye salmon (Oncorhynchus nerka) following gillnet release. Survival has been shown to vary with population (17.8 vs $34.2 \%$ survival for Harrison vs Weaver populations, respectively; 
Donaldson et al., 2012), sex and entanglement time (10 / $30 \%$ survival for females and 38 / 66\% survival for males experiencing 20 secs or 20 min entanglement time, respectively; Teffer et al., 2017), and maturation or river-location ( 35 vs $75 \%$ survival at lower vs upper river locations respectively; Bass et al., 2018b). Fisheries and Oceans Canada (DFO) currently estimates postrelease survival from gillnets to be $40 \%$ for Fraser River-caught salmon (DFO, 2019). Tangle nets are similar to gillnets except they typically have a smaller mesh size and larger hang-ratio intended to 'tangle' the fish in the net, as opposed to gillnets which tightly constrict around the operculum of the fish. Tangle nets can often be referred to as 'tooth tangle nets', typically when the design and use of the net is intended to tangle salmon around the mouth and teeth. Like gillnets, tangle nets can result in exhaustion, lacerations, and mucus loss, however survival following release is likely improved compared with gillnet capture (Vander Haegen et al., 2004; Donaldson et al., 2012). There have been comparatively fewer studies investigating the effects of tangle net entanglement on salmon, however Ashbrook et al. (2008) estimated survival to be $68.6 \%$ for adult Chinook salmon released from tangle nets in the Columbia River. DFO currently estimates survival from tooth tangle nets to be $90 \%$ for sockeye salmon in the Fraser River (DFO, 2019). Seine nets are typically less harmful to Pacific salmon (Bass et al., 2018b). Encounters with beach seines potentially harm fish by removing their mucus layer, and possibly through oxygen depletion in net sets with high densities (Raby et al., 2014a). There have been a number of studies investigating the impacts of beach seine release on adult salmon, and survival to spawning grounds has been reported from $33-82 \%$ for sockeye salmon (Donaldson et al., 2011; Robinson et al., 2015; Bass et al., 2018b). DFO has estimated survival to spawning grounds following a in-river beach seine encounter to be 95 \% (DFO 2019) for Fraser River sockeye salmon. 
Volitional gear escape (i.e. fish freeing themselves from entrapment in fishing gear prior to landing) differs from intentional release in that fish that escape do not experience air exposure or human handling. Fish that escape gillnets and tangle nets would likely have had to burst swim and push their way through, or out of, entanglement in the gillnet meshing. Fish that escape from seine nets would either need to swim under the lead line or jump over the float line. In all situations, we would expect fish to obtain some level of physical injury (e.g. removal of slime, wounds to skin, fins or gills, etc.). There are now a number of observational studies that have reported the number of sockeye salmon exhibiting clear signs of previous gillnet entrapment, and thus assuming these fish escaped from gillnets. In Bristol Bay, Alaska, authors found 6-44 \% of sockeye salmon on spawning grounds had markings consistent with gillnet entanglement, and 51 $\%$ of fish with these injuries failed to reproduce (Baker and Schindler, 2009). For Fraser River sockeye, Clarke et al. (1994) reported that between 1987-1994, 10 - >40 \% of certain populations of sockeye salmon on spawning grounds had markings consistent with gillnet entanglement. More recently, Bass et al. (2018a) found that between 2014-2016, 19-27\% of sockeye salmon captured on the Seton River had gillnet markings, and for these fish en-route mortality was increased by $16 \%$ and female pre-spawn mortality was increased by $18 \%$ compared with uninjured fish. Finally, Kanigan et al. (2019) observed an average of $19 \%$ of sockeye salmon on the Seton River to display gillnet markings between 2013-2016, and higher gillnet fishing efforts in the lower Fraser River was correlated with gillnet injury. These studies aimed to gain insight on the frequency and consequences of gillnet escape, however a number of limitations exist. First, gillnet escape is only assumed based on the presence of wounds consistent with gillnet entanglement. Second, we do not know the experience of the gillnet encounter (length of time entangled, number of encounters, when the net was encountered, etc.). Third, these findings only 
report the number of fish with gillnet markings at spawning grounds or a given location, and thus we do not know the number of fish that escaped gillnets but perished before study locations (the percentage of fish escaping gillnets is therefore likely higher). Further studies observing fish escape from experimental gear entanglements are needed to more accurately estimate the frequency of gear escape from common gear types.

It was recently observed that sockeye salmon seek out cooler water of thermal refuges in response to gillnet injuries (Bass, 2018). Thermal refuges are present along certain migration routes of Pacific salmon and allow fish to avoid high water temperatures (Newell and Quinn, 2005; Mathes et al., 2009; Keefer and Caudhill, 2015). Thermal refuges can include cooler water in lake hypolimnions or cooler glacial tributaries. In an era of warming water temperatures, thermal refuges may be increasingly important for the migration survival of Pacific salmon. Behavioural thermoregulation of Pacific salmon (in this context defined as the seeking of cooler water and holding in these areas) has been well documented, and it has been shown that fish seek out cooler water in response to warm water temperatures (Goniea et al., 2006), and energetic and reproductive statues (Roscoe et al., 2010), and this behaviour can increase survival to spawning grounds (Mathes et al., 2009), and increase spawning success (Minke-Martin et al., 2018). The finding by Bass (2018) that adult sockeye salmon seek out cooler water in lakes in response to gillnet injuries is interesting, and suggests that thermal refuges may be important at facilitating recovery and improving survival following fisheries interactions, although this has not been studied to date.

In this study, I aim to investigate the consequences of escape from common river fishing gears on migration behaviour and success for a population of adult sockeye salmon (Oncorhynchus nerka). Within riverine enclosures, I simulated gillnet, tangle net, and seine net 
fisheries allowing individual tagged fish to encounter and escape from gear. I then examined the subsequent short-term $(200 \mathrm{~m})$ and long-term migration $(50 \mathrm{~km})$ migration success, migration behaviour (migration rate and thermal selection in stratified lakes), and ultimate spawning success of females. During the fishery simulation, fish experienced no air exposure and minimal handling, but I limited the gear entanglement to a maximum of one minute. I hypothesized that migration success would be most negatively affected by escaping from gillnets and least affected by seine net escape. Consistent with previous studies (Mäkinen et al., 2000; Frank et al., 2009; Nguyen et al., 2014, Bass et al., 2019), I also predicted migration duration to be increased for fish that escape gear compared with control fish, because of the recovery time needed following exhaustive burst swimming and struggling while attempting gear escape. I hypothesized that fish that escape from fishing gear would choose to migrate at cooler temperatures through lakes compared with control fish. Using the same riverine enclosures, I also examined how long it took fish to volitionally escape from gillnets, and the subsequent effects of entanglement duration on migration survival and behaviour following escape. Gillnets were chosen for the entanglement duration study as they are the more harmful gear to salmon and typically result in higher FRIM (Bass et al., 2018b). I predicted that longer entanglement durations would result in lower migration survival following escape. 


\subsection{Methods}

\subsubsection{Study site}

Fish collection and tagging took place on the Seton River, a tributary of the Fraser River, British Columbia. Gates Creek sockeye salmon are an early summer-run population that migrate approximately $364 \mathrm{~km}$ from the Fraser River mouth to the tagging site on the Seton River, and a subsequent $50 \mathrm{~km}$ through the Seton Lake/Anderson Lake system to spawning grounds at Gates Creek (Fig. 2.1). The Seton Dam and fishway is situated $100 \mathrm{~m}$ upstream of the tagging site, and approximately $5 \mathrm{~km}$ upstream from the Seton River-Fraser River confluence (Fig. 2.1).

Migrating adult sockeye salmon must ascend the Seton Dam fishway en-route to spawning grounds. Passage success of adult sockeye salmon through the fishway has been extensively studied over the past decade and passage efficiency is extremely high ( $\sim 90 \%$; Harrower et al., 2019). An artificially enhanced spawning channel is operated $800 \mathrm{~m}$ upstream from the mouth of Gates Creek. A fish weir is constructed across the creek to divert fish towards the enhanced spawning channel entrance. This entrance is blocked by a gate that is manually operated to allow fish to enter the spawning channel or are instead allowed to pass further upstream into Gates Creek.

\subsubsection{Fish collection, gear simulation, and tagging}

In 2017 and 2018, I intercepted Gates Creek sockeye salmon on the Seton River using a river-spanning picket fence and trap (Fig. 2.2). This fence was constructed approximately $5 \mathrm{~km}$ upstream from the Fraser-Seton River confluence. After pulling pickets, fish were able to migrate freely upstream through the gaps in the fence. When all pickets were in place, fish were 
not able to migrate past the fence, except through one gap that was the entrance to an enclosed holding area. The fence was closed throughout the night for 10 hours to intercept sockeye during their peak hours of migration. The fence would then be opened for the remaining hours of the day to allow free movement of fish upstream. Fish would enter the holding area over night and would then be captured via dipnet for tagging and biopsy. Fish were captured in this way from Aug $8^{\text {th }}$ until Aug 20 $0^{\text {th }}$ in 2017, and from Aug $3^{\text {rd }}$ until Aug $15^{\text {th }}$ in 2018.

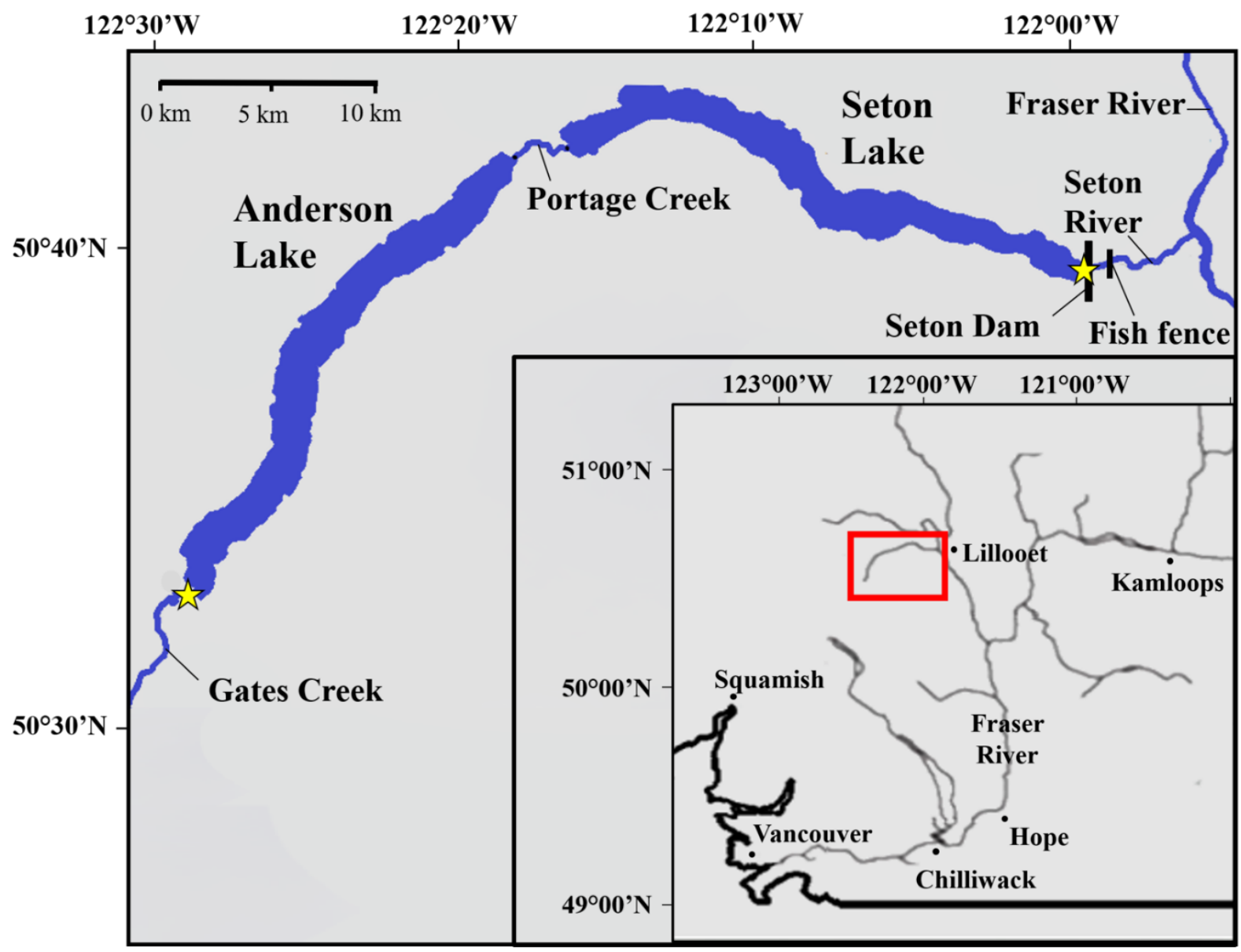

Figure 2.1. Map of the Seton system in British Columbia, Canada. The location of the Seton Dam and the fish fence are shown, and locations of PIT receivers on the Seton Dam fishway and at Gates Creek mouth are indicated by a yellow star. Map of the Fraser River is shown in the lower right-hand corner. The location of the Seton system is outlined by a red box on this map. 
Fish were captured from the holding area one at a time and transferred to a tagging trough with a continuous supply of river water. An initial assessment of fish condition was conducted that identify any wounds, an estimate of scale loss, and if the fish displayed old gillnet markings. Fish with any severe wounds, $>25 \%$ overall body scale loss, or any sign of old gillnet markings were not tagged as part of this study. Gross somatic energy (GSE) was also measured using a fish FatMeter (Model FM 692, Distell, West Lothian, Scotland, UK). GSE measurements from the FatMeter are helpful for differentiating sockeye populations (Casselman et al., 2016), thus I was able to identify Gates Creek sockeye salmon from other populations that may stray into the Seton River. Any straying sockeye, as identified through fat meter readings, were not used in this study to focus tagging and experimental efforts on a single population of sockeye salmon. Fish were then gastrically tagged using $32 \mathrm{~mm}$ half duplex (HDX) passive integrated transponder (PIT) tags (Oregon RFID, Portland, OR, USA) that had been inserted into smoothed acetal Delrin tube sections $1.59 \mathrm{~cm}$ in diameter, $3.81 \mathrm{~cm}$ in length. These gastric tags were inserted into the stomach of the fish using smoothed plungers. This gastric tagging procedure has been previously validated for use with adult sockeye salmon (Cooke et al., 2005). A subset of fish (N $=120$ in both years) also had temperature loggers (iButton Thermochron model DS1921Z or DS1922L; Maxim Integrated, San Jose, CA, USA) installed on their internal tag which were programmed to record the temperature of the fish every 30 minutes throughout the remainder of its migration. All internal tags were then waterproofed using Plasti Dip (International, St. Louis Park, MN, USA). Finally, fish were externally tagged using a $7.62 \mathrm{~cm}$ T-bar anchor tag (Floy Tag \& Mfg. Inc., Seattle, TA, USA) for visual identification of tagged fish. A total of 214 fish were tagged and sampled in this way at Seton River fish fence in 2017, and 230 fish were tagged and sampled in this way in 2018. 


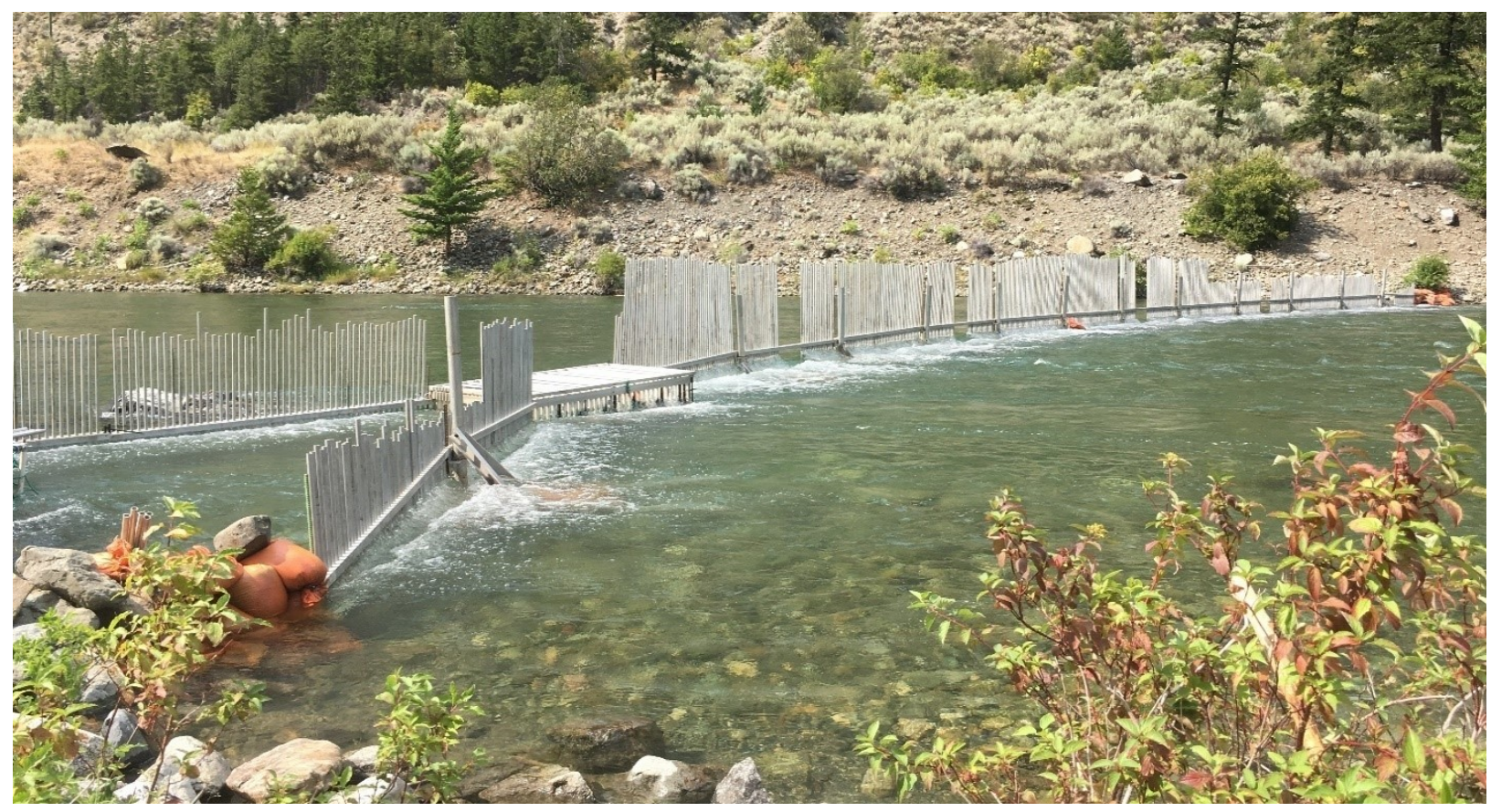

Figure 2.2. River-spanning fishing fence on the Seton River.

\subsubsection{Escape from various gear types (2017)}

In 2017, I aimed to investigate migration success and behaviour following fishing gear interaction and escape. I simulated fishing gear escapements using three gear types commonly used by in-river fisheries throughout the Fraser River. These gear types included beach seine net and 5.25-inch $(13.3 \mathrm{~cm})$ mesh gill net (mesh size most commonly used to target Fraser river sockeye) that mimicked either a loosely strung, high hang ratio net (here referenced to as "tangle net") or a tightly strung, low hang-ratio net (here referenced to as "gillnet"; Fig. 2.3). To simulate escape from a gillnet, fish were entangled for a maximum of $1 \mathrm{~min}$ (or less if the fish managed to volitionally escape) in small $(60 \mathrm{~cm}$ x $60 \mathrm{~cm})$ section of tightly strung gillnet and then quickly removed by cutting the net with no air exposure and minimal handling. To simulate a tangle net experience, fish were wrapped in a very loosely strung section of gillnet suspended in the water 
by two floats. In this simulation fish were in contact and tangled in the net often from their head to tail, as opposed to tightly around their operculum as in the gillnet simulation. Escape was mimicked by quickly unwrapping and/or cutting the net after 1 min of entanglement. For fish that experienced seine net escapement, a small section of seine net was used to corral the fish towards a sandy-rocky bank forcing the fish to escape under the lead line into a waiting dipnet. Following gear escape simulation, fish were quickly transferred back to the tagging trough and were re-assessed for any additional wounds, scale loss, fin damage, and net markings. Control treatment fish did not experience any gear escape simulation; these fish were dipnetted from the holding area of the fish fence, transferred to the tagging trough, and proceeded straight to tagging, as described above.

\subsubsection{Length of time entangled in a gillnet (2018)}

In 2018, I aimed to investigate migration success and migration behaviour following escape from a range of entanglement durations in a gillnet. In 2018, fish were again captured and tagged at Seton fence in the same way described above. For this part of the study, I entangled fish in a tightly strung gillnet (as described above). Fish were entangled for varying lengths of time until they escaped by themselves. A dipnet was held strategically behind the section of gillnet ready to quickly capture any escapees and quickly transfer them back to the tagging trough. For fish that were not able to escape, escape was mimicked by quickly cutting the net after various lengths of time, up to a maximum of 32 minutes. Again, a control group of fish were tagged but did not experience any gear escape simulation. Following escape simulation, fish were reassessed for injuries, scale loss, and net markings, then released on the upstream side of the fish fence. 


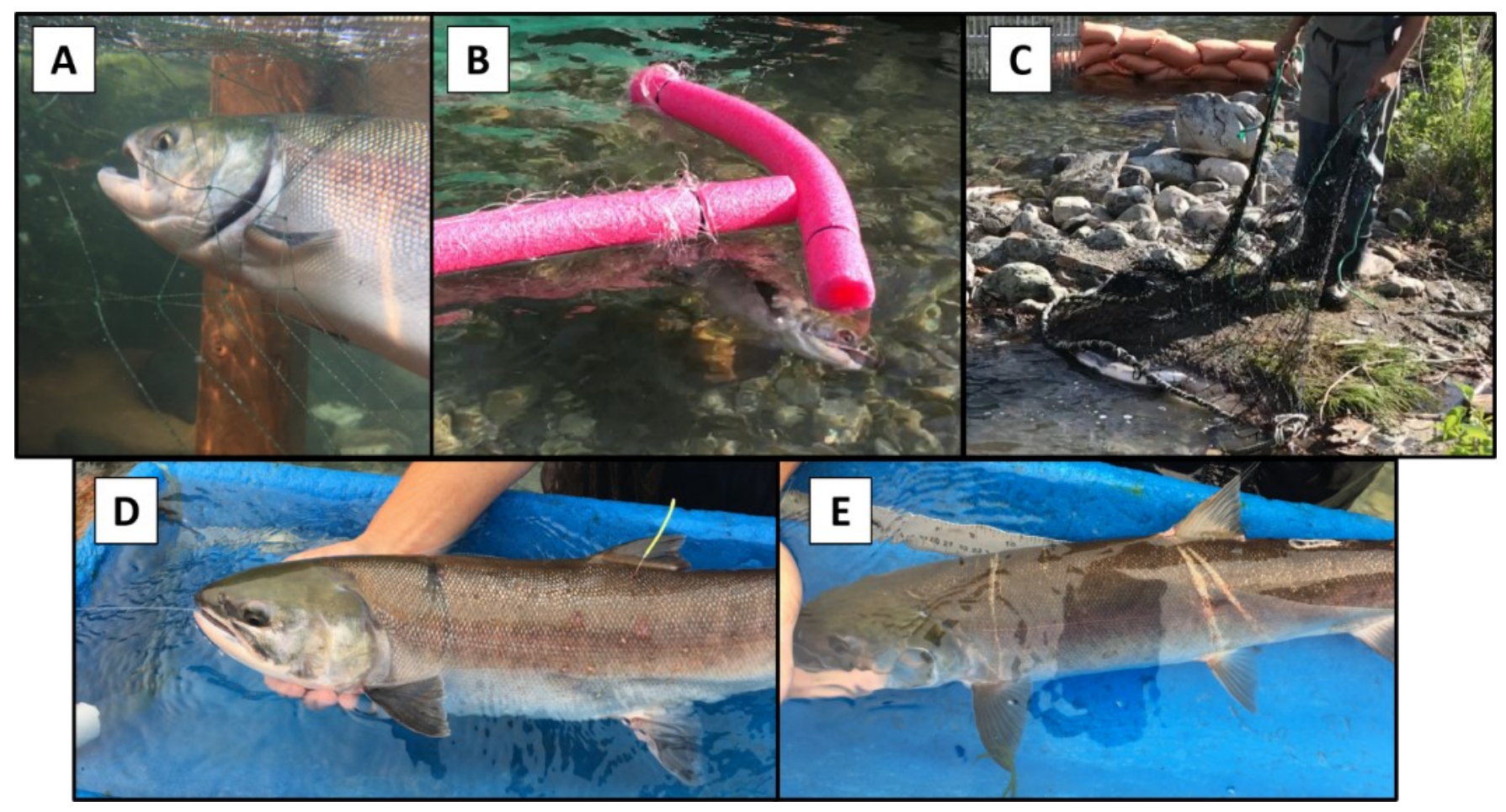

Figure 2.3. Photos of the experimental gear escape simulations performed in this study. (A) Gillnet entanglement simulation. Here a 5.25-inch $(13.25 \mathrm{~cm})$ mesh gillnet $(60 \mathrm{~cm} \mathrm{x} 60 \mathrm{~cm})$ was strung tightly across a wooden frame. As fish swam through the net they typically become entangled around their operculum, as shown. (B) Tangle net simulation. A 5.25-inch mesh gillnet was loosely strung between two floats. As fish swam through the loosely hung netting they typically became entangled in multiple places from their operculum to their caudal fin. (C) Seine net entrapment simulation. Fish were corralled into a shallow section of the riverbank and escape was simulated by dragging the lead line over the fish, as shown. (D) A tagged fish following gillnet escape simulation, displaying typical markings resulting from gillnet entanglement around the operculum. (E) Typical markings resulting from tangle net escape simulation.

\subsubsection{PIT telemetry}

To track the migration of fish from Seton fish fence to Gates Creek spawning channel three PIT antennas were installed along the migration route (Fig. 2.1). Two antennas were installed at Seton dam, one located at the fishway entrance and the second at the fishway exit. See Casselman et al. (2016) for a full description of these antennas installed at Seton Dam. A final antenna was installed approximately $100 \mathrm{~m}$ upstream from the mouth of Gates Creek. This 
was a pass-through antenna constructed from 1.5-inch PVC piping that measured $16 \mathrm{~m}$ in length (spanning the entire creek) and $1 \mathrm{~m}$ in diameter. Fish that were detected at this antenna were considered to have successfully migrated to spawning grounds.

\subsubsection{Recovery of carcasses}

Daily surveys of the artificial spawning channel were conducted to identify any carcasses of tagged fish. In addition, weekly creek walk surveys of the lower $6 \mathrm{~km}$ of Gates Creek were conducted to look for carcasses of tagged fish. Through these surveys I was able to recover temperature loggers, as well as determine spawning success for female fish. A failed female spawner was identified by egg retention. Female carcasses with approximately $50-100 \%$ of their eggs missing were determined successful spawners for this study.

\subsubsection{Statistical analyses}

2017 Study

Migration success to (a) Seton Dam and (b) Gates Creek was determined using detections at the PIT receivers placed at each site. The data were formatted as binary data representing either presence or absence of each fish at the receivers. Migration success to each of these sites was compared among the four treatment groups (control, gillnet, tangle net, and seine net) through mixed effects factorial logistic regression models using the glmer() function of the "Ime4" package (Bates et al., 2015). In these models, treatment, sex, and fork length were included as fixed effects and tagging date was included as a random effect to account for any 
differences in migration success due to date of tagging. In addition to investigating migration success to both Seton Dam and Gates Creek, I also tested for differences in migration time to these locations. Migration time was determined by calculating the difference in time (in days, minutes, hours) between fish release following tagging at Seton Fence, and first detection at each PIT receiver (separate models were constructed for migration success to Seton Dam or Gates Creek). Data was tested for normality using Shapiro-Wilks normality test, and log transformed where data was determined to not be normally distributed. I tested for differences in migration time between treatment groups using linear mixed effects models using the lmer() function from the "Ime4" package (Bates et al., 2015). These models included treatment, sex, and fork length as fixed effects and tagging date as a random effect.

Thermal experience through Seton and Anderson lakes was evaluated using temperature logger data from recovered carcasses at Gates Creek $(\mathrm{N}=50)$. I determined entrance into Seton lake as the first temperature recording following detection of the fish at the PIT receiver located at the fishway exit of Seton dam. I determined exit from Anderson lake as the final temperature recording before the first detection of the fish at the PIT receiver located at the mouth of Gates Creek. I eliminated temperature data as fish migrated through Portage Creek as fish are not able to thermally regulate in this section of creek. Temperatures as fish migrated through Portage Creek were determined by looking at the thermograph for each individual fish. The timespan of fish as they migrated through the creek was estimated as the temperature at which fish migrate through the creek (typically $19-20^{\circ} \mathrm{C}$ ) is much higher compared to the temperatures at which fish choose to migrate through in the lake (typically below $16^{\circ} \mathrm{C}$ ). The average temperature of each fish was then calculated for both Seton and Anderson lake separately, as well as both lakes combined. The maximum aerobic scope $\left(9.98 \mathrm{mg} \mathrm{O} 2 \cdot \mathrm{kg}^{-1} \cdot \mathrm{min}^{-1}\right)$ and optimum temperature 
$\left(16.4^{\circ} \mathrm{C}\right)$ of migration for Gates Creek sockeye has been previously determined through swim tunnel experiments (Eliason et al., 2011). I calculated the proportion of migration through the lakes at which fish migrated within $90 \%$ of their maximum aerobic scope as per Minke-Martin et al. (2018). I tested for differences in average migration temperature and proportion of time spent within $90 \%$ of their maximum aerobic scope between sexes and treatment groups using linear mixed effect models (lmer() function from the "lme4" package; Bates et al., 2015) that accounted for tagging date as a random variable.

For female carcasses recovered at Gates Creek spawning areas, I was able to test the impact of gear escape on ultimate spawning success. Spawning success was formatted as binary data as females were categorized as either successful or failed spawners. I tested the impacts of gear escape on spawning success using mixed effects factorial logistic regression models using the glmer() function from the "Ime4" package (Bates et al., 2015). In this model, treatment and fork length were included as fixed effects. Date of arrival to Gates Creek (first detection at Gates Creek PIT receiver) was included as a random effect to account for any differences date of arrival to spawning grounds might have here.

\section{Study}

To test the effects of length of time entangled in a gillnet, fish were categorized into five groups depending on the length of time they spent entangled: $<1 \mathrm{~min}, 1-5$ mins, 5-10 mins, 10-20 mins, 20-32 mins (groups 1-5, respectively). Migration success to either Seton Dam fishway exit or Gates Creek was compared among the six treatment groups (control, groups 1-5) using mixed effects factorial logistic regression models using the glmer() function from the "lme4" package 
(Bates et al. 2015). In these models, treatment group, sex, and fork length were included as fixed effects and tagging date was included as a random effect to account for any differences in migration success due to date of tagging. I tested for differences in migration time between groups using linear mixed effects models using the lmer() function from the "lme4" package (Bates et al., 2015). Data were tested for normality using Shapiro-Wilks normality test, and log transformed where data was determined to not be normally distributed. These models included treatment group, sex and fork length as fixed effects and tagging date as a random effect.

\subsection{Results}

\subsubsection{Consequences of gear escape simulations (2017)}

I found no significant difference in migration success past Seton Dam or to Gates Creek among treatment groups or sexes (Table 2.1). In 2017, $95.2 \%$ of all tagged fish successfully migrated to Seton Dam fishway exit PIT receiver, and $78.2 \%$ of all tagged fish successfully migrated to Gates Creek PIT receiver. However, I did find gear escape to significantly prolong migration time to both Seton Dam (Figure 2.4a) and Gates Creek (Figure 2.4b) compared to control fish (Table 2.1). Control fish were significantly quicker to pass Seton Dam (13.1 \pm 13.3 hours) compared to fish that experienced gillnet escape (20.0 \pm 16.5 hours) and seine net escape (21.5 \pm 16.5 hours) simulation. Fish that experienced tangle net escape simulation also took longer to pass Seton Dam (15.6 \pm 12.4 hours) compared to control fish, however this difference was not statistically significant. See Table 2.2 for a full comparison of migration success rates and migration times to both Seton Dam and Gates Creek across all treatments. 
Table 2.1. Model results for logistic and linear regression models testing the effects of treatment, and sex on various response variables related to migration success, time, and temperature.

Significant findings $(\mathrm{p}<0.05)$ are boldened.

\begin{tabular}{|c|c|c|c|c|c|c|c|c|}
\hline \multirow[b]{2}{*}{$\begin{array}{l}\text { Response } \\
\text { Variable }\end{array}$} & \multirow[b]{2}{*}{ Model Type } & \multirow[b]{2}{*}{$\mathrm{N}$ obs } & \multirow[b]{2}{*}{$\begin{array}{c}\text { Model } \\
\text { Parameter }\end{array}$} & \multicolumn{3}{|c|}{ Treatment } & \multirow[b]{2}{*}{ Sex } & \multirow[b]{2}{*}{$\begin{array}{c}\text { Fork } \\
\text { Length }\end{array}$} \\
\hline & & & & G & $\mathrm{S}$ & $\mathrm{T}$ & & \\
\hline \multirow{3}{*}{$\begin{array}{c}\text { Success } \\
\text { past Seton } \\
\text { Dam } \\
\end{array}$} & \multirow{3}{*}{$\begin{array}{l}\text { Logistic mixed } \\
\text { effects model }\end{array}$} & \multirow{3}{*}{214} & $\beta$ & -0.088 & 0.59 & 16.24 & 0.44 & -0.17 \\
\hline & & & SE & 0.92 & 1.14 & 1747.21 & 0.87 & 0.14 \\
\hline & & & $\mathrm{p}$ & 0.92 & 0.60 & 0.99 & 0.61 & 0.21 \\
\hline \multirow{3}{*}{$\begin{array}{c}\text { Migration } \\
\text { time past } \\
\text { Seton Dam }\end{array}$} & \multirow{3}{*}{$\begin{array}{l}\text { Linear mixed } \\
\text { effects model }\end{array}$} & \multirow{3}{*}{214} & $\beta$ & 0.47 & 0.58 & 0.20 & -0.065 & -0.022 \\
\hline & & & SE & 0.18 & 0.17 & 0.18 & 0.14 & 0.023 \\
\hline & & & $\mathrm{p}$ & 0.0099 & 0.0010 & 0.28 & 0.65 & 0.36 \\
\hline \multirow{3}{*}{$\begin{array}{c}\text { Success to } \\
\text { Gates } \\
\text { Creek }\end{array}$} & \multirow{3}{*}{$\begin{array}{l}\text { Logistic mixed } \\
\text { effects model }\end{array}$} & \multirow{3}{*}{214} & $\beta$ & -0.24 & 0.36 & 1.22 & 0.24 & 0.02 \\
\hline & & & SE & 0.44 & 0.48 & 0.66 & 0.38 & 0.06 \\
\hline & & & $\mathrm{p}$ & 0.59 & 0.45 & 0.06 & 0.52 & 0.81 \\
\hline \multirow{3}{*}{$\begin{array}{c}\text { Migration } \\
\text { time to } \\
\text { Gates } \\
\text { Creek }\end{array}$} & \multirow{3}{*}{$\begin{array}{l}\text { Linear mixed } \\
\text { effects model }\end{array}$} & \multirow{3}{*}{214} & $\beta$ & 2.12 & 2.41 & 1.38 & -0.014 & -0.15 \\
\hline & & & SE & 0.89 & 0.83 & 0.85 & 0.67 & 0.11 \\
\hline & & & $\mathrm{p}$ & 0.019 & 0.0045 & 0.11 & 0.98 & 0.19 \\
\hline \multirow{3}{*}{$\begin{array}{l}\text { Spawn } \\
\text { success }\end{array}$} & \multirow{3}{*}{$\begin{array}{l}\text { Logistic mixed } \\
\text { effects model }\end{array}$} & \multirow{3}{*}{214} & $\beta$ & -1.59 & 0.20 & -0.89 & - & -0.001 \\
\hline & & & SE & 1.21 & 0.79 & 0.84 & - & 0.13 \\
\hline & & & $\mathrm{p}$ & 0.19 & 0.80 & 0.29 & - & 0.99 \\
\hline \multirow{3}{*}{$\begin{array}{l}\text { Mean temp } \\
\text { Seton Lake }\end{array}$} & \multirow{3}{*}{$\begin{array}{l}\text { Linear mixed } \\
\text { effects model }\end{array}$} & \multirow{3}{*}{42} & $\beta$ & -0.74 & -0.48 & -0.05 & 0.64 & 0.0086 \\
\hline & & & SE & 0.93 & 0.81 & 0.75 & 0.66 & 0.10 \\
\hline & & & $\mathrm{p}$ & 0.43 & 0.55 & 0.94 & 0.33 & 0.93 \\
\hline \multirow{3}{*}{$\begin{array}{l}\text { Mean temp } \\
\text { Anderson } \\
\text { Lake }\end{array}$} & \multirow{3}{*}{$\begin{array}{l}\text { Linear mixed } \\
\text { effects model }\end{array}$} & \multirow{3}{*}{42} & $\beta$ & 0.34 & -0.27 & 0.33 & -0.23 & 0.059 \\
\hline & & & SE & 0.55 & 0.48 & 0.44 & 0.39 & 0.061 \\
\hline & & & $\mathrm{p}$ & 0.54 & 0.57 & 0.45 & 0.57 & 0.34 \\
\hline \multirow{3}{*}{$\begin{array}{l}\text { Proportion } \\
\text { of time in } \\
\mathrm{T}_{\mathrm{OPT}} \mathrm{AS}\end{array}$} & \multirow{3}{*}{$\begin{array}{l}\text { Linear mixed } \\
\text { effects model }\end{array}$} & \multirow{3}{*}{42} & $\beta$ & 0.079 & -0.047 & 0.054 & 0.037 & 0.004 \\
\hline & & & $\mathrm{SE}$ & 0.072 & 0.063 & 0.058 & 0.051 & 0.008 \\
\hline & & & $\mathrm{p}$ & 0.28 & 0.46 & 0.37 & 0.48 & 0.66 \\
\hline
\end{tabular}


Table 2.2. Summary of migration success and migration time ( \pm standard error) of fish to both Seton Dam fishway exit and Gates Creek spawning grounds for each gear escape treatment group ( $\mathrm{C}=$ control, $\mathrm{G}$ = gillnet escape, $\mathrm{S}=$ seine net escape, $\mathrm{T}=$ tangle net escape) and for both males $(\mathrm{M})$ and females $(\mathrm{F})$. The average migration temperatures ( \pm standard error) of fish through both Seton and Anderson Lakes is also shown.

\begin{tabular}{|c|cccc|cc|}
\hline & \multicolumn{5}{|c|}{ Treatment } & \multicolumn{3}{c|}{ Sex } \\
\cline { 2 - 7 } & $\mathrm{C}$ & $\mathrm{G}$ & $\mathrm{S}$ & $\mathrm{T}$ & $\mathrm{M}$ & $\mathrm{F}$ \\
\hline $\begin{array}{c}\text { Success past Seton Dam (\% } \\
\text { surviving) }\end{array}$ & 95.8 & 94.9 & 97.6 & 100 & 96.6 & 96.9 \\
Migration time past Seton Dam & $13.1 \pm$ & $20 \pm$ & $21.5 \pm$ & $15.6 \pm$ & $15 \pm$ & 18.3 \\
(hrs) & 13.3 & 17.1 & 16.5 & 12.4 & 13.4 & \pm 16.4 \\
& & & & & & \\
Success to Gates Creek (\% & 77.1 & 74.4 & 83.3 & 91.8 & 82 & 78 \\
surviving) & & & & & & \\
Migration time to Gates Creek & $12.6 \pm$ & $14.7 \pm$ & $14.9 \pm$ & $14.2 \pm$ & $13.5 \pm$ & $14.1 \pm$ \\
(days) & 3.6 & 4.17 & 4.18 & 4.51 & 3.41 & 4.85 \\
Average Temperature Seton & $15.1 \pm$ & $14.4 \pm$ & $14.4 \pm$ & $15.1 \pm$ & $15.2 \pm$ & $14.4 \pm$ \\
Lake ( $\left.{ }^{\circ} \mathrm{C}\right)$ & 1.92 & 2.15 & 1.61 & 1.37 & 1.55 & 2.06 \\
$\quad$ & & & & & & \\
Average Temperature Anderson & $12.6 \pm$ & $13.0 \pm$ & $12.3 \pm$ & $12.9 \pm$ & $12.7 \pm$ & $12.6 \pm$ \\
Lake $\left({ }^{\circ} \mathrm{C}\right)$ & 1.01 & 1.46 & 1.40 & 0.39 & 0.92 & 1.24 \\
\hline
\end{tabular}



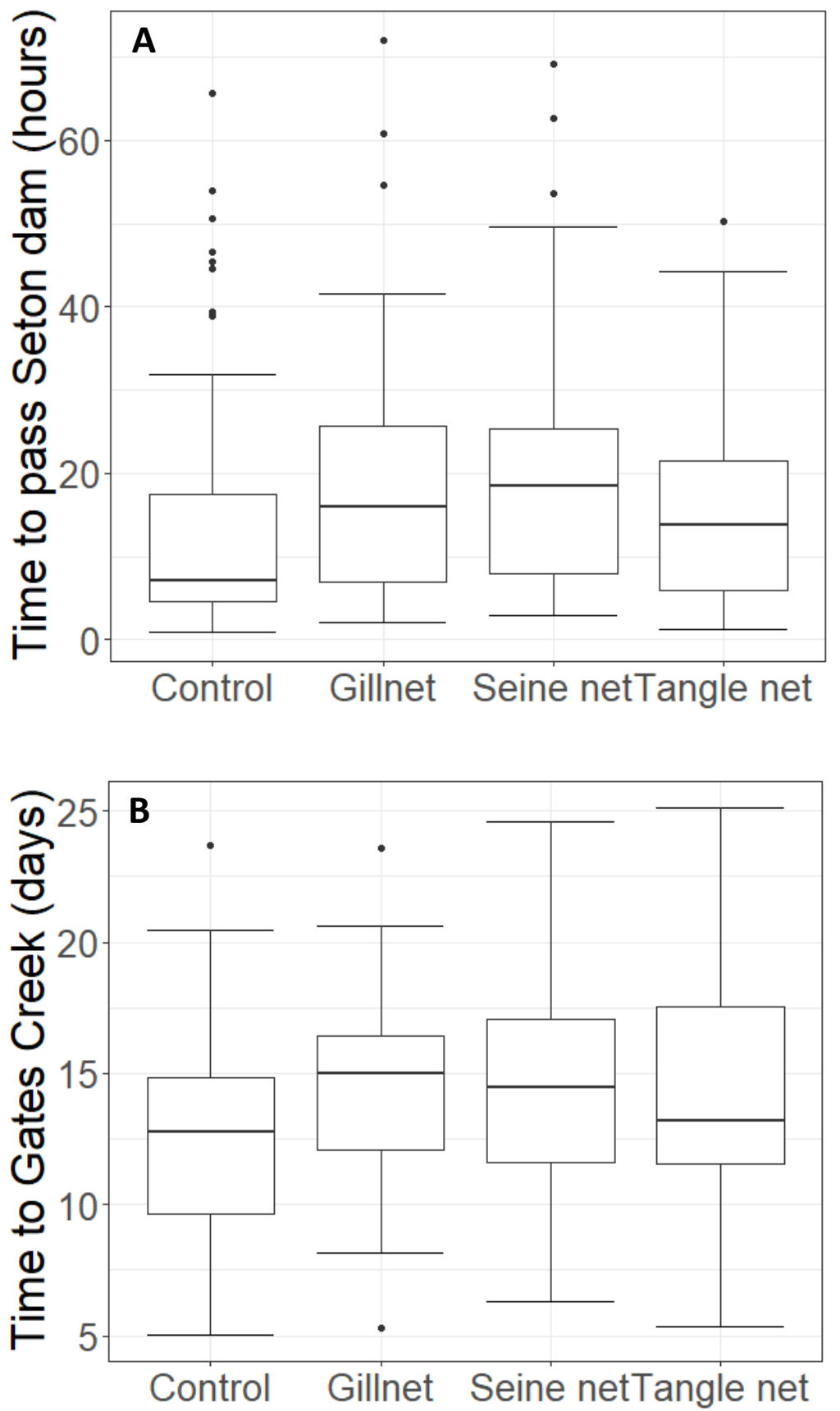

Figure 2.4. (A) Migration time to pass Seton Dam (as defined by time of release following tagging to final detection at dam fishway exit PIT receiver) across all treatment groups. Fish that experience gill net and seine net escape simulation take significantly longer to pass Seton Dam compared to control fish. (B) Migration time to Gates Creek spawning grounds (defined as time of release following tagging to first detection at PIT receiver located at the mouth of Gates Creek). Fish that experience gill net and seine net escape simulation take significantly longer to migrate to Gates Creek compared to control fish. For each boxplot, the centre black line of the box indicates the median, the upper and lower box limits represent the first and third quartiles, the whiskers represent 1.5 times the inter-quartile range, and the points represent outliers. 


\subsubsection{Thermal selection during lake migration}

A total of 42 temperature loggers were recovered from carcasses at Gates Creek in 2017. The average temperature at which fish migrated through Seton Lake was $14.89^{\circ} \mathrm{C}$, and in Anderson Lake was $12.66{ }^{\circ} \mathrm{C}$ (Table 2.1). For Seton Lake migration, fish that experienced gillnet $(p=0.0038)$ or seine net escape $(p=0.003)$ simulation migrated at significantly cooler temperatures compared with control fish (Fig. 2.5). The average Seton Lake temperature ( \pm standard error) of control fish was $15.1 \pm 1.92{ }^{\circ} \mathrm{C}$, of gillnet escape fish was $14.4 \pm 2.15^{\circ} \mathrm{C}$, of seine net escape fish was $14.4 \pm 1.61{ }^{\circ} \mathrm{C}$, and of tangle net escape fish was $15.1 \pm 1.37^{\circ} \mathrm{C}$ (Table 2.1). There was no significant difference in the average migration temperature through Anderson Lake between treatment groups (Table 2.1). There was also no significant difference in the proportion of time fish spent within $90 \%$ of their maximum aerobic scope, between treatment groups (Table 2.1).

\subsubsection{Female spawning success following gear escape}

A total of 44 female carcasses were recovered either in Gates Creek or the artificial spawning channel. Of these females, $47.7 \%$ had successfully spawned. I did not find gear escape simulation treatments $($ Table 2.1$)$ or migration temperature through the Seton $(\beta=-0.13, \mathrm{SE}=$ $0.25, \mathrm{p}=0.60)$ or Anderson Lakes $(\beta=0.58, \mathrm{SE}=0.51, \mathrm{p}=0.26)$ to have any significant effects on spawning success. 

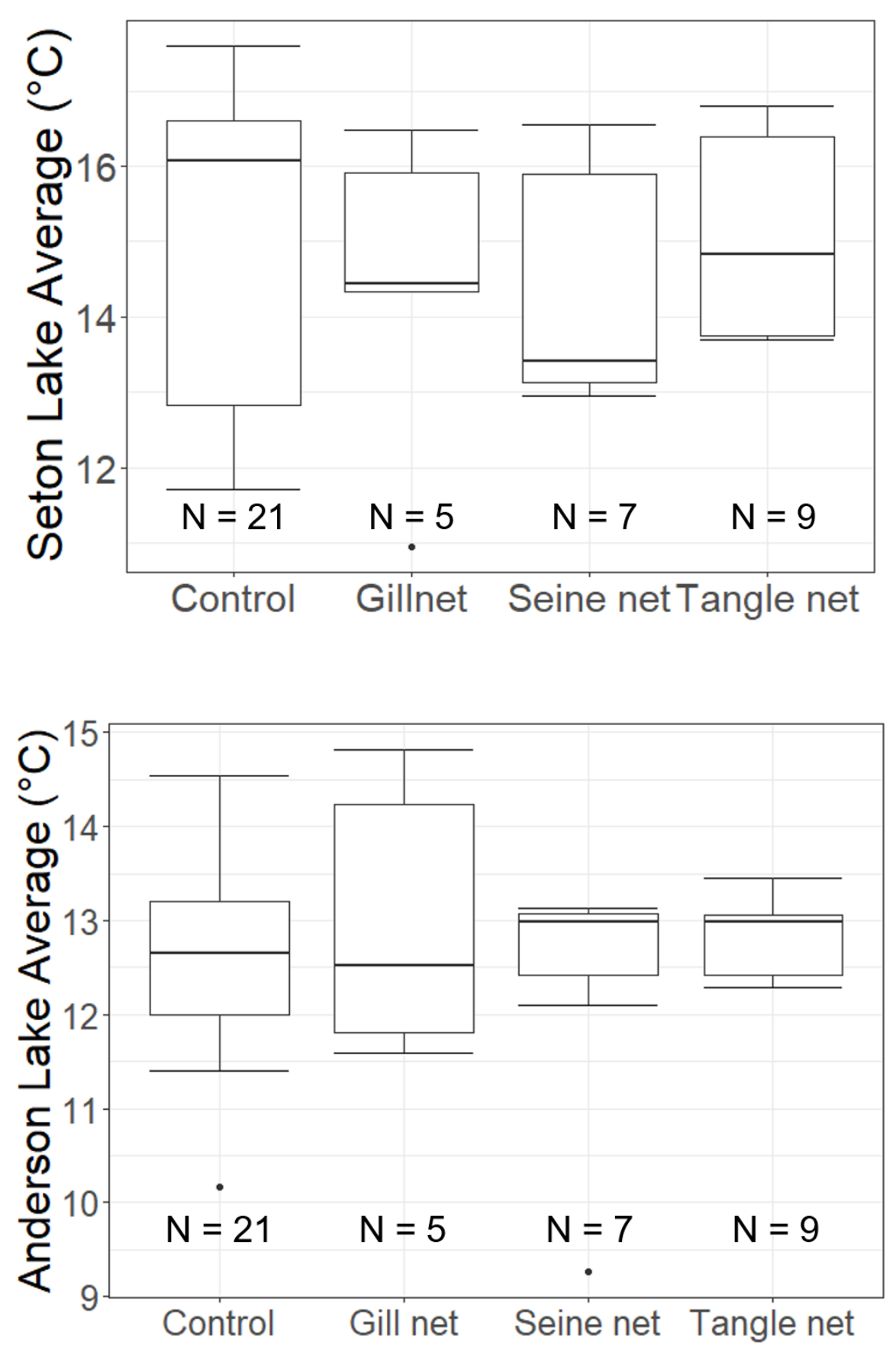

Figure 2.5. Temperature of migration through both Seton and Anderson lakes. Fish that experienced gillnet or seine net escapement migrated at significantly cooler temperatures through Seton Lake compared with control fish that did not encounter any fishing gear. There was no significant difference between treatment groups in Anderson Lake. For each boxplot, the centre black line of the box indicates the median, the upper and lower box limits represent the first and third quartiles, the whiskers represent 1.5 times the inter-quartile range, and the points represent outliers. 


\subsubsection{Initial estimate on proportion of fish that can escape from a gillnet (2018)}

I simulated gill net entanglement for 155 Gates Creek sockeye salmon. Of these, 72 (46.5 \%) were able to escape by themselves from the gillnet. Of these fish that successfully escaped, $41(56.9 \%)$ escaped in less than 10 seconds and $52(72.2 \%)$ escaped in less than 1 minute (Fig. 2.6). Fish were able to escape from 1 second -22 mins.

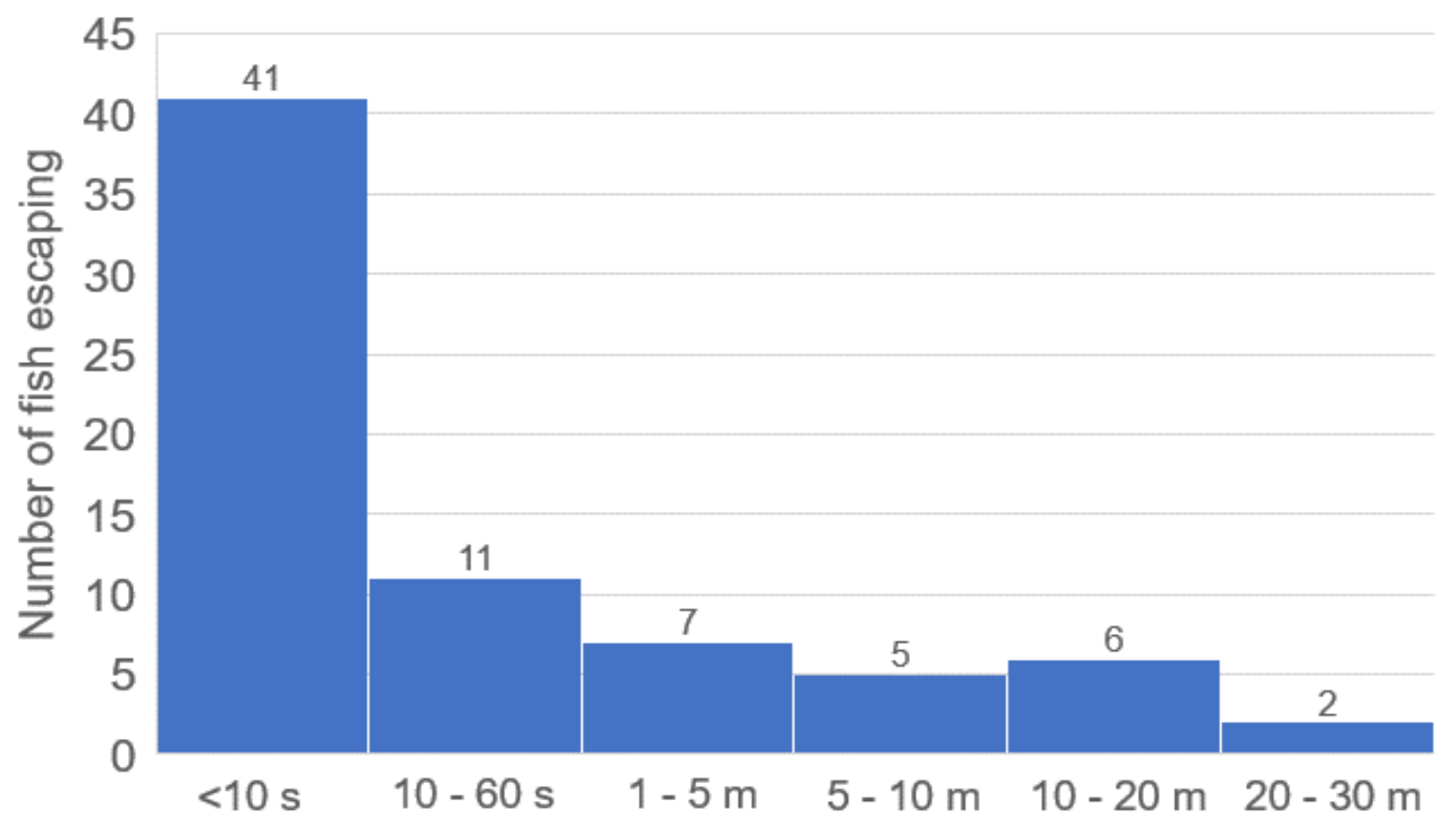

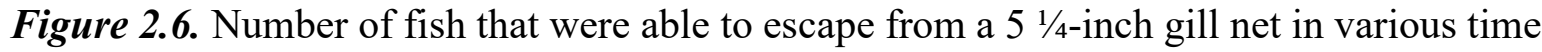
periods. The greatest proportion of fish $(46.5 \%)$ were able to escape in less than 10 seconds.

\subsubsection{Length of time entangled in gillnet (2018)}

I found no significant effect of length of time entangled in a gillnet on migration success or time to either Seton Dam or Gates Creek. During this year (2018), overall migration success past Seton Dam was 81.7 \% for all tagged fish. Migration success to Gates Creek was $21.7 \%$ for all tagged fish. Survival of male fish was higher than female fish ( $26 \%$ vs $18 \%$, respectively; $p$ 
$=0.082$ ). The average time for fish to reach the Seton Dam fishway exit PIT receiver was 1.36 days. The average time for fish to reach Gates Creek mouth PIT receiver was 23.66 days.

In 2018, only 13 fish carcasses were recovered during Gates Creek and Spawning Channel surveys. Of these, only 8 were females and 4 had temperature loggers. Due to these low sample sizes I was unable to statistically analyze spawn success or thermal experience through the Seton system in 2018. Of the eight females, three had successfully spawned (37.5 \% of all female carcasses recovered).

\subsection{Discussion}

Gear escape is likely a common occurrence that is unaccounted for in current escapement estimates. Through this study I have furthered our understanding of both the consequences of escape from three common fishing gears (gillnets, tangle nets, and seine nets), and the frequency at which this might occur. Contrary to my hypotheses, I found no effect of gear escape on migration- or spawning success for Gates Creek sockeye salmon. However, gear escape did prolong migration and the fish that escaped gear typically migrated through Seton Lake at cooler temperatures compared to control fish, thus supporting my original hypotheses. Despite having no direct impacts on mortality or spawning success for this population of sockeye salmon, I speculate that gear escape is a common stressor, and suggest that fish that escape gear modify their behaviour to facilitate recovery, and enhance survival, following escape. 
Consequences of gear escape from three common fishing gears on migration success and behaviour (2017)

For Gates Creek sockeye salmon captured on the Seton River, gear escape simulations had no impacts on mortality or spawning success. However, I would expect to find a different result for other populations of sockeye salmon, or for salmon that escape gear in different river locations (and thus at different maturation states). Previous work has shown that the consequences of fisheries interactions can vary with population and location (Donaldson et al., 2012; Bass et al., 2018b). Specifically, Bass et al. (2018b) found that survival of late-run Shuswap sockeye salmon following gillnet and seine net capture increased substantially as fish approached spawning grounds. During this study, Bass et al. (2018b) captured fish using either gillnets or seine nets at locations situated $10 \%, 26 \%$, or $72 \%$ of their $500 \mathrm{~km}$ freshwater migration, and survival was reported to be $35 \%, 46 \%$, and $75 \%$, respectively, thus highlighting the increased resilience to fisheries interactions as these fish mature. As salmon approach spawning grounds, they undergo a suite of physiological and maturation changes, including the thickening of skin (Robertson and Wexler, 1960), scale reabsorption (Kacem et al., 1998), and increases in blood cortisol levels (Baker and Vynne, 2014). These changes are likely the reason for increased resilience to fisheries interactions as salmon migrate and mature. During this study, Gates Creek sockeye salmon experienced gear escape simulations in the Seton River after completing approximately $88 \%$ of their total freshwater migration. I therefore expect resilience to fisheries interactions, and subsequent survival, to be high for these fish. I would predict survival to be greatly reduced for salmon that escape fishing gears at locations lower on the Fraser River, when fish are less mature and with longer distances still ahead of them to spawning grounds. 
Fish that experienced gillnet or seine net escape simulations showed increased migration time to spawning grounds, a common sub-lethal finding consistent with other telemetry research assessing migration rate following fisheries interactions (Mäkinen et al., 2000; Frank et al., 2009; Nguyen et al., 2014, Bass et al., 2019). Migration delay following fisheries interactions is likely due to anaerobic, exhaustive swimming while attempting to escape; fish must then 'repay' this oxygen debt before they can continue with their migration (Lee et al., 2003). Although I did not find any effect of gear escape on survival in this study, migration delay might have further negative sublethal or lethal consequences for fish under certain circumstances or if fish are challenged with additional stressors (i.e. high water temperatures, turbulent flows, re-capture or disease). In other systems, migration delay has been shown to be associated with reduced survival (Caudill et al., 2007) and potentially maladaptive spawning ground activity (Dickerson et al., 2005; Richard et al., 2014).

Through temperature-logging iButtons I observed fish that escape gillnets and seine nets to migrate at cooler temperatures through Seton Lake (average of $14.4^{\circ} \mathrm{C}$ ) compared with control fish $\left(15.1^{\circ} \mathrm{C}\right)$. This suggests that fish might seek out cool water refuge in response to fisheries interactions. Previous research tagging Gates Creek sockeye salmon on the Seton river aimed to assess the consequences of gillnet injuries for fish that were captured at the Seton fish fence (Bass, 2018). That study found fish with more severe gillnet injuries were more likely to migrate at cooler temperatures through Seton and Anderson lakes. Here, I found fish that escaped gillnets or seine nets utilized cooler temperatures in Seton Lake. This behavioural thermoregulation may be a response to mitigate stress (Goniea et al., 2006), to aid in healing wounds (Jensen et al., 2015), or to defend against infection (Mathes et al., 2009; Bradford et al., 2010) following fisheries escape. It may be possible that survival following fisheries interactions 
is improved if fish have the opportunity to seek out cooler water, however further research is needed to confirm this. A limitation of my study is that I only have temperature data for those fish that survived to spawning grounds. The thermal experience of those fish that die en-route may reveal interesting behaviours, or reveal the consequences of migrating at warmer, or even cooler, temperatures for fish following fisheries interactions.

Consequences of gillnet entanglement duration on migration success and behaviour (2018)

Due to unusually high mortality of Gates Creek sockeye salmon in 2018, I was unable to test my hypothesis that longer gillnet entanglement times would reduce survival and spawning success. In 2018, I found overall migration success past Seton Dam was $81.7 \%$ for all tagged fish and migration success to Gates Creek was $21.7 \%$ for all tagged fish. Through previous years of PIT tagging Gates Creek sockeye salmon at the Seton River fish fence (2014-2017), typical survival to spawning grounds of male fish ranged from $80-86 \%$, and for females ranged from 73-85 \% (Bass et al., 2018a; Harrower et al., 2019). In 2018 I found $26 \%$ of males and $18 \%$ of females survived to spawning grounds. Similarly, Seton Dam passage success was lower in 2018 compared with previous years. In 2014 and 2015 dam passage was reported to be 98 and $97 \%$, respectively (Casselman et al., 2016), and in 2017 I found that dam passage success was $96 \%$. However, in 2018 dam passage success was only 81.7 \%. In 2018, Fraser River water temperatures recorded at Hope and Texas Creek were very high with temperatures surpassing 20 ${ }^{\circ} \mathrm{C}$ for approximately 2 weeks during the peak Gates Creek sockeye salmon Fraser River migration period (DFO, Environmental Watch). I therefore speculated that extreme warm water temperatures in 2018 resulted in such high mortality and thus confounded my results on migration survival following gillnet entanglement simulations. Results of unusually high 
mortality recorded in 2018, which I speculated to be a result of extreme high-water temperatures, led to the development of Chapter 4.

Although I did not find any effect of gillnet entanglement duration on survival past Seton Dam or to Gates Creek spawning grounds in 2018, I recommend that this study be repeated in a year without such high-water temperatures. With warm water temperatures likely confounding results in 2018, I cannot make any conclusive statements regarding the consequences of gear escape following gillnet entanglement. A limitation of field studies that involve the tagging of salmon in the wild is the inability to control environmental conditions, such as water temperature. Teffer et al. (2017) studied the impacts of gillnet entanglement times (20 seconds vs 20 mins) on sockeye salmon in a holding study, where water temperature could be well controlled. In that study, researchers found that longer gillnet entanglement resulted in reduced survival. Other studies have examined the impacts of fisheries interactions and water temperature on survival, and generally reported that mortality was higher at warmer water temperatures, and warm water temperature confound the effects of fisheries interactions (Gale et al., 2013). I would therefore expect that if water temperatures were not so high, I would see reduced survival with longer gillnet entanglements.

An initial estimate on observed gillnet escape (2018)

In 2018 I also performed an experimental study to gain an initial estimate of the number of sockeye salmon that are able to volitionally escape from a 5.25-inch gillnet. I found that 46.5 $\%$ of fish were able to escape by themselves from the gillnet, $56.9 \%$ of these escaped in less than 10 seconds and $72.2 \%$ escaped in less than 1 minute. Previous observational studies have 
found a large percentage of fish often display markings consistent with previous gillnet entanglement, thus suggesting these fish have escaped (Baker and Schindler, 2009; Bass et al., 2018a; Kanigan et al., 2019). However, with these observational studies, a strong assumption is made that fish with gillnet markings volitionally escaped, but in fact the previous experience of that fish is not known. These studies also lack knowledge of the number of fish that had gillnet markings but died before reaching the research sampling sites, so it is likely the number of escapees is higher than estimated. Indeed, in this study, I witnessed $46.5 \%$ of sockeye entangled in gillnets were able to escape, which is a higher proportion of escapees than estimates from observational studies at the same location (19-27 \% from 2014-2016; Bass et al., 2018a; Kanigan et al., 2019). Collectively, these studies indicate that gillnet escape is a frequent occurrence. Baker and Schindler (2009) found that $51 \%$ of fish with gillnet markings (assumed to have escaped) failed to reproduce, and Bass et al. (2018a) found that for fish with gillnet markings, en-route mortality was increased by $16 \%$ and female prespawn mortality was increased by $18 \%$. Results suggest that gear escape can have numerous lethal, and sub-lethal, impacts on sockeye salmon. Currently, gear escape is not incorporated into escapement estimate models. Gear escape can have severe consequences for fish, and thus escapement estimates may be over-inflated by not considering gear escape frequency and consequences. I recommend further research to quantify the occurrence of gear escape, and the consequences of escape for other populations of fish, in lower sections of the Fraser River, where fish are less mature and likely less resilient to fisheries encounters (Bass et al., 2018b). The ability to escape fishing gear may also depend on a number of factors, including size and morphology of the fish in relation to mesh sizing, the size and strength of a fish, and burst swimming abilities (Broadhurst et al., 2006). 


\subsection{Conclusions}

I observed that nearly half of all fish entangled in a typical river gillnet were able to escape. For Gates Creek sockeye salmon that experienced gear escape simulations in the Seton River, I found no impact on survival, but I did find evidence of migration delay and behavioural thermoregulation in response to gear escape, indicating a need to recover from the stress and exhaustive exercise needed for escape. The observation of differential thermal experience by fish that escaped is fascinating and more work is needed to understand if the fish are actively seeking out cooler temperatures or if the consequences of the fisheries interaction is such that impaired behaviour simply results in cooler thermal experiences. To my knowledge this is one of the first studies of fish that suggests the potential for behavioural thermoregulation to be a mechanism for mediating fisheries stressors. I emphasize that upon entering the Seton system, Gates Creek sockeye are in a more advanced maturation state, with likely thicker skin and increased cortisol compared with fish in lower sections of the Fraser River. It is therefore important to repeat this study to investigate the consequences of gear escape for less mature fish (i.e., closer to river entry), as we would expect the consequences of escape to be more severe. Gear escape is currently not considered in escapement estimate models used by fisheries managers to sustainably regulate salmon fisheries. Here I demonstrate that gillnet escape is a common occurrence with the potential to reduce survival and spawning success, and thus current escapement estimates may be an over-inflation. Further research on gear escape is needed to quantify the rates of escape from various gears, for various locations and populations, to gain a full understanding of the frequency and consequences of escape for Pacific salmon during spawning migrations. 


\section{CHAPTER 3}

\section{Changes in biomarker expression and infectious agent profiles during spawning migrations and following experimental fisheries interactions of wild sockeye salmon (Oncorhynchus nerka)}

\subsection{Abstract}

For adult Pacific salmon (Oncorhynchus spp.), freshwater migration to natal spawning grounds presents numerous challenges, and fish must undergo a suite of morphological, physiological, and genomic changes to prepare for the riverine environment, and ultimately spawning success. A number of studies have investigated physiological changes associated with spawning migrations in Pacific salmon, however there are relatively fewer studies that have investigated genomic changes associated with this migration. In this study, I aim to investigate gene expression changes of 25 biomarkers associated with immune function, thermal stress, mortality, viral disease development, and general stress in adult Gates Creek sockeye salmon (Oncorhynchus nerka) during the final $50 \mathrm{~km}$ of a $360 \mathrm{~km}$ freshwater migration. I also investigate how the prevalence and load of 18 infectious agents change during this final migration. As fish enter freshwater environments, they are also faced with a number of novel challenges, such as in-river fisheries, which they must successfully evade or recover from if they are to survive. Here, I investigate if interactions with gillnets or seine nets impact biomarker 
expression changes or infectious agent prevalence and load in sockeye salmon during their final migration stretch. I found that as Gates Creek sockeye migrated their final $50 \mathrm{~km}$ to spawning grounds, thermal stress biomarkers decreased in expression, and biomarkers associated with viral disease development increased in expression. This suggests a reduction in thermal stress, likely due to thermoregulation during lake migration, and possible viral disease development or compromised immune function as these fish approach spawning grounds. I found that gillnet or seine net entanglement had no effect on biomarker expression. A total of seven infectious agents were detected in Gates Creek sockeye sampled during this study (bacterium and parasites). Of these, I found three to significantly increase in load as fish migrated: Candidatus Branchiomonas cysticola, Flavobacterium psychrophilum, and Parvicapsula minibicornis. In addition, Flavobacterium psychrophilum and Ichthyophthirius multifiliis significantly increased in prevalence as fish approached spawning grounds. I did not find gear escape to affect infectious agent loads or prevalence over migration. Collectively, these findings provide further evidence that fish undergo a suite of genomic changes, and that infectious agent profiles can change as Pacific salmon complete spawning migrations. Such temporal increases in infectious agent prevalence and load may have important implications for the fitness and survival of these fish. 


\subsection{Introduction}

During their challenging upstream migrations, adult Pacific salmon (Oncorhynchus spp.) undergo a suite of morphological, physiological, and genomic changes that allow them to move from ocean feeding grounds to freshwater spawning habitats. Riverine environments present migratory fish with a number of challenges, including freshwater infectious agents, higher and more variable water temperatures, and in-river fisheries targeting salmon in a more spatially confined environment. Each of these stressors can negatively affect salmon migration and survival, and there is now a large amount of literature that investigates the nature and extent of these impacts (for relevant reviews see: Hinch and Martins, 2011; Miller et al., 2014; Patterson et al., 2017a). It is now recognized that migratory salmon are often faced with multiple stressors, and these may have cumulative or interacting effects that also must be investigated if we are to better understand and predict salmon survival in the wild (Miller et al., 2014).

Many studies have investigated physiological changes associated with migration of Pacific salmon from ocean feeding grounds to natal spawning tributaries (Hinch et al., 2006; Hruska et al., 2010; Flores et al., 2012). Beginning in the marine environment, hormonal changes initiate the adult migration of Pacific salmon to spawning grounds (Crossin et al., 2009). Concurrently, salmon cease feeding and shift to metabolism of endogenous energy reserves, which they rely upon for the entirety of their upstream migration (Rand and Hinch, 1998; Kiessling et al., 2004). Physiological and functional shifts in osmoregulatory tissue, including gills and kidneys, facilitate movement from saltwater into fresh (Shrimpton et al., 2005; Flores et al., 2012). Responding to conditions in freshwater environments, which are typically higher in temperature, salmon up-regulate genes associated with protection from thermal stress and pathogen resistance (Miller et al., 2009; Evans et al., 2011). Finally, upon arriving at spawning 
grounds, fish undergo further physiological changes to prepare for spawning and death, such as decreases in plasma osmolality, increases in lactate and cortisol, and further decreases in gross somatic energy (Hruska et al., 2010). Most studies investigating physiological and genomic changes during migration involve sampling a group of salmon at one location, and another group of different individuals at a different location and time point. There are very few studies that take an individual-based approach to investigating physiological changes throughout the migration of Pacific salmon (however, see Hruska et al. 2010 for an example of such a repeated-measures study).

Infectious agents are a natural component of ecosystems and have important implications for the survival and fitness of wild salmon populations (Miller et al., 2014). At least 23 infectious agents are now known to infect sockeye salmon (Miller et al., 2014; Bass, 2018; Thakur et al., 2019), and likely many more remain undiscovered (Miller et al., 2014). Infectious agents have varying consequences for the host, depending on the prevalence and load of infectious agents. Many infectious agents are opportunistic and may not invade or cause harm or disease unless their host is in a compromised immune state (Pickering and Pottinger, 1989; Tort, 2011). Stressors, such as fisheries interactions, may compromise the immune function of fish, and injuries resulting from fisheries interactions may allow infectious agents to invade (Svendsen and Bøgwald, 1997). In addition, high water temperatures can affect productivity of certain infectious agents (Chiaramonte, 2013; Paull and Johnson, 2014) and further decrease host immune resilience (Jeffries et al., 2012; Dittmar et al., 2014). However, many infectious agents are present that are either not harmful, not in active disease states, or not present in high enough loads to cause disease. Detection of infectious agent presence is therefore not always indicative of fish in compromised or diseased states. Miller et al. (2017) developed a biomarker panel 
predictive of disease development across RNA-viral species (viral disease development panel; VDD). Detection of the VDD panel in salmon not only allows detection of fish is in a diseased state, but also indicates if fish that might have undiscovered viruses. For example, any individuals that are VDD positive, but for which we cannot detect any known viruses, may be infected with an undiscovered infectious agent (Di Cicco et al., 2018; Mordecai et al., 2019).

It is common for Pacific salmon to encounter in-river fishing gears such as gillnets and seine nets. Fish are retained as catch from these fishing practices, however an even greater number of fish that encounter fishing gear actually return to the river (known as "non-retention" fish; Patterson et al., 2017a). Non-retention fish may return to the river through escape or they may be intentionally released as by-catch. Despite initially surviving the fishery encounter, fish will experience a range of physiological and physical effects, which may ultimately result in mortality (Davis, 2002). The sub-lethal effects of fisheries encounters depend on the severity of the capture event (Gale et al., 2011; Donaldson et al., 2012; Teffer et al., 2017) and condition of the fish (Davis, 2002), but also water temperature (Gale et al., 2013) and infectious agents (Raby et al., 2015) which may affect an individual's ability to recover from a fisheries interaction. Gillnets are typically thought to be the most physically damaging to fish (Patterson et al., 2017a; Bass et al., 2018b) due to tight entanglement with thin nylon line which can result in suffocation, loss of mucus, and even severe lesions (Baker and Schindler, 2009). Seine nets have been demonstrated to be less physically damaging to fish because they typically do not entangle fish within the net (Bass et al., 2018b), but instead fish are corralled within the net. Physical damage may still occur if fish contact the netting which can remove mucus, or escape under the lead line of the net which may cause lacerations or further mucus removal due to rough substrate on the river floor, however this has not been demonstrated. 
The factors challenging Pacific salmon during their migrations (including infectious agents, high temperatures, and fisheries interactions) do not act in isolation, but the interactions between them and the ultimate impacts on salmon remain relatively poorly understood (Miller $e t$ al., 2014). Previous studies have evaluated the effects of temperature (e.g. Crossin et al., 2008; Martins et al., 2012; Jeffries et al., 2012, 2014; Gale et al., 2014) and fisheries interactions (e.g. Donaldson et al., 2010; Donaldson et al., 2011; Raby et al., 2014a; Teffer et al., 2017) in isolation and investigated the impacts of these stressors on physiological stress, physical damage, genomic responses, and ultimately fate of salmon species. The number of studies investigating genomic responses to various stressors is now increasing, and we now know numerous gene biomarkers associated with temperature (Akbarzadeh et al., 2018), hypoxia (Houde et al., 2019), immune function, and viral disease development (Miller et al., 2017) in salmonids. Highthroughput quantitative polymerase chain reaction (qPCR) techniques make it easier to study biomarker expression changes and infectious agent presence in salmonids (Miller et al., 2016). There are a growing numbers of studies that investigate how gene expression can be indicative of survival in wild migratory adult salmon (Miller et al., 2011; Drenner et al., 2018), and how stressors such as temperature and fisheries capture can affect gene expression changes of adult salmon in holding studies (Jeffries et al., 2012; Teffer et al., 2017).

In this paper, I investigated gene expression changes of wild, adult Gates Creek sockeye salmon (Oncorhynchus nerka) in the Fraser River of British Columbia over the final $50 \mathrm{~km}$ of their freshwater migration through the Seton watershed. I used an individual-based approach where the individuals were re-captured and gill biopsied both upon entering the Seton River and again at Gates Creek spawning grounds. Biopsies were analyzed for specific host biomarkers associated with immune function, disease, and thermal stress, as well as infectious agent 
presence and loads in each fish. First, I investigated how biomarker expression and infectious agent presence and load might change during this final migration segmentt. I hypothesized that biomarker expression would change over the final $50 \mathrm{~km}$ stretch of spawning migration for these fish. Specifically, I predicted that expression of thermal biomarkers would decrease throughout the migration, due to the ability to thermoregulate in lake habitats throughout this migration segment. I hypothesized infectious agent profiles would also change over migration. Second, I investigated how escape from two types of fishing gear (gillnet and seine net) affected biomarker expression and infectious agent prevalence and load. I hypothesized that fish that experience gear escape simulations would show alter biomarker expression and infectious agent profiles at spawning grounds compared with control fish that did not interact with any fishing gear. In this study, I present the first data showing both biomarker expression and infectious agent changes of repeat sampled sockeye salmon in the wild.

\subsection{Methods}

\subsubsection{Study site}

This study targeted Gates Creek sockeye, an early summer-run population of Fraser River sockeye salmon. All fish collection and tagging took place on the Seton River, a tributary of the Fraser River, British Columbia. Gates Creek sockeye migrate approximately 364 km upstream through the Fraser, and a following $50 \mathrm{~km}$ through the Seton system, to ultimately spawn in Gates Creek. Migrating fish must navigate the Seton Dam fish ladder before passing through both Seton and Anderson Lakes to reach Gates Creek (approximately $50 \mathrm{~km}$ in total). Seton Lake and Anderson Lake are connected by Portage Creek, which is approximately $3 \mathrm{~km}$ in length. 
Through previous tracking studies it has been estimated that Gates Creek sockeye take an average of 10 days to migrate from the mouth of the Fraser River to the mouth of the Seton River (Crossin et al., 2009), then an additional 10 days to migrate through the Seton system before reaching Gates Creek (Minke-Martin et al., 2018). The Seton system is a unique study site in that a second fish fence can also be constructed at Gates Creek. An artificially enhanced spawning channel is operated $800 \mathrm{~m}$ upstream from the mouth of Gates Creek, and a fish weir is constructed across the creek to divert fish towards the enhanced spawning channel entrance. This entrance is blocked by a gate that is manually operated to allow fish to enter either the enhanced spawning channel or to pass further upstream into Gates Creek.

\subsubsection{Fish collection, biopsy, and tagging at Seton River fish fence}

Gates Creek sockeye salmon were captured on the Seton River using a river-spanning picket fence and trap located approximately $5 \mathrm{~km}$ upstream from the Fraser-Seton River confluence. This fence consisted of removable pickets, which when all were in place blocked any upstream movement of fish in the river. One small gap in the fence was created by removing pickets, and this was the entrance to an enclosed holding area. The fence was closed throughout the night for 10 hours to intercept sockeye during their peak hours of migration, and during this time fish would enter the holding area and become trapped. Through pulling pickets, fish were able to migrate freely upstream through the gaps in the fence for the remaining hours of the day. Fish were captured in this way from Aug $8^{\text {th }}$ until Aug $20^{\text {th }}, 2017$.

Fish were captured from the holding area via dipnet and transferred to a tagging trough with a continuous supply of river water. Any fish with severe wounds, old gillnet markings, or 
$>25 \%$ total body scale loss were not tagged as part of this study. Gross somatic energy (GSE) was then measured using a fish FatMeter (Model FM 692, Distell, West Lothian, Scotland, UK). GSE measurements have previously been related to various sockeye salmon populations (Casselman et al., 2016), thus I was able to identify Gates Creek sockeye salmon from other straying sockeye entering the Seton system (fish with an average GSE measurement $\leq 2.7$ ). Only Gates Creek sockeye, as identified through GSE measurements, were tagged as part of this study.

For a subset of fish, I then simulated fishing gear escapements using two gear types commonly used by in-river fisheries throughout the Fraser River: beach seine net and 5.25-inch $(13.3 \mathrm{~cm})$ mesh gillnet (mesh size most commonly used to target Fraser River sockeye). For gillnet escape simulations, fish were entangled in a tightly strung section of gillnet $(60 \mathrm{~cm} \times 60$ $\mathrm{cm}$ ) for a maximum of $1 \mathrm{~min}$ (or less if the fish genuinely escaped by itself). Escape was then simulated by quickly cutting the gillnet with no air exposure. Beach seine escapement was simulated using a small section of seine net to corral the fish towards a sandy-rocky bank, thus forcing the fish to escape under the lead line into a waiting dipnet, again with no air exposure. Control treatment fish were dipnetted from the fence holding area, transferred to the tagging trough, but experienced no gear escape simulations.

All fish were gill biopsied by taking a small tissue sample (approximately $3 \mathrm{~mm}$ from the tips of 2-3 gill filaments) which was then transferred into $1.5 \mathrm{~mL}$ RNAlater solution (Qiagen, MD, USA) and stored at $-80{ }^{\circ} \mathrm{C}$ for future laboratory analyses of infectious agents and biomarker expression. Fish were then tagged with $32 \mathrm{~mm}$ half duplex (HDX) passive integrated transponder (PIT) tags (Oregon RFID, Portland, OR, USA). To allow these PIT tags to be inserted gastrically, they had been inserted into smoothed acetal Delrin tube sections $1.59 \mathrm{~cm}$ in diameter, $3.81 \mathrm{~cm}$ in length, and were then inserted into the stomach of the fish using smoothed plungers. 
A subset of fish $(\mathrm{N}=120)$ also had temperature loggers (iButton Thermochron model DS1921Z or DS1922L; Maxim Integrated, San Jose, CA, USA) installed on their internal tag which were programmed to record the temperature of the fish every 30 minutes. All internal tags with iButtons were waterproofed using Plasti Dip (International, St. Louis Park, MN, USA). Finally, fish were also externally tagged using a fluorescent yellow $7.62 \mathrm{~cm}$ T-bar anchor tag (Floy Tag \& Mfg. Inc., Seattle, TA, USA) to allow visual identification of tagged fish. Each of these external tags had a unique identification number specific to each individual fish. A total of 214 fish were tagged and sampled in this way at Seton River fish fence.

\subsubsection{Sampling of mortalities}

The river-spanning fish fence was constructed approximately $100 \mathrm{~m}$ downstream from Seton dam. This dam is a substantial barrier to fish passage upstream as migrating fish are presented with fast, turbulent flows and must find and navigate a fish ladder behind the dam outflows (Burnett et al., 2014). As such, many fish in poor condition are unable to navigate the dam and suffer en-route mortality. These mortalities collect on the river-spanning fish fence downstream of the dam. Regular fence walks were conducted every $1-2$ hours to collect fresh mortalities for organ sampling. Tissue samples were taken from gill, heart, head kidney, spleen, and liver organs using sterilized tools. Approximately $0.5 \mathrm{mg}$ tissue was taken and preserved in 1.5 mL RNAlater solution (Qiagen, MD, USA) for future analysis of infectious agent presence and loads. 


\subsubsection{PIT telemetry}

Three PIT antennas were installed along the Seton migration route in order to track the migration of sockeye from Seton fish fence to Gates Creek spawning grounds. Two antennas were installed at Seton Dam, one located at the fish ladder entrance, and the second at the fish ladder exit (see Casselman et al., 2016). These two antennas allowed assessment of dam passage success and passage efficiency. The final antenna was installed approximately $100 \mathrm{~m}$ upstream from the mouth of Gates Creek. This was a pass-through antenna constructed from 1.5-inch PVC piping that measured $16 \mathrm{~m}$ in length and $1 \mathrm{~m}$ in diameter. This antenna spanned the creek and thus any fish that entered Gates Creek would swim over this receiver. Fish detected at this antenna were considered to have successfully migrated to spawning grounds.

\subsubsection{Recapture of tagged fish at spawning grounds}

A second river-spanning fence was constructed across Gates Creek near the entrance to the artificially enhanced spawning channel, approximately $800 \mathrm{~m}$ upstream from the mouth of Gates Creek. Two 'gates' are installed into the fence, one opens allowing fish into the artificially enhanced spawning channel, and the other opens to allow fish further upstream into Gates Creek. Both gates also have fish counters installed to count the number of fish that pass through them. Again, sockeye migrating into Gates Creek hold behind this fence when the gates are closed. This fence is constructed in a section of the river with a steep gradient and rapids which represent a difficult natural barrier that needs to be passed. On river-right, where both gates in the fence are situated, there is a natural pool with calm flows meaning fish naturally migrate toand hold in that area. 
For this study, tagged fish were recaptured and biopsied for a second time at spawning grounds. Because fish naturally hold in a pool at Gates Creek fish fence, tagged fish were able to be identified through their external anchor tag and were recaptured from this pool using dipnets. Fish were immediately transferred to a tagging trough and re-assessed for wounds, scale loss, fin damage, and net markings, as before. Finally, a second gill sample was taken and preserved in $1.5 \mathrm{~mL}$ RNAlater solution (Qiagen, MD, USA). These recaptured fish were then released upstream of the fence into the spawning channel. A total of 48 fish were recaptured and resampled in this way at spawning grounds.

In addition to recapturing live fish as they entered Gates Creek, visual surveys were also performed to look for carcasses of tagged fish. Weekly creek walks and visual inspection of all sockeye carcasses in both Gates Creek and the artificially enhanced spawning ground allowed us to recover tagged fish and recover any temperature loggers from these fish. A total of 50 temperature loggers were recovered in this way.

\subsubsection{Laboratory analyses}

All laboratory analyses were performed at Pacific Biological Station (Nanaimo, BC, Canada). Gill samples were analyzed for RNA expression of select host stress- and immune biomarkers and infectious agent RNA copy numbers using high-throughput nanofluidic qPCR (Fluidigm ${ }^{\circledR}$ BioMark ${ }^{\mathrm{TM}}$ Dynamic Array, CA, USA). For a comprehensive overview of this technology see Miller et al. (2016). Fish mortalities that were collected from Seton fish fence were initially screened for 47 different infectious agents known or suspected to infect Fraser River sockeye. The five organ tissue samples collected from these fish (gill, heart, kidney, spleen 
and liver) were homogenized, and aliquots of the aqueous phase for each fish were then pooled. Infectious agents that were detected in these pooled organ samples from dead fish were then selected to be screened in non-lethal gill samples taken from tagged fish. In total, 18 infectious agents and 25 host biomarkers were assayed in the gill tissue of tagged fish; see Tables 3.1 and 3.2 for an overview of biomarker assays and infectious agent assays run, respectively. Host biomarkers included 7 genes associated with salmonid thermal stress (Houde et al., 2019), 5 genes shown to be associated with a mortality related signatures (MRS; Miller et al., 2011), 10 genes associated with viral disease detection (VDD) that are predictive of fish in a diseased state (Miller et al., 2017), and 3 genes associated with immune function and general stress.

Gill tissue was thawed and removed from RNAlater solution and transferred to microtubes containing stainless steel beads for homogenization. This tissue was then homogenized using TRI-reagent (Ambion Inc., Austin, TX, USA) and vigorous shaking in a MM301 mixer mill (Retsch Inc., Newtown, PA, USA), then separated using 1-bromo-3chloropropane and centrifugation $(1500 \mathrm{~g}, 6.5 \mathrm{~min})$. The aqueous phase was aliquoted into 96well plates and RNA extraction was performed using MagMAX-96 for Microarrays Total RNA Isolation Kits (Ambion Inc.) with a Biomek NXP automated liquid-handling machine using the "spin method" as per the manufacturer's instructions. DNase treatment was incorporated at this step to reduce any DNA contamination. RNA quantity (A260; ng/mL) and quality (A260/A280) was measured using a Beckman Coulter DTX 880 Multimode Detector (Brea, CA, USA). All samples were then normalized to $62.5 \mathrm{ng} \mu \mathrm{L}^{-1}$ using the Biomek NXP automated liquid-handling machine. RNA quantity was checked again following normalization. Reverse transcription of 1 $\mu \mathrm{g}$ normalized RNA was performed using a SuperScript VILO MasterMix Kit (Invitrogen, Carlsbad, CA) to create cDNA using PCR cycling conditions of $25^{\circ} \mathrm{C}$ for $10 \mathrm{~min}, 42{ }^{\circ} \mathrm{C}$ for 60 
min, and $85^{\circ} \mathrm{C}$ for $5 \mathrm{~min}$. Specific target amplification (STA) of select host biomarkers and infectious agent biomarkers was performed using $1.25 \mu \mathrm{L}$ cDNA, assay $200 \mathrm{nM}$ primer pairs (see Tables 3.1 and 3.2), TaqMan Preamp Master Mix (Applied Biosystems, Foster City, California) and cycling at $95^{\circ} \mathrm{C}$ for $10 \mathrm{~min}$ followed by 15 cycles of $95^{\circ} \mathrm{C}$ for $10 \mathrm{~s}$ and $60{ }^{\circ} \mathrm{C}$ for 4 min. This allowed pre-amplification of select biomarkers, a necessary step before qPCR due to the small assay volume $(5 \mu \mathrm{L})$ required. All STA assays were run in duplicate. Following STA, any unincorporated primers were removed using ExoSAP-IT (Affymetrix, Santa Clara, California) and cycling at $37^{\circ} \mathrm{C}$ for $15 \mathrm{~min}$, and $80^{\circ} \mathrm{C}$ for $15 \mathrm{~min}$. Finally, samples were diluted 5fold using DNA Suspension Buffer (Teknova, Hollister, California).

For qPCR, both samples (pre-amplified cDNA product from every gill biopsy) and assays (qPCR assays for all host- and infectious agent biomarkers) needed to be prepared and loaded onto the Fluidigm chip. A sample mix was prepared using pre-amplified cDNA, $1 \times$ TaqMan Universal Master Mix (Life Technologies) and 1× GE Sample Loading Reagent (Fluidigm PN 85000746). An assay mix was then prepared with $10 \mu \mathrm{M}$ primer pairs, $3 \mu \mathrm{M}$ probes, and assay loading reagent (Fluidigm PN 85000736). Sample and assay mixes were then pipetted into the chip and were loaded using an IFC controller HX (Fluidigm). Assay mixes were pipetted onto the chip in duplicate. Finally, qPCR was conducted $\left(50^{\circ} \mathrm{C}\right.$ for $2 \mathrm{~min}, 95^{\circ} \mathrm{C}$ for $10 \mathrm{~min}$, followed by 40 cycles of $95{ }^{\circ} \mathrm{C}$ for $15 \mathrm{~s}$ and $60^{\circ} \mathrm{C}$ for $1 \mathrm{~min}$ ). Probes (with FAM dye) quantified target amplicons during the qPCR cycling.

Two serial dilutions were also added to the dynamic array to allow for calculation of assay efficiency. The first was a serial dilution of pooled cDNA. This pooled cDNA contained 1 $\mu \mathrm{L}$ of every sample from this study. A serial 10-fold dilution of the pooled cDNA was prepared and was included on the dynamic array to determine host biomarker assay efficiency. A second 
serial dilution of artificial positive constructs (APC clones) was also included on the dynamic array which can be used to determine infectious agent loads and biomarker efficiency (Miller et al., 2016). A probe (with NED ${ }^{\mathrm{TM}}$ dye, Applied Biosystems, Foster City, CA, USA) was also included to detect APC contamination in samples. Positive and negative controls were also included on the dynamic array for RNA extraction, cDNA synthesis, STA, and qPCR stages.

Table 3.1. Sockeye salmon host biomarkers evaluated using qPCR. A total of 25 biomarkers were assayed, as well as 3 house-keeping genes (HKG). Biomarkers are categorized as genes involved with viral disease development (VDD), morality-related signatures (MRS), thermal stress, immune response, or general stress. Forward (F) and reverse (R) primer sequences and probe $(\mathrm{P})$ sequences are given.

\begin{tabular}{|c|c|c|c|c|}
\hline $\begin{array}{l}\text { Assay } \\
\text { name }\end{array}$ & $\begin{array}{c}\text { Gene } \\
\text { category }\end{array}$ & Gene Name & $\begin{array}{c}\text { Accession } \\
\#\end{array}$ & Primer and probe sequences \\
\hline 52RO & VDD & $\begin{array}{l}52 \mathrm{kDa} \text { Ro } \\
\text { protein-2 - } \\
\text { 52Ro }\end{array}$ & CX141267 & $\begin{array}{l}\text { F: TGCACTATTGCCCAGTAACCAT } \\
\text { R: TGCAAGAGGAGATGCCAACA } \\
\text { P: AGTAGGATTCACAGAGAGTT }\end{array}$ \\
\hline $\begin{array}{c}\text { ATP5 } \\
\text { G3 }\end{array}$ & MRS & ATP synthase & CB493164 & $\begin{array}{l}\text { F: GGAACGCCACCATGAGACA } \\
\text { R: CGCCATCCTGGGCTTTG } \\
\text { P: AGCCCCATTGCCTC }\end{array}$ \\
\hline $\mathrm{C} 7$ & $\begin{array}{l}\text { Immune/ } \\
\text { MRS }\end{array}$ & $\begin{array}{l}\text { Complement } \\
\text { factor }\end{array}$ & CA052045 & $\begin{array}{l}\text { F: ACCTCTGTCCAGCTCTGTGTC } \\
\text { R: GATGCTGACCACATCAAACTGC } \\
\text { P: AACTACCAGACAGTGCTG } \\
\end{array}$ \\
\hline $\begin{array}{c}\text { CA05 } \\
4694\end{array}$ & VDD & $\begin{array}{l}\text { Mitochondrial } \\
\text { ribosomal } \\
\text { protein (VAR1) }\end{array}$ & CA054694 & $\begin{array}{l}\text { F: CACCTGAGGTACTGAAGATAAGACA } \\
\text { R: TTAAGTCCTCCTTCCTCATCTGGTA } \\
\text { P: TCTACCAGGCCTTAAAG }\end{array}$ \\
\hline$\overline{\mathrm{DEXH}}$ & VDD & $\begin{array}{l}\text { ATP-dependent } \\
\text { RNA helicase }\end{array}$ & FN396359 & $\begin{array}{l}\text { F: CCATAAGGAGGGTGTCTACAATAAGAT } \\
\text { R: CTCTCCCCCTTCAGCTTCTGT } \\
\text { P: TGGCGCGCTACGTG }\end{array}$ \\
\hline ef2_14 & Thermal & $\begin{array}{l}\text { Elongation } \\
\text { factor } 2\end{array}$ & CB498321 & $\begin{array}{l}\text { F: AGGTCACAGCCGCCCTTAG } \\
\text { R: ACACAGTCTCTGTCTGCACACACA } \\
\text { P: CGACTGCGTCTCAGGT }\end{array}$ \\
\hline GAL3 & VDD & $\begin{array}{l}\text { Galectin-3- } \\
\text { binding protein } \\
\text { precursor }\end{array}$ & CB515011 & $\begin{array}{l}\text { F: TTGTAGCGCCTGTTGTAATCATATC } \\
\text { R: TACACTGCTGAGGCCATGGA } \\
\text { P: CTTGGCGTGGTGGC }\end{array}$ \\
\hline $\begin{array}{l}\text { HERC } \\
6\end{array}$ & VDD & $\begin{array}{l}\text { Probable E3 } \\
\text { ubiquitin- } \\
\text { protein ligase } \\
\text { HERC6 } \\
\end{array}$ & CA060884 & $\begin{array}{l}\text { F: AGGGACAACTTGGTAGACAGAAGAA } \\
\text { R: TGACGCACACACAGCTACAGAGT } \\
\text { P: CAGTGGTCTCTGTGGCT }\end{array}$ \\
\hline
\end{tabular}




\begin{tabular}{|c|c|c|c|c|}
\hline hsp70 & Thermal & $\begin{array}{l}\text { Heat shock } 70 \\
\text { kDa protein }\end{array}$ & C249R043 & $\begin{array}{l}\text { F: TCAACGATCAGGTCGTGCAA } \\
\text { R: CGTCGCTGACCACCTTGAA } \\
\text { P: CCGACATGAAGCACTGG }\end{array}$ \\
\hline $\begin{array}{c}\text { hsp90a } \\
-15\end{array}$ & Thermal & $\begin{array}{l}\text { Heat shock } \\
\text { protein } 90 \\
\text { alpha }\end{array}$ & CA062155 & $\begin{array}{l}\text { F: ATGACCCTCAGACACACTCCAA } \\
\text { R: CCTCATCAATACCCAGTCCTAGCT } \\
\text { P: CGCATCTACAGAATGA }\end{array}$ \\
\hline $\begin{array}{l}\text { HSP90 } \\
\text { alike_- } \\
6\end{array}$ & Thermal & $\begin{array}{l}\text { Heat shock } \\
\text { protein } 90 \\
\text { alpha like }\end{array}$ & C020R155 & $\begin{array}{l}\text { F: TTGGATGACCCTCAGACACACT } \\
\text { R: CGTCAATACCCAGGCCTAGCT } \\
\text { P: CCGAATCTACCGGATGAT }\end{array}$ \\
\hline HTA & MRS & $\begin{array}{l}\text { HIV-1 Tat } \\
\text { interactive } \\
\text { protein }\end{array}$ & - & $\begin{array}{l}\text { F: CTTGTAACAGTTCGACATGGCTTATT } \\
\text { R: TGGTGAAGCATTTCTGTATGTCAA } \\
\text { P: TCTGTACTGAGCATCCCCGCACATTACA }\end{array}$ \\
\hline $\begin{array}{c}\text { IFI44 } \\
\text { A }\end{array}$ & VDD & $\begin{array}{l}\text { IFN-induced } \\
\text { protein } 44-1\end{array}$ & GS365948 & $\begin{array}{l}\text { F: CGGAGTCCAGAGCAGCCTACT } \\
\text { R: TCCAGTGGTCTCCCCATCTC } \\
\text { P: CGCTGGTCCTGTGTGA }\end{array}$ \\
\hline IFIT5 & VDD & $\begin{array}{l}\text { Interferon- } \\
\text { induced protein } \\
\text { with } \\
\text { tetratricopeptid } \\
\text { e repeats } 5\end{array}$ & CA051350 & $\begin{array}{l}\text { F: CCGTCAATGAGTCCCTACACATT } \\
\text { R: CACAGGCCAATTTGGTGATG } \\
\text { P: CTGTCTCCAAACTCCCA }\end{array}$ \\
\hline JUN & $\begin{array}{c}\text { General } \\
\text { stress }\end{array}$ & $\begin{array}{l}\text { Transcription } \\
\text { factor AP-1 }\end{array}$ & CA056351 & $\begin{array}{l}\text { F: TTGTTGCTGGTGAGAAAACTCAGT } \\
\text { R: CCTGTTGCCCTATGAATTGTCTAGT } \\
\text { P: AGACTTGGGCTATTTAC }\end{array}$ \\
\hline $\begin{array}{l}\text { MMP2 } \\
5\end{array}$ & MRS & $\begin{array}{c}\text { Matrix } \\
\text { metalloproteina } \\
\text { se-25 precursor }\end{array}$ & & $\begin{array}{l}\text { F: TGCAGTCTTTTCCCCTTGGAT } \\
\text { R: TCCACATGTACCCACACCTACAC } \\
\text { P: AGGATTGGCTGGAAGGT }\end{array}$ \\
\hline $\begin{array}{c}\text { MX_O } \\
\text { NTS }\end{array}$ & VDD & $\begin{array}{l}\text { Interferon- } \\
\text { induced GTP- } \\
\text { binding protein } \\
\text { Mx }\end{array}$ & CB516446 & $\begin{array}{l}\text { F: AGATGATGCTGCACCTCAAGTC } \\
\text { R: CTGCAGCTGGGAAGCAAAC } \\
\text { P: ATTCCCATGGTGATCCGCTACCTGG }\end{array}$ \\
\hline PRAS & MRS & $\begin{array}{c}\text { Oncorhynchus } \\
\text { mykiss G- } \\
\text { protein (P-ras) } \\
\text { mRNA, } \\
\text { complete cds }\end{array}$ & CA059617 & $\begin{array}{l}\text { F: GCAGGATGAGCAGAGGAAGAA } \\
\text { R: GGCCTGGGCAATGTAACACT } \\
\text { P: CCCCCTAAAGATGCAG }\end{array}$ \\
\hline RIG1 & Immune & $\begin{array}{c}\text { Retinoic acid } \\
\text { inducible gene I }\end{array}$ & $\begin{array}{c}\text { NM_0011 } \\
63699\end{array}$ & $\begin{array}{l}\text { F: ACAGCTGTTACACAGACGACATCA } \\
\text { R: TTTAGGGTGAGGTTCTGTCCGA } \\
\text { P: TCGTGTTGGACCCCACTCTGTTCTCTC }\end{array}$ \\
\hline RSAD & VDD & $\begin{array}{l}\text { Radical S- } \\
\text { adenosyl } \\
\text { methionine } \\
\text { domain- } \\
\text { containing } \\
\text { protein } 2\end{array}$ & CA038316 & $\begin{array}{l}\text { F: GGGAAATTAGTCCAATACTGCAAAC } \\
\text { R: GCCATTGCTGACAATACTGACACT } \\
\text { P: CGACCTCCAGCTCC }\end{array}$ \\
\hline SCG & MRS & Secretogranin2 & CA053613 & $\begin{array}{l}\text { F: GGATGTGAAGAATCCAACACTGAT } \\
\text { R: ACACCACTTCAAACTAGCCATACATT } \\
\text { P: CGGCTGTATGTGCACTG }\end{array}$ \\
\hline $\begin{array}{l}\text { SERPI } \\
\text { N9 }\end{array}$ & Thermal & $\begin{array}{l}\text { Serpin H1 } \\
\text { precursor } \\
(\mathrm{HSP} 47)\end{array}$ & C236R132 & $\begin{array}{l}\text { F: GAGGTCAGCGACCCAAAGAC } \\
\text { R: GCCGTAGAGGCGGTTACTGAT } \\
\text { P: CGGAACGTCACATGGA }\end{array}$ \\
\hline
\end{tabular}




\begin{tabular}{|c|c|c|c|l|}
\hline $\begin{array}{c}\text { SERPI } \\
\text { N20 }\end{array}$ & Thermal & $\begin{array}{c}\text { Serpin H1 } \\
\text { precursor } \\
\text { (HSP47) }\end{array}$ & CA063723 & $\begin{array}{l}\text { F: ACTATGACCACTCGAAGATCAACCT } \\
\text { R: CCCATTCGTTGATGGAGTTCA } \\
\text { P: AGGGACAAGAGGAGC }\end{array}$ \\
\hline SFRS2 & Thermal & $\begin{array}{c}\text { Splicing factor, } \\
\text { arginine/serine- } \\
\text { rich 2 }\end{array}$ & CB493433 & $\begin{array}{l}\text { F: TCCAGATGGCCCGTTACG } \\
\text { R: CACCACCGCCTCCATGAT } \\
\text { P: TCCCCCAGATTCT }\end{array}$ \\
\hline $\begin{array}{c}\text { STAT } \\
1\end{array}$ & VDD & $\begin{array}{c}\text { Signal } \\
\text { transducer and } \\
\text { activator of } \\
\text { transcription 1- } \\
\text { alpha/beta }\end{array}$ & CA050950 & $\begin{array}{l}\text { F: TGTCACCGTCTCAGACAGATCTG } \\
\text { R: TGTTGGTCTCTGTAAGGCAACGT } \\
\text { P: AGTTGCTGAAAACCGG }\end{array}$ \\
\hline 78d16. & HKG & $\begin{array}{c}\text { S100 calcium } \\
\text { binding protein }\end{array}$ & CA056739 & $\begin{array}{l}\text { F: GTCAAGACTGGAGGCTCAGAG } \\
\text { R: GATCAAGCCCCAGAAGTGTTTG } \\
\text { P: AAGGTGATTCCCTCGCCGTCCGA }\end{array}$ \\
\hline $\begin{array}{c}\text { COIL- } \\
\text { P84-2 }\end{array}$ & HKG & $\begin{array}{c}\text { Coiled-coil } \\
\text { domain- } \\
\text { containing } \\
\text { protein } 84\end{array}$ & CA053789 & $\begin{array}{l}\text { F: GCTCATTTGAGGAGAAGGAGGATG } \\
\text { R: CTGGCGATGCTGTTCCTGAG } \\
\text { P: TTATCAAGCAGCAAGCC }\end{array}$ \\
\hline MRPL & HKG & $\begin{array}{c}\text { 39S ribosomal } \\
\text { protein L40, } \\
\text { mitochondrial } \\
\text { precursor }\end{array}$ & CK991258 & $\begin{array}{l}\text { F: CCCAGTATGAGGCACCTGAAGG } \\
\text { R: GTTAATGCTGCCACCCTCTCAC } \\
\text { P: ACAACAACATCACCA }\end{array}$ \\
\hline
\end{tabular}

Table 3.2. Infectious agents assayed in sockeye salmon during this study. A total of 18 infectious agents were evaluated through qPCR. Forward primer $(\mathrm{F})$, reverse prime $(\mathrm{R})$ and probe $(\mathrm{P})$ sequences are given.

\begin{tabular}{|c|c|l|c|l|l|}
\hline $\begin{array}{c}\text { Assay } \\
\text { name }\end{array}$ & Type & \multicolumn{1}{|c|}{ Full name } & $\begin{array}{c}\text { Accession } \\
\#\end{array}$ & \multicolumn{1}{|c|}{ Primer and probe sequences } & $\begin{array}{l}\text { Assay } \\
\text { reference }\end{array}$ \\
\hline arena2 & Virus & $\begin{array}{l}\text { Arenavirus } \\
\text { Type II }\end{array}$ & - & $\begin{array}{l}\text { F: AACATGAAGGGCGATTCGTT } \\
\text { R: CAGCCCGCGGACTGAGT } \\
\text { P: CAAGTGATGTAAGCTTG }\end{array}$ & $\begin{array}{l}\text { Gideon } \\
\text { Mordecai }\end{array}$ \\
\hline ascv & Virus & $\begin{array}{l}\text { Atlantic Salmon } \\
\text { Calicivirus } \\
\text { (ASCV) }\end{array}$ & - & $\begin{array}{l}\text { F: ACCGACTGCCCGGTTGT } \\
\text { R: CTCCGATTGCCTGTGATAATACC } \\
\text { P: CTTAGGGTTAAAGCAGTCG }\end{array}$ & $\begin{array}{l}\text { Gideon } \\
\text { Mordecai }\end{array}$ \\
\hline c_b_cys & Bacterium & $\begin{array}{l}\text { Candidatus } \\
\text { Branchiomonas } \\
\text { cysticola }\end{array}$ & JQ723599 & $\begin{array}{l}\text { F: AATACATCGGAACGTGTCTAGTG } \\
\text { R: GCCATCAGCCGCTCATGTG } \\
\text { P: CTCGGTCCCAGGCTTTCCTCTCCCA }\end{array}$ & $\begin{array}{l}\text { Mitchell al., } \\
\text { 2013 }\end{array}$ \\
\hline
\end{tabular}




\begin{tabular}{|c|c|c|c|c|c|}
\hline ce_sha & Myxozoan & $\begin{array}{l}\text { Ceratomyxa } \\
\text { shasta }\end{array}$ & AF001579 & $\begin{array}{l}\text { F: CCAGCTTGAGATTAGCTCGGTAA } \\
\text { R: CCCCGGAACCCGAAAG } \\
\text { P: } \\
\text { CGAGCCAAGTTGGTCTCTCCGTGAA } \\
\text { AAC }\end{array}$ & $\begin{array}{l}\text { Hallett } \\
\text { and } \\
\text { Bartholo } \\
\text { mew, } \\
2006\end{array}$ \\
\hline $\operatorname{cov}$ & Virus & Coronavirus & - & $\begin{array}{l}\text { F: GGATAATCCCAACCGAAAAGTTT } \\
\text { R: GCATGAAATGTTGTCTCGGTTTAA } \\
\text { P: CGATCCCGATTATC }\end{array}$ & $\begin{array}{l}\text { Miller et } \\
\text { al., } 2016\end{array}$ \\
\hline ctv & Virus & $\begin{array}{l}\text { Cutthroat Trout } \\
\text { Virus (CTV) }\end{array}$ & - & $\begin{array}{l}\text { F: CCACTTGTCGCTACGATGAAAC } \\
\text { R: CGCCTCCTTTGCCTTTCTC } \\
\text { P: ATGCCGGGCCATC }\end{array}$ & $\begin{array}{l}\text { Miller et } \\
\text { al., } 2016\end{array}$ \\
\hline de_sal & Protozoan & $\begin{array}{l}\text { Dermocystidium } \\
\text { salmonis }\end{array}$ & U21337 & $\begin{array}{l}\text { F: CAGCCAATCCTTTCGCTTCT } \\
\text { R: GACGGACGCACACCACAGT } \\
\text { P: AAGCGGCGTGTGCC }\end{array}$ & $\begin{array}{l}\text { Miller et } \\
\text { al., } 2016\end{array}$ \\
\hline fl_psy & Bacterium & $\begin{array}{l}\text { Flavobacterium } \\
\text { psychrophilum }\end{array}$ & - & $\begin{array}{l}\text { F: } \\
\text { GATCCTTATTCTCACAGTACCGTCAA } \\
\text { R: TGTAAACTGCTTTTGCACAGGAA } \\
\text { P: AAACACTCGGTCGTGACC }\end{array}$ & $\begin{array}{l}\text { Duesund } \\
\text { et al., } \\
2010\end{array}$ \\
\hline ic_hof & Protozoan & $\begin{array}{l}\text { Ichthyophonus } \\
\text { hoferi }\end{array}$ & AF467793 & $\begin{array}{l}\text { F: GTCTGTACTGGTACGGCAGTTTC } \\
\text { R: TCCCGAACTCAGTAGACACTCAA } \\
\text { P: } \\
\text { TAAGAGCACCCACTGCCTTCGAGAA } \\
\text { GA }\end{array}$ & $\begin{array}{l}\text { White et } \\
\text { al., } 2013\end{array}$ \\
\hline ic_mul & Ciliate & $\begin{array}{l}\text { Ichthyophthirius } \\
\text { multifiliis }\end{array}$ & IMU17354 & $\begin{array}{l}\text { F: AAATGGGCATACGTTTGCAAA } \\
\text { R: } \\
\text { AACCTGCCTGAAACACTCTAATTTTT } \\
\text { P: } \\
\text { ACTCGGCCTTCACTGGTTCGACTTGG }\end{array}$ & $\begin{array}{l}\text { Miller et } \\
\text { al., } 2016\end{array}$ \\
\hline lo_sal & $\begin{array}{c}\text { Micro- } \\
\text { sporidian }\end{array}$ & Loma salmonae & $\begin{array}{c}\text { HM62624 } \\
3\end{array}$ & $\begin{array}{l}\text { F: GGAGTCGCAGCGAAGATAGC } \\
\text { R: } \\
\text { CTTTTCCTCCCTTTACTCATATGCTT } \\
\text { P: } \\
\text { TGCCTGAAATCACGAGAGTGAGACT } \\
\text { ACCC }\end{array}$ & $\begin{array}{l}\text { Miller et } \\
\text { al., } 2016\end{array}$ \\
\hline ortho & Virus & OrthoMyxoV & - & $\begin{array}{l}\text { F: GGAAGCAGTGGACGCTAACC } \\
\text { R: TCGCGAAGGTCTCTCAATGTC } \\
\text { P: ATTCTTCTCATCAAAGGCA }\end{array}$ & $\begin{array}{l}\text { Miller et } \\
\text { al., } 2016\end{array}$ \\
\hline pa_kab & Myxozoan & $\begin{array}{l}\text { Parvicapsula } \\
\text { kabatai }\end{array}$ & DQ515821 & $\begin{array}{l}\text { F: CGACCATCTGCACGGTACTG } \\
\text { R: ACACCACAACTCTGCCTTCCA } \\
\text { P: CTTCGGGTAGGTCCGG }\end{array}$ & $\begin{array}{l}\text { Miller et } \\
\text { al., } 2016\end{array}$ \\
\hline
\end{tabular}




\begin{tabular}{|c|c|c|c|c|c|}
\hline pa_min & Myxozoan & $\begin{array}{l}\text { Parvicapsula } \\
\text { minibicornis }\end{array}$ & AF201375 & $\begin{array}{l}\text { F: AATAGTTGTTTGTCGTGCACTCTGT } \\
\text { R: } \\
\text { CCGATAGGCTATCCAGTACCTAGTA } \\
\text { AG } \\
\text { P: TGTCCACCTAGTAAGGC }\end{array}$ & $\begin{array}{l}\text { Miller et } \\
\text { al., } 2016\end{array}$ \\
\hline pa_ther & $\begin{array}{l}\text { Micro- } \\
\text { sporidian }\end{array}$ & $\begin{array}{l}\text { Paranucleospor } \\
\text { a theridion }\end{array}$ & FJ59481 & $\begin{array}{l}\text { F: CGGACAGGGAGCATGGTATAG } \\
\text { R: GGTCCAGGTTGGGTCTTGAG } \\
\text { P: TTGGCGAAGAATGAAA }\end{array}$ & $\begin{array}{l}\text { Nylund } \\
\text { et al., } \\
2010\end{array}$ \\
\hline reov & Virus & ReoVirus MGL & - & $\begin{array}{l}\text { F: AACTTTCGGCTTTCTGCTATGC } \\
\text { R: GAGGACAAGGGTCTCCATCTGA } \\
\text { P: TTAATTGCGGTACTGCTC }\end{array}$ & $\begin{array}{l}\text { Miller } e t \\
\text { al., } 2016\end{array}$ \\
\hline rlo & Bacterium & $\begin{array}{l}\text { Rickettsia-like } \\
\text { organism }\end{array}$ & EU555284 & $\begin{array}{l}\text { F: GGCTCAACCCAAGAACTGCTT } \\
\text { R: GTGCAACAGCGTCAGTGACT } \\
\text { P: CCCAGATAACCGCCTTCGCCTCCG }\end{array}$ & $\begin{array}{l}\text { Lloyd et } \\
\text { al., } 2011\end{array}$ \\
\hline sp_des & $\begin{array}{l}\text { Mesomy- } \\
\text { cetozoea }\end{array}$ & $\begin{array}{l}\text { Sphaerothecum } \\
\text { destructuens }\end{array}$ & AY267346 & $\begin{array}{l}\text { F: GGGTATCCTTCCTCTCGAAATTG } \\
\text { R: CCCAAACTCGACGCACACT } \\
\text { P: CGTGTGCGCTTAAT }\end{array}$ & $\begin{array}{l}\text { Miller et } \\
\text { al., } 2016\end{array}$ \\
\hline
\end{tabular}

\subsubsection{Statistical analyses}

All statistical analyses were performed using R statistical software (R Core Team, 2015). As the aims of this study were to investigate differences in biomarker expression from time point 1 at Seton fish fence (T1) compared with time point 2 at Gates Creek spawning channel (T2), any individual that did not have two successful samples at $\mathrm{T} 1$ and $\mathrm{T} 2$ were removed from these analyses. The final dataset therefore consisted of fish $(\mathrm{N}=48)$ with two gill samples (thus $\mathrm{N}=$ 96 gill samples) taken at different time points in their freshwater migration.

For all host gene biomarkers and infectious agent biomarkers, the BioMark Real-Time PCR analysis software generated a quantification cycle threshold $(\mathrm{Ct})$ value. All assays were performed in duplicate, and thus $\mathrm{Ct}$ values for each host gene or infectious agent biomarker in every fish were averaged. For infectious agents, assays not detected in duplicate were failed. 
Using custom functions in R statistical software (R Core Team, 2015), the efficiency of every host gene assay was calculated. All samples were screened for outliers which were then removed from further analyses. Relative expression of host genes was derived by calculating the fold change difference in $\mathrm{Ct}$ value relative to a reference gene as per Pfaffl (2001). The resulting dataset therefore consisted of relative expression ratios of every host gene $\mathrm{Ct}$ value compared to the reference gene $\mathrm{Ct}$ value. For infectious agents, the number of RNA copies per sample was calculated using the standard curves of APC clone dilutions that were run on each dynamic array. Any APC contaminated samples were detected by fluorescence of the NED probe, and these were removed. Infectious agent RNA copy number was log transformed for all analyses.

\section{Biomarker expression analyses}

To compare differences in host gene expression between Seton fence and Gates Creek I performed non-metric multidimensional scaling analysis (NMDS) using R package "vegan" (Oksanen et al., 2019). NMDS is in iterative, rank-based procedure that reduces dimensions in a multidimensional dataset (Taguchi and Oono, 2005). The metaMDS() function was used to create a Bray-Curtis distance matrix of individual fish based on their host biomarker expression values. Two dimensions were included in this ordination. Host biomarkers ('species') scores were calculated as weighted averages in the ordination space. To test for differences in host gene expression between my two sampling locations (Seton fence and Gates Creek) I performed PERMANOVA analysis using R package "vegan" (Oksanen et al., 2019). PERMANOVA is a multivariate permutation test that allows for the geometric partitioning of variation in a multivariate 'response' dataset in response to explanatory variable in a linear-regression style analysis (Anderson, 2017). Here, the normalized fold change values for all 25 biomarkers 
represented the multivariate response dataset. Sampling location (Seton fence or Gates Creek) represented the explanatory variable. PERMANOVA was used to test if the mean centroid of gene expression differed at Seton fence compared with Gates Creek. Sex was also included as a covariate to account for variation in gene expression between males and females. PERMANOVA was performed using the adonis() function in "vegan" R package (Oksanen et al., 2019). I also tested for differences in the variance, or dispersion, of gene expression between Seton fence and Gates Creek using the betadisper() function in "vegan".

To determine if gear escape simulations affected gene expression I used both PERMANOVA and redundancy analysis (RDA) to test for differences in the mean centroid of host gene expression at Seton fence and Gates Creek locations, separately, between control and treatment (fish that experience gear escape simulation) groups. In this analysis, my dataset was treated as a before-after-control-impact (BACI) study design. RDA is a constrained ordination technique that can regress linear explanatory variables against multivariate responses. For this analysis, experimental groups (control, gillnet escape, seine net escape) were coded into dichotomous variables for input into models. PERMANOVA was performed using metaMDS() function, and RDA was performed using $r d a()$ function, both from the "vegan" R package. Differences in variance or dispersion of gene expression was also tested using betadisper() function. Visualization of the data was performed using NMDS analysis using the metaMDS() function of package "vegan". A Bray-Curtis distance matrix of individual fish based at both locations was created using their host biomarker expression values. Two dimensions were included in this ordination. Host biomarkers ('species') scores were calculated as weighted averages to plot on the ordination space. 


\section{Infectious agent analyses}

Infectious agent prevalence was calculated by dividing the number of fish that tested positive for a given infectious agent, by the total number of fish sampled in that group. Prevalence of each infectious agent was calculated at both Seton fence and at Gates Creek. Additionally, the prevalence of each infectious agent at both locations was calculated for fish in each treatment group (control, gillnet escape, seine net escape). Logistic regression models were used to compare the prevalence of common infectious agents between sampling locations (Seton fence vs Gates Creek). Only infectious agents with prevalence over $5 \%$ were chosen for this further analysis to avoid zero counts and unbalanced distributions of positive samples, as per Nekouei et al. (2019). Bonferroni correction was applied for multiple comparisons.

I investigated changes in infectious agent load (RNA copies) over migration and following gear escape simulation through the Seton system using linear mixed effects model from the "Ime4" package (Bates et al., 2015). Models were constructed that included sex as a fixed effect variable, and gill sample (i.e. sample taken at T1 or T2) and treatment (control, gillnet escape, or seine net escape treatment) as interacting fixed effect variables. Fish identification number and tagging date were also included as random effect variables. These models were constructed for all 7 infectious agents detected in this study, and only included those individuals that tested positive for that infectious agent. Models were then tested using a two-way ANOVA. Post-hoc comparison among treatment groups was performed using the emmeans() function of "emmeans" package (Lenth 2018) with Tukey adjustment. Through these mixed effect models, I could test which, if any, infectious agents significantly changed in load from Seton fence to Gates Creek, and if gear escape influenced infectious agent load. 
Finally, I also calculated relative infection burden (RIB) for each individual as per Bass et al. (2019). RIB allows us to collapse all infectious agent load data for an individual into a single metric that represents the overall burden (loads) of infectious agents on an individual. RIB is calculated using the following formula:

$$
\sum_{i \in m}^{m} \frac{L i}{\operatorname{Lmaxi}}
$$

The RNA copy number of the i'th positively detected infectious agent $(\mathrm{Li})$ is divided by the maximum RNA copy number within the population of fish sampled for that i'th infectious agent (Lmaxi). This is repeated for every infectious agent detected within the population of fish sampled, and all calculated values are then summed. I tested the effect of gear escape simulation on changes in RIB as fish migrated from Seton fence to Gates Creek using linear mixed effects models, as described above. I also tested for differences in average migration temperature through Seton and Anderson lakes and RIB. Thermal experience through Seton and Anderson lakes was evaluated using temperature logger data from recovered carcasses at Gates Creek $(\mathrm{N}=$ 50). I determined entrance into Seton lake as the first temperature recording following detection of the fish at the PIT receiver located at the fishway exit of Seton dam. I determined exit from Anderson lake by the first detection of the fish at the PIT receiver at the mouth of Gates Creek. I eliminated data as fish migrated through Portage Creek as fish are not able to thermally regulate in this section of creek like they can in lakes. Temperatures as fish migrated through Portage Creek were determined by looking at the thermograph for each individual fish. The timespan of fish as they migrated through the creek was estimated as it is much higher in temperature (typically $19-20^{\circ} \mathrm{C}$ ) compared to the temperatures at which fish choose to migrate through the 
lake (typically below $16^{\circ} \mathrm{C}$ ). The average temperature experienced by each fish was then calculated for both Seton and Anderson lake separately, as well as for both lakes combined.

\subsection{Results}

\subsubsection{Changes in infectious agent load and prevalence}

A total of 7 infectious agents were detected in sockeye salmon sampled at either Seton fence or Gates Creek (Fig. 3.1). There were no significant differences in infectious agent loads between sexes (Table 3.3). A total of 3 infectious agents had significantly different loads at Seton fence compared with Gates Creek (Table 3.3). Mean load of Candidatus Branchiomonas cysticola $(\mathrm{p}=0.048)$, Flavobacterium psychrophilum $(\mathrm{p}=<0.0001)$, and Parvicapsula minibicornis $(\mathrm{p}=<0.0001)$ were all significantly higher at Seton fence compared to Gates Creek (Table 3.3; Fig. 3.1). Two infectious agents had significantly higher prevalence at Gates Creek: F. psychrophilum $(\mathrm{p}=<0.00001)$ and Ichthyophthirius multifiliis $(\mathrm{p}=0.0068$; Table 3.4; Fig. 3.1). At Seton fence, $28.6 \%$ of all fish sampled were positive for F. psychrophilum, however at Gates Creek $83.9 \%$ of all fish were positive for this agent. For I. multifillis, $28.6 \%$ of all fish were positive for this agent at Seton fence and 53.6\% of all fish at Gates were positive for this agent. I did not find gear escape to have a significant effect changing the load or prevalence of any of the infectious agents detected in this study (Table 3.4). 
Table 3.3. Model results for linear mixed effects models testing the effects of sex, treatment (gillnet and seine net escape simulations), and location (Seton fence vs Gates Creek) on infectious agent loads (RNA copy numbers). $\mathrm{G}=$ gillnet escape simulation, $\mathrm{S}=$ seine net escape simulation. Significant findings $(\mathrm{p}<0.05)$ are boldened.

\begin{tabular}{|c|c|c|c|c|c|c|c|c|c|}
\hline \multirow{3}{*}{$\begin{array}{l}\text { Response } \\
\text { Variable }\end{array}$} & \multirow{3}{*}{$\begin{array}{l}\text { Model } \\
\text { type }\end{array}$} & \multirow{3}{*}{$\begin{array}{l}\mathrm{N} \\
\text { obs }\end{array}$} & \multirow{3}{*}{$\begin{array}{c}\text { Model } \\
\text { Parameter }\end{array}$} & \multicolumn{6}{|c|}{ Explanatory Variables } \\
\hline & & & & \multirow[b]{2}{*}{ Sex } & \multirow[b]{2}{*}{ Location } & \multicolumn{2}{|c|}{ Treatment } & \multicolumn{2}{|c|}{ Treatment:Location } \\
\hline & & & & & & $\mathrm{G}$ & $S$ & Location:G & Location:S \\
\hline \multirow{3}{*}{$\begin{array}{l}\mathrm{Ca} . \mathrm{B} . \\
\text { cysticola }\end{array}$} & \multirow{3}{*}{$\begin{array}{l}\text { Linear } \\
\text { mixed } \\
\text { effects } \\
\text { model }\end{array}$} & \multirow{3}{*}{92} & $\beta$ & 0.43 & 1.28 & 3.35 & -0.8 & -1 & 2.08 \\
\hline & & & $\mathrm{SE}$ & 0.95 & 0.69 & 1.62 & 1.55 & 1.51 & 1.42 \\
\hline & & & $\mathrm{p}$ & 0.65 & 0.048 & 0.043 & 0.61 & 0.51 & 0.15 \\
\hline \multirow{3}{*}{ C. shasta } & \multirow{3}{*}{$\begin{array}{l}\text { Linear } \\
\text { mixed } \\
\text { effects } \\
\text { model }\end{array}$} & \multirow{3}{*}{58} & $\beta$ & 0.68 & 0.87 & -2.98 & - & 2.66 & - \\
\hline & & & $\mathrm{SE}$ & 1.59 & 1.26 & 3.06 & - & 3.48 & - \\
\hline & & & $\mathrm{p}$ & 0.67 & 0.5 & 0.35 & - & 0.45 & - \\
\hline \multirow{3}{*}{$\begin{array}{c}F . \\
\text { psychrophilum }\end{array}$} & \multirow{3}{*}{$\begin{array}{l}\text { Linear } \\
\text { mixed } \\
\text { effects } \\
\text { model }\end{array}$} & \multirow{3}{*}{34} & $\beta$ & 0.35 & 4.57 & 1.2 & - & -2.39 & - \\
\hline & & & SE & 0.71 & 0.86 & 1.51 & - & 2.1 & - \\
\hline & & & $\mathrm{p}$ & 0.63 & 0.000012 & 0.43 & - & 0.27 & - \\
\hline \multirow{3}{*}{ I. multifiliis } & \multirow{3}{*}{$\begin{array}{l}\text { Linear } \\
\text { mixed } \\
\text { effects } \\
\text { model }\end{array}$} & \multirow{3}{*}{14} & B & $\begin{array}{c}- \\
4.18\end{array}$ & -2.24 & -6.56 & - & 5.86 & - \\
\hline & & & SE & 3.12 & 2.32 & 5.06 & - & 5.68 & - \\
\hline & & & $\mathrm{p}$ & 0.27 & 0.39 & 0.25 & - & 0.36 & - \\
\hline \multirow{3}{*}{ L. salmonae } & \multirow{3}{*}{$\begin{array}{l}\text { Linear } \\
\text { mixed } \\
\text { effects } \\
\text { model }\end{array}$} & \multirow{3}{*}{20} & $\beta$ & 5.53 & 0.25 & -0.58 & - & -0.42 & - \\
\hline & & & SE & 2.78 & 4.05 & 1.16 & - & 3.06 & - \\
\hline & & & $\mathrm{p}$ & 0.22 & 0.83 & 0.91 & - & 0.89 & - \\
\hline \multirow{3}{*}{$\begin{array}{c}P . \\
\text { minibicornis }\end{array}$} & \multirow{3}{*}{$\begin{array}{l}\text { Linear } \\
\text { mixed } \\
\text { effects } \\
\text { model }\end{array}$} & \multirow{3}{*}{88} & $\beta$ & 0.35 & 5.99 & 1.79 & 1.15 & -1.16 & -0.33 \\
\hline & & & SE & 0.49 & 0.65 & 1.02 & 0.96 & 1.39 & 1.31 \\
\hline & & & $\mathrm{p}$ & 0.48 & $<0.00001$ & 0.083 & 0.23 & 0.41 & 0.8 \\
\hline
\end{tabular}


Table 3.4. Model results for logistic regression models testing the effects of sex, treatment (control vs gillnet and seine net escape simulations), and location (Seton fence vs Gates Creek) on infectious agent prevalence (presence or absence of each infectious agent in a fish). $\mathrm{G}=$ gillnet escape simulation, $\mathrm{S}=$ seine net escape simulation. Significant findings $(\mathrm{p}<0.05)$ are boldened.

\begin{tabular}{|c|c|c|c|c|c|c|c|}
\hline \multirow[t]{3}{*}{$\begin{array}{l}\text { Response } \\
\text { Variable }\end{array}$} & \multirow[t]{3}{*}{$\begin{array}{l}\text { Model } \\
\text { Type }\end{array}$} & \multirow[t]{3}{*}{$\mathrm{N}$ obs } & \multirow[t]{3}{*}{$\begin{array}{c}\text { Model } \\
\text { Parameter }\end{array}$} & \multicolumn{4}{|c|}{ Explanatory Variables } \\
\hline & & & & \multirow[b]{2}{*}{ Sex } & \multirow[b]{2}{*}{ Location } & \multicolumn{2}{|c|}{ Treatment } \\
\hline & & & & & & G & $\mathrm{S}$ \\
\hline \multirow{3}{*}{ Ca. B. cysticola } & \multirow{3}{*}{$\begin{array}{l}\text { Logistic } \\
\text { regression }\end{array}$} & \multirow{3}{*}{96} & $\beta$ & 0.28 & 18.31 & -0.45 & 17.54 \\
\hline & & & SE & 1.46 & 3986.75 & 1.46 & 6887.72 \\
\hline & & & $\mathrm{p}$ & 0.85 & 0.99 & 0.76 & 0.99 \\
\hline \multirow{3}{*}{ C. shasta } & \multirow{3}{*}{$\begin{array}{l}\text { Logistic } \\
\text { regression }\end{array}$} & \multirow{3}{*}{96} & $\beta$ & -0.21 & -0.81 & -0.13 & 0.095 \\
\hline & & & SE & 0.42 & 0.42 & 0.45 & 0.64 \\
\hline & & & $\mathrm{p}$ & 0.62 & 0.051 & 0.78 & 0.88 \\
\hline \multirow{3}{*}{$\begin{array}{c}F . \\
\text { psychrophilum }\end{array}$} & \multirow{3}{*}{$\begin{array}{l}\text { Logistic } \\
\text { regression }\end{array}$} & \multirow{3}{*}{96} & $\beta$ & 0.12 & 4.57 & -0.44 & -2.92 \\
\hline & & & SE & 0.57 & 1.08 & 0.61 & 1.21 \\
\hline & & & $\mathrm{p}$ & 0.83 & $<0.00001$ & 0.47 & 0.16 \\
\hline \multirow{3}{*}{ I. multifiliis } & \multirow{3}{*}{$\begin{array}{l}\text { Logistic } \\
\text { regression }\end{array}$} & \multirow{3}{*}{96} & $\beta$ & -1.03 & 1.22 & -0.86 & 0.02 \\
\hline & & & SE & 0.45 & 0.45 & 0.51 & 0.64 \\
\hline & & & $\mathrm{p}$ & 0.022 & 0.0068 & 0.089 & 0.97 \\
\hline \multirow{3}{*}{ L. salmonae } & \multirow{3}{*}{$\begin{array}{l}\text { Logistic } \\
\text { regression }\end{array}$} & \multirow{3}{*}{96} & $\beta$ & -0.94 & -0.083 & 0.11 & 0.96 \\
\hline & & & SE & 0.42 & 0.41 & 0.45 & 0.63 \\
\hline & & & $\mathrm{p}$ & 0.024 & 0.84 & 0.81 & 0.13 \\
\hline \multirow{3}{*}{ P. minibicornis } & \multirow{3}{*}{$\begin{array}{l}\text { Logistic } \\
\text { regression }\end{array}$} & \multirow{3}{*}{96} & $\beta$ & 0.08 & 19.04 & 19.03 & 19.05 \\
\hline & & & SE & 1.47 & 5846 & 6890 & 10330 \\
\hline & & & $\mathrm{p}$ & 0.96 & 0.99 & 0.99 & 0.99 \\
\hline \multirow{3}{*}{ P. theridion } & \multirow{3}{*}{$\begin{array}{l}\text { Logistic } \\
\text { regression }\end{array}$} & \multirow{3}{*}{96} & B & 0.39 & -0.61 & 18.91 & 18.75 \\
\hline & & & SE & 0.82 & 0.79 & 2436.62 & 2436.62 \\
\hline & & & $\mathrm{p}$ & 0.63 & 0.44 & 0.99 & 0.99 \\
\hline
\end{tabular}




\subsubsection{Infectious agent burden and thermal selection}

Linear regression of relative infection burden (RIB) with average migration temperature showed a significantly negative relationship ( $\mathrm{df}=40, \mathrm{p}=0.009, R^{2}=0.16$; Fig. 3.2). I did not find any significant correlations between individual infectious agent loads and migration temperature through Seton or Anderson lake.

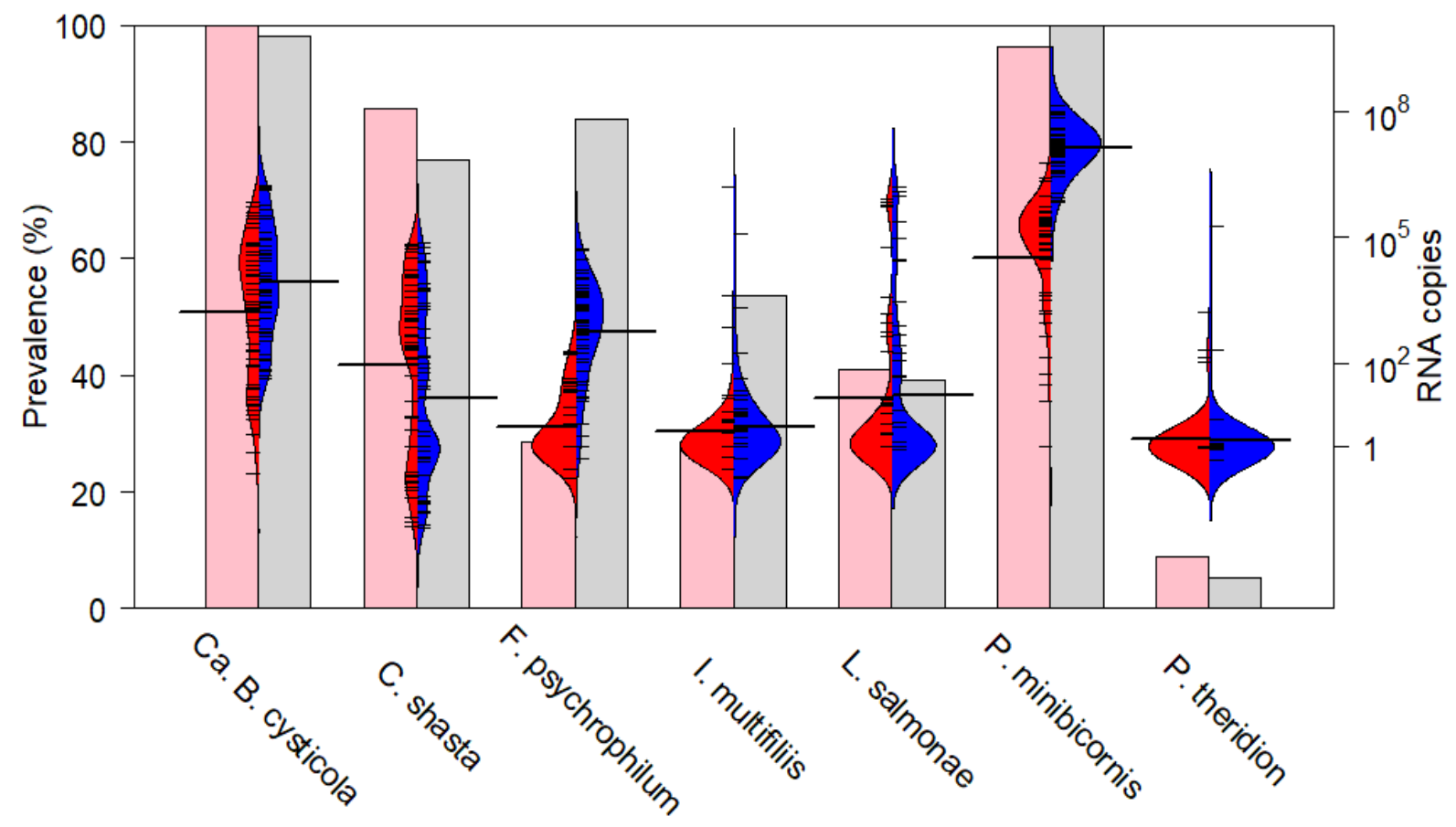

Figure 3.1. Barplots and Beanplots showing the prevalence and load, respectively, of infectious agents detected at Seton Fence and Gates Creek sockeye in 2017. Small hash marks represent individual fish and the larger horizontal line represents the group mean at either Seton fence or Gates Creek locations. Data from Seton fence is shown on the left-hand side of the plots (red). Data from Gates Creek is shown on the right-hand side (blue). 


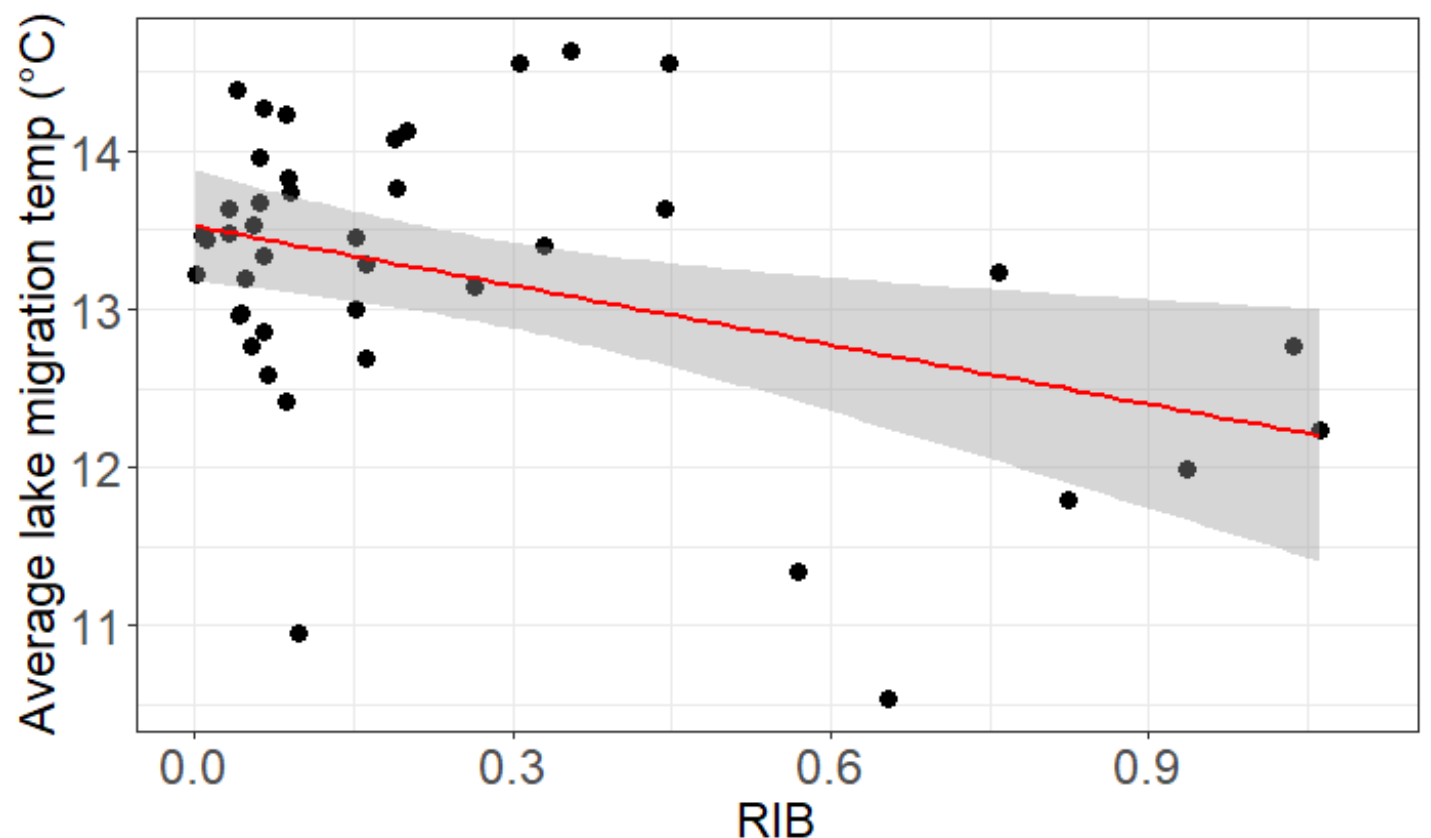

Figure 3.2. Relationship between relative infection burden (RIB) and the average migration temperature through both Seton and Anderson lakes. The red line represents the mean response, and the shaded area represents the $95 \%$ confidence level interval for predictions from the linear model.

\subsubsection{Changes in gene expression over migration}

NMDS successfully reduced host gene expression data into a 2-dimensional ordination $($ stress $=0.196)$. Samples taken at Seton fence were closer in ordination space to three thermal stress biomarkers (HSP90alike_6, SERPIN9, and SERPIN20), whereas all other biomarkers were closer in ordination space to samples taken at Gates Creek (Fig 3.3). PERMANOVA and betadisper testing revealed that both mean centroid $(\mathrm{p}=0.001)$ and variance of host gene expression $(\mathrm{p}=<0.0001)$ differed between Seton fence and Gates Creek. 


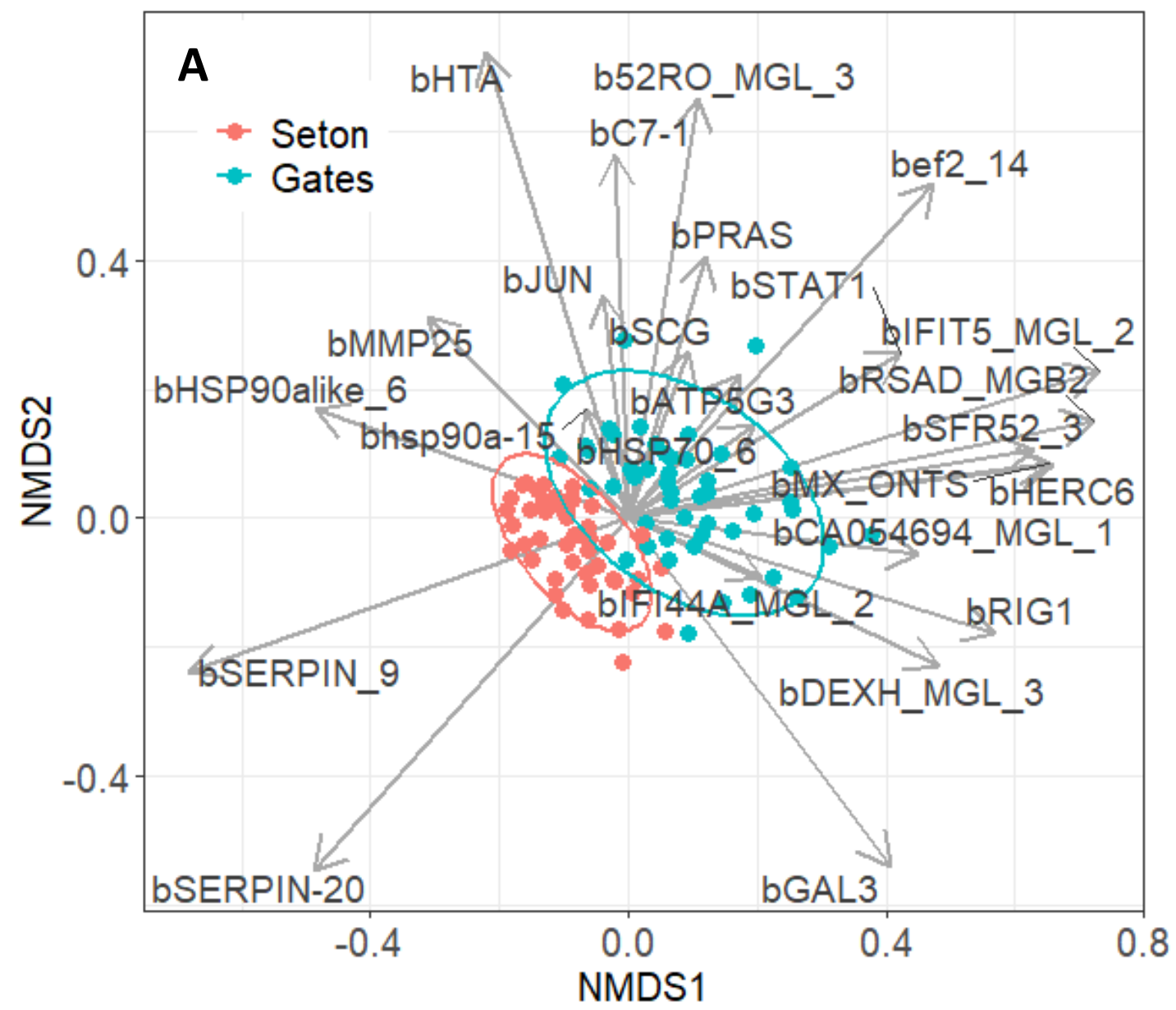




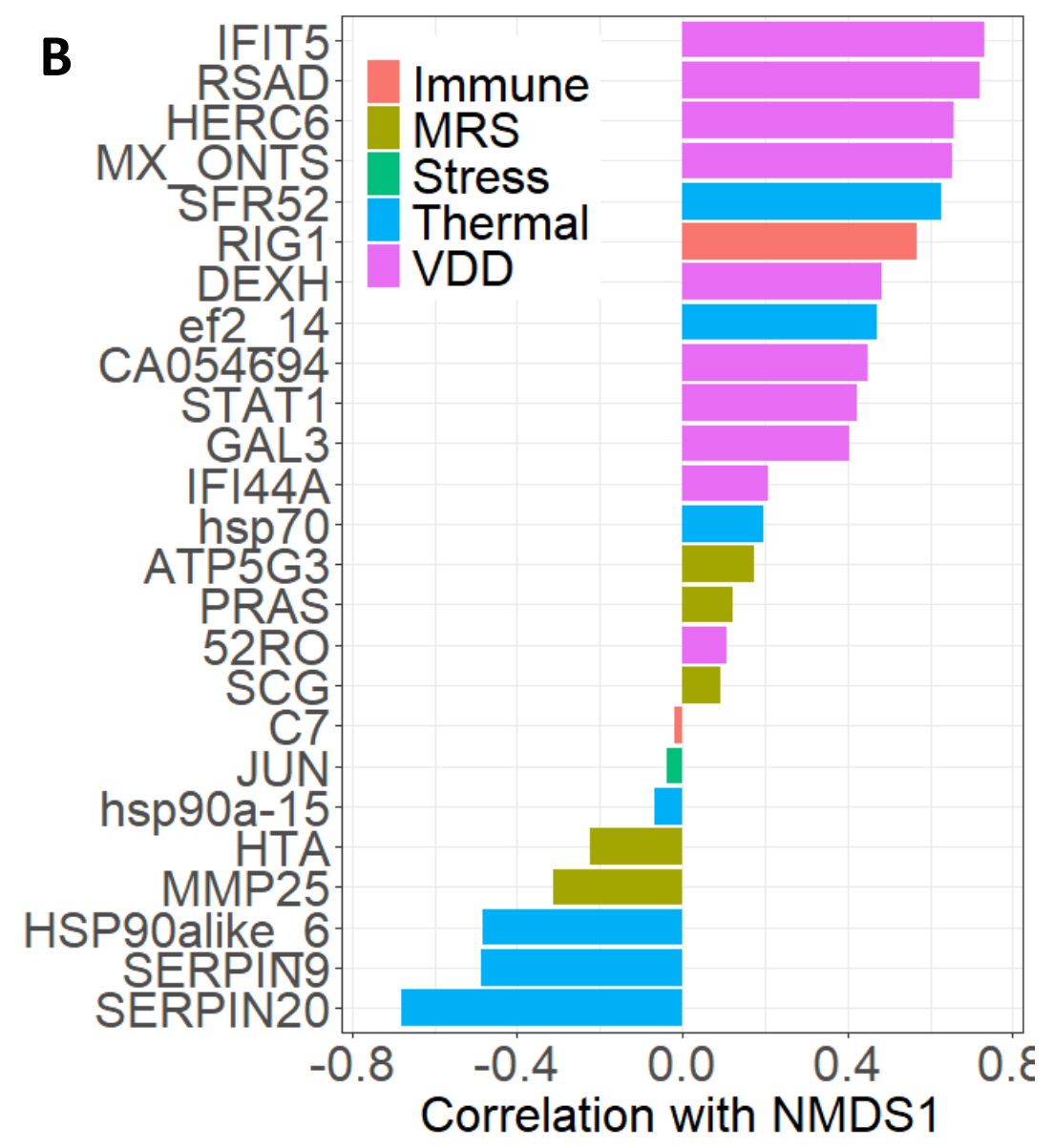

Figure 3.3. (A) NMDS plot comparing samples taken from fish at Seton fence (red points) to samples taken from those same fish at Gates Creek (blue points). Host biomarkers scores were calculated as weighted averages and plot on the ordination space. (B) Correlation of individual biomarkers with NMDS1. Biomarkers are categorized based on their function: thermal stress, viral disease development (VDD), mortality-related signature (MRS), immune response, and general stress.

\subsubsection{Biomarker expression changes following gear escape}

I found no significant differences in gene expression between control and gear escape treatment groups at the Seton fence location using either PERMANOVA or RDA analyses. At Gates Creek I again found no significant differences between control group fish and gillnet or seine net escapement groups using either PERMANOVA $(p=0.34)$ or RDA $(p=0.09)$ approaches (Fig. 3.4). 


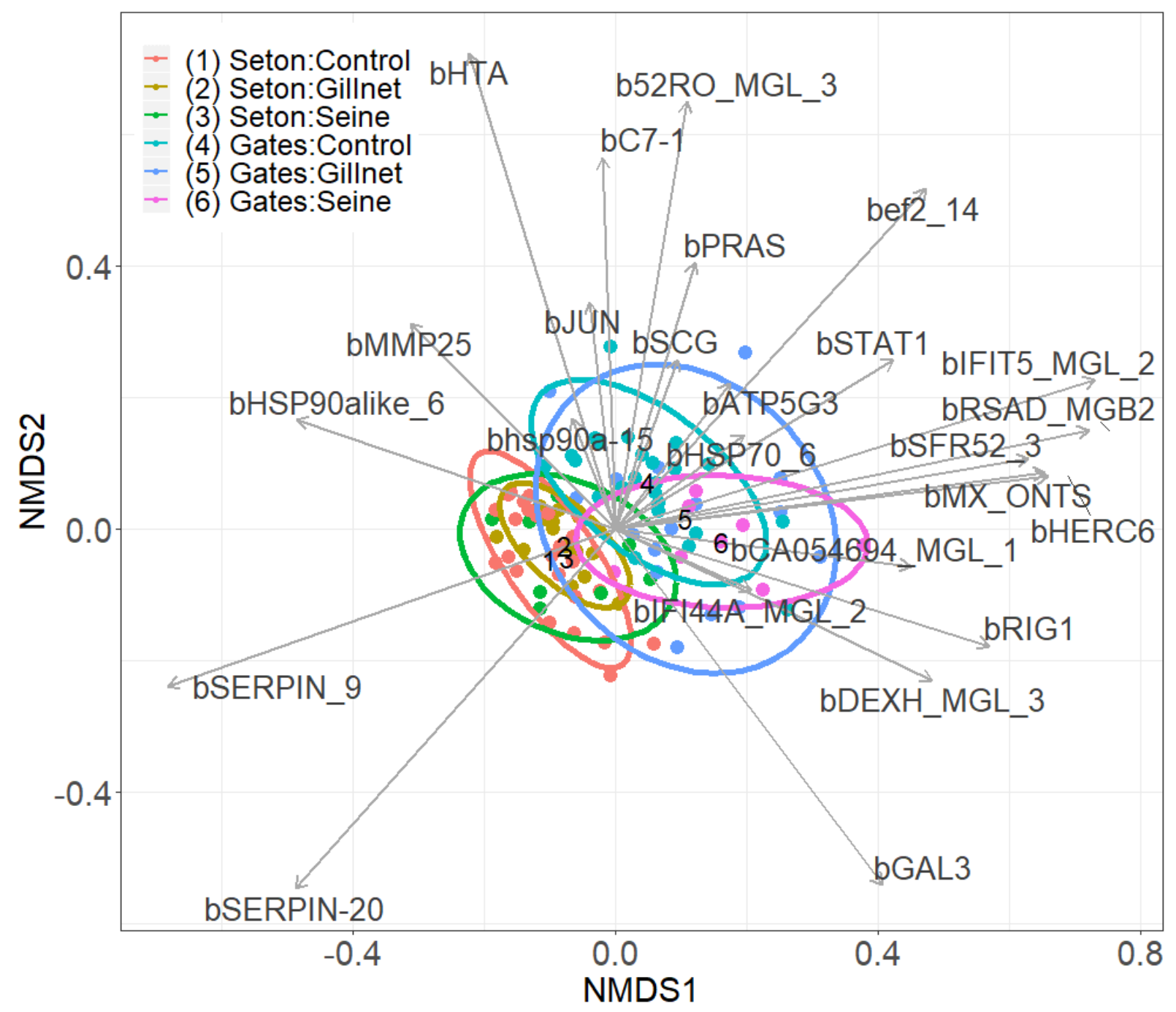

Figure 3.4. NMDS ordination plot comparing biomarker expression of fish at Seton fence and Gates Creek for each treatment group (control, gillnet escape, seine net escape). Numbers correspond to each treatment group mean at either Seton fence or Gates Creek locations. Ellipses represent $95 \%$ confidence intervals for each group at each location. Host biomarkers scores were calculated as weighted averages and plot on the ordination space. 


\subsection{Discussion}

I investigated differences in biomarker- and infectious agent profiles of recaptured, wild sockeye salmon between two locations throughout their freshwater migration. Repeat sampling of individuals allowed me to first investigate how biomarker expression and infectious agent prevalence and load might change for sockeye salmon on an individual-basis, and second, how fisheries interactions might affect non-retention sockeye salmon at a gene- and infectious agent level. I found that both biomarker expression and infectious agent profiles changed significantly over the final $50 \mathrm{~km}$ of migration for Gates Creek sockeye salmon, but gear escape simulations did not result in any significant impact.

\section{Changes in infectious agent profiles during Seton system migration}

I determined the presence and load of 18 infectious agents known or suspected to infect Fraser River sockeye salmon with validated, high-throughput qPCR assays. I detected a total of 7 infectious agents in Gates Creek sockeye salmon sampled in Seton River and again at Gates Creek spawning grounds. Of these, two infectious agents were bacterium, five were parasites, and no viruses were detected. The loads and prevalence of these infectious agents is comparable to previous findings for Gates Creek sockeye (Bass, 2018). Three infectious agents increased in load as sockeye migrated from the Seton River fish fence to Gates Creek spawning grounds: Candidatus Branchiomonas cysticola, Flavobacterium psychrophilum, and Parvicapsula minibicornis. Previous studies have reported that the load of $P$. minibicornis increases following initial exposure in the lower Fraser River (Jones et al., 2003; Wagner et al., 2005), and similarly $\mathrm{Ca}$. B. cysticola has been found to increase in productivity over days surviving in sockeye 
salmon (Teffer et al., 2017) and F. psychrophilum has been shown to increase in prevalence towards spawning grounds (Miller et al., 2014). Agents that show temporal increases in loads during the course of freshwater migrations may be of particular interest with respect to disease development, mortality, and overall fitness for adult salmon. For these infectious agents, it could be speculated that fish may reach a certain "load threshold", and at this point the infectious agent begins to have serious fitness-decreasing impacts and eventually cause mortality. In this study, a major limitation exists in that my dataset only includes individuals that survived to spawning grounds. Those individuals that died en-route are not accounted for, and the infectious agent profiles of unsuccessful migrants is unknown. It is possible that these unsuccessful migrants experienced even greater increases in loads of infectious agents during migration, and as a result perished en-route.

Contrary to my initial hypothesis, I did not find any effect of gear escape, from either gillnet or seine net, on infectious agent load or prevalence following escape. However, I again emphasize that the data presented in this study are only from fish that survived to spawning grounds, and thus I am missing a large portion of data from those fish that died en-route. Stress and injuries resulting from fisheries interactions may make fish more susceptible to infectious agents and disease following escape (Pickering and Pottinger, 1989; Svendsen and Bøgwald, 1997; Baker et al., 2013), and due to the greater stress and injury of gillnet entanglement compared with seine nets (Bass et al., 2018b), I predicted that fish surviving gillnets to have greater loads of certain infectious agents. Although my results did not support this, gear escape might be causing fatal increases in certain infectious agents and these data are missing from my dataset. I also note that my gear escape simulations were relatively mild and rarely resulted in injury. As salmon approach spawning grounds, their skin thickens (Robertson and Wexler, 
1960), scales are reabsorbed (Kacem et al., 1998), and cortisol levels increase (Baker and Vynne, 2014). Proximity to spawning grounds is therefore an important factor to consider as it can affect the consequences of fisheries interactions (Bass et al., 2018b). For this study, gear escape simulations were performed when Gates Creek sockeye entered the Seton River and had completed approximately $88 \%$ of their total spawning migration. Therefore, these fish are expected to be more resilient to fisheries interactions and, due to thicker skin, are less prone to injury, compared with fish that interact with fisheries gear earlier during their spawning migration. With reduced injury and damage to the integument of fish, and increased resilience to the stressor, opportunistic pathogens may be less likely to invade and proliferate.

\section{Changes in biomarker expression during Seton system migration}

When analyzing data from 48 fish that were sampled at Seton River fish fence and again at Gates Creek spawning grounds, I found a difference in multivariate gene expression as sockeye migrated through the Seton system. Three thermal biomarkers decreased in expression between these two sampling locations. HSP90alike_6, SERPIN9, and SERPIN20 are a known cluster of thermal biomarkers that have been previously shown to be strong indicators of thermal stress (Akbarzadeh et al., 2018; Houde et al., 2019). The expression of these thermal biomarkers decreased throughout Seton system migration in this study. During this final $50 \mathrm{~km}$ stretch of their migration, Gates Creek sockeye travel through Seton and Anderson Lakes where they have the opportunity to exploit thermal layers and avoid high water temperatures (Minke-Martin et al., 2018). Lakes are thermal refuges for migrating salmon in freshwater environments, and this is important to reduce the effects of thermal stress and increase migration success to spawning grounds (Newell and Quinn, 2005; Mathes et al., 2009; Keefer and Caudill, 2015). The results 
presented in this study suggest that thermal refuge in lakes reduces expression of thermal biomarkers of sockeye salmon in the wild, and this suggests thermal stress is reduced for these fish.

As sockeye migrated from Seton fence to Gates Creek, I also observed increases in expression of a number of genes associated with viral disease development (VDD). I found all 10 VDD biomarkers assayed for in this study to increase in expression as sockeye migrated through the Seton system. In particular, the VDD biomarkers IFIT5, MX_ONTS, RSAD, HERC6, and STAT1 showed the greatest increases in expression. I found no viruses to be detected in sampled sockeye during this study, and thus it could be a possibility that there may be a novel virus infecting certain individuals. New infectious agents are being discovered every year (Mordecai et al., 2019, 2020), and some known infectious agents do not have fully developed or validated assays. Gates Creek sockeye sampled in this study may therefore have other infectious agents that either do not have assays or are completely novel. I note that this is highly speculative and further testing is needed to understand the VDD gene response seen in this study. In order to more accurately infer that viral infection is causing the increase in VDD gene expression observed, qPCR would need to be performed assaying expression of these VDD genes alongside positive and negative controls from fish known to be infected and non-infected by viruses, respectively, as per Miller et al. (2017) and Di Cicco et al. (2018). If this further testing elucidates that fish are burdened with novel viral infection, metatranscriptomic sequencing can be used to identify potential novel viruses in gill tissue samples.

The increase in VDD biomarker expression I found in this study may also be a function of maturation, senescence, or preparation for spawning grounds as fish transition through the final stretch of their spawning migration. Pacific salmon undergo a suite of physiological (Hinch 
et al., 2006; Hruska et al., 2010; Flores et al., 2012), morphological (Burgner, 1991), and genomic (Miller et al., 2009; Evans et al., 2011) changes during their spawning migrations. There is also evidence of inherent immunological changes during spawning migrations for Pacific salmon (Schouten et al., 2013; Dolan et al., 2016). Dolan et al. (2016) found that both innate and adaptive immune responses diminish as fish approach spawning grounds, whereas Schouten et al. (2013) found certain aspects of adaptive immune responses to be retained, or to even increase, as fish approach spawning. If the fish sampled as part of this study are not exhibiting increased VDD biomarker in response to viral infection, it could be speculated that the VDD biomarker increases might be an inherent immune response that occurs during the spawning migrations of Pacific salmon.

I did not find gear escape (from either gillnets or seine nets) to alter biomarker expression in this study. Biomarker expression profiles at Gates Creek did differ slightly between treatment groups compared with at Seton fence (Fig. 3.4), however this change was not significant. Results from Chapter 2 of this thesis showed that fish that experienced gear escape simulations migrated at cooler temperatures through Seton lake compared with control fish. We may therefore expect gear escape fish to show reduced expression of thermal biomarkers upon reaching Gates Creek compared with control fish. However, the results from this study did not support this. Migration from Seton fence to Gates Creek predominantly consists of lake migration and thus minimal exposure to high river temperatures. This thermal refuge greatly reduces thermal stress for all fish, and may explain why we did not see a difference in thermal biomarker expression between control and gear escape treatment fish. Results from Chapter 2 also showed no difference in mortality between control and gear escape treatment fish, and thus we might expect to see no difference in MRS biomarkers. I would predict that gear escape would impact expression of 
specific genes for Pacific salmon, likely genes associated with stress or metabolic shifts. However, the biomarkers that were assayed in this study were not likely not affected by gear escape simulations. I also acknowledge that biopsies taken at Gates Creek were, on average, 11 days after gear escape simulations were performed, which may have allowed sufficient time for recovery of normal gene expression.

\section{Evidence of behavioural thermoregulation in response to infectious agent burden}

Lake environments represent a thermal refuge for migrating Pacific salmon. Thermally stratified lakes allow migrating salmon to avoid high river temperatures and choose the depth (and thus temperatures) at which they migrate. Thermal refuges may be increasingly important in an era of rapid climate change and warming water temperatures, and behavioural thermoregulation has been demonstrated to increase survival (Newell and Quinn, 2005; Mathes et al., 2009; Keefer and Caudill, 2015). Here, higher overall infectious agent burdens (RIB) was correlated with cooler migration temperatures in both Seton and Anderson lakes. This is likely a behaviour to reduce temperature-mediated increases in infection burden. Mathes et al. (2009) demonstrated that early-arriving Weaver Creek sockeye salmon only survived to spawning grounds if they utilized the cooler temperatures of Harrison Lake, and the authors predicted that this behaviour slowed development of infectious agents, in particular P. minibicornis, however this was not conclusively proved. Here, I found a negative correlation between RIB and migration temperature, which I speculate to be a behavioural response to hinder temperaturemediated development of certain infectious agents. 


\subsection{Conclusions}

This study investigates temporal changes in infectious agent and biomarker expression profiles of repeat-sampled, wild Pacific salmon during the final stage of their spawning migration. I found that several infectious agents increased in load and prevalence as fish approach spawning grounds, and agents that display such temporal increases may have important implications for the survival and spawning success of Pacific salmon. I also provide evidence that thermal refuge may be important for mitigating the effects, or slowing the progression, of infectious agent burden during spawning migrations; a behaviour that may be increasingly important in an era of climate change and increasing water temperatures. Genomic changes were also observed as fish migrated through the Seton system, with most prominent changes being decreases in thermal stress biomarkers (likely as a result of thermoregulation in lake refuges). I did not find gear escape simulations to impact infectious agent load or prevalence, or biomarker expression, during this study. However, I emphasize that advanced maturation due to proximity

to spawning grounds, 'gentle' gear escape simulations that rarely resulted in injury, and sampling of only survivors to spawning grounds may have affected results on the impacts of fisheries interactions on infectious agents. 


\section{CHAPTER 4}

\section{Survival, biomarker expression, and infectious agents of wild sockeye salmon (Oncorhynchus nerka) in a year of high Fraser River water temperatures}

\subsection{Abstract}

Rivers that have historically supported Pacific salmon runs are facing warming temperatures. For Pacific salmon, warm water temperatures can have a number of negative effects, including increased physiological and metabolic stress that can ultimately lead to mortality and spawning failure. There are now many studies that investigate physiological, behavioural, and genomic responses to elevated water temperatures, and the ultimate impacts on species and populations of salmon. However, these studies are mostly controlled holding studies with experimentally selected water temperatures. Here, I compare migration success, biomarker expression, and infectious agent profiles in the wild for a population of Fraser River sockeye salmon in a relatively 'cool' year vs a relatively 'warm' year for water temperatures. Average migration temperatures for Gates Creek sockeye salmon were $18.7^{\circ} \mathrm{C}$ in 2017 compared with $20.2{ }^{\circ} \mathrm{C}$ in 2018 . Temperatures above $19{ }^{\circ} \mathrm{C}$ have been associated with physiological stress and migration delay, and temperatures above $20{ }^{\circ} \mathrm{C}$ are known to greatly increase mortality for Pacific salmon. In agreement with this I found migration success to spawning grounds to be considerably lower in 2018 (26\%) compared with 2017 (78 \%). Further, in 2018, a year of warm 
water temperatures, I found evidence of thermal stress through elevated expression of known thermal biomarkers HSP90a15, SERPIN20, SERPIN9, HSP70_6, HSPalike6, and SFR52. In 2018, I also found the external variables water temperature at time of tagging, and relative loads of Candidatus Branchiomonas cysticola and Ceratomyxa shasta to be correlated with gene expression, whereas in 2017 only the relative load of Parvicapsula minibicornis was correlated with gene expression. When comparing infectious agent profiles between 2017 (cool) and 2018 (warm), I observed that in the warm year, Paranucleospora theridion was more prevalent in sampled fish, and Ceratomyxa shasta was detected at higher loads. However, in the cooler year Flavobacterium psychrophilum was more prevalent and Ichthyophthirius multifiliis was detected at higher loads. Collectively, these findings suggest that warmer water has severe consequences for mortality for Pacific salmon, and that temperature is also likely having a number of consequences on both gene expression and infectious agent profiles during adult salmon spawning migrations. 


\subsection{Introduction}

Pacific salmon (Oncorhynchus spp.) are anadromous fish that begin their life in freshwater habitats before migrating to ocean feeding environments. After ocean residence, salmon begin a vast migration back to natal freshwater habitats where they ultimately spawn and die (Groot and Margolis, 1991). Every salmon species and population must spawn during a specific time period to allow for appropriate egg incubation time in natal spawning habitats, and the adult freshwater migration timing relies on favourable temperature and discharge conditions in rivers (Keefer et al., 2004; Hinch et al., 2006). In recent decades, increases in water temperature and decreases in discharge have been observed in most rivers on the Pacific coast of North America (Patterson et al., 2007; Grant et al., 2019). Temperature is a critically important environmental factor known to have many effects on the physiology, ecology, and behaviour on all species of Pacific salmon (Fry, 1971), and there are now many studies highlighting the effects of warmer water temperatures on salmonid species. High temperatures have numerous physiological effects, including depletion of internal energy stores needed for migration and spawning (Hinch and Rand, 1998; Rand et al., 2006), altered metabolic (Brett, 1995) and heart rates (Prystay et al., 2017), and collapse of aerobic scope (Lee et al., 2003; Farrell et al., 2008). The ultimate consequences of warmer water temperatures on salmon can be costly, and include reduced recovery from stress and exercise (Macdonald et al., 2000), increased egg retention in females (West and Mason, 1987; Quinn et al., 2007), and increased mortality (Crossin et al., 2008; Keefer et al., 2008; Hinch et al., 2012) which can result in zero lifetime fitness for these one-time (i.e., capital) spawners.

Increased water temperature also causes a suite of gene-level changes in fish. Advances in high-throughput microarray and quantitative polymerase chain reaction (qPCR) techniques 
(Miller et al., 2016) have contributed to a growing number of studies detailing genomic changes in response to warmer temperatures (Miller et al., 2014). Jeffries et al. (2012) used cDNA microarrays to compare gene expression profiles of sockeye salmon held at either cool $\left(14{ }^{\circ} \mathrm{C}\right)$ or warm $\left(19^{\circ} \mathrm{C}\right)$ water temperatures. That study found that at warmer water temperatures, sockeye upregulated many heat shock response genes, immune response genes, and transcription factors associated with cellular apoptosis. In a similar study, Jeffries et al. (2014) found that warm water temperatures resulted in differential expression of genes associated with protein synthesis and folding, oxidative stress, and ion transport in both sockeye (Oncorhynchus nerka) and pink (Oncorhynchus gorbuscha) salmon, indicative of a cellular stress response. Transcriptome changes have been detailed through microarray analysis for a number of other species, including Arctic char (Salvelinus alpinus: Quinn et al., 2011), rainbow trout (Oncorhynchus mykiss; Lewis et al., 2010), and killifish (Fundulus heteroclitus; Healy et al., 2010). Knowledge of gene expression changes in response to warm water temperatures has led to the development of specific biomarkers indicative of thermal stress in salmon species (Akbarzadeh et al., 2018; Houde et al., 2019).

Temperature and infectious agents have complex interactions and outcomes for salmonids (reviewed in Miller et al., 2014). Warmer temperatures can directly affect the virulence and development of certain infectious agents, for example the bacterium Flexibacter columnaris shows increased virulence at higher temperatures (Gilhousen, 1990) which can increase gill damage inflicted on the salmonid host. Parvicapsula minibicornis has been shown to develop faster at warmer water temperatures, and this myxosporean parasite has been shown to reduced swimming performance (Wagner et al., 2005) and increase mortality (Crossin et al., 2008) in sockeye salmon. Replication of Ichthyophthirius multifiliis, a freshwater parasite that 
has been shown to increase mortality in spawning sockeye salmon (Traxler et al. 1998), has also been observed to increase at warmer temperatures (Ewing et al. 1986). Temperature can also influence the infectious dose of an infectious agent in the environment. For example, in a study of rainbow trout (Oncorhynchus mykiss) in the Klamath River, California, the myxosporean parasite Ceratomyxa shasta was present at increased doses in areas of warmer water temperature, leading to higher mortality (Stocking et al., 2006). Further, high temperatures and stress in salmonids can reduce the resilience of hosts to infectious agents (Barton, 2002; Mateus et al., 2017).

In this study I aim to investigate changes in survival, infectious agent profiles, and expression of select biomarkers in two years with different thermal conditions, with a focus on Gates Creek sockeye salmon (Oncorhynchus nerka) during their spawning migration. Using temperature loggers placed in the Fraser River, and known migration rates of sockeye salmon, I characterized the thermal experience of individuals as they migrated up the Fraser River in both 2017 and 2018. I found that these two years differed in water temperature, with 2017 being a relatively 'cool' year, and 2018 being relatively 'warm'. Survival, biomarker expression and infectious agent prevalence and loads (RNA copy numbers) in migrating sockeye was compared between the two years. This study represents a novel and unique opportunity to compare Pacific salmon gene expression in response to different thermal conditions in the wild, as opposed to that observed in recent controlled laboratory studies (e.g. Teffer et al., 2018, 2019). I hypothesized that mortality would be higher in the warmer year compared to the cooler year. I also hypothesized that in the warmer year, fish would exhibit an upregulation of both thermal and mortality-related signature biomarkers, and that infectious agent profiles (prevalence and loads of various infectious agents) would vary between the two years. 


\subsection{Methods}

\subsubsection{Study site}

Gates Creek sockeye are an early summer-run salmon that migrate up the Fraser and Seton Rivers to spawn in Gates Creek. Gates Creek is approximately $414 \mathrm{~km}$ from the mouth of the Fraser River. Migrating Gates Creek sockeye enter the Seton River (approximately $364 \mathrm{~km}$ from the mouth of the Fraser), and then must navigate Seton Dam fish ladder, before passing through both Seton and Anderson Lakes to reach Gates Creek natal spawning grounds (approximately $50 \mathrm{~km}$ in total). See Figure 4.1 for a map of the Seton System.

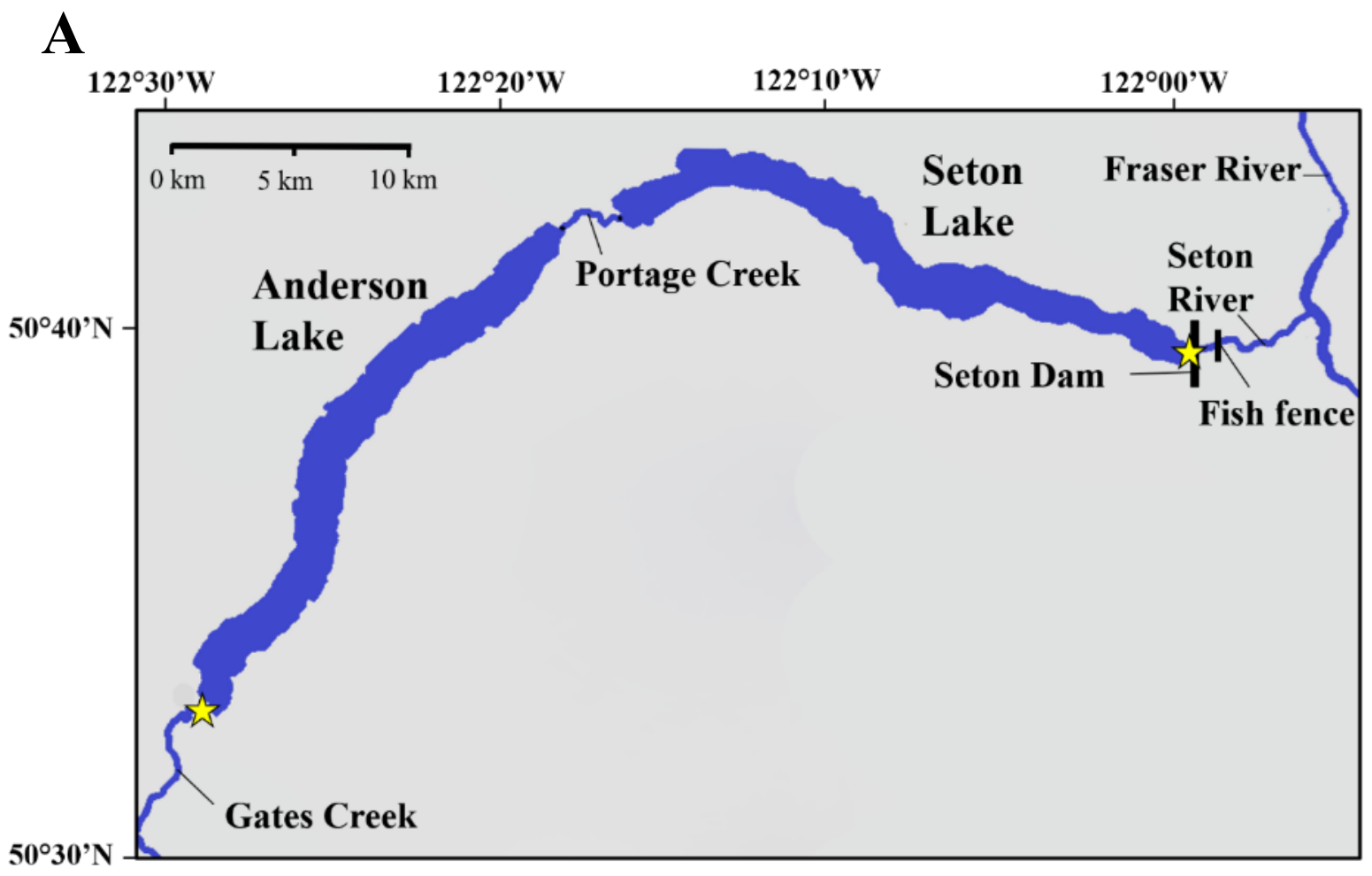




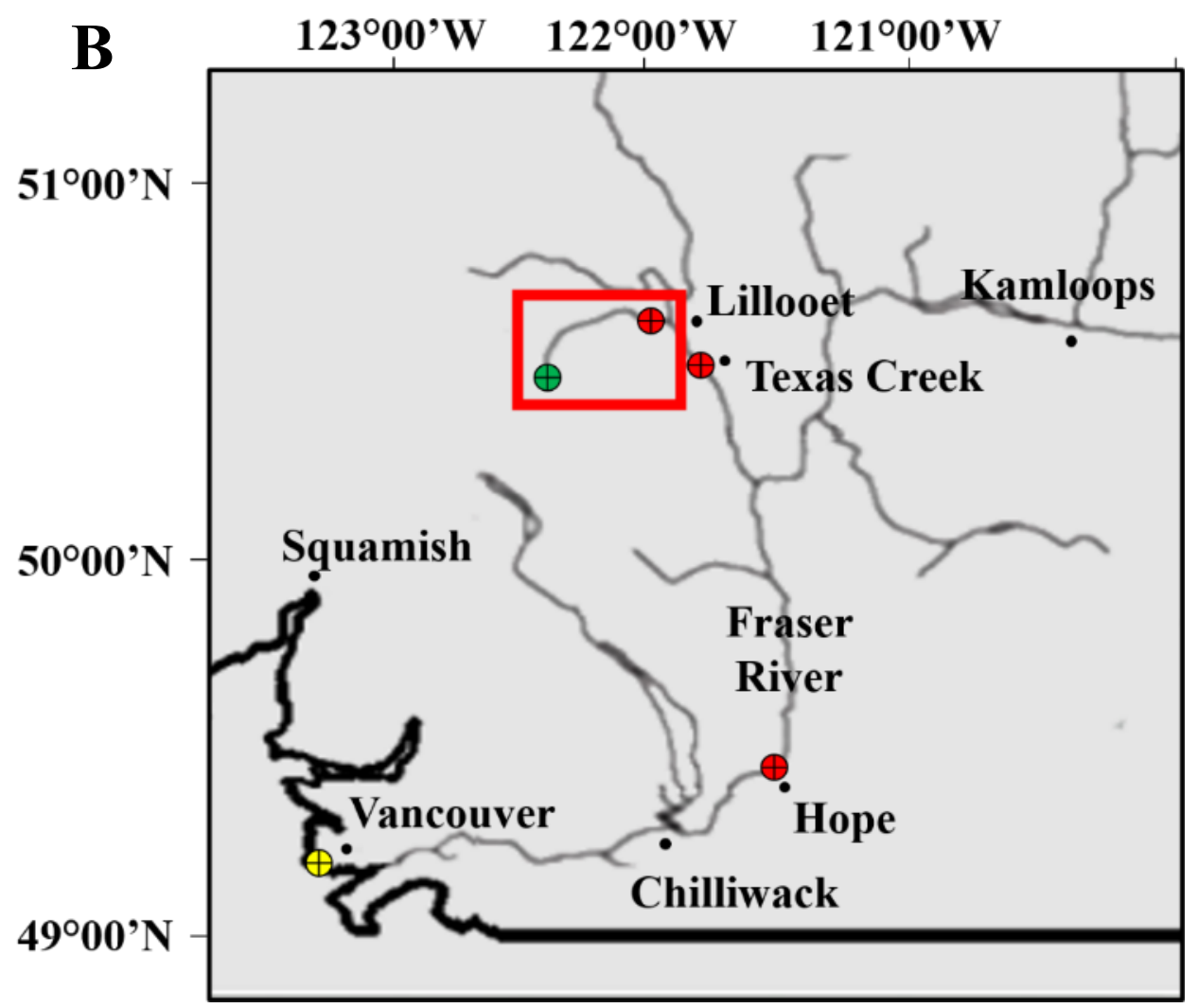

Figure 4.1. (A) Map of the Seton System in British Columbia, Canada. The locations of the Seton Dam and the fish fence used to capture fish for this study are shown on the map. Locations of PIT receivers are indicated by yellow stars. (B) Map of the Fraser River watershed. The Seton System is outlined by a red box on the map. Locations of temperature loggers at Hope, Texas Creek, and Seton fish fence, are indicated by red points. Steveston and Gates Creek are indicated by yellow and green points, respectively.

\subsubsection{Fish collection, biopsy, and tagging}

Gates Creek sockeye were intercepted in the Seton River in both 2017 and 2018 using a river-spanning picket fence. This fence was constructed approximately $4 \mathrm{~km}$ upstream from the Seton-Fraser Rivers confluence (Fig. 4.1A). The picket fence was built in a "V" shape that pointed upstream, with a trap box at the tip of the "V" and an enclosed 'holding area' on riverright of the "V" formed by a second arm of the fence from the trap box to the river bank. Upstream migration was blocked by placing all pickets across the fence except for 2 pickets, 
which were removed on the downstream arm of the holding area. This allowed fish to migrate only through this small gap in the fence, enter the holding area, and remain in the holding area until tagging and biopsy. This allowed the capture of fish in a very effective, yet low-stress and low-injury manner. For tagging and biopsy, fish were individually removed from the holding area via a knotless-nylon dipnet into an adjacent water-filled tagging trough with a constant supply of river water directed towards the snout of the fish. Fish were captured in this way from Aug 8th until Aug 20 ${ }^{\text {th }}$ in 2017, and from Aug $3^{\text {rd }}$ until Aug $11^{\text {th }}$ in 2018.

Once in the trough, each fish was assessed for injuries and overall condition. These included estimates of percentage scale loss, number of fins damaged and their severity of damage, and any visible injuries and their severity. Only fish in overall good condition (i.e. no severe injuries, no scale loss $>25 \%$, and no severe fin damage) were tagged as part of this study. Sockeye from other Fraser River stocks have been known to stray into the Seton system, so to ensure only Gates Creek sockeye were tagged as part of this study gross somatic energy (GSE) was measured using a fish FatMeter (Model FM 692, Distell, West Lothian, Scotland, UK). GSE measurements have previously been related to various sockeye salmon populations (Casselman et al., 2016), and fish with an average GSE measurement $\leq 2.7$ were considered to be of Gates Creek origin in this study. Fish were gastrically tagged using a $32 \mathrm{~mm}$ half duplex (HDX) passive integrated transponder (PIT) tag (Oregon RFID, Portland, OR, USA) that had been inserted into smoothed acetal Delrin tube sections 0.625 inches $(1.59 \mathrm{~cm})$ in diameter, 1.5 inches $(3.81 \mathrm{~cm})$ in length to allow the tag to be inserted into the empty stomach of the fish. To allow assessment of gene expression and infectious agent loads and prevalence, each fish was biopsied by removing 2-3 $\mathrm{mm}$ from the tips of 2-3 gill filaments with sterilized clippers. This gill biopsy was preserved in $1.5 \mathrm{~mL}$ of RNAlater solution (Qiagen, MD, USA) and stored at -80 Celsius for 
future analyses. Finally, fish were also externally tagged using a $7.62 \mathrm{~cm} \mathrm{T-bar} \mathrm{anchor} \mathrm{tag} \mathrm{(Floy}$ Tag \& Mfg. Inc., Seattle, TA, USA) to allow easy visual identification of tagged fish. Note that fish were tagged in this same way in both 2017 and 2018. The gastric tagging and biopsy procedure have previously been validated for use of adult sockeye salmon (Cooke et al., 2005).

\subsubsection{PIT telemetry}

Following release of tagged fish upstream of the river-spanning fish fence, fish must then navigate Seton Dam, approximately $150 \mathrm{~m}$ upstream from the fish fence. The dam is equipped with a vertical slot fishway to allow migration of fish past the dam. The fishway had two PIT receivers installed at both the entrance and the exit. This allowed investigation into dam passage success of these fish. A final PIT receiver was installed in Gates Creek, approximately $800 \mathrm{~m}$ from the mouth of the creek. This allowed investigation of overall migration success and timing (duration of migration) of Gates Creek sockeye to their natal spawning grounds.

\subsubsection{Characterizing thermal experience during Fraser River migration}

To characterize the thermal experience of Gates Creek sockeye salmon in both 2017 and 2018, I calculated the temperature each individual fish would have experienced during their upriver migration using information from two temperature logger stations in the Fraser River (one located near the city of Hope, and the other at Texas Creek, Fig. 4.1B). Donaldson et al. (2009) showed that temperatures are largely invariant along the lower Fraser River migration corridor, so two Fraser River temperature loggers is assumed sufficient for extrapolating thermal experience along their entire Fraser River migration. The date and time at which each individual 
would have passed these temperature loggers was estimated using the date and time the fish was tagged at Seton fish fence, and the average migration rate up the Fraser River from the ocean of Gates Creek sockeye salmon. The average migration rate of this stock was estimated to be 34.6 $\mathrm{km}$ /day by Kanigan et al. (2019) using previous telemetry data for early summer-run populations (D. Patterson, Fisheries and Oceans Canada, unpublished data; Hanson et al., 2008). Distances from each of the Fraser River temperature loggers to the Seton River fish fence (Fig. 4.1) were calculated, and divided by the average migration rate for Gates Creek sockeye $(34.6 \mathrm{~km} /$ day $)$, allowing me to estimate the amount of time taken for each individual to migrate from that temperature logger to Seton fish fence (Table 4.1). Using temperature logger data, I was then able to estimate the Fraser River temperature experienced by every individual that I ultimately tagged in the Seton River. A temperature logger was also placed at the Seton River fish fence, and thus the water temperature of the Seton River at the time of tagging was recorded and included when characterizing thermal experience for each fish.

Table 4.1. Migration time estimated for Gates Creek sockeye salmon for various intervals from the Fraser River mouth to Gates Creek spawning grounds.

\begin{tabular}{|c|c|c|}
\hline & Distance (river km) & $\begin{array}{c}\text { Migration time } \\
\text { (days) }\end{array}$ \\
\hline Steveston to Hope & 120.7 & 4 \\
Hope to Texas Creek & 160.3 & 1 \\
Texas Creek to Seton fence & 13.1 & 10 \\
\hline Seton fence to Gates Creek & 48.2 & 5 \\
\hline
\end{tabular}




\subsubsection{Laboratory analyses}

Gill samples preserved in RNAlater solution (Qiagen, MD, USA) were analyzed for RNA expression of select host- and infectious agent biomarkers at Pacific Biological Station

(Nanaimo, BC, Canada). RNA expression was quantified using high-throughput nanofluidic qPCR (Fluidigm ${ }^{\circledR}$ BioMark ${ }^{\mathrm{TM}}$ Dynamic Array, CA, USA). In total, 18 infectious agents and 25 host biomarkers were screened in gill tissue of all fish (see Tables 4.2 and 4.3, respectively). Host biomarkers included 7 genes associated with salmonid thermal stress (Houde et al., 2019), 5 genes shown to be associated with a mortality related signatures (MRS; Miller et al., 2011), 10 genes associated with viral disease detection (VDD; Miller et al., 2017), and 3 genes associated with immune function and general stress. Laboratory procedures in the present study were identical to those described in Chapter 3. Refer to section 3.3.6 for more detail, or see Miller et al. (2016) for a complete overview of this technology and laboratory procedures.

Gill tissue was thawed and removed from RNAlater solution then transferred into sterile microtubes that contained a stainless-steel bead. Tissues were then homogenized in TRI-reagent (Ambion Inc., Austin, TX, USA) and vigorous shaking using a MM301 mixer mill (Retsch Inc., Newtown, PA, USA), then separated using 1-bromo-3-chloropropane and centrifugation. Following separation, the aqueous phase was then aliquoted into 96-well plates to proceed with RNA extraction using MagMAX-96 for Microarrays Total RNA Isolation Kits (Ambion Inc.) with a Biomek NXP automated liquid-handling. Spectrophotometry was used to measure RNA quantity (ng/mL) and quality (A260/A280) using a Beckman Coulter DTX 880 Multimode Detector (Brea, CA, USA). All samples were normalized to $62.5 \mathrm{ng} \mu \mathrm{L}-1$ using the Biomek NXP automated liquid-handling machine. Reverse transcription of $1 \mu \mathrm{g}$ normalized RNA was then performed using a SuperScript VILO MasterMix Kit (Invitrogen, Carlsbad, CA). Specific target 
amplification (STA) of select host biomarkers and infectious agent biomarkers was then performed. STA required $1.25 \mu \mathrm{L}$ cDNA, assay primer pairs (see Tables 4.2 and 4.3), and TaqMan Preamp Master Mix (Applied Biosystems, Foster City, California). This preamplification of biomarkers is a necessary step before quantitative PCR (qPCR) due to the small assay volume (5 $\mu \mathrm{L})$ required (Miller et al., 2016). All assays were run in duplicate. Any unincorporated primers from STA were removed using ExoSAP-IT (Affymetrix, Santa Clara, California), and samples were diluted 5-fold using DNA Suspension Buffer (Teknova, Hollister, California). The pre-amplified cDNA product was then prepared for qPCR. A sample mix was prepared using pre-amplified cDNA, $1 \times$ TaqMan Universal Master Mix (Life Technologies) and $1 \times$ GE Sample Loading Reagent (Fluidigm PN 85000746). An assay mix was then prepared with $10 \mu \mathrm{M}$ primer pairs, $3 \mu \mathrm{M}$ probes, and assay loading reagent (Fluidigm PN 85000736). Sample and assay mixes were pipetted onto the chip and were loaded using an IFC controller HX (Fluidigm). Finally, qPCR was conducted $\left(50^{\circ} \mathrm{C}\right.$ for $2 \mathrm{~min}, 95^{\circ} \mathrm{C}$ for $10 \mathrm{~min}$, followed by 40 cycles of $95^{\circ} \mathrm{C}$ for $15 \mathrm{~s}$ and $60{ }^{\circ} \mathrm{C}$ for $\left.1 \mathrm{~min}\right)$.

Two serial dilutions were also added to the dynamic array to allow for calculation of assay efficiency. The first was a serial dilution of pooled cDNA of every sample on the dynamic array (a serial 10-fold dilution run in 5 wells of the dynamic array) which can be used to determine host biomarker assay efficiency. The second was a serial dilution of artificial positive constructs (APC clones; run in 6 cells of the dynamic array) which can be used to determine infectious agent loads and biomarker efficiency (Miller et al., 2016). APC clones were synthesized for each of the infectious agents, and serial dilutions of these constructs were loaded into negative Chinook embryo cell control nucleic acids (CHSE) in order to be run on the dynamic array. These CHSE controls were then assayed for each infectious agent, and one 
house-keeping gene, during qPCR. Positive and negative controls were also included on the dynamic array for RNA extraction, cDNA synthesis, STA, and qPCR stages. As a further control for comparing dynamic arrays from two different years, the undiluted cDNA pool from all 2017 samples was also included on dynamic arrays containing samples from 2018.

Table 4.2. Sockeye salmon host biomarkers evaluated using qPCR. A total of 25 biomarkers were assayed, including 3 house-keeping genes (HKG). Biomarkers are categorized as genes involved with viral disease development (VDD), morality-related signatures (MRS), thermal stress, immune response, or general stress. Forward (F) and reverse (R) primer sequences and probe $(\mathrm{P})$ sequences are given.

\begin{tabular}{|c|c|c|c|c|}
\hline $\begin{array}{l}\text { Assay } \\
\text { name }\end{array}$ & $\begin{array}{c}\text { Gene } \\
\text { category }\end{array}$ & Gene Name & $\begin{array}{c}\text { Accession } \\
\#\end{array}$ & Primer and probe sequences \\
\hline $52 \mathrm{RO}$ & VDD & $\begin{array}{l}52 \mathrm{kDa} \text { Ro } \\
\text { protein-2 - } \\
\text { 52Ro } \\
\end{array}$ & CX141267 & $\begin{array}{l}\text { F: TGCACTATTGCCCAGTAACCAT } \\
\text { R: TGCAAGAGGAGATGCCAACA } \\
\text { P: AGTAGGATTCACAGAGAGTT }\end{array}$ \\
\hline $\begin{array}{c}\text { ATP5 } \\
\text { G3 }\end{array}$ & MRS & ATP synthase & CB493164 & $\begin{array}{l}\text { F: GGAACGCCACCATGAGACA } \\
\text { R: CGCCATCCTGGGCTTTG } \\
\text { P: AGCCCCATTGCCTC }\end{array}$ \\
\hline $\mathrm{C} 7$ & $\begin{array}{l}\text { Immune/ } \\
\text { MRS }\end{array}$ & $\begin{array}{l}\text { Complement } \\
\text { factor }\end{array}$ & CA052045 & $\begin{array}{l}\text { F: ACCTCTGTCCAGCTCTGTGTC } \\
\text { R: GATGCTGACCACATCAAACTGC } \\
\text { P: AACTACCAGACAGTGCTG } \\
\end{array}$ \\
\hline $\begin{array}{l}\text { CA05 } \\
4694\end{array}$ & VDD & $\begin{array}{l}\text { Mitochondrial } \\
\text { ribosomal } \\
\text { protein (VAR1) }\end{array}$ & CA054694 & $\begin{array}{l}\text { F: CACCTGAGGTACTGAAGATAAGACA } \\
\text { R: TTAAGTCCTCCTTCCTCATCTGGTA } \\
\text { P: TCTACCAGGCCTTAAAG }\end{array}$ \\
\hline DEXH & VDD & $\begin{array}{l}\text { ATP-dependent } \\
\text { RNA helicase }\end{array}$ & FN396359 & $\begin{array}{l}\text { F: CCATAAGGAGGGTGTCTACAATAAGAT } \\
\text { R: CTCTCCCCCTTCAGCTTCTGT } \\
\text { P: TGGCGCGCTACGTG }\end{array}$ \\
\hline ef2_14 & Thermal & $\begin{array}{l}\text { Elongation } \\
\text { factor } 2\end{array}$ & CB498321 & $\begin{array}{l}\text { F: AGGTCACAGCCGCCCTTAG } \\
\text { R: ACACAGTCTCTGTCTGCACACACA } \\
\text { P: CGACTGCGTCTCAGGT }\end{array}$ \\
\hline GAL3 & VDD & $\begin{array}{c}\text { Galectin-3- } \\
\text { binding protein } \\
\text { precursor }\end{array}$ & CB515011 & $\begin{array}{l}\text { F: TTGTAGCGCCTGTTGTAATCATATC } \\
\text { R: TACACTGCTGAGGCCATGGA } \\
\text { P: CTTGGCGTGGTGGC }\end{array}$ \\
\hline $\begin{array}{c}\text { HERC } \\
6\end{array}$ & VDD & $\begin{array}{l}\text { Probable E3 } \\
\text { ubiquitin- } \\
\text { protein ligase } \\
\text { HERC6 }\end{array}$ & CA060884 & $\begin{array}{l}\text { F: AGGGACAACTTGGTAGACAGAAGAA } \\
\text { R: TGACGCACACACAGCTACAGAGT } \\
\text { P: CAGTGGTCTCTGTGGCT }\end{array}$ \\
\hline
\end{tabular}




\begin{tabular}{|c|c|c|c|c|}
\hline hsp70 & Thermal & $\begin{array}{c}\text { Heat shock } 70 \\
\text { kDa protein }\end{array}$ & C249R043 & $\begin{array}{l}\text { F: TCAACGATCAGGTCGTGCAA } \\
\text { R: CGTCGCTGACCACCTTGAA } \\
\text { P: CCGACATGAAGCACTGG }\end{array}$ \\
\hline $\begin{array}{l}\text { hsp90a } \\
-15\end{array}$ & Thermal & $\begin{array}{l}\text { Heat shock } \\
\text { protein } 90 \\
\text { alpha }\end{array}$ & CA062155 & $\begin{array}{l}\text { F: ATGACCCTCAGACACACTCCAA } \\
\text { R: CCTCATCAATACCCAGTCCTAGCT } \\
\text { P: CGCATCTACAGAATGA }\end{array}$ \\
\hline $\begin{array}{l}\text { HSP90 } \\
\text { alike_- } \\
\quad 6\end{array}$ & Thermal & $\begin{array}{l}\text { Heat shock } \\
\text { proteina } 90 \\
\text { alpha like }\end{array}$ & C020R155 & $\begin{array}{l}\text { F: TTGGATGACCCTCAGACACACT } \\
\text { R: CGTCAATACCCAGGCCTAGCT } \\
\text { P: CCGAATCTACCGGATGAT }\end{array}$ \\
\hline HTA & MRS & $\begin{array}{l}\text { HIV-1 Tat } \\
\text { interactive } \\
\text { protein }\end{array}$ & - & $\begin{array}{l}\text { F: CTTGTAACAGTTCGACATGGCTTATT } \\
\text { R: TGGTGAAGCATTTCTGTATGTCAA } \\
\text { P: TCTGTACTGAGCATCCCCGCACATTACA }\end{array}$ \\
\hline $\begin{array}{c}\text { IFI44 } \\
\text { A }\end{array}$ & VDD & $\begin{array}{l}\text { IFN-induced } \\
\text { protein } 44-1\end{array}$ & GS365948 & $\begin{array}{l}\text { F: CGGAGTCCAGAGCAGCCTACT } \\
\text { R: TCCAGTGGTCTCCCCATCTC } \\
\text { P: CGCTGGTCCTGTGTGA }\end{array}$ \\
\hline IFIT5 & VDD & $\begin{array}{l}\text { Interferon- } \\
\text { induced protein } \\
\text { with } \\
\text { tetratricopeptid } \\
\text { e repeats } 5\end{array}$ & CA051350 & $\begin{array}{l}\text { F: CCGTCAATGAGTCCCTACACATT } \\
\text { R: CACAGGCCAATTTGGTGATG } \\
\text { P: CTGTCTCCAAACTCCCA }\end{array}$ \\
\hline JUN & $\begin{array}{c}\text { General } \\
\text { stress }\end{array}$ & $\begin{array}{l}\text { Transcription } \\
\text { factor AP-1 }\end{array}$ & CA056351 & $\begin{array}{l}\text { F: TTGTTGCTGGTGAGAAAACTCAGT } \\
\text { R: CCTGTTGCCCTATGAATTGTCTAGT } \\
\text { P: AGACTTGGGCTATTTAC }\end{array}$ \\
\hline $\begin{array}{l}\text { MMP2 } \\
5\end{array}$ & MRS & $\begin{array}{c}\text { Matrix } \\
\text { metalloproteina } \\
\text { se-25 precursor }\end{array}$ & & $\begin{array}{l}\text { F: TGCAGTCTTTTCCCCTTGGAT } \\
\text { R: TCCACATGTACCCACACCTACAC } \\
\text { P: AGGATTGGCTGGAAGGT }\end{array}$ \\
\hline $\begin{array}{l}\text { MX_O } \\
\text { NTS }\end{array}$ & VDD & $\begin{array}{l}\text { Interferon- } \\
\text { induced GTP- } \\
\text { binding protein } \\
\text { Mx }\end{array}$ & CB516446 & $\begin{array}{l}\text { F: AGATGATGCTGCACCTCAAGTC } \\
\text { R: CTGCAGCTGGGAAGCAAAC } \\
\text { P: ATTCCCATGGTGATCCGCTACCTGG }\end{array}$ \\
\hline PRAS & MRS & $\begin{array}{l}\text { Oncorhynchus } \\
\text { mykiss G- } \\
\text { protein (P-ras) } \\
\text { mRNA, } \\
\text { complete cds }\end{array}$ & CA059617 & $\begin{array}{l}\text { F: GCAGGATGAGCAGAGGAAGAA } \\
\text { R: GGCCTGGGCAATGTAACACT } \\
\text { P: CCCCCTAAAGATGCAG }\end{array}$ \\
\hline RIG1 & Immune & $\begin{array}{c}\text { Retinoic acid } \\
\text { inducible gene I }\end{array}$ & $\begin{array}{c}\text { NM_0011 } \\
63699\end{array}$ & $\begin{array}{l}\text { F: ACAGCTGTTACACAGACGACATCA } \\
\text { R: TTTAGGGTGAGGTTCTGTCCGA } \\
\text { P: TCGTGTTGGACCCCACTCTGTTCTCTC }\end{array}$ \\
\hline RSAD & VDD & $\begin{array}{l}\text { Radical S- } \\
\text { adenosyl } \\
\text { methionine } \\
\text { domain- } \\
\text { containing } \\
\text { protein } 2\end{array}$ & CA038316 & $\begin{array}{l}\text { F: GGGAAATTAGTCCAATACTGCAAAC } \\
\text { R: GCCATTGCTGACAATACTGACACT } \\
\text { P: CGACCTCCAGCTCC }\end{array}$ \\
\hline SCG & MRS & Secretogranin2 & CA053613 & $\begin{array}{l}\text { F: GGATGTGAAGAATCCAACACTGAT } \\
\text { R: ACACCACTTCAAACTAGCCATACATT } \\
\text { P: CGGCTGTATGTGCACTG }\end{array}$ \\
\hline $\begin{array}{l}\text { SERPI } \\
\text { N9 }\end{array}$ & Thermal & $\begin{array}{l}\text { Serpin } \mathrm{H} 1 \\
\text { precursor } \\
(\mathrm{HSP} 47)\end{array}$ & C236R132 & $\begin{array}{l}\text { F: GAGGTCAGCGACCCAAAGAC } \\
\text { R: GCCGTAGAGGCGGTTACTGAT } \\
\text { P: CGGAACGTCACATGGA }\end{array}$ \\
\hline
\end{tabular}




\begin{tabular}{|c|c|c|l|l|}
\hline $\begin{array}{c}\text { SERPI } \\
\text { N20 }\end{array}$ & Thermal & $\begin{array}{c}\text { Serpin H1 } \\
\text { precursor } \\
\text { (HSP47) }\end{array}$ & CA063723 & $\begin{array}{l}\text { F: ACTATGACCACTCGAAGATCAACCT } \\
\text { R: CCCATTCGTTGATGGAGTTCA } \\
\text { P: AGGGACAAGAGGAGC }\end{array}$ \\
\hline SFRS2 & Thermal & $\begin{array}{c}\text { Splicing factor, } \\
\text { arginine/serine- } \\
\text { rich } 2\end{array}$ & CB493433 & $\begin{array}{l}\text { F: TCCAGATGGCCCGTTACG } \\
\text { R: CACCACCGCCTCCATGAT } \\
\text { P: TCCCCCAGATTCT }\end{array}$ \\
\hline $\begin{array}{c}\text { STAT } \\
1\end{array}$ & VDD & $\begin{array}{c}\text { Signal } \\
\text { transducer and } \\
\text { activator of } \\
\text { transcription 1- } \\
\text { alpha/beta }\end{array}$ & CA050950 & $\begin{array}{l}\text { F: TGTCACCGTCTCAGACAGATCTG } \\
\text { R: TGTTGGTCTCTGTAAGGCAACGT } \\
\text { P: AGTTGCTGAAAACCGG }\end{array}$ \\
\hline 78d16. & HKG & $\begin{array}{c}\text { S100 calcium } \\
\text { binding protein }\end{array}$ & CA056739 & $\begin{array}{l}\text { F: GTCAAGACTGGAGGCTCAGAG } \\
\text { R: GATCAAGCCCCAGAAGTGTTG } \\
\text { P: AAGGTGATTCCCTCGCCGTCCGA }\end{array}$ \\
\hline $\begin{array}{c}\text { COIL- } \\
\text { P84-2 }\end{array}$ & HKG & $\begin{array}{c}\text { Coiled-coil } \\
\text { domain- } \\
\text { containing } \\
\text { protein } 84\end{array}$ & CA053789 & $\begin{array}{l}\text { F: GCTCATTTGAGGAGAAGGAGGATG } \\
\text { R: CTGGCGATGCTGTTCCTGAG } \\
\text { P: TTATCAAGCAGCAAGCC }\end{array}$ \\
\hline MRPL & HKG & $\begin{array}{c}\text { 39S ribosomal } \\
\text { protein L40, } \\
\text { mitochondrial } \\
\text { precursor }\end{array}$ & CK991258 & $\begin{array}{l}\text { F: CCCAGTATGAGGCACCTGAAGG } \\
\text { R: GTTAATGCTGCCACCCTCTCAC } \\
\text { P: ACAACAACATCACCA }\end{array}$ \\
\hline
\end{tabular}


Table 4.3. Infectious agents assayed in sockeye salmon. A total of 18 infectious agents were evaluated through qPCR. Forward primer $(\mathrm{F})$, reverse primer $(\mathrm{R})$, and probe $(\mathrm{P})$ sequences are given.

\begin{tabular}{|c|c|c|c|c|c|}
\hline $\begin{array}{l}\text { Assay } \\
\text { name }\end{array}$ & Type & Full name & $\begin{array}{c}\text { Accession } \\
\#\end{array}$ & Primer and probe sequences & $\begin{array}{l}\text { Assay } \\
\text { reference }\end{array}$ \\
\hline arena2 & Virus & $\begin{array}{l}\text { Arenavirus } \\
\text { Type II }\end{array}$ & - & $\begin{array}{l}\text { F: AACATGAAGGGCGATTCGTT } \\
\text { R: CAGCCCGCGGACTGAGT } \\
\text { P: CAAGTGATGTAAGCTTG }\end{array}$ & $\begin{array}{l}\text { Gideon } \\
\text { Mordecai }\end{array}$ \\
\hline ascr & Virus & $\begin{array}{l}\text { Atlantic } \\
\text { Salmon } \\
\text { Calicivirus } \\
\text { (ASCV) }\end{array}$ & - & $\begin{array}{l}\text { F: ACCGACTGCCCGGTTGT } \\
\text { R: } \\
\text { CTCCGATTGCCTGTGATAATACC } \\
\text { P: CTTAGGGTTAAAGCAGTCG }\end{array}$ & $\begin{array}{l}\text { Gideon } \\
\text { Mordecai }\end{array}$ \\
\hline c_b_cys & Bacterium & $\begin{array}{l}\text { Candidatus } \\
\text { Branchiomon } \\
\text { as cysticola }\end{array}$ & JQ723599 & $\begin{array}{l}\text { F: } \\
\text { AATACATCGGAACGTGTCTAGTG } \\
\text { R: GCCATCAGCCGCTCATGTG } \\
\text { P: } \\
\text { CTCGGTCCCAGGCTTTCCTCTCCC } \\
\text { A }\end{array}$ & $\begin{array}{l}\text { Mitchell et } \\
\text { al., } 2013\end{array}$ \\
\hline ce_sha & $\begin{array}{l}\text { Myxo- } \\
\text { zoan }\end{array}$ & $\begin{array}{l}\text { Ceratomyxa } \\
\text { shasta }\end{array}$ & AF001579 & $\begin{array}{l}\text { F: } \\
\text { CCAGCTTGAGATTAGCTCGGTAA } \\
\text { R: CCCCGGAACCCGAAAG } \\
\text { P: } \\
\text { CGAGCCAAGTTGGTCTCTCCGTGA } \\
\text { AAAC }\end{array}$ & $\begin{array}{l}\text { Hallett and } \\
\text { Bartholomew, } \\
2006\end{array}$ \\
\hline $\operatorname{cov}$ & Virus & Coronavirus & - & $\begin{array}{l}\text { F: } \\
\text { GGATAATCCCAACCGAAAAGTTT } \\
\text { R: } \\
\text { GCATGAAATGTTGTCTCGGTTTAA } \\
\text { P: CGATCCCGATTATC }\end{array}$ & $\begin{array}{l}\text { Miller et al., } \\
2016\end{array}$ \\
\hline ctv & Virus & $\begin{array}{l}\text { Cutthroat } \\
\text { Trout Virus } \\
\text { (CTV) }\end{array}$ & - & $\begin{array}{l}\text { F: CCACTTGTCGCTACGATGAAAC } \\
\text { R: CGCCTCCTTTGCCTTTCTC } \\
\text { P: ATGCCGGGCCATC }\end{array}$ & $\begin{array}{l}\text { Miller et al., } \\
2016\end{array}$ \\
\hline de_sal & Protozoan & $\begin{array}{l}\text { Dermocystidi } \\
\text { um salmonis }\end{array}$ & U21337 & $\begin{array}{l}\text { F: CAGCCAATCCTTTCGCTTCT } \\
\text { R: GACGGACGCACACCACAGT } \\
\text { P: AAGCGGCGTGTGCC }\end{array}$ & $\begin{array}{l}\text { Miller et al., } \\
2016\end{array}$ \\
\hline
\end{tabular}




\begin{tabular}{|c|c|c|c|c|c|}
\hline fl_psy & Bacterium & $\begin{array}{l}\text { Flavobacteri } \\
\text { um } \\
\text { psychrophilu } \\
m\end{array}$ & - & $\begin{array}{l}\text { F: } \\
\text { GATCCTTATTCTCACAGTACCGTC } \\
\text { AA } \\
\text { R: } \\
\text { TGTAAACTGCTTTTGCACAGGAA } \\
\text { P: AAACACTCGGTCGTGACC }\end{array}$ & $\begin{array}{l}\text { Duesund } e t \\
\text { al., } 2010\end{array}$ \\
\hline ic_hof & Protozoan & $\begin{array}{l}\text { Ichthyophonu } \\
\text { s hoferi }\end{array}$ & AF467793 & $\begin{array}{l}\text { F: GTCTGTACTGGTACGGCAGTTTC } \\
\text { R: } \\
\text { TCCCGAACTCAGTAGACACTCAA } \\
\text { P: } \\
\text { TAAGAGCACCCACTGCCTTCGAGA } \\
\text { AGA }\end{array}$ & $\begin{array}{l}\text { White et al., } \\
2013\end{array}$ \\
\hline ic_mul & Ciliate & $\begin{array}{l}\text { Ichthyophthir } \\
\text { ius multifiliis }\end{array}$ & IMU17354 & $\begin{array}{l}\text { F: AAATGGGCATACGTTTGCAAA } \\
\text { R: } \\
\text { AACCTGCCTGAAACACTCTAATTT } \\
\text { TT } \\
\text { P: } \\
\text { ACTCGGCCTTCACTGGTTCGACTT } \\
\text { GG }\end{array}$ & $\begin{array}{l}\text { Miller et al., } \\
2016\end{array}$ \\
\hline lo_sal & $\begin{array}{l}\text { Micro- } \\
\text { sporidian }\end{array}$ & $\begin{array}{l}\text { Loma } \\
\text { salmonae }\end{array}$ & HM626243 & $\begin{array}{l}\text { F: GGAGTCGCAGCGAAGATAGC } \\
\text { R: } \\
\text { CTTTTCCTCCCTTTACTCATATGCT } \\
\text { T } \\
\text { P: } \\
\text { TGCCTGAAATCACGAGAGTGAGA } \\
\text { CTACCC }\end{array}$ & $\begin{array}{l}\text { Miller et al., } \\
2016\end{array}$ \\
\hline ortho & Virus & OrthoMyxoV & - & $\begin{array}{l}\text { F: GGAAGCAGTGGACGCTAACC } \\
\text { R: TCGCGAAGGTCTCTCAATGTC } \\
\text { P: ATTCTTCTCATCAAAGGCA }\end{array}$ & $\begin{array}{l}\text { Miller et al., } \\
2016\end{array}$ \\
\hline pa_kab & $\begin{array}{l}\text { Myxo- } \\
\text { zoan }\end{array}$ & $\begin{array}{l}\text { Parvicapsula } \\
\text { kabatai }\end{array}$ & DQ515821 & $\begin{array}{l}\text { F: CGACCATCTGCACGGTACTG } \\
\text { R: ACACCACAACTCTGCCTTCCA } \\
\text { P: CTTCGGGTAGGTCCGG }\end{array}$ & $\begin{array}{l}\text { Miller et al., } \\
2016\end{array}$ \\
\hline pa_min & $\begin{array}{l}\text { Myxo- } \\
\text { zoan }\end{array}$ & $\begin{array}{l}\text { Parvicapsula } \\
\text { minibicornis }\end{array}$ & AF201375 & $\begin{array}{l}\text { F: } \\
\text { AATAGTTGTTTGTCGTGCACTCTGT } \\
\text { R: } \\
\text { CCGATAGGCTATCCAGTACCTAGT } \\
\text { AAG }\end{array}$ & $\begin{array}{l}\text { Miller et al., } \\
2016\end{array}$ \\
\hline
\end{tabular}




\begin{tabular}{|c|c|c|c|c|c|}
\hline & & & & P: TGTCCACCTAGTAAGGC & \\
\hline pa_ther & $\begin{array}{l}\text { Micro- } \\
\text { sporidian }\end{array}$ & $\begin{array}{l}\text { Paranucleos } \\
\text { pora } \\
\text { theridion }\end{array}$ & FJ59481 & $\begin{array}{l}\text { F: CGGACAGGGAGCATGGTATAG } \\
\text { R: GGTCCAGGTTGGGTCTTGAG } \\
\text { P: TTGGCGAAGAATGAAA }\end{array}$ & $\begin{array}{l}\text { Nylund et al., } \\
2010\end{array}$ \\
\hline reov & Virus & $\begin{array}{l}\text { ReoVirus } \\
\text { MGL }\end{array}$ & - & $\begin{array}{l}\text { F: AACTTTCGGCTTTCTGCTATGC } \\
\text { R: GAGGACAAGGGTCTCCATCTGA } \\
\text { P: TTAATTGCGGTACTGCTC }\end{array}$ & $\begin{array}{l}\text { Miller et al., } \\
2016\end{array}$ \\
\hline rlo & Bacterium & $\begin{array}{l}\text { Rickettsia- } \\
\text { like organism }\end{array}$ & EU555284 & $\begin{array}{l}\text { F: GGCTCAACCCAAGAACTGCTT } \\
\text { R: GTGCAACAGCGTCAGTGACT } \\
\text { P: } \\
\text { CCCAGATAACCGCCTTCGCCTCCG }\end{array}$ & $\begin{array}{l}\text { Lloyd et al., } \\
2011\end{array}$ \\
\hline sp_des & $\begin{array}{l}\text { Meso- } \\
\text { mycetozo } \\
\text { ea }\end{array}$ & $\begin{array}{l}\text { Sphaerothecu } \\
m \\
\text { destructuens }\end{array}$ & AY267346 & $\begin{array}{l}\text { F: GGGTATCCTTCCTCTCGAAATTG } \\
\text { R: CCCAAACTCGACGCACACT } \\
\text { P: CGTGTGCGCTTAAT }\end{array}$ & $\begin{array}{l}\text { Miller et al., } \\
2016\end{array}$ \\
\hline
\end{tabular}

\subsubsection{Statistical analyses}

All statistical analyses were performed using R statistical software (R Core Team, 2015). The BioMark Real-Time PCR analysis software generated a Quantification cycle threshold $(\mathrm{Ct})$ value generated for all host gene and infectious agent biomarkers. As all assays were performed in duplicate, $\mathrm{Ct}$ values were averaged for every assay in each sample. Infectious agents that were not detected in duplicate were failed. Prior to any analyses, outliers were detected based on their $\mathrm{Ct}$ values and removed from the dataset. Using custom functions in R statistical software (R Core Team, 2015), the relative expression of host genes was derived by calculating the fold change difference in Ct value relative to a reference gene as per Pfaffl (2001). Infectious agent RNA copies per sample was calculated using the standard curves of APC clone dilutions that were run on each dynamic array. Any APC contaminated samples were detected by fluorescence of the 
NED probe, and these samples were removed from all analyses. Infectious agent RNA copy number was $\log$ transformed for all analyses.

To compare gene expression between 2017 and 2018, I first needed to confirm that any differences I might see in biomarker expression were not due to differences in laboratory technique and technology across the two years of genomic analyses, but instead were due to differences in environmental or physiological conditions experienced by the fish. To test this, the Ct of the CHSE control house-keeping gene was compared across all chips run in year 2017 (4 chips) vs all chips ran in year 2018 ( 2 chips). Because the APC were created and tested to be of a certain concentration, the $\mathrm{Ct}$ spikes should be the same across any chip or year. Any differences in CHSE Ct spikes were tested by comparing the Ct of both replicates across all six samples of the serial dilutions for dynamic arrays ran in 2017 vs 2018 . I did not find any statistical difference in any CHSE Ct spikes between years; thus I can assume that any differences in host or infectious agent biomarkers I might detect in further analyses are not due to differences in laboratory technique or technology differences among years.

Next, I proceeded with non-metric multidimensional scaling analysis (NMDS) using R package "vegan" (Oksanen et al., 2019) to analyze host biomarker expression data. NMDS is in iterative, rank-based procedure that reduces dimensions in a multidimensional dataset (Taguchi and Oono, 2005). The metaMDS() function was used to create a Bray-Curtis distance matrix of individual fish based on their host biomarker expression values. Two dimensions were included in this ordination. Host biomarkers ('species') scores were calculated as weighted averages in the ordination space. PERMANOVA was used to test if the mean centroid of gene expression differed in 2017 compared with 2018. Sex was also included as a covariate to account for variation in gene expression between males and females. If this covariate had no significant 
impact on the model it was removed. PERMANOVA was performed using the adonis() function in "vegan" R package (Oksanen et al., 2019). I also tested for differences in the variance, or dispersion, of gene expression in 2017 and 2018 using the betadisper() function in "vegan".

Separate NMDS analyses were performed for fish sampled in 2017 and in 2018 to determine if any infectious agents, the size of individuals, or water temperature at the time of tagging were correlated with biomarker expression in separate years. Again, a Bray-Curtis distance matrix was created using the metaMDS() function, and host biomarker scores were calculated as weighted averages in the ordination space. Extrinsic variables were fit onto the ordination using the envfit() function in package "vegan". This function fits extrinsic variables onto the ordination space by maximizing correlation between these variables and predicted points. For the 2017 and 2018 separate NMDS analyses, the extrinsic variables fork length and water temperature at the time of tagging were fit to the ordination. The relative loads of Parvicapsula minibicornis, Candidatus Branchiomonas cysticola, and Ceratomyxa shasta were also fit to the ordination. These three infectious agents were chosen due to high prevalence amongst individuals. Infectious agents with low prevalence were not fit to the ordination to avoid bias (as per Teffer et al., 2017). PERMANOVA was performed using the adonis() function in "vegan" R package (Oksanen et al., 2019) to test if the mean centroid of gene expression differed between fish that successfully migrated to spawning grounds compared with those that did not successfully migrate to spawning grounds. Sex was also included as a covariate to account for variation in gene expression between males and females. I also tested for differences in the variance, or dispersion, of gene expression between successful and unsuccessful migrants using the betadisper() function in package "vegan". 
I investigated differences in infectious agent copy number in 2017 vs 2018, and between sexes using linear models. Models were constructed that included sex and year as fixed effect variables. These models were constructed for all 7 infectious agents detected in fish, and only included those individuals that tested positive for that infectious agent. To compare the overall infectious agent burden between fish sampled in 2017 and 2018 I calculated the relative infection burden (RIB) for each individual as per Bass et al. (2019). RIB allows us to collapse all infectious agent load data for an individual into a single metric that represents the overall burden (loads) of infectious agents on an individual. RIB is calculated using the following formula:

$$
\sum_{i \in m}^{m} \frac{L i}{\operatorname{Lmaxi}}
$$

The RNA copy number of the i'th positively detected infectious agent (Li) is divided by the maximum RNA copy number within the population of fish sampled for that i'th infectious agent (Lmaxi). This is repeated for every infectious agent detected within the population of fish sampled, and all calculated values are then summed. I used generalized linear models (glms) to look for an effect of year on RIB (link = logit). This model was tested used a two-way ANOVA followed by post-hoc comparison among treatment groups using emmeans() function with Tukey adjustment. RIB was log transformed for all analyses due to its long-tailed distribution.

I tested for differences in prevalence of infectious agents in 2017 compared with 2018 by first formatting infectious agent as dichotomous variables to represent either presence or absence of each agent. Generalized linear models (glms) were used to look for an effect of year (2017 vs 2018) on prevalence of each infectious agent (link = logit). Sex was also included as a covariate in these models. 


\subsection{Results}

\subsubsection{Characterizing thermal migration experience in the Fraser River}

Using average migration rates known for Gates Creek sockeye salmon, the temperature each individual would have experienced at the temperature loggers at Hope and at Texas Creek was estimated. The average, minimum and maximum temperatures experienced by sampled individuals was estimated in both 2017 and 2018 (Table 4.4). During 2018, Gates Creek sockeye salmon sampled for this study experienced higher average Fraser River water temperatures at Hope in $2018\left(20.2^{\circ} \mathrm{C}\right)$ compared with $2017\left(18.7^{\circ} \mathrm{C}\right)$. Similarly, sockeye sampled in 2018 experienced higher average Fraser River water temperatures at Texas Creek in $2018\left(19.8^{\circ} \mathrm{C}\right)$ compared to those fish sampled in $2017\left(18.8^{\circ} \mathrm{C}\right)$. In 2017 and 2018 , Seton River water temperatures for sampled fish were similar; $18.4{ }^{\circ} \mathrm{C}$ and $18.6^{\circ} \mathrm{C}$, respectively. See Figure 4.2 to see average daily Fraser River water temperatures recorded by thermal loggers placed at Hope and Texas Creek in 2017 and 2018. 
Table 4.4. Average, minimum, and maximum temperatures $\left({ }^{\circ} \mathrm{C}\right)$ estimated to be experienced by sampled Gates Creek sockeye salmon at 3 temperature loggers along their migration route to spawning grounds.

\begin{tabular}{|c|c|c|c|}
\hline \multicolumn{4}{|c|}{ Fraser River at Hope } \\
\hline & $\begin{array}{c}\text { Average temperature } \\
\left({ }^{\circ} \mathrm{C}\right)\end{array}$ & $\begin{array}{c}\text { Minimum } \\
\text { temperature }\left({ }^{\circ} \mathrm{C}\right)\end{array}$ & $\begin{array}{c}\text { Maximum } \\
\text { temperature }\left({ }^{\circ} \mathrm{C}\right)\end{array}$ \\
\hline 2017 & 18.7 & 18.3 & 19.7 \\
\hline 2018 & 20.2 & 19.1 & 20.7 \\
\hline \multicolumn{4}{|c|}{ Fraser River at Texas Creek } \\
\hline & $\begin{array}{c}\text { Average temperature } \\
\left({ }^{\circ} \mathrm{C}\right)\end{array}$ & $\begin{array}{c}\text { Minimum } \\
\text { temperature }\left({ }^{\circ} \mathrm{C}\right)\end{array}$ & $\begin{array}{c}\text { Maximum } \\
\text { temperature }\left({ }^{\circ} \mathrm{C}\right)\end{array}$ \\
\hline 2017 & 18.8 & 17.2 & 20.0 \\
\hline 2018 & 19.8 & 19.4 & 20.4 \\
\hline \multicolumn{4}{|c|}{ Seton River at fish fence } \\
\hline & $\begin{array}{c}\text { Average temperature } \\
\left({ }^{\circ} \mathrm{C}\right)\end{array}$ & $\begin{array}{c}\text { Minimum } \\
\text { temperature }\left({ }^{\circ} \mathrm{C}\right)\end{array}$ & $\begin{array}{c}\text { Maximum } \\
\text { temperature }\left({ }^{\circ} \mathrm{C}\right)\end{array}$ \\
\hline 2017 & 18.4 & 16.9 & 19.8 \\
\hline 2018 & 18.6 & 17.1 & 20.3 \\
\hline
\end{tabular}




\section{(A) Fraser River at Hope}

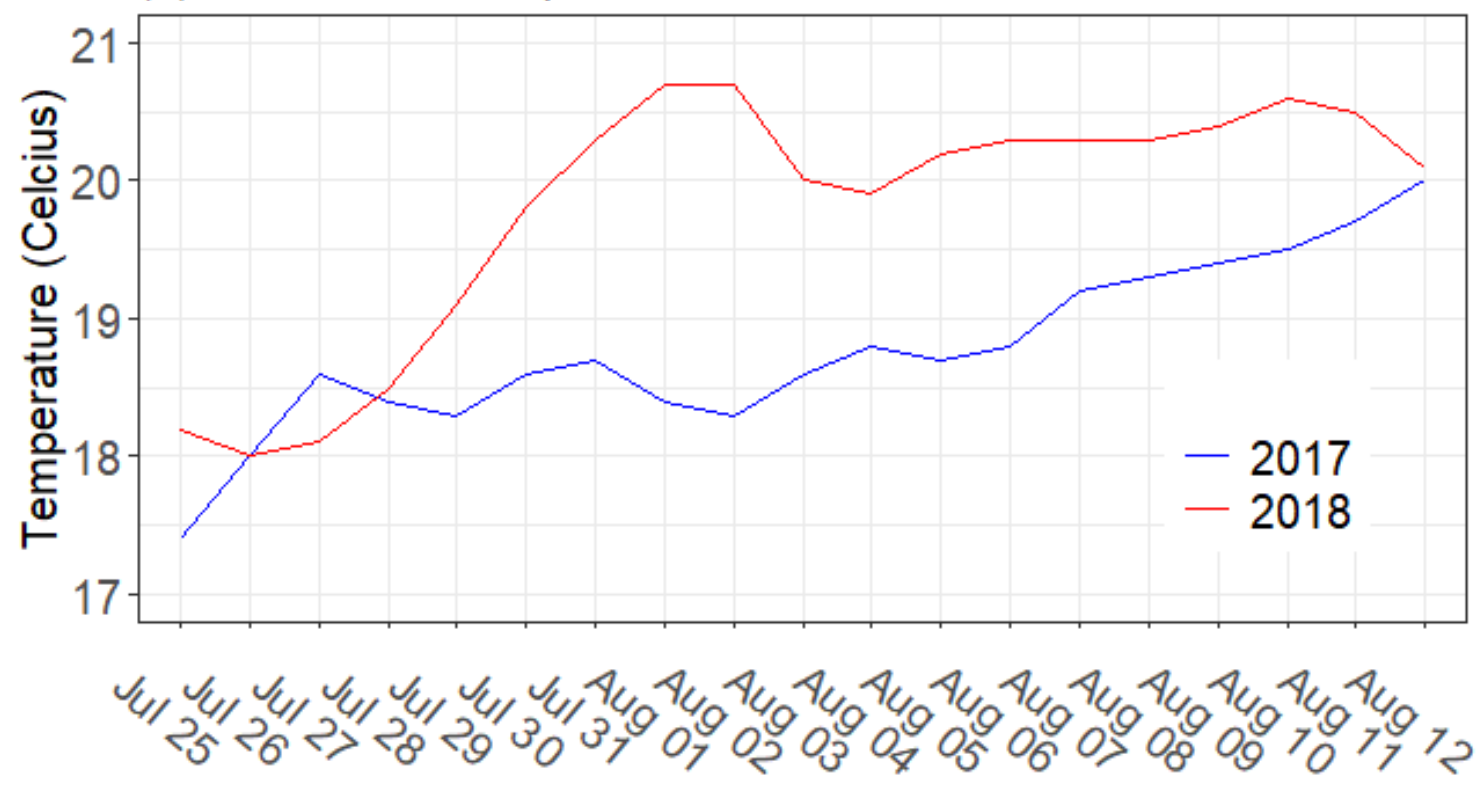

(B) Fraser River at Texas Creek

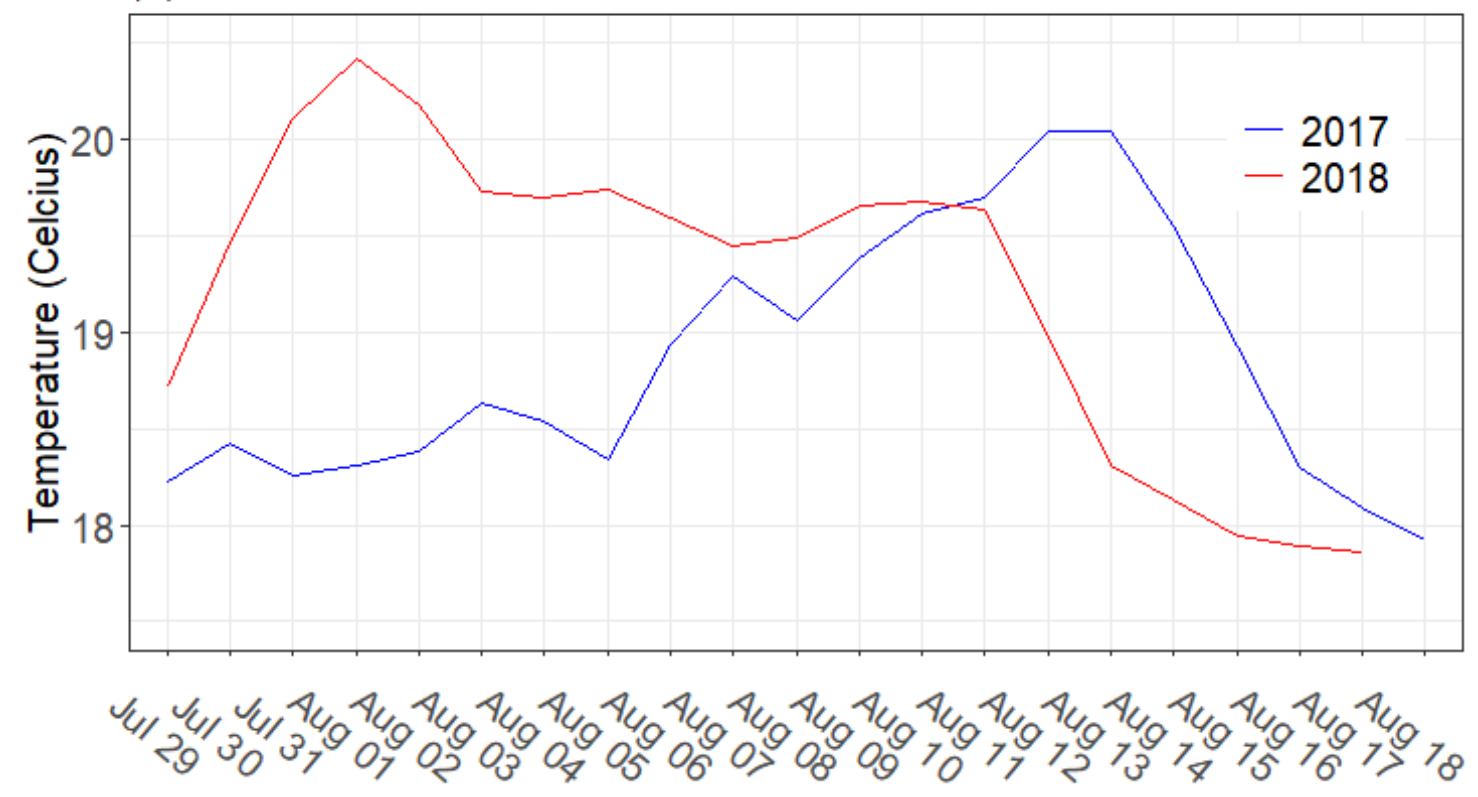

Figure 4.2. Average daily water temperature recorded by thermal loggers placed in the Fraser River at Hope (A) and at Texas Creek (B) in 2017 and 2018. The time period displayed in each figure shows only relevant dates that fish sampled at the fish fence in Gates Creek were estimated to be at these thermal logger sites in both years. Due to largely invariant temperatures along the lower Fraser River migration corridor, temperatures recorded at these thermal loggers are sufficient for extrapolating the thermal experience along the Fraser River migration route for Gates Creek sockeye salmon in this study. 


\subsubsection{Migration success}

Through detections of tagged fish at PIT receivers located at the mouth of Gates Creek, I found overall migration success to spawning grounds to be $78.2 \%$ in $2017(\mathrm{~N}=124)$ and $26.2 \%$ in $2018(\mathrm{~N}=70)$. In 2017 and 2018, female survival to Gates Creek was $72.9 \%$ and 22.9\%, respectively. Male survival was higher than females in both 2017 and $2018(81.2 \%$ and $30.8 \%$, respectively), however these differences in survival between sexes were not statistically significant in either year. Migration success past Seton dam was determined using detection at a receiver at the fish ladder exit. Overall migration success past Seton dam was found to be $95.3 \%$ and $88.5 \%$ in 2017 and 2018, respectively.

\subsubsection{Biomarker expression in 2017 vs 2018}

NMDS analysis successfully reduced host gene expression data into a 3-dimensional ordination ( stress $=0.15$, Fig. 4.3A). PERMANOVA testing revealed that individuals sampled in 2017 vs 2018 varied significantly in mean multivariate centroid location $(p=0.001)$. Gene expression only varied significantly with NMDS2 $(\mathrm{p}=<0.0001)$. Gene expression displayed significantly more variance in 2017 compared with $2018(\mathrm{p}=<0.0001)$. The genes most positive on the NMDS2 axis include the thermal biomarkers HSP90a-15, SERPIN20, HSP70_6, HSP90alike_6, SERPIN9, SFR52_3, and viral disease development (VDD) biomarkers RIG1, MX_ONTS, and GAL3 (Fig. 4.3B). The six thermal biomarkers showed significantly higher expression in 2018 compared to 2017 (Fig. 4.4). Fish sampled in 2018 were closer in ordination space to thermal biomarkers and mortality-related signature (MRS) biomarkers. Fish sampled in 2017 were closer in ordination space to VDD biomarkers such as HERC6, DEXH_MGL_3 and IFI44A_MGL_2. 


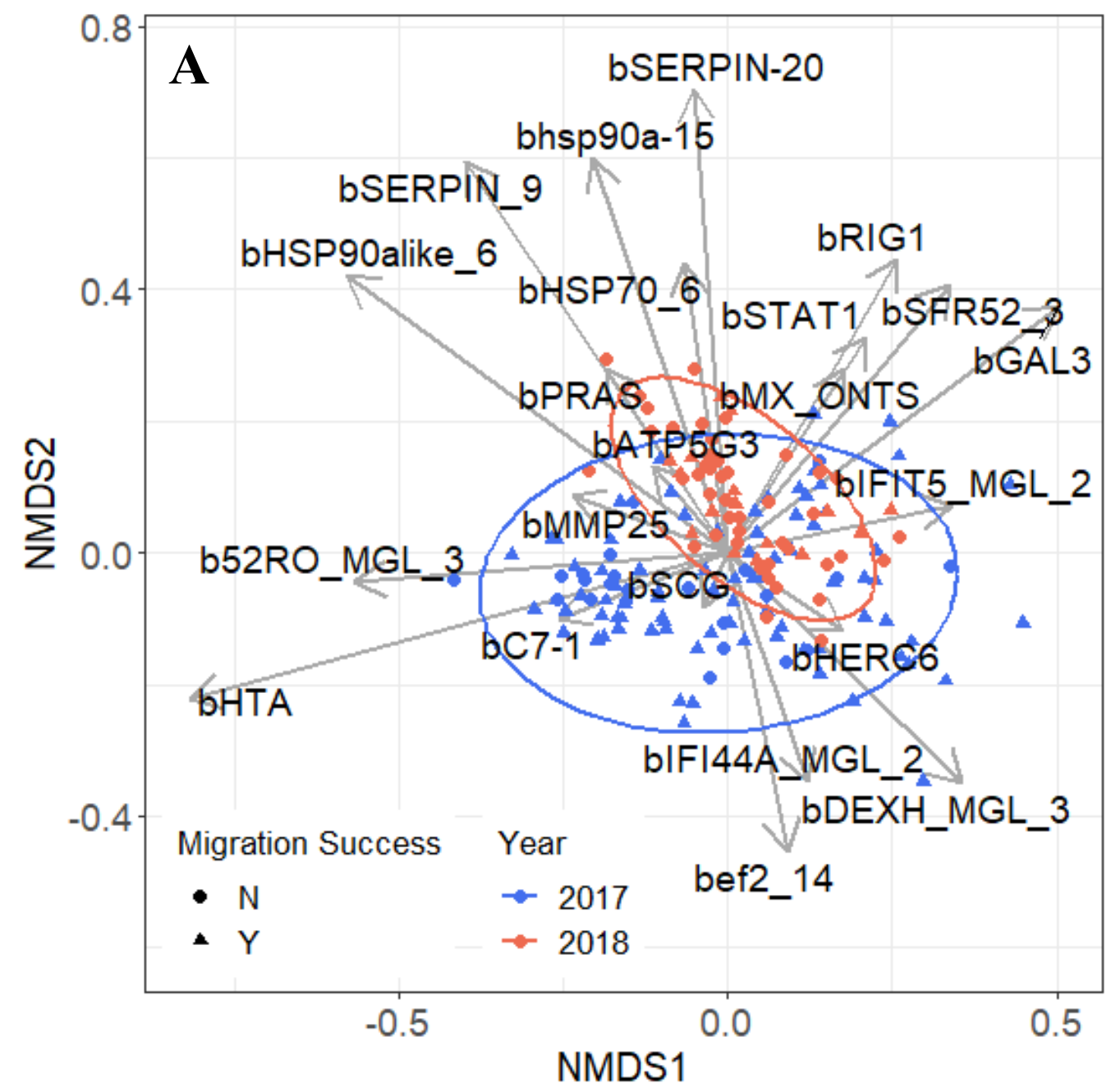




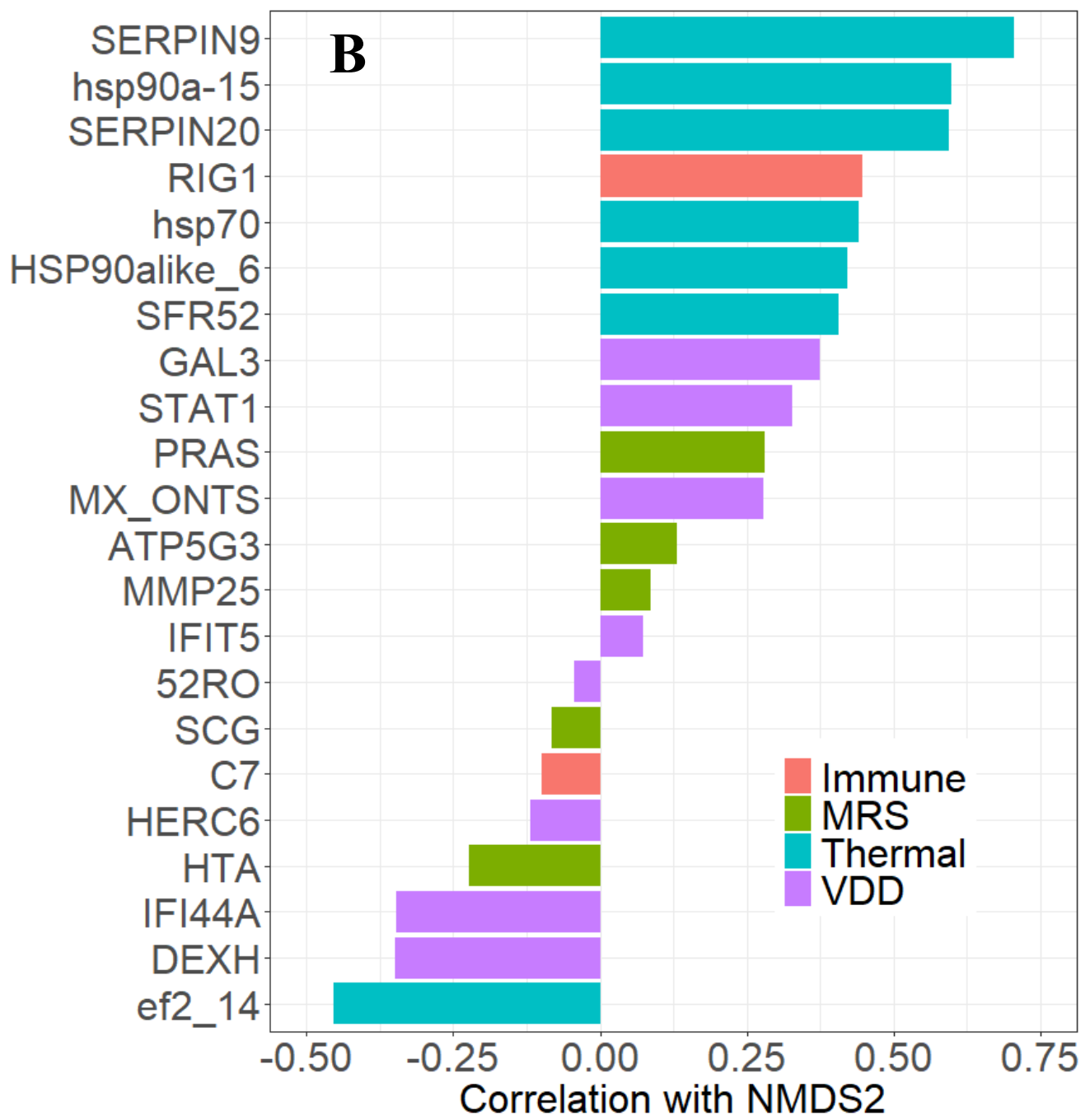

Figure 4.3. (A) NMDS plot of host biomarker expression of Gates Creek sockeye salmon sampled in both 2017 and 2018. The colour of points corresponds to the year each individual was sampled; red in 2018 (warmer water temperature year) and blue in 2017 (cooler water temperature year). Confidence ellipses $(95 \%)$ are also shown for each year. Circular points correspond to fish that did not successfully migrate to spawning grounds, and triangular points correspond to fish that did successfully migrate to spawning grounds. (B) Correlation of individual biomarkers with NMDS2. Biomarkers are categorized based on their function: thermal stress, viral disease development (VDD), mortality-related signature (MRS), immune response, and general stress. 

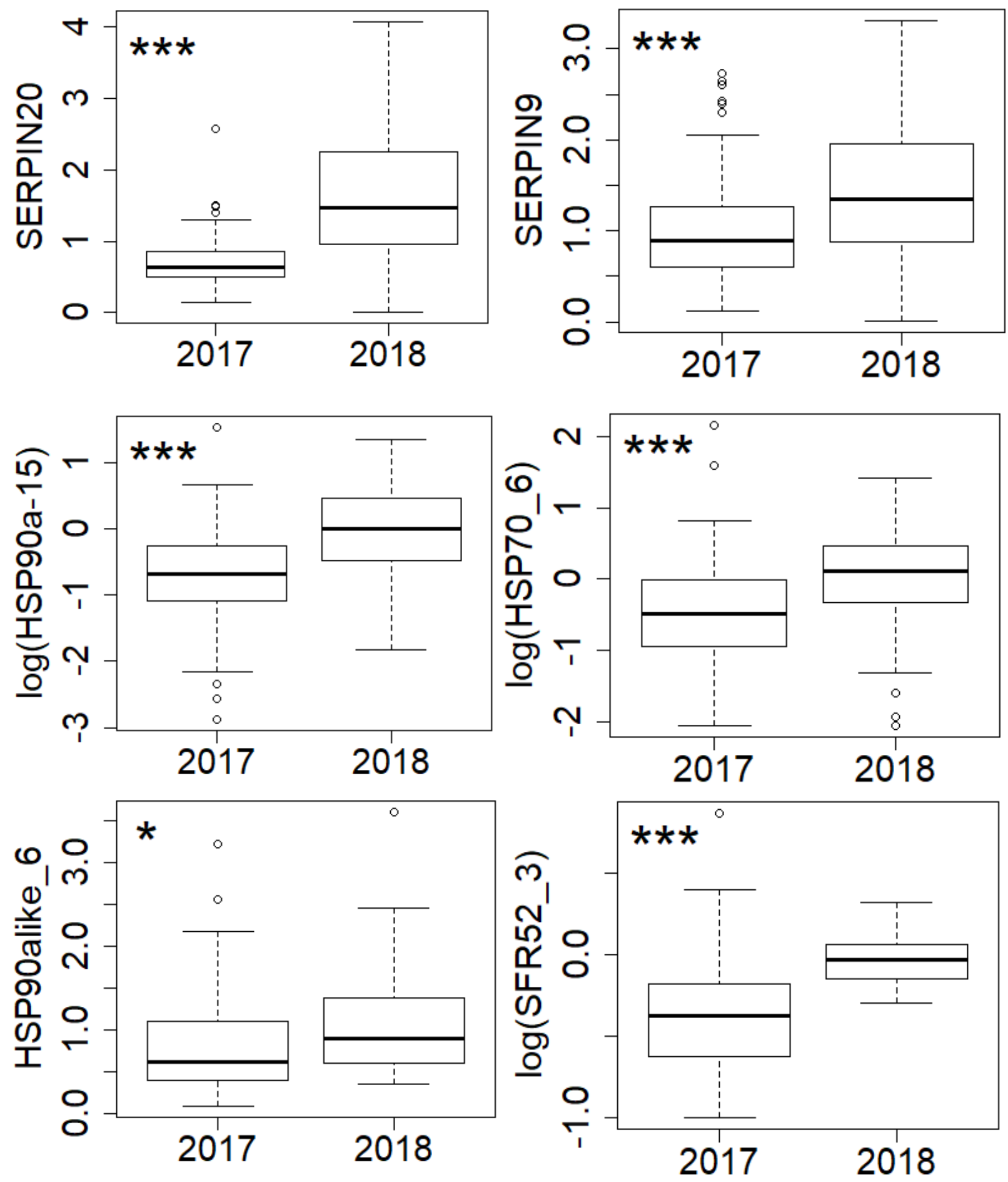

Figure 4.4. Boxplots comparing the relative expression of six thermal biomarkers. Expression of all thermal biomarkers was significantly higher in 2018 compared with 2017. For each plot, * indicates $\mathrm{p}<0.01, * *$ indicates $\mathrm{p}<0.001$, and $* * *$ indicates $\mathrm{p}<0.0001$. For each boxplot, the thicker black line indicates the median, the upper and lower box limits represent the first and third quartiles, the whiskers represent 1.5 times the inter-quartile range, and the circles represent outliers. 


\subsubsection{Biomarker expression in 2017}

NMDS analysis successfully reduced host gene expression data into a 2-dimensional ordination for fish sampled in 2017 (stress $=0.185$, Fig. 4.5). I found no significant differences in either multivariate centroid location or variance between those fish that successfully migrated to Gates Creek vs those that did not. I also found no significant effect of sex on these values. Relative load of Parvicapsula minibicornis was significantly correlated with the ordination gradient $\left(\mathrm{r}^{2}=0.13, \mathrm{p}=0.02\right)$. All other extrinsic variables were not significantly correlated with the ordination gradient: Ceratomyxa shasta $\left(\mathrm{r}^{2}=0.036, \mathrm{p}=0.19\right)$, Candidatus Branchiomonas $\left(\mathrm{r}^{2}\right.$ $=0.0029, \mathrm{p}=0.87)$, water temperature at tagging $\left(\mathrm{r}^{2}=0.066, \mathrm{p}=0.057\right)$, and fork length $\left(\mathrm{r}^{2}=\right.$ $0.044, \mathrm{p}=0.15)$

\subsubsection{Biomarker expression in 2018}

NMDS analysis successfully reduced host gene expression data into a 2-dimensional ordination for fish sampled in 2018 (stress $=0.20$, Fig. 4.6). I found no significant differences in either multivariate centroid location or variance between successful and unsuccessful migrants in 2018. I also found no significant effect of sex on these values. Relative loads of Candidatus Branchiomonas cysticola $\left(\mathrm{r}^{2}=0.25, \mathrm{p}=0.003\right)$, Ceratomyxa shasta $\left(\mathrm{r}^{2}=0.14, \mathrm{p}=0.045\right)$, and water temperature at tagging $\left(r^{2}=0.43, p=0.001\right)$ were all significantly correlated with the ordination gradient. Relative load of Parvicapsula minibicornis $\left(\mathrm{r}^{2}=0.031, \mathrm{p}=0.93\right)$ and fork length $\left(\mathrm{r}^{2}=0.014, \mathrm{p}=0.71\right)$, were not significantly correlated with the ordination gradient. 


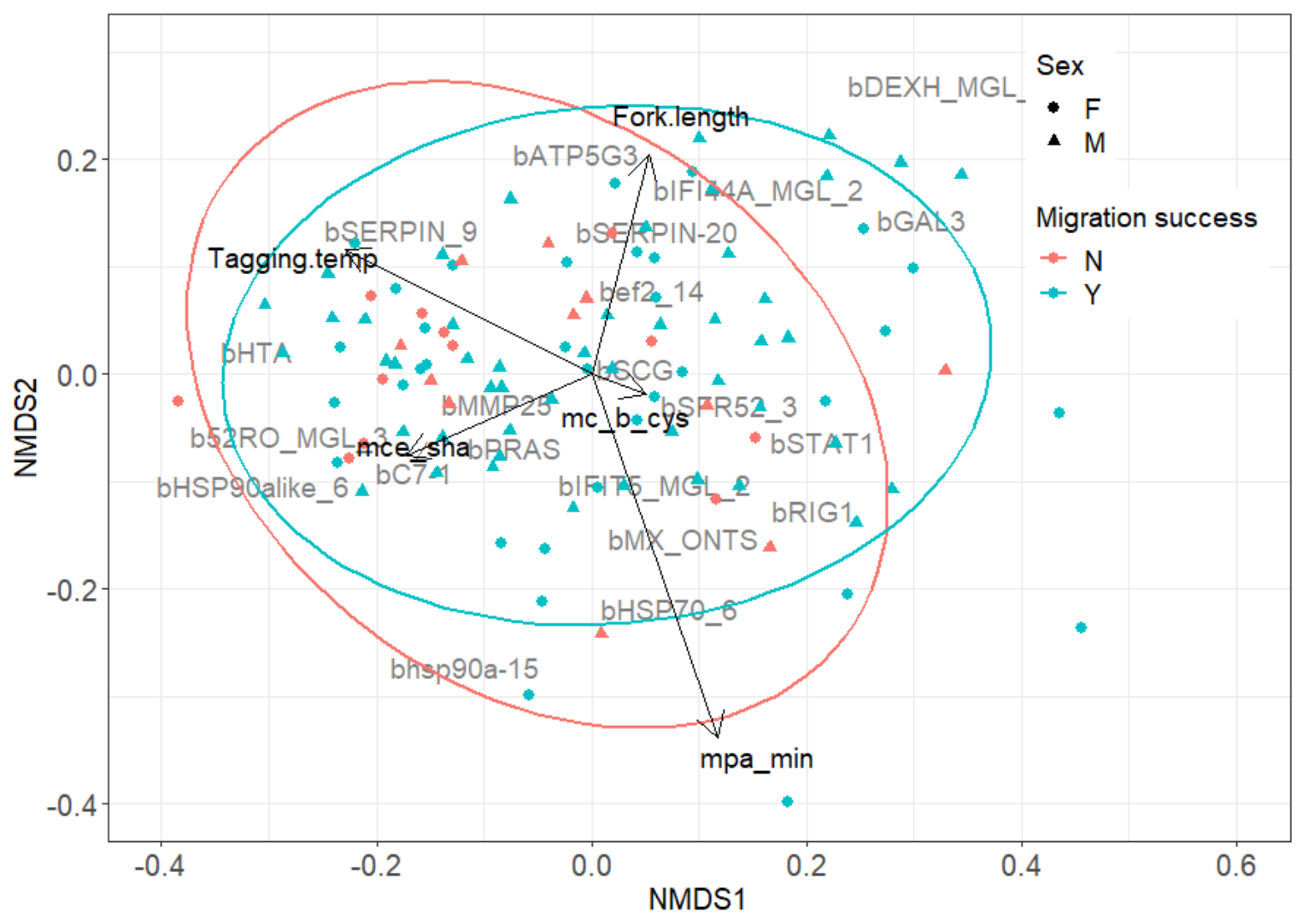

Figure 4.5. NMDS plot of host biomarker expression of Gates Creek sockeye salmon sampled in 2017. Biomarkers (shown in grey) are referenced in Table 4.2. The colour of points corresponds to whether each individual went on to successfully migrate to Gates Creek spawning grounds following sampling and tagging. Red points are individuals that did not successfully migrate to Gates Creek, blue points are those that were successfully detected at Gates Creek. Circular points correspond to females and triangular points correspond to males. Confidence ellipses (95\%) are also shown for each year. Vectors represent extrinsic variables fit onto the ordination. These extrinsic variables included the relative loads of Parvicapsula minibicornis (mpa_min), Ceratomyxa shasta (mce_sha), and Candidatus Branchiomonas cisticola (mc_b_cys), fork length, and Seton River water temperature at the time of tagging. 


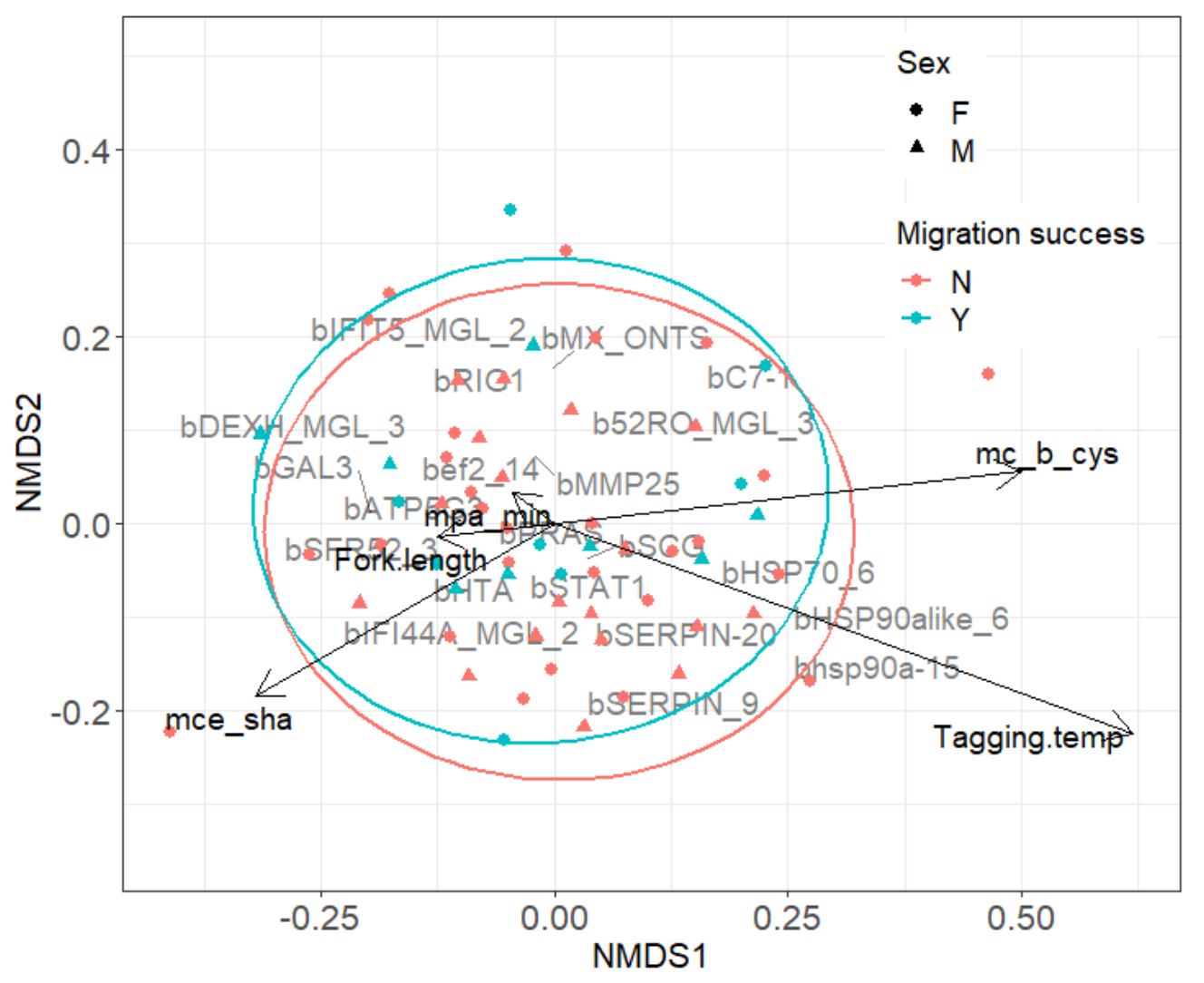

Figure 4.6. NMDS plot of host biomarker expression of Gates Creek sockeye salmon sampled in 2018. Biomarkers (shown in grey) are referenced in Table 4.2. The colour of points corresponds to whether each individual went on to successfully migrate to Gates Creek spawning grounds following sampling and tagging. Red points are individuals that did not successfully migrate to Gates Creek, blue points are those that were successfully detected at Gates Creek. Circular points correspond to females and triangular points correspond to males. Confidence ellipses (95\%) are also shown for each year. Vectors represent extrinsic variables fit into the ordination. These extrinsic variables included the relative loads of Parvicapsula minibicornis (mpa min), Ceratomyxa shasta (mce_sha), and Candidatus Branchiomonas cisticola (mc_b_cys), fork length, and Seton River water temperature at the time of tagging. 


\subsubsection{Infectious agents}

In both 2017 and 2018 I detected a total of 7 infectious agents (Fig. 4.7). Of all the infectious agents detected in Gates Creek sockeye salmon in 2017 and 2018, only Ceratomyxa shasta RNA copies differed significantly between the sexes. I found females to have significantly higher copy numbers of $C$. shasta compared with males $(\mathrm{p}=0.0006)$. When comparing RNA copy numbers between 2017 and 2018, I found significantly higher loads of Ichthyophthirius multifiliis in 2017 compared with 2018 ( $\mathrm{p}=0.00027$, Fig. 4.7), and significantly higher loads of $C$. shasta in 2018 compared with 2017 ( $\mathrm{p}=0.0074$, Fig. 4.7). No significant difference in the overall relative infection burden (RIB) was detected between individuals in 2017 and 2018.

Two infectious agents differ in prevalence between 2017 and 2018. Flavobacterium psychrophilum was significantly more prevalent in 2017 compared with 2018 (logistic regression, $\beta=-2.32, \mathrm{SE}=0.51, \mathrm{df}=167, \mathrm{p}<0.00001$; Fig. 4.7 ); this parasite was detected in $47.7 \%$ of fish sampled in 2017, and $8.2 \%$ of fish sampled in 2018. Paranucleospora theridion was significantly more prevalent in 2017 compared with 2018 (logistic regression, $\beta=2.14$, SE $=0.54, \mathrm{df}=167, \mathrm{p} \leq 0.0001$; Fig. 4.7). In 2017, $4.7 \%$ of fish were positive for $P$. theridion, and in $2018,29.5 \%$ of fish were positive. 


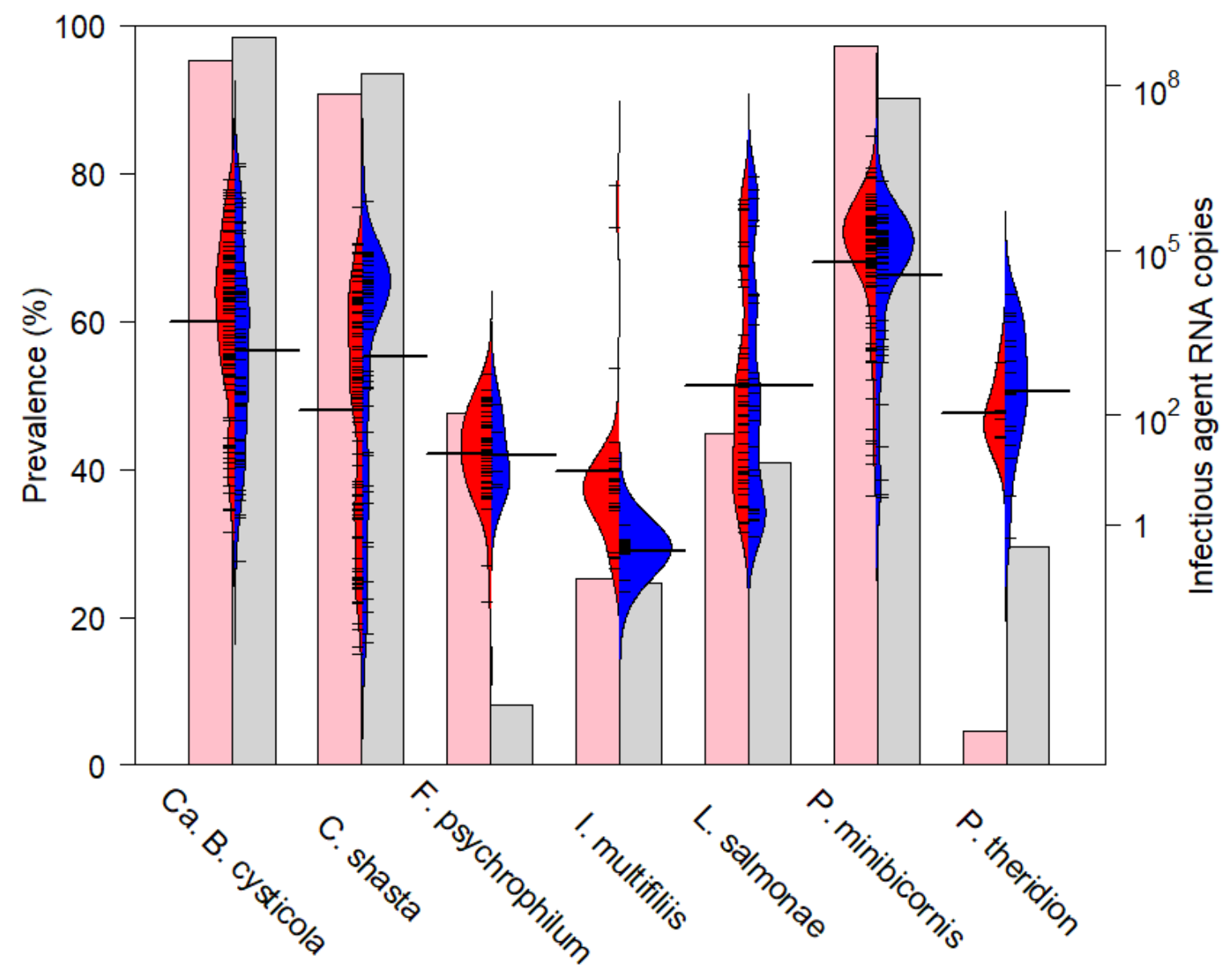

Figure 4.7. Comparison of infectious agent prevalence and loads in 2017 (red) and 2018 (blue). Bars represent prevalence of each infectious agent (\% of fish sampled that were positive for each infectious agent). Beans represent infectious agent load (RNA copy number). Small lines represent the RNA copy number in individual fish. The longer, boldened line represents the group average.

\subsection{Discussion}

During the main migration window for Gates Creek sockeye salmon, I found that average Fraser River water temperatures were approximately $1.5^{\circ} \mathrm{C}$ warmer in 2018 compared to 2017 . In 2018, Fraser River water temperatures experienced by migrating Gates Creek sockeye were 
above $20^{\circ} \mathrm{C}$ for approximately 2 weeks, a temperature known to be stressful and often lethal to migrating Pacific salmon (Hinch et al., 2012) thus allowing me to ask interesting and important questions about the impacts of high water temperature on survival, infectious agent profiles, and gene expression for adult Pacific salmon in the wild. I found survival to spawning grounds to be considerably reduced in 2018 (a warm year; $26.2 \%$ survival) compared with 2017 (a cool year; $77.6 \%$ survival). Severe consequences of warm water temperatures to Pacific salmon is not abnormal, and my findings are consistent with other studies that have investigated the consequences of water temperature for salmonids. Gene expression and the prevalence and loads of certain infectious agents also differed between years and these interannual differences were likely a consequence of water temperature differences.

\section{Higher Fraser River water temperatures associated with poorer migration survival}

The migration of Gates Creek sockeye salmon through the Seton River and passage through the Seton Dam Fishway has been studied over the past 15 years (reviewed in Bett et al., 2020). Since 2014, Gates Creek sockeye have been captured at a fish fence, PIT-tagged, and tracked through the Seton Dam Fishway and to Gates Creek in a similar manner as described in this study. From 2014-2016 inclusive, survival from Seton fence to Gates Creek spawning grounds averaged between $80-86 \%$ for males and $73-85 \%$ for females (Bass et al., 2018a; Harrower et al., 2019). In those years, sustained temperatures above $20^{\circ} \mathrm{C}$ were never observed in the Fraser River during the Gates Creek migration (Harrower et al., 2019) and those temperatures are reflective of the migration experience I observed in 2017, as were the survival levels (males $81 \%$, females $72 \%$ ). However, in 2018, Fraser River water temperatures were elevated above $20{ }^{\circ} \mathrm{C}$ for approximately 2 weeks during the peak migration window for Gates 
Creek sockeye salmon, and much poorer survival was observed in this year (31\% males, $23 \%$ females. This is a considerable reduction in survival compared to previous years of cooler water temperatures. In a recent 'high temperature' year (2013), Fraser River water temperatures were sustained for several days above $20^{\circ} \mathrm{C}$ and even surpassed $21^{\circ} \mathrm{C}$, and survival to spawning grounds was also low in that year for Gates Creek sockeye ( 40\%; D. Patterson, DFO, unpublished data). The survival of sockeye across the Seton Dam was lower in 2018 (81\% males, $89 \%$ females) compared to 2017 (95\% males, $96 \%$ females) and in other recent cooler years (98\% males, $95 \%$ females; Harrower et al., 2019; Bett et al., 2020), suggesting that warm temperatures may affect the ability of migrating sockeye salmon to locate and ascend the fishway. Thus, there is compelling evidence that warm temperatures, such as those observed in 2018, have a large negative effect on the survival and migration success of sockeye salmon.

Absolute differences in average Fraser River water temperatures between 2017 and 2018 may not seem considerable (approximately $1.5^{\circ} \mathrm{C}$ ), yet this difference is metabolically significant for Pacific salmon, especially when the aerobic scope of Gates Creek sockeye is considered. Aerobic scope is the difference between routine and maximum oxygen consumption during aerobic activity (Fry, 1947), and is directly related to temperature. There is an optimal temperature ( $\left.\mathrm{T}_{\mathrm{OPT}} \mathrm{AS}\right)$ and an optimal temperature range for aerobic performance $\left(\mathrm{T}_{\mathrm{OPT}} \mathrm{AS}\right.$ window). When temperatures exceed this optimal range, aerobic performance is reduced until it completely collapses at high temperatures (TCRIT; Portner, 2002). Cellular and genomic responses protect cellular functions of fish as temperatures approach $\mathrm{T}_{\mathrm{CRIT}}$, for example upregulation and activity of heat shock proteins and antioxidant defences (Portner, 2002; Kassahn et al., 2009). Previous research using swim tunnel experiments determined the maximum aerobic scope of Gates Creek sockeye salmon to be $11.08 \mathrm{mgO}_{2} / \mathrm{kg} / \mathrm{min}$ and $\mathrm{T}_{\text {OPT }} \mathrm{AS}$ 
for aerobic scope to be $16.4{ }^{\circ} \mathrm{C}$ (Eliason et al., 2011). Eliason et al. (2011) suggested that sockeye require $90 \%$ of their aerobic scope to complete their migration. The TOPтAS window (which provides $90 \%$ of their aerobic scope) for Gates Creek sockeye is $13.4-19.5^{\circ} \mathrm{C}$, and a recent study with Gates Creek sockeye found that the more time fish spent migrating within this temperature range (through natal lakes en-route to spawning grounds, Fig. 4.1A), the greater their spawning ground reproductive longevity and egg deposition (Minke-Martin et al., 2018). In other words, Gates Creek sockeye that migrate in their optimal thermal range have higher reproductive outputs. In 2018 , Fraser River temperatures exceeded $20^{\circ} \mathrm{C}$ for several days, and along this migratory corridor there is no opportunity for thermal refuge (Donaldson et al., 2009). Temperatures were thus beyond the TOPTAS window for Gates Creek sockeye, and a consequent large reduction in metabolic scope likely caused poor migratory abilities and contributed to higher mortality. Such high consequences of high temperature for migration is not unusual in Fraser River sockeye; in late-run sockeye salmon populations, over $90 \%$ mortality has resulted when migrants encountered temperatures $3-6{ }^{\circ} \mathrm{C}$ higher than their metabolic thermal optima (Cooke et al., 2004; Hinch et al., 2012).

Large changes in gene expression between years

I found large differences in select biomarker expression between years. The genes with the greatest differential expression between years were thermal biomarkers supporting the idea that temperature difference between years was a driving force for differences in gene expression profiles and thus survival. The six thermal biomarkers have all been validated to increase in response to high temperature and collectively are indicative of 'thermal stress' (Akbarzadeh et al., 2018; Houde et al., 2019). Jeffries et al. (2014) found increases in temperature to be 
correlated with increases in expression of genes associated with the cellular stress response.

Genomic responses to temperature allow fish to maintain cellular function and homeostasis when above their thermal optimum. However, if high temperatures are sustained over long periods, cellular functions and homeostasis cannot be maintained and this can result in mortality.

Miller et al. (2011) identified a common genomic profile that was correlated with survival in both ocean- and river-captured salmon (known as the mortality-related signature; MRS). I found no differences in expression of select MRS genes between 2017 and 2018, despite finding differences in mortality between these years. Miller et al. (2011) found that in the lower Fraser River, these MRS gene signatures were associated with a $50 \%$ increase in en-route mortality for one of three stocks tested. Here, I did not find MRS gene expression to be elevated in a year of high mortality compared with a year of low mortality. In this study, I captured and sampled fish in the Seton River, approximately $364 \mathrm{~km}$ from the mouth of the Fraser River. Salmon are therefore in very different physiological and maturation states compared with fish in the lower Fraser River. Miller et al. (2011) sampled salmon at two sites in the lower Fraser River and found MRS gene signatures to be associated with mortality. However, as fish mature throughout their freshwater migration, these same MRS genes signatures may no longer be predictive of mortality. I also note that due to such high water temperatures in 2018, and resultingly high thermal biomarker expression, it may be that thermal gene expression is the dominant genomic response, and other genomic responses are dampened. Indeed, I found variance of gene expression to be significantly lower in 2018 compared with 2017. However, this is highly speculative and further research is needed to (a) determine if MRS genes are predictive of mortality for fish further into freshwater migration and (b) the effect of temperature on potentially dampening other genomic responses. 


\section{Differences in prevalence and load of infectious agents}

I found two of the seven infectious agents detected in Gates Creek sockeye salmon to differ in prevalence between 2017 and 2018. Flavobacterium psychrophilum was found in lower prevalence in 2018 (8.2\%) compared with 2017 (47.7\%) but average load (number of RNA copies) was consistent between years. F. psychrophilum is typically found in high prevalence in salmonids (Bass, 2018; Miller et al., 2014), and increasing in prevalence as these fish approach spawning grounds (Miller et al., 2014). This bacterium is known to cause bacterial coldwater

disease (Starliper, 2011; Robert, 2012), and shows greater virulence at temperatures below $16^{\circ} \mathrm{C}$ (Starliper, 2011). F. psychrophilum is capable of growing when temperatures are $4-20{ }^{\circ} \mathrm{C}$ (Hesami et al., 2011), however optimal growth occurs from $15-16{ }^{\circ} \mathrm{C}$ (Starliper, 2011; Bernardet and Bowman, 2006). In the present study, temperatures in 2018 surpassed $20^{\circ} \mathrm{C}$, thus the reduced prevalence of $F$. psychrophilum may be due to temperatures surpassing its optimal growth conditions. I also found prevalence of Paranucleospora theridion was higher in 2018 (29.5\%) compared with 2017 (4.7\%). P. theridion is a marine microsporidian suspected to be associated with proliferative gill inflammation (Nylund et al., 2011) and thought to be associated with mortality in farmed Atlantic salmon (Salmo salar; Gunnarsson et al., 2017). This parasite has been detected in sea lice (Freeman and Somerville, 2009; Jones et al., 2012), and sea lice may transmit $P$. theridion to salmonids (Nylund et al., 2010). Bass (2018) found $50 \%$ of Chinook salmon in marine environments to be positive for $P$. theridion, yet only one fish tested positive in freshwater. Miller et al. (2014) found 19\% of sockeye sampled (combined from both marine and freshwater environments) were positive for $P$. theridion. In 2017, I found $P$. theridion at low prevalence (4.7\%), however in 2018 it was much more prevalent $(29.5 \%)$. Previous work in Atlantic salmon (Salmo salar) smolts has suggested that low temperatures 
(approximately $10^{\circ} \mathrm{C}$ ) inhibit its development compared with warm temperatures (approximately $16{ }^{\circ} \mathrm{C}$ ) upon ocean entry. Results from the present study suggest $P$. theridion development may be temperature-dependent, and thus could explain why I found prevalence of this parasite to be significantly higher in a warmer year compared with a cooler year. However, further research is needed to test this hypothesis.

I found that loads (RNA copy numbers) of two infectious agents differed between years. Ceratomyxa shasta, a salmonid parasite, was found at much higher loads in 2018 compared with 2017. C. shasta is a myxosporean parasite that requires a freshwater polychaete as an alternate host (Bartholomew et al., 1997). Water temperature can affect the timing of release of $C$. shasta from intermediate hosts (Ray et al., 2012; Chiaramonte, 2013), as well as increase the virulence of this parasite at higher temperatures (Chiaramonte et al., 2013). I suspect that at warmer temperatures in 2018, there was an increase in spore release of $C$. shasta from its intermediate host in the Fraser River. Greater spore release would result in higher spore density of C. shasta and thus greater infections and ultimately higher loads in salmonids. I also observed Ichthyophthirius multifiliis, a freshwater parasite known to cause white spot disease (Noe and Dickerson, 1995), to have higher loads in 2017. I. multifiliis shows faster development at high temperatures (Gratzek, 1993), with peak development at $24{ }^{\circ} \mathrm{C}$; Ewing et al., 1986), however I found loads of this parasite to be lower in the warmer year (2018). A limitation of this study is that I was only sampling those fish that had survived to the Seton River, and many fish in 2018 could have perished en-route before reaching the Seton. It is possible that fish with higher loads of I. multifiliis in 2018 may have perished before reaching the Seton fence, as this parasite is known to cause high mortality in migrating sockeye salmon (Traxler, 1998). 


\section{Correlation of extrinsic variables with gene expression}

I found different extrinsic variables to correlate with gene expression in 2017 compared with 2018. In 2018, Seton River water temperature at the time of tagging was most strongly correlated to gene expression, particularly to the expression of thermal biomarkers. This finding makes sense considering 2018 was a year of warmer water temperatures that would drive upregulation of thermal biomarkers for salmonids (Akbarzadeh et al., 2018; Houde et al., 2019). In 2017, a cooler water temperature year, I did not find water temperature to be correlated with gene expression. Loads of Candidatus Branchiomonas cysticola and Ceratomyxa shasta were also correlated with gene expression in 2018. I found loads of C. shasta to be higher in 2018 compared with 2017. Higher loads of C. shasta in 2018 may therefore be driving an immune response. C. shasta load was close in ordination space to the gene IFI44A, and this gene is associated this viral response, immunity and smoltification (Miller et al., 2017; Houde et al., 2020), and may be responding to relatively higher $C$. shasta loads in 2018. Ca. B. cysticola was significantly correlated with gene expression in 2018, but not in 2017 . This infectious agent showed no differences in load or prevalence in fish between these two years in this study, however previous work has shown loads of $\mathrm{Ca}$. B. cysticola to increase with warmer water

temperatures (Teffer, 2018). It may therefore be possible that $\mathrm{Ca}$. B. cysticola is more virulent in 2018 and therefore eliciting a genomic response. 


\subsection{Conclusions}

This study supports a large amount of previous literature documenting the severe consequences of high water temperature for salmonids (Fry, 1971; Cooke et al., 2004; Eliason et al., 2013; Hinch et al., 2012, Martins et al., 2011, 2012). Unique to this study is the tagging and tracking of wild Pacific salmon, for which the thermal history during their Fraser River migration can be well characterised. High water temperature can have many impacts on Pacific salmon metabolism and physiology, as well as a suite of effects on infectious agents development, replication, and virulence. Combined, these effects likely play an integrated role and collectively contribute to mortality. When temperatures exceed thermal optima, the consequences for survival can be devastating, and temperature-mediated mortality can confound impacts of other stressors (Brett, 1971; Gale et al., 2013; Chapter 2). Future research should therefore always consider both the thermal experience fish may have faced before experimental interactions, as well as the temperatures experienced during and after experimental interactions. If temperatures have been high for migrating salmonids, it may exacerbate mortality during experimental studies. However, in an era of climate change and warming waters, the consequences of various other stressors (such as fisheries interactions, infection, dam passage) in warm water conditions it is important to know, and very important for fisheries managers to consider to prevent over-inflation of escapement estimates.

Thermal refuge has previously been shown to increase survival and reproductive success for salmonids (Newell and Quinn, 2005; Mathes et al., 2010; Keefer and Caudill, 2015; MinkeMartin et al., 2018). In years of warming water temperatures, thermal refuges may be increasingly important. However, not every migration route contains thermal refuges, and salmon that travel along routes without refugia may be particularly vulnerable to the effects of 
warm water temperatures. The lower Fraser River migration route, before Gates Creek sockeye reach the Seton River, contains no thermal refuges (Donaldson et al., 2009). The Seton system contains two lakes, Seton and Anderson Lake, and thus fish have a large area of thermal refuge after passing Seton Dam. Despite this access to thermal refuge in the Seton system, I still found mortality to be exceptionally high for Gates Creek sockeye in 2018. This suggests that unless thermal refuges are present throughout freshwater migration routes, the effects of prolonged warm water temperatures in rivers will still have severe consequences for salmonids, even if they have access to thermal refuges near the end of their migration. As climate change continues and water temperatures rise (Patterson et al., 2007; Grant et al., 2019), many Fraser River salmon populations with no access to thermal refuges may be especially vulnerable to population declines in the future. 


\section{CHAPTER 5}

\section{Comparing the prevalence, load, and diversity of infectious agents in live sockeye salmon (Oncorhynchus nerka) and those that died during their final segment of freshwater migration.}

\subsection{Abstract}

Drivers of individual variation in fitness are of great interest to animal ecologists, yet relatively little is known about why some individuals live and thrive while others perish. This is the case for wild adult sockeye salmon. Spawning migrations for these capital breeders can be associated with high levels of en-route mortality which means that their lifetime fitness is zero, and this may be a strong contributing factor to population declines. There are a number of reasons why fish may die en-route during freshwater migration, and recently infectious agents have been suggested to be a major causative factor in en-route mortality. Here I compare the prevalence, load, and diversity of infectious agents between fish that die en-route and live sockeye in the Seton River over three years. In this study, biopsies were taken from five major organs and tested for the presence and load of 47 infectious agents known or suspected to infect Fraser River sockeye. Aeromonas salmonicida, Dermocystidium salmonis, and Flavobacterium psychrophilum were all found to be more prevalent in fish that die en-route compared with live fish. Additionally, I found that loads (RNA copy numbers) of Flavobacterium psychrophilum 
and Parvicapsula minibicornis were higher in dead fish compared with live fish. I found no difference in the overall diversity of infectious agents. As I sampled fish in this way over three years $(2015,2017$, and 2018) which differed in average temperature for migration of summerrun sockeye $\left(19.4^{\circ} \mathrm{C}, 18.9^{\circ} \mathrm{C}\right.$, and $20.1{ }^{\circ} \mathrm{C}$, respectively), I also looked for differences in infectious agents profiles among years. Interannual differences in the prevalence and load of certain infectious agent were observed, and this is speculated to be a function of river temperature. The overall relative infection burden (RIB) for both live and dead fish was found to be highest in 2018, which was the warmest of the three years. For 2018, I also observed a difference in RIB between live and dead fish, with dead fish in this warm year having higher RIB. This novel study provides insight into how infectious agents might influence individual variation in fitness in a wild population of migratory animals, and suggests that environmental variables, such as temperature, are likely affecting infectious agent productivity and this may have important consequences for animal migrants. 


\subsection{Introduction}

Individual variation in fitness is a foundational concept in ecology and evolutionary biology (Haldane, 1937; Prosser, 1955; Spicer and Gaston, 2009). Differences in fitness allow natural selection and adaptation to changing habitats and environmental conditions (Ellegren and Sheldon, 2008; Orr, 2009). This individual variation in fitness is widely observed in nature but is particularly prominent during large-scale migrations where some animals succeed while others fail. Migration fate can be influenced by variations in physiology (tolerances and capacity), energetics, disease, immune function, behaviour, or a complex interplay of many of these. Pacific salmon (Oncorhynchus spp.) represent excellent model organisms to investigate the impacts of infectious agents on fitness as they are capital spawners, meaning lifetime fitness is reliant on a single spawning event following a strenuous and physiologically demanding spawning migration. Those fish that perish en-route during this migration are therefore considered to have zero lifetime fitness.

Pacific salmon are fundamentally important species within their environment, forming part of many food chains in both marine and freshwater ecosystems and ultimately providing essential nutrients in riparian ecosystems upon death (Naiman et al., 2002). As well as their ecological importance, Pacific salmon species also offer great economic and cultural significance, and it is therefore necessary to protect abundant and sustainable stocks (Lichatowich, 1999). However, many Pacific salmon populations have been declining in recent decades. For sockeye salmon (Oncorhynchus nerka), numbers have been decreasing since the early 90s (Peterman and Dorner, 2012), and widespread declines eventually received national attention leading to a public inquiry in an attempt to identify the causes behind these declines (Cohen, 2012). No single factor was attributed to these declines, but instead a number of factors 
are believed to contribute. Warming water temperatures as a result of climate change (Petersen and Kitchell, 2001; Patterson et al., 2007), predation (Miller et al., 2014), fishing practices (Baker and Schindler, 2009), and infectious diseases (Miller et al., 2014) have all been shown to negatively impact sockeye salmon and have potential for population-level impacts.

The final freshwater migration of adult Pacific salmon to natal spawning streams is particularly challenging, and fish are faced with a suite of novel challenges which can have severe consequences potentially leading to mortality (Cooke et al., 2006; Hinch et al., 2012). This en-route mortality (here defined as fish that die during their adult, freshwater migration) has been reported to be as high as $90 \%$ for sockeye salmon in some years (Cooke et al., 2004), and thus can be a serious threat for this species, and has likely contributed to declines in population numbers. Research into the causes behind en-route mortality have identified thermal (Jeffries $e t$ al., 2012; Martins et al., 2012) and fishery stressors (Gilhousen, 1990; Donaldson et al., 2011; Gale et al., 2013; Raby et al., 2015) as contributing factors. More recently, infectious agents have been identified as a potential factor behind en-route mortality, however this is often more difficult to study and thus less is known (Altizer et al., 2011; Kent, 2011; Cohen, 2012; Miller et al., 2014). Upon entering freshwater riverine environments, salmon are faced with a higher density of novel infectious agents compared with the marine environment (Miller et al., 2014). Exposure to this suite of infectious agents, at a time when salmon immune function is compromised due to beginning senescence (Dolan et al., 2016), may mean these fish are more vulnerable to disease. In addition, other stressors may have synergistic effects, such as high water temperatures increasing the productivity of certain infectious agents (Chiaramonte, 2013; Paull and Johnson, 2014), or water temperature and fishery stressors further compromising host resilience (Jeffries et al., 2012; Dittmar et al., 2014). 
Although research into infectious agents and en-route mortality in Pacific salmon is relatively new and often difficult to study in the wild, there are some studies that have highlighted the severe consequences infectious agents can have. Immune responses to viruses have been associated with mortality in wild salmon smolts and adults (Miller et al., 2011; Jeffries et al., 2014) and in salmon farm net pens in the marine environment (Miller et al., 2017; Di Cicco et al., 2018). Further, Jeffries et al. (2014) found immune responses to viruses were associated with mortality in sockeye salmon smolts. In a study on adult sockeye salmon, infection intensities of the bacterium Flavobacterium psychrophilum and the parasite Ceratomyxa shasta were greater in fish that died sooner during a holding study (Teffer et al., 2017). New infectious agents are still being discovered (Mordecai et al., 2019; Mordecai et al., 2020), and together these studies suggest infectious agents may strongly contribute to increased en-route mortality for wild, adult salmon (Kent, 2011; Miller et al., 2014).

In this paper, I investigate the potential association of infectious agents and individual variation in fitness, and ultimately en-route mortality, of adult Fraser River sockeye salmon during spawning migrations. I compare the prevalence, diversity, and load of infectious agents between sockeye salmon that perish failing to pass Seton Dam to those that are still swimming and in good visual condition at the same location. Mortalities and live fish were sampled over 3 years between 2015 and 2018, each year with different thermal profiles, allowing further investigation into inter-annual variation in infectious agent prevalence, load, and diversity. I predict that if infectious agents are a large contributing factor to en-route mortality of adult sockeye salmon, then fish that die en-route would have higher prevalence, diversity, and loads of certain infectious agents compared with live fish. Further, I predict that only select infectious agents (with more harmful or damaging effects to their host) might be contributing to mortality. 


\subsection{Methods}

\subsubsection{Study Site}

The Seton River is a tributary of the Fraser River approximately $364 \mathrm{~km}$ from its mouth. Gates Creek sockeye migrate through the Seton system to ultimately spawn in Gates Creek. Spawning typically occurs in late August-early September. Throughout the late summer, other sockeye salmon are also migrating through the Fraser River, past the Seton River to other systems further north, such as the Chilko, Quesnel, and late-Stuart stocks. The Seton River flows approximately $5.5 \mathrm{~km}$ from Seton Lake to the confluence with the Fraser River. Sockeye travelling through the Seton system must then navigate both Seton and Anderson Lakes, before finally reaching Gates Creek spawning grounds. Seton dam has been constructed where Seton Lake empties into Seton River. Fish are able to pass this dam by navigating a fish ladder, although it can be a challenge for fish to locate the entrance of this fish ladder due to high flows in the dam tailrace (Burnett et al., 2014). The need to burst-swim to navigate Seton dam tailrace is known to cause mortality for some sockeye, either delayed mortality within days of passing the dam, or more imminent mortality meaning the fish does not pass the dam (Roscoe et al., 2011; Burnett et al., 2014).

\subsubsection{Collection and sampling of mortalities}

Approximately $100 \mathrm{~m}$ downstream from Seton dam, a river-spanning picket fence was constructed across the Seton River. This fence stretched from one bank of the river to the other in a "V" shape that pointed upstream. On one side of the fence a 'holding area' was constructed through a second arm which connected the fence to the riverbank, creating an enclosed area 
adjacent to the bank. When all pickets were in place the fence was considered 'closed' and this blocked any upstream migration for fish wishing to pass. When the fence was closed, two pickets would be removed from the downstream arm of the holding area, thus any fish trying to pass the fence would eventually find this small gap and would then hold in this area. The fence was closed for approximately 10 hours over night to capture sockeye in the holding area of the fence. During daylight hours, pickets were removed near the centre of the fence allowing any fish still holding behind the fence to pass. Because Seton dam is located $100 \mathrm{~m}$ upstream of the fish fence, any fish that died trying to navigate the high flows of the dam tailrace would float downstream and collect on the fence. Regular fence walks were conducted every hour to collect any moribund or recently deceased fish from the fence for assessment of condition and sample collection.

Sockeye collected from the fence were taken to a sterilized table where fork length, the presence of any visible injuries and the predicted source of these injuries, and finally the severity of these injuries on an arbitrary scale from 0 (no injury) to 6 (very severe injury exposing large amounts of flesh) were recorded. Using sterilized tools, fish were dissected and approximately 3 $\mathrm{mm}^{2}$ biopsies were taken from five major organs (gill, liver, heart, spleen, and head kidney). These organ biopsies were preserved in $1.5 \mathrm{~mL}$ RNAlater solution (Qiagen, MD, USA) and stored at $-80{ }^{\circ} \mathrm{C}$ for future laboratory analyses of infectious agents. Collection and sampling of mortalities downstream of Seton dam was performed in this way for 3 years: 2015, 2017, and 2018.

In addition to collection and sampling of mortalities at the fish fence, destructive sampling was also performed on live fish with no visible injuries. These fish were captured from the holding area of the fence after the fence had been closed over night. Fish would be dipnetted 
from the holding area into an adjacent trough with a continuous supply of river water. Here we would assess the condition of the fish, take GSE measurements, and record the presence, cause and severity of any visible injuries. Only live fish in visually 'great' condition were selected for destructive sample, these fish had no visible wounds, $<5 \%$ total body scale loss, and healthy red gills with no visible cysts. The fish would be sacrificed and transferred to a sterilized dissection table for organ sampling as previously described.

\subsubsection{Characterizing thermal experience during Fraser River migration}

The thermal experience of both dead and live sockeye salmon sampled at Seton fish fence was estimated in 2015, 2017 and 2018. To achieve this, I calculated the temperature each individual would have experienced at two temperature loggers placed in the Fraser River; the first logger was located in the Fraser River at Hope, and the second located further upstream at Texas Creek. Due to largely invariant water temperatures along the lower Fraser River migration corridor (Donaldson et al., 2009), these two temperature loggers are assumed sufficient for extrapolating thermal experience of these fish along their entire lower Fraser River migration. Using the average migration rate of Gates Creek sockeye salmon (34.6 km/day; Kanigan et al., 2019), the date at which each individual sampled fish would have been at both Hope and Texas Creek was estimated. Distances from each Fraser River temperature logger to the Seton River fish fence were calculated, and divided by the average migration rate for Gates Creek sockeye (34.6 km/day), providing an estimate for the amount of time taken for each individual to migrate from that thermal logger to Seton fish fence (Table 5.1). Using temperature logger data, I was then able to estimate the Fraser River temperature experienced by every individual we sampled at Seton fence each year. 
Table 5.1. Migration time estimated for Gates Creek sockeye salmon for various intervals from the Fraser River mouth to Gates Creek spawning grounds.

\begin{tabular}{|c|c|c|}
\hline & Distance (river km) & Migration time (days) \\
\hline Steveston to Hope & 120.7 & 4 \\
Hope to Texas Creek & 160.3 & 1 \\
Texas Creek to Seton fence & 13.1 & 10 \\
Seton fence to Gates Creek & 48.2 & \\
\hline
\end{tabular}

\subsubsection{Laboratory analyses}

All laboratory analyses of organ tissue samples across years was performed in the Molecular Genetics Lab of Pacific Biological Station (Nanaimo, BC, Canada). Samples were analyzed for the presence and load (RNA copy number) of 47 infectious agents known or suspected to infect Pacific salmon. From each fish, 5 organ samples (gill, heart, spleen, liver and head kidney) were thawed and transferred to microtubes containing stainless steel beads for homogenization. Samples were individually homogenized in TRI-reagent (Ambion Inc., Austin, TX, USA) and vigorous shaking using a MM301 mixer mill (Retsch Inc., Newtown, PA, USA) before separation into aqueous and organic phases using 1-bromo-3-chloropropane and centrifugation. Equal volumes of the aqueous phases of the 5 tissues were combined for each induvial fish in a 96-well plate, creating 'pooled' organ samples for each fish. RNA extraction was performed using MagMAX-96 for Microarrays Total RNA Isolation Kits (Ambion Inc.) with a Biomek NXP automated liquid-handling machine. RNA extraction was performed using 
the "spin method" from manufacturer instructions and included DNase treatment to avoid DNA contamination. Spectrophotometry was then used to measure RNA quantity (ng/mL) and quality (A260/A280) using a Beckman Coulter DTX 880 Multimode Detector (Brea, CA, USA). All samples were normalized to $62.5 \mathrm{ng} \mu \mathrm{L}-1$ using the Biomek NXP automated liquid-handling machine. To create cDNA required for $\mathrm{qPCR}, 1 \mu \mathrm{g}$ of normalized RNA was reverse transcribed using a SuperScript VILO MasterMix Kit (Invitrogen, Carlsbad, CA). Specific target amplification (STA) of 47 select infectious agent biomarkers was then performed using $1.25 \mu \mathrm{L}$ cDNA, assay primer pairs (Table 5.2), and TaqMan Preamp Master Mix (Applied Biosystems, Foster City, California). This allowed pre-amplification of select infectious agent biomarkers, a step recommended by the manufacture (Biomark ${ }^{\mathrm{TM}}$ ) before quantitative PCR (qPCR) due to the small assay volume $(5 \mu \mathrm{L})$ required. All assays were run in duplicate. Following STA, any unincorporated primers were removed using ExoSAP-IT (Affymetrix, Santa Clara, California), and samples were diluted 5-fold using DNA Suspension Buffer (Teknova, Hollister, California). Fluidigm technology requires both samples and assays to be loaded separately onto a qPCR chip. A qPCR sample mix was prepared using pre-amplified cDNA, $1 \times$ TaqMan Universal Master Mix (Life Technologies) and 1× GE Sample Loading Reagent (Fluidigm PN 85000746). An assay mix was prepared with $10 \mu \mathrm{M}$ primer pairs, $3 \mu \mathrm{M}$ probes, and assay loading reagent (Fluidigm PN 85000736). Sample and assay mixes were then pipetted into the chip and were loaded using an IFC controller HX (Fluidigm). Finally, qPCR was conducted $\left(50{ }^{\circ} \mathrm{C}\right.$ for 2 min, $95^{\circ} \mathrm{C}$ for $10 \mathrm{~min}$, followed by 40 cycles of $95^{\circ} \mathrm{C}$ for $15 \mathrm{~s}$ and $60{ }^{\circ} \mathrm{C}$ for $1 \mathrm{~min}$ ). See Miller et al. (2016) for a complete overview of this high-throughput qPCR workflow.

A serial dilution of artificial positive constructs (APC clones; run in 6 cells of the dynamic array) was added to the dynamic array to allow for calculation of assay efficiency. 
Ultimately, this can be used to determine infectious agent loads and biomarker efficiency (Miller et al., 2016). APCs also contained a probe (with NED ${ }^{\mathrm{TM}}$ dye, Applied Biosystems, Foster City, CA, USA) to detect any APC contamination in samples Positive and negative controls were also included on the dynamic array for RNA extraction, cDNA synthesis, STA, and qPCR stages.

Table 5.2. Infectious agents assayed in sockeye salmon during this study. A total of 47 infectious agents, and one host reference gene, were evaluated through qPCR. Forward primer (F), reverse primer $(\mathrm{R})$ and probe $(\mathrm{P})$ sequences are given.

\begin{tabular}{|c|c|c|c|c|c|}
\hline Agent & Type & Full name & $\begin{array}{l}\text { Accession } \\
\#\end{array}$ & Primer and probe sequences & $\begin{array}{l}\text { Assay } \\
\text { Reference }\end{array}$ \\
\hline ae_sal & Bacterium & $\begin{array}{l}\text { Aeromonas } \\
\text { salmonicida }\end{array}$ & M64655 & $\begin{array}{l}\text { F: TAAAGCACTGTCTGTTACC } \\
\text { R: GCTACTTCACCCTGATTGG } \\
\text { P: } \\
\text { ACATCAGCAGGCTTCAGAGTCAC } \\
\text { TG }\end{array}$ & $\begin{array}{l}\text { Keeling et } a \\
2013 \\
\text { (modified) }\end{array}$ \\
\hline arenal & Virus & $\begin{array}{l}\text { Arenavirus } \\
\text { Type I }\end{array}$ & - & $\begin{array}{l}\text { F: CCTGCCTCTTTGCTCATTGTG } \\
\text { R: } \\
\text { AGAAAAAGCTGTGGTACTTTAGA } \\
\text { AAGC } \\
\text { P: ATCCGCCTAACGGTTGG }\end{array}$ & $\begin{array}{l}\text { Gideon } \\
\text { Mordecai }\end{array}$ \\
\hline arena2 & Virus & $\begin{array}{l}\text { Arenavirus } \\
\text { Type II }\end{array}$ & - & $\begin{array}{l}\text { F: AACATGAAGGGCGATTCGTT } \\
\text { R: CAGCCCGCGGACTGAGT } \\
\text { P: CAAGTGATGTAAGCTTG }\end{array}$ & $\begin{array}{l}\text { Gideon } \\
\text { Mordecai }\end{array}$ \\
\hline ascr & Virus & $\begin{array}{l}\text { Atlantic Salmon } \\
\text { Calicivirus } \\
\text { (ASCV) }\end{array}$ & - & $\begin{array}{l}\text { F: ACCGACTGCCCGGTTGT } \\
\text { R: } \\
\text { CTCCGATTGCCTGTGATAATACC } \\
\text { P: CTTAGGGTTAAAGCAGTCG }\end{array}$ & $\begin{array}{l}\text { Gideon } \\
\text { Mordecai }\end{array}$ \\
\hline c_b_cys & Bacterium & $\begin{array}{l}\text { Candidatus } \\
\text { Branchiomonas } \\
\text { cysticola }\end{array}$ & JQ723599 & $\begin{array}{l}\text { F: } \\
\text { AATACATCGGAACGTGTCTAGTG } \\
\text { R: GCCATCAGCCGCTCATGTG } \\
\text { P: } \\
\text { CTCGGTCCCAGGCTTTCCTCTCCC } \\
\text { A }\end{array}$ & $\begin{array}{l}\text { Mitchell et } \\
\text { al. } 2013\end{array}$ \\
\hline ce_sha & Myxozoan & $\begin{array}{l}\text { Ceratomyxa } \\
\text { shasta }\end{array}$ & AF001579 & $\begin{array}{l}\text { F: } \\
\text { CCAGCTTGAGATTAGCTCGGTAA } \\
\text { R: CCCCGGAACCCGAAAG } \\
\text { P: } \\
\text { CGAGCCAAGTTGGTCTCTCCGTG } \\
\text { AAAAC }\end{array}$ & $\begin{array}{l}\text { Hallett and } \\
\text { Bartholom } \\
\text { ew, } 2006\end{array}$ \\
\hline
\end{tabular}




\begin{tabular}{|c|c|c|c|c|c|}
\hline cov & Virus & Coronavirus & - & $\begin{array}{l}\text { F: } \\
\text { GGATAATCCCAACCGAAAAGTTT } \\
\text { R: } \\
\text { GCATGAAATGTTGTCTCGGTTTA } \\
\text { A } \\
\text { P: CGATCCCGATTATC }\end{array}$ & $\begin{array}{l}\text { Miller et } \\
\text { al., } 2016\end{array}$ \\
\hline cr_sal & Protozoan & $\begin{array}{l}\text { Trypanoplasma } \\
\text { salmositica }\end{array}$ & - & $\begin{array}{l}\text { F: TCAGTGCCTTTCAGGACATC } \\
\text { R: GAGGCATCCACTCCAATAGAC } \\
\text { P: } \\
\text { AGGAGGACATGGCAGCCTTTGTA } \\
\text { T }\end{array}$ & $\begin{array}{l}\text { Miller et } \\
\text { al., } 2016\end{array}$ \\
\hline ctv & Virus & $\begin{array}{l}\text { Cutthroat Trout } \\
\text { Virus (CTV) }\end{array}$ & - & $\begin{array}{l}\text { F: } \\
\text { CCACTTGTCGCTACGATGAAAC } \\
\text { R: CGCCTCCTTTGCCTTTCTC } \\
\text { P: ATGCCGGGCCATC }\end{array}$ & $\begin{array}{l}\text { Miller et } \\
a l ., 2016\end{array}$ \\
\hline de_sal & Protozoan & $\begin{array}{l}\text { Dermocystidium } \\
\text { salmonis }\end{array}$ & U21337 & $\begin{array}{l}\text { F: CAGCCAATCCTTTCGCTTCT } \\
\text { R: GACGGACGCACACCACAGT } \\
\text { P: AAGCGGCGTGTGCC }\end{array}$ & $\begin{array}{l}\text { Miller et } \\
\text { al., } 2016\end{array}$ \\
\hline fa_mar & Microsporidian & $\begin{array}{l}\text { Facilispora } \\
\text { margolisi }\end{array}$ & HM800849 & $\begin{array}{l}\text { F: AGGAAGGAGCACGCAAGAAC } \\
\text { R: CGCGTGCAGCCCAGTAC } \\
\text { P: TCAGTGATGCCCTCAGA }\end{array}$ & $\begin{array}{l}\text { Miller et } \\
\text { al., } 2016\end{array}$ \\
\hline fl_psy & Bacterium & $\begin{array}{l}\text { Flavobacterium } \\
\text { psychrophilum }\end{array}$ & - & $\begin{array}{l}\text { F: } \\
\text { GATCCTTATTCTCACAGTACCGT } \\
\text { CAA } \\
\text { R: } \\
\text { TGTAAACTGCTTTTGCACAGGAA } \\
\text { P: AAACACTCGGTCGTGACC }\end{array}$ & $\begin{array}{l}\text { Duesund } e t \\
a l ., 2010\end{array}$ \\
\hline hkg & $\begin{array}{l}\text { Host reference } \\
\text { gene }\end{array}$ & $\begin{array}{l}\text { Si:dkey- } \\
78 \mathrm{~d} 16.1 \\
\text { protein }\end{array}$ & - & $\begin{array}{l}\text { F: GTCAAGACTGGAGGCTCAGAG } \\
\text { R: } \\
\text { GATCAAGCCCCAGAAGTGTTTG } \\
\text { P: } \\
\text { AAGGTGATTCCCTCGCCGTCCGA }\end{array}$ & $\begin{array}{l}\text { Miller et } \\
\text { al., } 2016\end{array}$ \\
\hline ic_hof & Protozoan & $\begin{array}{l}\text { Ichthyophonus } \\
\text { hoferi }\end{array}$ & AF467793 & $\begin{array}{l}\text { F: } \\
\text { GTCTGTACTGGTACGGCAGTTTC } \\
\text { R: } \\
\text { TCCCGAACTCAGTAGACACTCAA } \\
\text { P: } \\
\text { TAAGAGCACCCACTGCCTTCGAG } \\
\text { AAGA }\end{array}$ & $\begin{array}{l}\text { White } e t \\
\text { al., } 2013\end{array}$ \\
\hline ic_mul & Ciliate & $\begin{array}{l}\text { Ichthyophthirius } \\
\text { multifiliis }\end{array}$ & IMU17354 & $\begin{array}{l}\text { F: AAATGGGCATACGTTTGCAAA } \\
\text { R: } \\
\text { AACCTGCCTGAAACACTCTAATT } \\
\text { TTT } \\
\text { P: } \\
\text { ACTCGGCCTTCACTGGTTCGACT } \\
\text { TGG }\end{array}$ & $\begin{array}{l}\text { Miller et } \\
\text { al., } 2016\end{array}$ \\
\hline
\end{tabular}




\begin{tabular}{|c|c|c|c|c|c|}
\hline ihnv & Virus & $\begin{array}{l}\text { Infectious } \\
\text { hematopoietic } \\
\text { necrosis virus }\end{array}$ & NC_001652 & $\begin{array}{l}\text { F: AGAGCCAAGGCACTGTGCG } \\
\text { R: TTCTTTGCGGCTTGGTTGA } \\
\text { P: TGAGACTGAGCGGGACA }\end{array}$ & $\begin{array}{l}\text { Purcell et } \\
\text { al., } 2013\end{array}$ \\
\hline ku_thy & Microsporidian & Kudoa thyrsites & AF031412 & $\begin{array}{l}\text { F: TGGCGGCCAAATCTAGGTT } \\
\text { R: } \\
\text { GACCGCACACAAGAAGTTAATCC } \\
\text { P: TATCGCGAGAGCCGC }\end{array}$ & $\begin{array}{l}\text { Funk et al. } \\
2007\end{array}$ \\
\hline lo_sal & Microsporidian & Loma salmonae & HM626243 & $\begin{array}{l}\text { F: GGAGTCGCAGCGAAGATAGC } \\
\text { R: } \\
\text { CTTTTCCTCCCTTTACTCATATGC } \\
\text { TT } \\
\text { P: } \\
\text { TGCCTGAAATCACGAGAGTGAG } \\
\text { ACTACCC }\end{array}$ & $\begin{array}{l}\text { Miller et } \\
\text { al., } 2016\end{array}$ \\
\hline mitov & Virus & MitoV & - & $\begin{array}{l}\text { F: TGTCCCTGAAGATTCATTTCGA } \\
\text { R: } \\
\text { CTATGTAAAGCCTCGTCGGTGAT } \\
\text { P: TCCTAGGTGATGATATAAT }\end{array}$ & $\begin{array}{l}\text { Miller } e t \\
\text { al., } 2016\end{array}$ \\
\hline my_arc & Myxozoan & $\begin{array}{l}\text { Myxobolus } \\
\text { arcticus }\end{array}$ & HQ113227 & $\begin{array}{l}\text { F: } \\
\text { TGGTAGATACTGAATATCCGGGT } \\
\text { TT } \\
\text { R: AACTGCGCGGTCAAAGTTG } \\
\text { P: CGTTGATTGTGAGGTTGG }\end{array}$ & $\begin{array}{l}\text { Miller } \text { et } \\
\text { al., } 2016\end{array}$ \\
\hline my_ins & Myxozoan & $\begin{array}{l}\text { Myxobolus } \\
\text { Insidiosus }\end{array}$ & EU346375 & $\begin{array}{l}\text { F: CCAATTTGGGAGCGTCAAA } \\
\text { R: } \\
\text { CGATCGGCAAAGTTATCTAGATT } \\
\text { CA } \\
\text { P: CTCTCAAGGCATTTAT }\end{array}$ & $\begin{array}{l}\text { Miller } e t \\
\text { al., } 2016\end{array}$ \\
\hline na_sal & Fluke & $\begin{array}{l}\text { Nanophyetus } \\
\text { salmincola }\end{array}$ & AY269674 & $\begin{array}{l}\text { F: } \\
\text { CGATCTGCATTTGGTTCTGTAAC } \\
\text { A } \\
\text { R: } \\
\text { CCAACGCCACAATGATAGCTATA } \\
\text { C } \\
\text { P: TGAGGCGTGTTTTATG }\end{array}$ & $\begin{array}{l}\text { Miller } \text { et } \\
\text { al., } 2016\end{array}$ \\
\hline ne_per & Amoeba & $\begin{array}{l}\text { Paramoeba } \\
\text { Perurans }\end{array}$ & EF216905 & $\begin{array}{l}\text { F: GTTCTTTCGGGAGCTGGGAG } \\
\text { R: GAACTATCGCCGGCACAAAAG } \\
\text { P: CAATGCCATTCTTTTCGGA }\end{array}$ & $\begin{array}{l}\text { Fringuelli } \\
\text { et al., } 2012\end{array}$ \\
\hline ortho & Virus & OrthoMyxoV & - & $\begin{array}{l}\text { F: GGAAGCAGTGGACGCTAACC } \\
\text { R: TCGCGAAGGTCTCTCAATGTC } \\
\text { P: ATTCTTCTCATCAAAGGCA }\end{array}$ & $\begin{array}{l}\text { Miller } e t \\
\text { al., } 2016\end{array}$ \\
\hline pa_kab & Myxozoan & $\begin{array}{l}\text { Parvicapsula } \\
\text { kabatai }\end{array}$ & DQ515821 & $\begin{array}{l}\text { F: CGACCATCTGCACGGTACTG } \\
\text { R: ACACCACAACTCTGCCTTCCA } \\
\text { P: CTTCGGGTAGGTCCGG }\end{array}$ & $\begin{array}{l}\text { Miller } \text { et } \\
\text { al., } 2016\end{array}$ \\
\hline
\end{tabular}




\begin{tabular}{|c|c|c|c|c|c|}
\hline pa_min & Myxozoan & $\begin{array}{l}\text { Parvicapsula } \\
\text { minibicornis }\end{array}$ & AF201375 & $\begin{array}{l}\text { F: } \\
\text { AATAGTTGTTTGTCGTGCACTCT } \\
\text { GT } \\
\text { R: } \\
\text { CCGATAGGCTATCCAGTACCTAG } \\
\text { TAAG } \\
\text { P: TGTCCACCTAGTAAGGC }\end{array}$ & $\begin{array}{l}\text { Miller } e t \\
\text { al., } 2016\end{array}$ \\
\hline pa_pse & Myxozoan & $\begin{array}{l}\text { Parvicapsula } \\
\text { Pseudo- } \\
\text { branchicola }\end{array}$ & AY308481 & $\begin{array}{l}\text { F: CAGCTCCAGTAGTGTATTTCA } \\
\text { R: TTGAGCACTCTGCTTTATTCAA } \\
\text { P: } \\
\text { CGTATTGCTGTCTTTGACATGCA } \\
\text { GT }\end{array}$ & $\begin{array}{l}\text { Jørgensen } \\
\text { et al., } 2011\end{array}$ \\
\hline pa_ther & Microsporidian & $\begin{array}{l}\text { Paranucleo- } \\
\text { spora theridion }\end{array}$ & FJ59481 & $\begin{array}{l}\text { F: CGGACAGGGAGCATGGTATAG } \\
\text { R: GGTCCAGGTTGGGTCTTGAG } \\
\text { P: TTGGCGAAGAATGAAA }\end{array}$ & $\begin{array}{l}\text { Nylund } e t \\
\text { al., } 2010\end{array}$ \\
\hline pch_sal & Bacterium & $\begin{array}{l}\text { Ca. } \\
\text { Piscichlamydia } \\
\text { salmonisa }\end{array}$ & EU326495 & $\begin{array}{l}\text { F: TCACCCCCAGGCTGCTT } \\
\text { R: GAATTCCATTTCCCCCTCTTG } \\
\text { P: CAAAACTGCTAGACTAGAGT }\end{array}$ & $\begin{array}{l}\text { Nylund et } \\
\text { al., } 2008\end{array}$ \\
\hline pisck_sal & Bacterium & $\begin{array}{l}\text { Piscirickettsia } \\
\text { salmonis }\end{array}$ & U36943 & $\begin{array}{l}\text { F: TCTGGGAAGTGTGGCGATAGA } \\
\text { R: } \\
\text { TCCCGACCTACTCTTGTTTCATC } \\
\text { P: } \\
\text { TGATAGCCCCGTACACGAAACGG } \\
\text { CATA }\end{array}$ & $\begin{array}{l}\text { Corbeil et } \\
\text { al., } 2003\end{array}$ \\
\hline prv & Virus & Piscine reovirus & - & $\begin{array}{l}\text { F: } \\
\text { TGCTAACACTCCAGGAGTCATTG } \\
\text { R: TGAATCCGCTGCAGATGAGTA } \\
\text { P: CGCCGGTAGCTCT }\end{array}$ & $\begin{array}{l}\text { Wiik- } \\
\text { Nielsen et } \\
\text { al., } 2012\end{array}$ \\
\hline pspv & Virus & $\begin{array}{l}\text { Pacific salmon } \\
\text { parvovirus }\end{array}$ & - & $\begin{array}{l}\text { F: CCCTCAGGCTCCGATTTTTAT } \\
\text { R: } \\
\text { CGAAGACAACATGGAGGTGACA } \\
\text { P: CAATTGGAGGCAACTGTA }\end{array}$ & $\begin{array}{l}\text { Miller } \text { et } \\
\text { al., } 2016\end{array}$ \\
\hline re_sal & Bacterium & $\begin{array}{l}\text { Renibacterium } \\
\text { salmoninarum }\end{array}$ & AF123890 & $\begin{array}{l}\text { F: } \\
\text { CAACAGGGTGGTTATTCTGCTTT } \\
\text { C } \\
\text { R: } \\
\text { CTATAAGAGCCACCAGCTGCAA } \\
\text { P: CTCCAGCGCCGCAGGAGGAC }\end{array}$ & $\begin{array}{l}\text { Powell et } \\
\text { al., } 2005\end{array}$ \\
\hline reov & Virus & ReoVirus MGL & - & $\begin{array}{l}\text { F: AACTTTCGGCTTTCTGCTATGC } \\
\text { R: } \\
\text { GAGGACAAGGGTCTCCATCTGA } \\
\text { P: TTAATTGCGGTACTGCTC }\end{array}$ & $\begin{array}{l}\text { Miller } e t \\
\text { al., } 2016\end{array}$ \\
\hline rlo & Bacterium & $\begin{array}{l}\text { Rickettsia-like } \\
\text { organism }\end{array}$ & EU555284 & $\begin{array}{l}\text { F: GGCTCAACCCAAGAACTGCTT } \\
\text { R: GTGCAACAGCGTCAGTGACT }\end{array}$ & $\begin{array}{l}\text { Lloyd et } \\
\text { al., } 2011\end{array}$ \\
\hline
\end{tabular}




\begin{tabular}{|c|c|c|c|c|c|}
\hline & & & & $\begin{array}{l}\text { P: } \\
\text { CCCAGATAACCGCCTTCGCCTCC } \\
\text { G }\end{array}$ & \\
\hline sch & Bacterium & $\begin{array}{l}\mathrm{Ca} . \\
\text { Syngnamydia } \\
\text { salmonis }\end{array}$ & FJ897519 & $\begin{array}{l}\text { F: } \\
\text { GGGTAGCCCGATATCTTCAAAGT } \\
\text { R: CCCATGAGCCGCTCTCTCT } \\
\text { P: TCCTTCGGGACCTTAC }\end{array}$ & $\begin{array}{l}\text { Duesund et } \\
\text { al., } 2010\end{array}$ \\
\hline $\operatorname{sgp} x$ & Virus & Poxvirus & - & $\begin{array}{l}\text { F: } \\
\text { ATCCAAAATACGGAACATAAGC } \\
\text { AAT } \\
\text { R: CAACGACAAGGAGATCAACGC } \\
\text { P: CTCAGAAACTTCAAAGGA }\end{array}$ & $\begin{array}{l}\text { Miller et } \\
\text { al., } 2016\end{array}$ \\
\hline smallUK & Virus & $\begin{array}{l}\text { Small } \\
\text { Unknown } \\
\text { RNA virus }\end{array}$ & - & $\begin{array}{l}\text { F: } \\
\text { GTACCTAATTTAACTGGAACAGT } \\
\text { AGAC } \\
\text { R: } \\
\text { CGTTCAGTAACACAAGTATCCAA } \\
\text { A } \\
\text { P: } \\
\text { TGCAACAGGCAAGTGATATGCTT } \\
\text { GA }\end{array}$ & $\begin{array}{l}\text { Miller et } \\
\text { al., } 2016\end{array}$ \\
\hline sp_des & $\begin{array}{l}\text { Meso- } \\
\text { mycetozoea }\end{array}$ & $\begin{array}{l}\text { Sphaerothecum } \\
\text { destructuens }\end{array}$ & AY267346 & $\begin{array}{l}\text { F: } \\
\text { GGGTATCCTTCCTCTCGAAATTG } \\
\text { R: CCCAAACTCGACGCACACT } \\
\text { P: CGTGTGCGCTTAAT }\end{array}$ & $\begin{array}{l}\text { Miller et } \\
\text { al., } 2016\end{array}$ \\
\hline te_bry & Myxozoan & $\begin{array}{l}\text { Tetra- } \\
\text { capsuloides } \\
\text { Bryosalmonae }\end{array}$ & AF190669 & $\begin{array}{l}\text { F: } \\
\text { GCGAGATTTGTTGCATTTAAAAA } \\
\text { G } \\
\text { R: GCACATGCAGTGTCCAATCG } \\
\text { P: } \\
\text { CAAAATTGTGGAACCGTCCGACT } \\
\text { ACGA }\end{array}$ & $\begin{array}{l}\text { Bettge et } \\
a l ., 2009\end{array}$ \\
\hline te_mar & Bacterium & $\begin{array}{l}\text { Tenacibaculum } \\
\text { Maritimum }\end{array}$ & - & $\begin{array}{l}\text { F: } \\
\text { TGCCTTCTACAGAGGGATAGCC } \\
\text { R: } \\
\text { CTATCGTTGCCATGGTAAGCCG } \\
\text { P: CACTTTGGAATGGCATCG }\end{array}$ & $\begin{array}{l}\text { Fringuelli } \\
\text { et al., } 2012\end{array}$ \\
\hline toti & Virus & $\begin{array}{l}\text { Putative } \\
\text { Totiviridae }\end{array}$ & - & $\begin{array}{l}\text { F: TCTGCGCGCTGCACCTA } \\
\text { R: ATGCGGAGGAACTCACACACT } \\
\text { P: CAAGTGCTACACTGCG }\end{array}$ & $\begin{array}{l}\text { Gideon } \\
\text { Mordecai }\end{array}$ \\
\hline ven & Virus & $\begin{array}{l}\text { Viral } \\
\text { erythrocytic } \\
\text { necrosis virus }\end{array}$ & & $\begin{array}{l}\text { F: CGTAGGGCCCCAATAGTTTCT } \\
\text { R: } \\
\text { GGAGGAAATGCAGACAAGATTT } \\
\text { G }\end{array}$ & $\begin{array}{l}\text { Purcell et } \\
\text { al., } 2016\end{array}$ \\
\hline
\end{tabular}




\begin{tabular}{|c|c|c|c|c|c|}
\hline & & & & $\begin{array}{l}\text { P: } \\
\text { TCTTGCCGTTATTTCCAGCACCC } \\
\text { G }\end{array}$ & \\
\hline venv & Virus & $\begin{array}{l}\text { Viral } \\
\text { encephalopathy } \\
\text { and retinopathy } \\
\text { virus }\end{array}$ & AJ245641 & $\begin{array}{l}\text { F: TTCCAGCGATACGCTGTTGA } \\
\text { R: CACCGCCCGTGTTTGC } \\
\text { P: AAATTCAGCCAATGTGCCCC }\end{array}$ & $\begin{array}{l}\text { Korsnes et } \\
\text { al., } 2005\end{array}$ \\
\hline vhsv & Virus & $\begin{array}{l}\text { Viral } \\
\text { hemorrhagic } \\
\text { septicemia virus }\end{array}$ & Z93412 & $\begin{array}{l}\text { F: } \\
\text { AAACTCGCAGGATGTGTGCGTCC } \\
\text { R: } \\
\text { TCTGCGATCTCAGTCAGGATGAA } \\
\text { P: } \\
\text { TAGAGGGCCTTGGTGATCTTCTG }\end{array}$ & $\begin{array}{l}\text { Jonstrup et } \\
\text { al., } 2013\end{array}$ \\
\hline vi_ang & Bacterium & $\begin{array}{l}\text { Vibrio } \\
\text { anguillarum }\end{array}$ & L08012 & $\begin{array}{l}\text { F: } \\
\text { CCGTCATGCTATCTAGAGATGTA } \\
\text { TTTGA } \\
\text { R: CCATACGCAGCCAAAAATCA } \\
\text { P: } \\
\text { TCATTTCGACGAGCGTCTTGTTC } \\
\text { AGC }\end{array}$ & $\begin{array}{l}\text { Miller et } \\
\text { al., } 2016\end{array}$ \\
\hline vi_sal & Bacterium & $\begin{array}{l}\text { Aliivibrio } \\
\text { Salmonicida }\end{array}$ & AF452135 & $\begin{array}{l}\text { F: GTGTGATGACCGTTCCATATTT } \\
\text { R: } \\
\text { GCTATTGTCATCACTCTGTTTCTT } \\
\text { P: } \\
\text { TCGCTTCATGTTGTGTAATTAGG } \\
\text { AGCGA }\end{array}$ & $\begin{array}{l}\text { Miller et } \\
\text { al., } 2016\end{array}$ \\
\hline ye_ruc & Bacterium & Yersinia ruckeri & - & $\begin{array}{l}\text { F: TCCAGCACCAAATACGAAGG } \\
\text { R: ACATGGCAGAACGCAGAT } \\
\text { P: } \\
\text { AAGGCGGTTACTTCCCGGTTCCC }\end{array}$ & $\begin{array}{l}\text { Keeling et } \\
\text { al., } 2012\end{array}$ \\
\hline
\end{tabular}




\subsubsection{Statistical analyses}

All statistical analyses were performed using R statistical software (R Core Team, 2015). This study had a final dataset of 87 fish sampled over 3 years $(2015, \mathrm{~N}=17 ; 2017, \mathrm{~N}=31,2018$, $\mathrm{N}=39)$. I categorized fish by year $(2015,2017$, or 2018$)$ and by group ('live' fish in good condition destructively sampled, and 'dead' fish collected from Seton fence). This allowed me to assess differences in infectious agents between years, as well as between live and dead fish, in the Seton River. I investigated the impact of group (live vs dead fish) and year on the prevalence, diversity, and load of infectious agents in Gates Creek sockeye salmon. For each infectious agent assay I applied the analytically applied limit of detection (LOD) to the average Ct value (from duplicates) for each individual and each assay. This allowed categorization infectious agents as either present or absent for each individual. The limit of detection is defined as the estimated $\mathrm{Ct}$ number under which a given assay is expected to provide true positive results $95 \%$ of the time (Miller et al., 2016).

\section{Prevalence}

The prevalence of an infectious agent across a group was calculated by dividing the number of fish that tested positive for a given infectious agent, by the total number of fish sampled in that group. Multivariate analysis of variance (MANOVA) was used to compare the prevalence of common infectious agents between years and between live and dead fish. Only infectious agents with prevalence over $5 \%$ were chosen for this further analysis to avoid zero counts and unbalanced distributions of positive samples, as per Nekouei et al. (2019). Multiple pairwise comparisons were used to test for differences in prevalence between the three years of 
data (2015, 2017 and 2018) following statistically significant MANOVA results. Homogeneity of variance was tested using Levene's test. Where homogeneity of variance was not met, the Games-Howell post-hoc test was used to perform multiple pairwise comparisons.

\section{Diversity}

The diversity of pathogens in each fish was calculated by counting the number of positive infectious agent detections for each fish. I used a Poisson regression model to compare the diversity of infectious agents between both live and dead fish, and year.

\section{Load}

To compare the infectious agent burden between dead and live sockeye, I calculated the relative infection burden (RIB) for each individual as per Bass et al. (2019). RIB is calculated using the following formula:

$$
\sum_{i \in m}^{m} \frac{L i}{\operatorname{Lmaxi}}
$$

The RNA copy number of the i'th positively detected infectious agent (Li) is divided by the maximum RNA copy number within the population of fish sampled for that i'th infectious agent (Lmaxi). This is repeated for every infectious agent detected within the population of fish sampled, and all calculated values are then summed. RIB allows us to collapse all infectious agent load data for an individual into a single metric that represents the overall burden (loads) of infectious agents on an individual. I used generalized linear models (glms) to look for an effect 
of both group (dead vs live fish) and year on RIB. This model was tested used a two-way ANOVA followed by post-hoc comparison among treatment groups using emmeans() function with Tukey adjustment. RIB was log transformed for all analyses due to its long-tailed distribution.

As well as testing RIB, the RNA copy number of each infectious agent was also compared between years and between live and dead fish individually. I used MANOVA to compare the RNA copy number of each infectious agent between years and groups. RNA copy number was log transformed for all analyses. Multiple pairwise comparisons were used to test for differences in prevalence between the three years of data $(2015,2017$ and 2018) following statistically significant MANOVA results. Homogeneity of variance was tested using Levene's test. Where homogeneity of variance was not met, the Games-Howell post-hoc test was used to perform multiple pairwise comparisons.

\subsection{Results}

\subsubsection{Fraser River temperature experience}

In 2018, as summer-run sockeye migrated through the lower Fraser River past Hope, they likely experienced an average temperature of $20.1^{\circ} \mathrm{C}$. For this section of river, 2015 was a cooler year and fish likely experienced an average temperature of $19.4^{\circ} \mathrm{C}$. In 2017 , the coolest of the

three years, fish likely experienced an average temperature of $18.9^{\circ} \mathrm{C}$ as they migrated past Hope (Table 5.3). Temperatures around Texas Creek were more comparable among years. The warmest year was 2018 (average of $19.2^{\circ} \mathrm{C}$; Table 5.3), the coolest year was $2015\left(18.4^{\circ} \mathrm{C}\right.$ ) and 2017 was intermediate $\left(19.0^{\circ} \mathrm{C}\right)$. 
Table 5.3. Average, minimum, and maximum temperatures $\left({ }^{\circ} \mathrm{C}\right)$ estimated to be experienced by Gates Creek sockeye salmon sampled as part of this study in 2015, 2017, and 2018. Temperatures are estimated at two temperature loggers placed in the Fraser River.

\begin{tabular}{|c|c|c|c|}
\hline \multicolumn{4}{|c|}{ Fraser River at Hope } \\
\hline & $\begin{array}{c}\text { Average temperature } \\
\left({ }^{\circ} \mathrm{C}\right)\end{array}$ & $\begin{array}{c}\text { Minimum } \\
\text { temperature }\left({ }^{\circ} \mathrm{C}\right)\end{array}$ & $\begin{array}{c}\text { Maximum } \\
\text { temperature }\left({ }^{\circ} \mathrm{C}\right)\end{array}$ \\
\hline 2015 & 19.4 & 19.0 & 19.8 \\
\hline 2017 & 18.9 & 17.4 & 20.0 \\
\hline 2018 & 20.1 & 18.5 & 20.7 \\
\hline \multicolumn{4}{|c|}{ Fraser River at Texas Creek } \\
\hline & $\begin{array}{c}\text { Average temperature } \\
\left({ }^{\circ} \mathrm{C}\right)\end{array}$ & $\begin{array}{c}\text { Minimum } \\
\text { temperature }\left({ }^{\circ} \mathrm{C}\right)\end{array}$ & $\begin{array}{c}\text { Maximum } \\
\text { temperature }\left({ }^{\circ} \mathrm{C}\right)\end{array}$ \\
\hline 2015 & 18.4 & 17.1 & 19.1 \\
\hline 2017 & 19.0 & 17.2 & 20.1 \\
\hline 2018 & 19.2 & 17.4 & 20.4 \\
\hline
\end{tabular}




\subsubsection{Prevalence}

Three infectious agents differed in prevalence between live and dead fish (Table 5.4; Fig. 5.1). The bacterium, Aeromonas salmonicida, was significantly more prevalent in dead fish compared with live fish $(\mathrm{p}=0.0050)$. In total, $19.1 \%$ of dead fish and $1.8 \%$ of live fish were infected with $A$. salmonicida, when averaged over the 3 years of sampling. Dermocystidium salmonis also differed significantly in prevalence in dead vs live fish $(\mathrm{p}=0.033) ; 30.0 \%$ of live fish were infected with $D$. salmonis, whereas only $6.4 \%$ of dead fish were infected when averaged over the years. Finally, Flavobacterium psychrophilum also differed significantly in prevalence between live and dead fish $(\mathrm{p}=0.023)$, where $50.3 \%$ of live fish and $23.2 \%$ of dead fish were found to be infected by this bacterium when averaged over the years.

Significant differences in the prevalence six infectious agents were also observed between years (Table 5.4; Fig. 5.1). The prevalence of D. salmonis was significantly higher in $2015(41.2 \%)$ compared with $2017(3.2 \% ; p=0.021)$ when averaged over both dead and live fish. The prevalence of $F$. psychrophilum was significantly lower in 2018 (10.3\%) compared with $2017(61.3 \% ; p=<0.00001)$ when averaged over both dead and live fish. The prevalence of Aeromonas salmonicida was significantly higher in 2018 (25.6\%) compared with 2017 (0\%; $\mathrm{p}=0.002)$. The prevalence of Ceratomyxa shasta was significantly higher in $2018(100 \%)$ compared with 2017 (80.6\%; $\mathrm{p}=0.031)$. The prevalence of Paranucleospora theridion was also significantly higher in 2018 (41.0\%) compared with 2017 (3.2\%; p =0.00017). Finally, the prevalence of Loma salmonae was significantly lower in 2018 (43.6 \%) compared with 2017 $(77.4 \% ; p=0.009)$ 
Table 5.4. MANOVA results comparing infectious agent prevalence and load (RNA copy numbers) between live and dead fish (condition) and among years. Significant findings ( $\mathrm{p}<$ 0.05 ) are boldened.

\begin{tabular}{|c|c|c|c|c|c|c|c|c|c|c|c|c|}
\hline & \multicolumn{6}{|c|}{ Prevalence } & \multicolumn{6}{|c|}{ Load (RNA copy numbers) } \\
\hline & \multicolumn{3}{|c|}{ Condition } & \multicolumn{3}{|c|}{ Year } & \multicolumn{3}{|c|}{ Condition } & \multicolumn{3}{|c|}{ Year } \\
\hline & $\mathrm{df}$ & $\mathrm{F}$ & $\mathrm{p}$ & df & $\mathrm{F}$ & $\mathrm{p}$ & df & $\mathrm{F}$ & $\mathrm{p}$ & df & $\mathrm{F}$ & $\mathrm{p}$ \\
\hline $\begin{array}{c}A . \\
\text { salmonicida }\end{array}$ & 85 & 8.3 & 0.005 & 84 & 6.18 & 0.0031 & 85 & 1.93 & 0.17 & 84 & 1.25 & 0.29 \\
\hline cysticola & 85 & 0.0049 & 0.94 & 84 & 1.9 & 0.16 & 85 & 0.64 & 0.43 & 84 & 0.48 & 0.62 \\
\hline C. shasta & 85 & 1.17 & 0.28 & 84 & 4.77 & 0.011 & 85 & 1.11 & 0.3 & 84 & 5.4 & 0.0062 \\
\hline $\begin{array}{c}\text { D. salmonis } \\
\text { F. }\end{array}$ & 85 & 4.7 & 0.033 & 84 & 11.23 & 0.000047 & 85 & 0.57 & 0.45 & 84 & 0.17 & 0.85 \\
\hline psychrophilum & 85 & 5.38 & 0.0023 & 84 & 12.77 & 0.000014 & 85 & 1.63 & 0.0012 & 84 & 1.24 & 0.3 \\
\hline I. hoferei & - & - & - & - & - & - & 85 & 0.93 & 0.34 & 84 & 0.9 & 0.41 \\
\hline I. multifiliis & 85 & 0.64 & 0.42 & 84 & 0.41 & 0.67 & 85 & 1.03 & 0.31 & 84 & 0.56 & 0.57 \\
\hline K. thyrsites & 85 & 0.3 & 0.58 & 84 & 1.54 & 0.22 & 85 & 0.67 & 0.42 & 84 & 1.98 & 0.14 \\
\hline Lo. salmonae & 85 & 0.15 & 0.7 & 84 & 4.51 & 0.014 & 85 & 1.45 & 0.23 & 84 & 1.14 & 0.32 \\
\hline $\begin{array}{c}\text { P. kabatai } \\
P .\end{array}$ & - & - & - & - & - & - & 85 & 1.56 & 0.21 & 84 & 1.52 & 0.22 \\
\hline minibicornis & 85 & 1.07 & 0.3 & 84 & 2.11 & 0.13 & 85 & 6.39 & 0.013 & 84 & 1.76 & 0.18 \\
\hline P. theridion & 85 & 1.42 & 0.24 & 84 & 8.25 & 0.00054 & 85 & 0.021 & 0.89 & 84 & 0.28 & 0.75 \\
\hline $\begin{array}{l}\text { Pacific salmon } \\
\text { parvovirus } \\
\text { Rickettsia-like }\end{array}$ & 85 & 0.23 & 0.63 & 84 & 1.23 & 0.3 & 85 & 0.76 & 0.38 & 84 & 0.59 & 0.56 \\
\hline $\begin{array}{c}\text { organism } \\
\text { S. }\end{array}$ & - & - & - & - & - & - & 85 & 1.85 & 0.18 & 84 & 1.21 & 0.3 \\
\hline $\begin{array}{c}\text { destructuens } \\
T .\end{array}$ & - & - & - & - & - & - & 85 & 2.2 & 0.14 & 84 & 1.86 & 0.16 \\
\hline Bryosalmonae & 85 & 0.088 & 0.77 & 84 & 0.43 & 0.65 & 85 & 0.58 & 0.45 & 84 & 0.65 & 0.53 \\
\hline
\end{tabular}



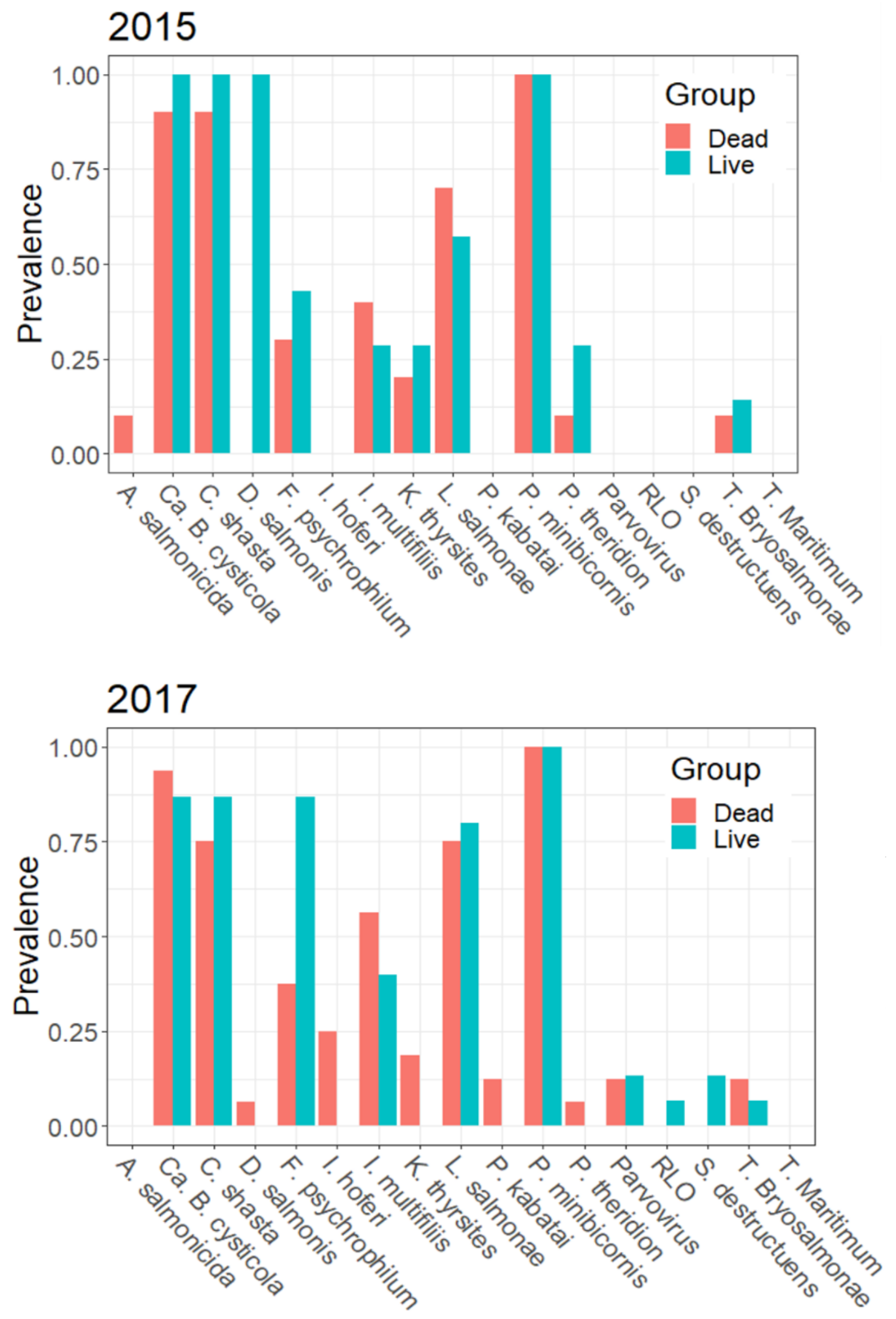


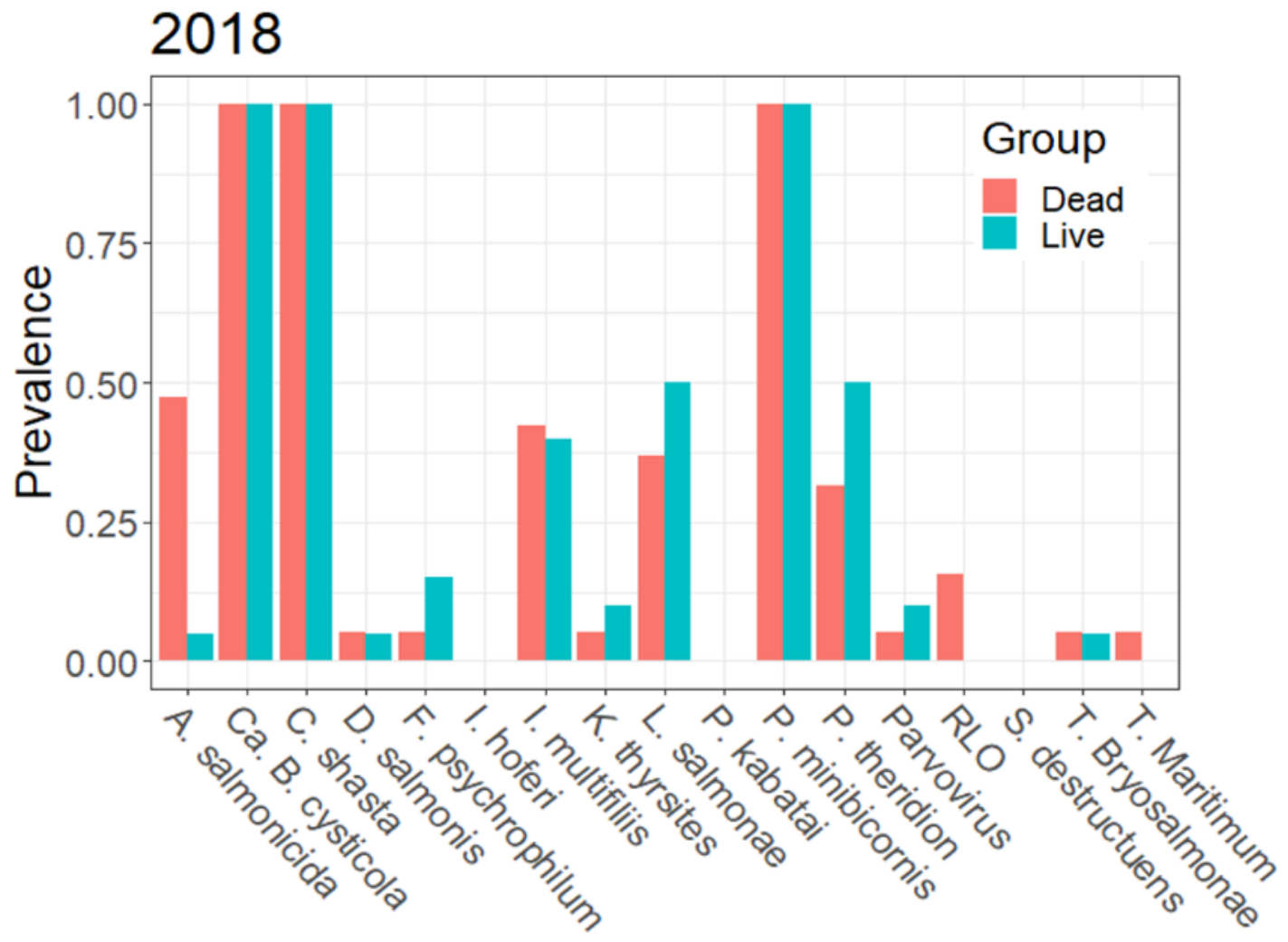

Figure 5.1. Infectious agent prevalence ( $\%$ of total fish sampled that tested positive for each infectious agent) during each study year. Prevalence of each infectious agent in both dead (red bars) and live (blue bars) sampled fish.

\subsubsection{Diversity}

The diversity of infectious agents detected in each fish was calculated by counting all positive infectious agents detected per individual. Poisson regression models tested the effect of both group (dead vs live; $\mathrm{p}=0.837)$ and year $(\mathrm{p}=0.554)$ on the diversity of infectious agents per individual, and I found no significant effect of either factor. 
Loads (RNA copy numbers) of Ceratomyxa shasta differed significantly among years. Loads of C. shasta were significantly higher in 2018 (31,356 RNA copies/fish) compared with 2015 (572 RNA copies/fish; $p=0.019$ ) and 2017 (2387 RNA copies/fish; $p=0.010$; Figure 5.2A). Flavobacterium psychrophilum was present in higher loads in dead fish $(67,073$ RNA copies/fish) compared with live fish (106 RNA copies/fish; $p=0.0012$; Table 5.4; Fig. 5.2B). Parvicapsula minibicornis was also present in significantly higher loads in dead fish (400,292 RNA copies/fish) compared with live fish (24,027 RNA copies/fish; $p=0.013$; Table 5.4; Fig. $5.2 \mathrm{C})$.

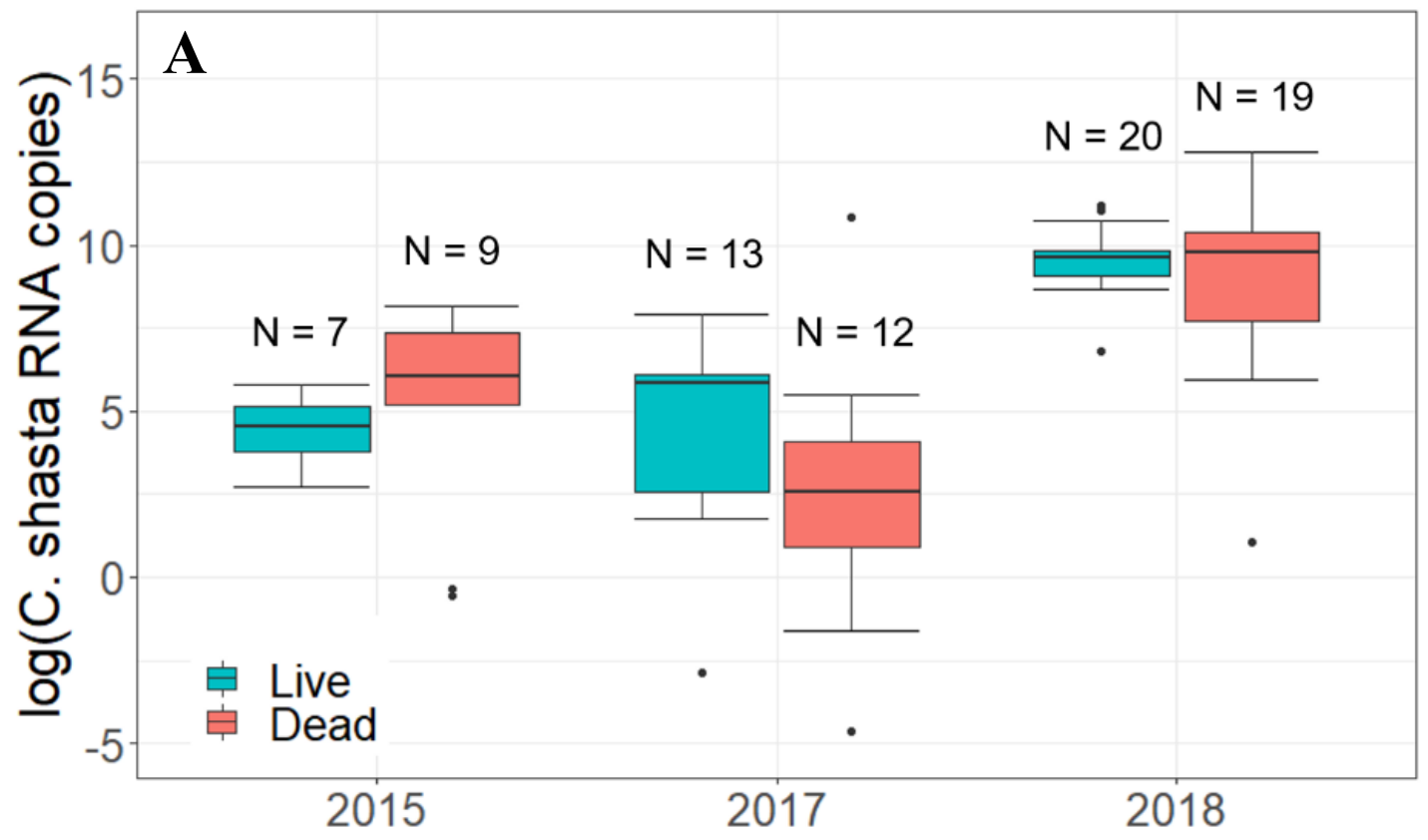



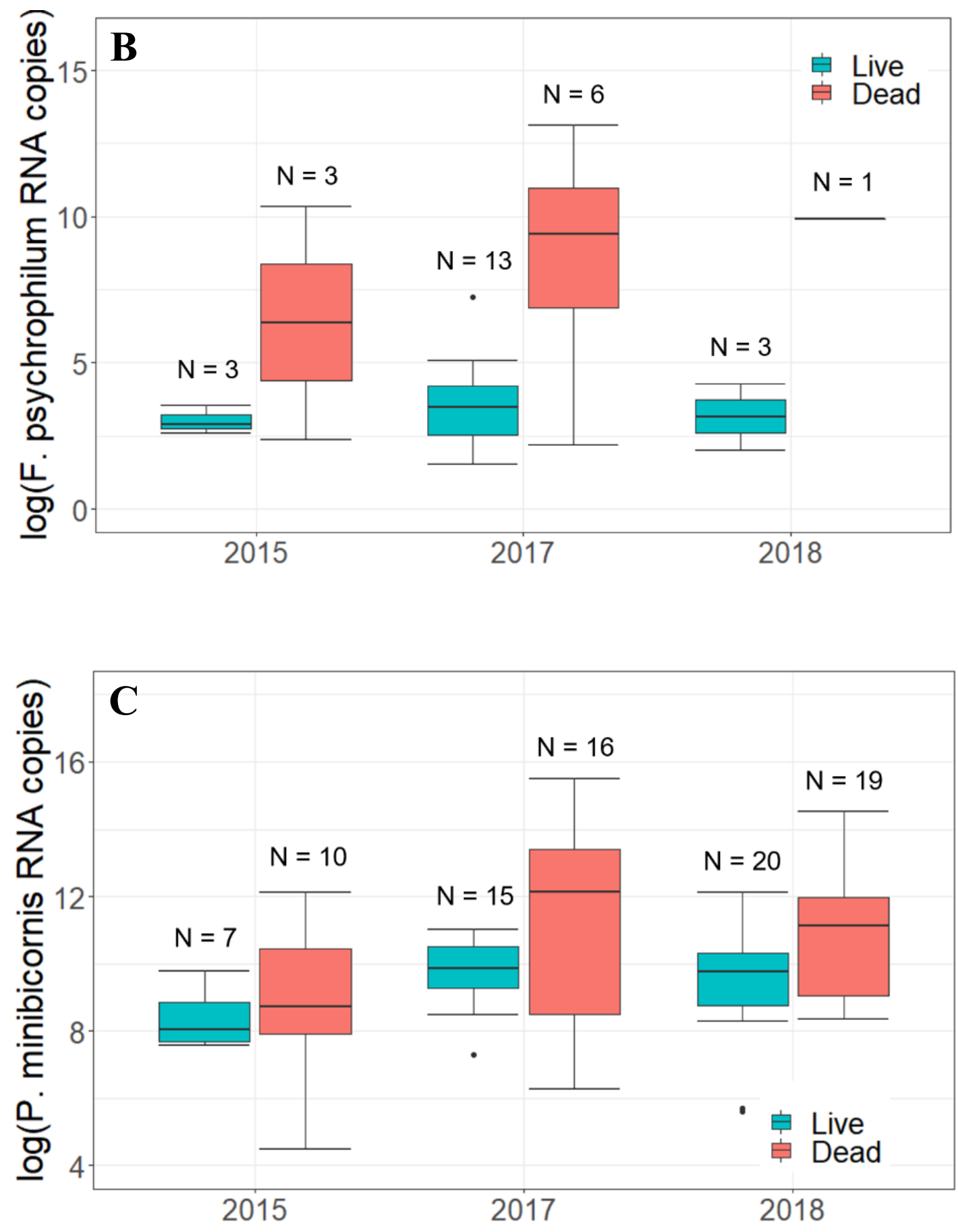

Figure 5.2. RNA copy numbers of (A) Ceratomyxa shasta, (B) Flavobacterium psychrophilum and (C) Parvicapsula minibicornis. RNA copy numbers are compared between live and dead sampled fish in each year. For each boxplot, the thicker black line indicates the median, the upper and lower box limits represent the first and third quartiles, the whiskers represent 1.5 times the inter-quartile range, and the points represent outliers. 
I found RIB to be significantly higher in fish during $2018(\mathrm{glm}, \beta=1.47, \mathrm{SE}=0.60 . \mathrm{df}=$ $86, p=0.048)$ when averaged over both live and dead sampled fish. Further, in 2018, there is a significant difference in RIB between live and dead fish $(\mathrm{glm}, \beta=1.01, \mathrm{SE}=0.46, \mathrm{df}=38, \mathrm{p}=$ 0.032), where in $2015(\mathrm{glm}, \beta=0.24, \mathrm{SE}=0.87, \mathrm{df}=30, \mathrm{p}=0.53)$ and $2017(\mathrm{glm}, \beta=-0.81$, SE $=1.28, \mathrm{df}=16, \mathrm{p}=0.78) \mathrm{I}$ did not find any difference between live and dead fish (Fig. 5.3).

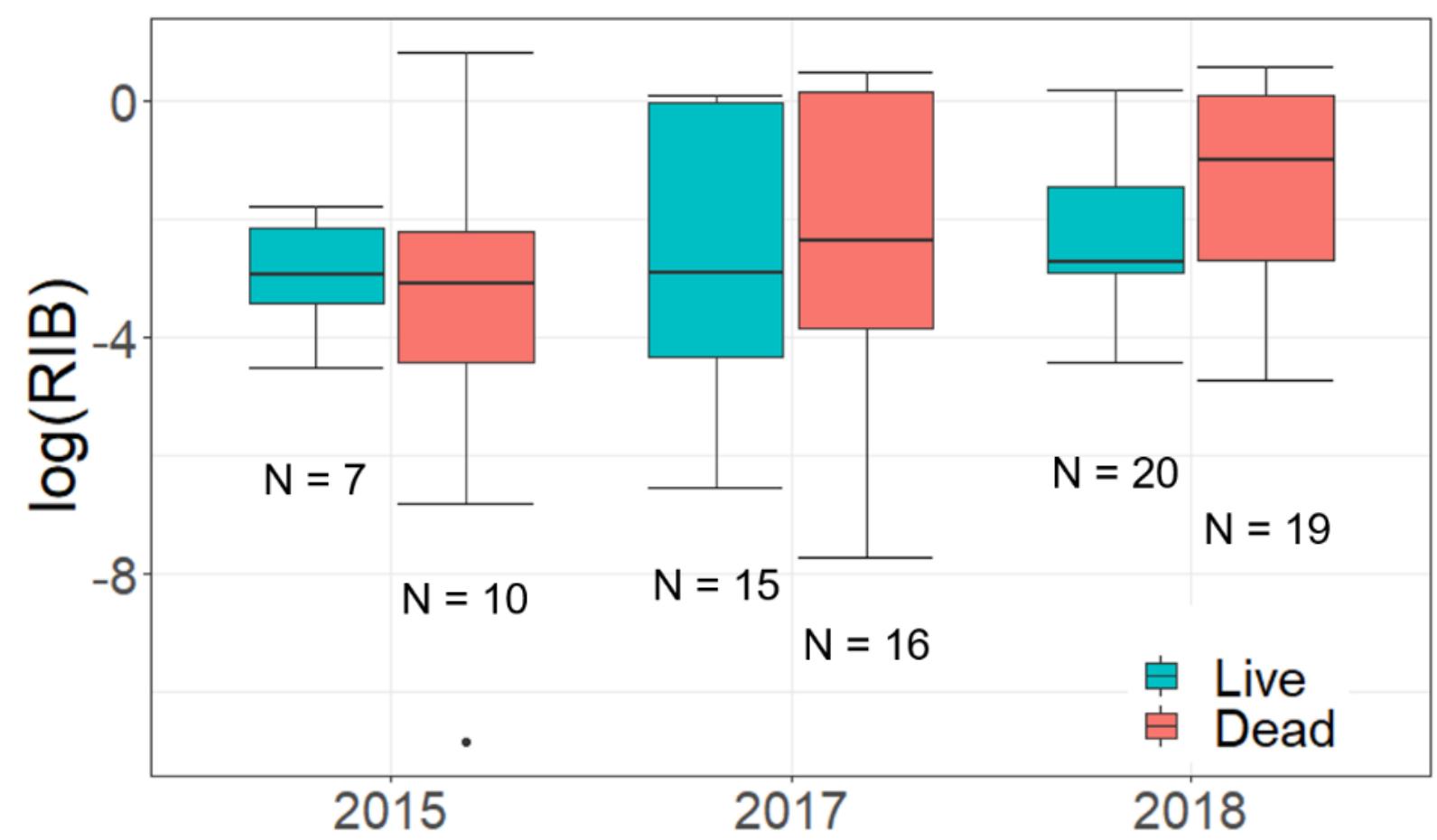

Figure 5.3. Relative infection burden (RIB) compared between live and dead sampled fish over three years. RIB was significantly higher in fish during $2018(\mathrm{p}=0.048)$. RIB also differed significantly between live and dead fish in 2018 only; dead fish had significantly higher RIB compared with live fish $(p=0.027)$. For each boxplot, the thicker black line indicates the median, the upper and lower box limits represent the first and third quartiles, the whiskers represent 1.5 times the inter-quartile range, and the points represent outliers. 


\subsection{Discussion}

I present a unique assessment of how infectious agents might affect the fitness of wild animals, with ultimate consequences for migration survival. Constructing a river-spanning fishing fence on the Seton River provided a rare opportunity to collect recently deceased sockeye salmon that perished in the tailrace of Seton Dam. Using high-throughput qPCR technology, I was able to investigate the prevalence, diversity, and load of infectious agents in fish that died en-route compared with infectious agent profiles in live fish at the same location over three years (2015-2018). Supporting my initial hypothesis, I found that two infectious agents differed in prevalence, and another two agents differed in load (RNA copy numbers) between live and dead fish. The bacterium Aeromonas salmonicida was more prevalent in dead fish compared with live fish, but the parasite Dermocystidium salmonis was more prevalent in live fish (in only 2015). The bacterium Flavobacterium psychrophilum and the myxozoan parasite Parvicapsula minibicornis were both found to be present in higher loads (RNA copy numbers) in dead fish compared with live fish, suggesting potential implications of these infectious agents in reducing fitness, and contributing to en-route mortality for wild Pacific salmon. As sampling took place over three years, I also investigated the interannual variation in infectious agent profiles, where differences may be a result of different Fraser River thermal profiles between these years. I found differences in the prevalence of D. salmonis and F. psychrophilum, and differences in the average loads of Candidatus Branchiomonas cysticola, Ceratomyxa shasta and Parvicapsula minibicornis between these years. Collectively, these results suggest that infectious agents may be important factors reducing the fitness of Pacific salmon species and weakening their ability to navigate challenging hydraulic river sections, such as dam tailraces. Environmental conditions in 
a given year, such as water temperature, are also likely capable of altering infectious agent profiles which, in turn, may have consequences for overall population fitness of migratory fish.

\section{Variation in the loads of infectious agents}

The myxozoan parasite Parvicapsula minibicornis was present in higher loads (RNA copy numbers) in dead fish compared with live fish. This parasite is endemic to the Fraser River (Jones et al., 2003) and requires a freshwater polychaete intermediate host that releases actinospores into the water that subsequently infect salmonids (Bartholomew et al., 2006). $P$. minibicornis has previously been associated with pre-spawn mortality for sockeye salmon (Bradford et al., 2010; St Hilaire et al., 2012) and Kent (2011) deemed this parasite to be of high risk to Fraser River sockeye. It is therefore possible that higher loads of P. minibicornis are contributing to the mortalities at Seton Dam collected and sampled in this study. Further, Wagner et al. (2005) found that when sockeye salmon were infected with P. minibicornis, high loads were associated with decreased prolonged swimming performance and impaired recovery from exhaustive exercise. Previous research on Gates Creek sockeye at Seton Dam has revealed that these fish require burst swimming and exhaustive exercise to navigate the tailrace of the dam and ascend the vertical slot fish ladder (Burnett et al., 2014). The authors also found that burst swimming, exhaustive behaviours were associated with increased risk of mortality for these fish. In the present study, I found that those fish that perished downstream of Seton dam had higher loads of $P$. minibicornis. Consequences of decreased swimming performance for fish with high P. minibicornis loads (Wagner et al., 2005) may therefore reduce the ability of these fish to pass Seton dam, thus contributing to mortality. 
I also found $P$. minibicornis to differ in load between years. This parasite was present in lower loads in 2015 compared with both 2017 and 2018. P. minibicornis has been shown to develop faster at warmer water temperatures and has been associated with accumulated degree days for migrating salmon (Wagner et al., 2005). Differences in load of P. minibicornis among years may therefore be a result of temperature or migration rates (water flow) for these fish. With 2018 being the warmest of the three years, we might expect to see highest loads of $P$.

minibicornis in this year. For Pacific salmon, load of $P$. minibicornis is also dependent on the dosage of actinospores in the environment, and thus the load of this infectious agent can be related to (a) the number of actinospores in the water and (b) the swimming speed of the fish (i.e. the slower a fish swims through the lower sections of the Fraser River, where P. minibicornis actinospores are most prevalent, the greater the infection the fish is likely to obtain). There are a number of factors, aside from temperature, that can influence infectious agent load in a given year. However, from this study alone it is not possible to explain why load might be lower in 2015 compared with other years.

Flavobacterium psychrophilum loads were higher in dead fish compared with live fish. This bacterium is the aetiological agent of Bacterial Coldwater Disease (Roberts, 2012) and is considered an opportunistic infectious agent of moderate risk to Fraser River sockeye salmon (Kent, 2011). F. psychrophilum has been shown to increase in prevalence as salmon approach spawning grounds (Miller et al., 2014; Bass et al., 2017). Teffer et al. (2017) found that sockeye salmon that died sooner in a holding study had higher loads of F. psychrophilum and Ceratomyxa shasta, and that these infectious agents were positively associated with indicators of stress and injury as well as weakened immune responses and osmoregulatory impairment in these dying fish. The authors speculate that increased loads of $F$. psychrophilum may result from 
this opportunistic bacterium infecting compromised fish, and further contributes to mortality. In the present study, I found that $F$. psychrophilum loads were higher in fish that died at Seton dam compared with live fish, providing further indication that this bacterium may be involved in reduced fitness and premature mortality in Pacific salmon. I also note that the majority of dead fish we sampled at Seton Dam showed signs of previous injury, most often severe. These injured fish are therefore severely compromised and thus may allow for the opportunistic bacterium $F$. psychrophilum to invade and further accelerate mortality.

Finally, to assess the impacts of infectious agent burden on the fitness of wild Pacific salmon, I calculated relative infection burden (RIB) which allowed me to collapse all infectious agent load data into a single metric that represents the overall burden of infectious agents for each fish. RIB was greatest for fish in 2018, and this was also the only year I found a difference in RIB between live and dead fish. This result is interesting because 2018 was the warmest of the three sampling years, and average temperatures likely experienced by these fish surpassed $20^{\circ} \mathrm{C}$ in the lower Fraser River. Water temperature is a critical environmental variable that can not only compromise host immune responses (Dominguez et al., 2004; Magnadottir et al., 1999), but can also alter infectious agent virulence, replication rates and development (Marcogliese, 2008; Ray et al., 2012; Chiaramonte, 2013). For example, loads of C. shasta were higher in 2018 compared with other years, which is likely a result of increased water temperatures which has been shown to increase the replication of this parasite (Chiaramonte, 2013) and can result in higher host mortality at these elevated temperatures (Ray et al., 2012). Although I did not find any other infectious agents to be present in higher loads in 2018 compared with other years, I did find infectious agents such as $\mathrm{Ca}$. B. cysticola and $R L O$ to be present in higher loads in 2018 (but not significant), and calculating RIB allows us to look at smaller, combined differences in loads 
of all infectious agents for individuals. I speculate that my finding that RIB was higher for dead fish only in 2018 was a function of increased water temperature in this year, which had consequences of increased development and replication of certain infectious agents, and thus ultimate consequences decreasing fitness of certain individuals in this year.

\section{Variation in the prevalence of infectious agents}

The prevalence of Aeromonas salmonicida and Dermocystidium salmonis differed between live and dead fish sampled below Seton Dam. A. salmonicida was more prevalent in dead fish (19.1\%) compared with live fish (1.8\%) across all years. This bacterium causes furunculosis, an acute, severe disease that can result in high mortality and was thus deemed high risk to Fraser River sockeye salmon (Evelyn et al., 1998; Hiney and Oliver, 1999; Kent 2011). A. salmonicida has been detected in hatcheries (Woo et al., 2011) and marine netpens (Kent et al., 1992; Evelyn et al., 1998) where close contact between fish likely accelerates transmission of this infectious agent. Here, I found A. salmonicida to be more prevalent in wild sockeye salmon that died en-route to spawning grounds compared with live fish, which suggests that this bacterium may be a threat to the fitness and survival of wild Pacific salmon, as well as reared salmon. However, more research is needed to examine the threat of $A$. salmonicida to wild Pacific salmon, and the effects of this bacterium on fish behaviour and survival should be assessed through challenge studies.

D. salmonis is a mesomycetozoean parasite known to infect the gills of salmonids (Davis 1947; Olson et al., 1991; Olson and Holt, 1995). This parasite has been associated with prespawn mortality in adult salmon (Pauley, 1967; Allen et al., 1968; Hoskins et al., 1976). 
Interestingly in this study, $100 \%$ of live fish sampled in 2015 were positive for $D$. salmonis whereas $0 \%$ of dead fish were positive for this parasite. Further, in 2017 and 2018, the prevalence of $D$. salmonis in both live and dead fish was very low and did not differ between live and dead fish. Olson et al. (1991) observed that juvenile pink salmon (Oncorhynchus gorbuscha) were capable of shedding $D$. salmonis and able to recover from infection. Outbreaks of this microparasite may therefore occur in certain temporal windows where they infect fish, develop in the fish, and are then shed as a mechanism of transmission or to complete their life cycle. Olson et al. (1991) also reported that $D$. salmonis has a free-swimming life-stage, and this stage is infective to salmon, which supports the theory of microparasite shedding from salmonid hosts to complete its life cycle. Bass (unpublished data) also found that during multiple sampling events of sockeye salmon on the Thompson River, BC, D. salmonis was present in initial sampling events, but absent in some subsequent sampling events. Again, this supports the theory that this microparasite may have temporal windows where it infects salmonids. In the present study, sampling of live fish in each year took place on a single day, whereas dead fish were sampled over a period of approximately 3 weeks. It is therefore possible that in 2015 , live fish were sampled during a period of D. salmonis infection in these fish, whereas in 2017 and 2018 live fish were sampled when $D$. salmonis had been shed from fish.

The prevalence of $F$. psychrophilum was lower in 2018 (10.1\% of all fish were positive for this bacterium) compared with both 2017 (61.8 \%) and 2015 (38.3 \%). F. psychrophilum is the aetiological agent of bacterial Coldwater Disease (Roberts, 2012) and this bacterium is typically associated with cooler water as it shows greater virulence at temperatures below $16^{\circ} \mathrm{C}$ (Starliper, 2011). Previous research has shown that optimal growth of this bacterium occurs between $15-16^{\circ} \mathrm{C}$ (Starliper, 2011; Bernardet and Bowman, 2006), however it is capable of 
growing from at least $4-20{ }^{\circ} \mathrm{C}$ (Hesami et al., 2011). For F. psychrophilum, warmer temperatures are therefore associated with hindered growth and reduced virulence. In the present study I found F. psychrophilum to be significantly less prevalent in 2018, which was the warmest of the three sampling years and temperatures in the lower Fraser surpassed $20^{\circ} \mathrm{C}$ for Pacific salmon during this time period. These warm temperatures in 2018 therefore had potential to reduce growth and development of $F$. psychrophilum compared with other years, thus resulting in reduced infection and prevalence in salmonids.

\section{Study limitations}

A major limitation to this study is that due to the destructive sampling of 'live' fish captured at Seton fence, it is not known if they would have successfully survived to pass Seton Dam. Destructive sampling was necessary in order to get more complete and accurate infectious agent profiles for each fish; some infectious agents are only detected in organs other than the gill, and thus non-destructive gill sampling would miss these infectious agents and result in false negatives (see Teffer et al., 2017 for a comparison between gill and pooled organ tissues for detecting infectious agents). In this study I made the assumption that live sampled fish would have successfully migrated to pass Seton Dam, had they been released. Live fish were selected as fish in seemingly 'great' condition (i.e. they had no visible wounds, $<5 \%$ total body scale loss, and healthy red gills with no visible cysts). From previous research at Seton fish fence, dam passage is usually very high (>95\%) since improved dam flow conditions were put into effect in 2014 (Casselman et al., 2016; Harrower et al., 2019). Those fish that did not successfully pass Seton Dam were typically observed to have severe wounds or were compromised in some way. When I calculated dam passage success in 2017 including only fish in 'great' condition (i.e. no 
wounds at all), dam passage was as high as $99 \%$. Due to such high dam passage success and observations of severe wounds hindering dam passage, I therefore assumed that good condition fish captured at Seton fish fence would have survived to pass Seton Dam.

I also acknowledge that detecting the presence of infectious agents is not indicative of disease. Many infectious agents can exist as 'carrier states', meaning they do not compromise their host or cause disease. It is therefore not known if fish sampled in this study are in active disease states, nor if the infectious agent detected in a tissue is viable and actively replicating (Purcell et al., 2013). There is a need to differentiate fish in carrier states from active disease states to demonstrate the impacts of infectious agents in wild populations (Miller et al., 2014, 2017). Future work should merge qPCR detection of infectious agent RNA biomarkers with host histopathology, gene expression analysis, and molecular monitoring to determine if fish are compromised or diseased by the presence and load of infectious agents (Miller et al., 2014). For example, Di Cicco et al. (2018) used histopathology to determine disease following Piscine orthoreovirus (PRV) infection through observations of inflammatory lesions in heart and skeletal muscle tissues indicative of heart and skeletal muscle inflammation (HSMI) disease. Host gene expression can also reveal disease or compromised states resulting from infection. For example, Miller et al. (2017) developed a biomarker panel [viral disease detection (VDD) panel] capable of distinguishing fish in active viral disease states from those in viral carrier states. In this study I used qPCR to determine the presence and load of 47 infectious agents in these sockeye salmon, but I did not take any additional measures to analyze fish for disease states. The detection of infectious agents is still valuable, and this study has revealed interesting differences in the prevalence and loads of moderate- and high-risk infectious agents between live and dead fish. In many cases sick fish that are diseased or compromised will likely die before they can be 
sampled, and damage at the cellular level that characterizes different diseases can be difficult to resolve using histology (Miller et al., 2014). This study is unique in that the construction of a river-spanning fish fence below Seton Dam provides a rare opportunity to collect and sample moribund, or recently deceased, fish that die during migration. I reveal that there are differences in infectious agent prevalence and load, and overall burden, between live and deceased fish, and it is likely that these infections are contributing to mortality in some way. This information may be important for guiding future research on the contributions of infectious agents to en-route mortality of Pacific salmon.

\subsection{Conclusions}

Variation in fitness is particularly prominent during large-scale migrations as some individuals succeed whereas others perish en-route. For Pacific salmon, migration is necessary for a one-time spawning event, and thus their lifetime fitness relies on successful spawning migrations. Pacific salmon populations are declining, and the role of infectious agents in reducing migratory fitness is suspected to be a major contributing factor to these declines (Altizer et al., 2011; Kent, 2011; Cohen, 2012; Miller et al., 2014). The role infectious agents might play in en-route mortality is often very difficult to study in the wild, as migrants that die are typically difficult to access and sample consistently. Construction of a river-spanning fish fence below Seton Dam provided a very rare opportunity to collect and sample animals that perish during large-scale migrations. This study site allowed me to investigate the potential role infectious agents might play in variation of individual fitness for Pacific salmon through comparing infectious agent profiles between those fish that perish, compared with live swimming fish. I found differences in the prevalence and loads of certain infectious agents 
between live and dead fish sampled on the Seton River. For dead fish, Aeromonas salmonicida was more prevalent, and Flavobacterium psychrophilum and Parvicapsula minibicornis were present in higher loads. These three infectious agents were all deemed moderate- or high risk to Fraser River sockeye by Kent (2011), and it is therefore plausible that these agents are contributing to mortality of fish below Seton Dam. However, more research is needed to confirm the role of these infectious agents in en-route mortality, and to determine how these agents compromise, and reduce fitness of their host. This study highlights three infectious agents that warrant further investigate into their effects on Pacific salmon fitness, and maybe population declines.

This study also revealed inter-annual variation in infectious agent profiles that I speculate is most likely a result of varying thermal profiles between years. In a warm year of Fraser River water temperatures, where temperatures were unusually sustained above $20{ }^{\circ} \mathrm{C}$, fish had higher overall relative infection burden (RIB), and this was the only year where dead fish were observed to have higher RIB when compared with live fish. This suggests that warm water temperature increases the development, replication, and virulence of various infectious agents, and this is having negative impacts reducing fitness of fish in that year. This may have more serious consequences as climate change continues. Warming water temperatures cause a suite of negative consequences for Pacific salmon, but water temperature is also a critical environmental factor for infectious agents. This study suggests that warming waters can increase RIB of Pacific salmon, and when RIB likely reaches a threshold, fitness of the fish is substantially reduced, and this can result in death. For some salmon populations, behavioural thermoregulation may be an important behaviour to reduce or mitigate the impacts of high RIB (Chapter 3), however not all salmon populations have access to thermal refuges along their migration routes. There is a 
complex interplay between water temperature and infectious agents for Pacific salmon, and

likely many more factors are impacting infectious agent prevalence, load, and virulence (such as injury, fisheries interaction stressors, etc.). 


\section{CHAPTER 6}

\section{Conclusion}

As Pacific salmon populations continue to decline, we must further our understanding of the stressors faced by these fish and the consequences they might have. In 2009, record low returns of sockeye salmon in the Fraser River triggered a national inquiry into causes behind these declines and recommendations for future management of the fishery (Cohen, 2012). However, since 2009 poor returns of sockeye salmon have continued, and in 2016 a new record low was reported for Fraser River sockeye, stressing a continued need to understand drivers of population declines. The Cohen Commission of Inquiry identified no "silver bullet" that was the cause of sockeye salmon declines, but speculated that climate change, infectious disease, predators, aquaculture, and fisheries were among the largest threats to wild salmon populations (Cohen, 2012). Cohen (2012) also stressed the importance of understanding the impacts of multiple, cumulative stressors and their combined consequences on salmon species. In this thesis. I aimed to further our understanding of three major stressors faced by Pacific salmon: fisheries interactions, temperature, and infectious agents. Specifically, I aimed to investigate the consequences of these stressors on migration behaviour (migration rate and behavioural thermoregulation), survival to spawning grounds, and spawning success for a population of Fraser River sockeye salmon. Further, I investigated the impacts of multiple, coinciding stressors (cumulative effects) for sockeye salmon, and how these three factors might impact each other (interactive effects) with ultimate consequences for the fish. 
All research for this thesis was conducted on the Seton River and targeted the Gates Creek sockeye salmon population. Fish were captured, sampled, and tracked in the wild, thus allowing an investigation into cumulative stressors that often impact Pacific salmon populations. Holding studies offer several advantages including controlled conditions and replication; however, field studies allow investigation of variation in fitness between individuals as it would occur in wild, natural environments where fish are most often facing multiple factors with complex cumulative and interactive effects. This thesis includes an investigation into the occurrence and consequences of fisheries escape (a stressor that is currently not considered in escapement estimate models; Chapters 2 and 3), and has also furthered our understanding of the impacts of high water temperature (Chapter 4) and infectious agents (Chapter 5) for Pacific salmon in the wild. Results from Chapter 2 revealed that gillnet escape is a common occurrence that is currently unaccounted for by fisheries managers in escapement estimates. For sockeye salmon that escape fishing gear in the Seton River, migration delay and behavioural thermoregulation were demonstrated, but no impacts on survival or spawning success were found. From Chapter 3, I found no effect of gear escape simulations on changing biomarkers expression or infectious agent profiles between escape and arrival at spawning grounds. However, I did find that both biomarker expression and infectious agent profiles change significantly over this $50 \mathrm{~km}$ migration segment. Attempts to investigate the impact of gillnet entanglement duration and subsequent escape were confounded by exceptionally high water temperatures in that year, leading to the development of Chapter 4 where survival, biomarker expression, and infectious agent profiles were compared between 'warm' and 'cool' years. This chapter emphasized the devastating impacts high water temperature can have for Pacific salmon as survival to spawning grounds was reduced from $78 \%$ in a cool year to $26 \%$ in a warm year 
where temperatures were sustained above $20^{\circ} \mathrm{C}$. In the warmer year, fish showed elevated expression of thermal stress biomarkers, as well as differences in the prevalence and load of certain infectious agents. The potential role of infectious agents in reducing fitness of Pacific salmon was investigated in Chapter 5, and differences in the prevalence and burden of certain high- or moderate risk infectious agents were found between sockeye salmon that perished enroute compared with live fish. I will discuss these findings further, and the importance of their implications, in the following sections.

\subsection{Consequences of fisheries escape for Pacific salmon}

Literature concerning the consequences and occurrence of fisheries escape, as opposed to by-catch or intentional release, is very limited (Patterson et al., 2017a). Recent research has estimated the occurrence of gillnet escape through observations of gillnet markings on sockeye salmon (Baker and Schindler, 2009; Bass et al., 2018a; Kanigan et al., 2019). However, these observational approaches make a strong assumption that fish with gillnet markings volitionally escaped, but in fact the previous experience of that fish is not known and the number of fish that perished before sampling locations is not accounted for, likely resulting in an underestimate of the number of fish that escape gillnets. Through experimental methods, this thesis has furthered our knowledge on both the occurrence (or frequency) at which gillnet escape might be occurring and the consequences of escape from three common fishing practices on adult sockeye salmon, and I highlight important areas needed for future research on fisheries escape. This initial investigation into the occurrence of gillnet escape for sockeye salmon (Chapter 2) revealed that $46.5 \%$ of fish that interacted with the net were observed to escape without human intervention. This category of fish (those that escape fishing gear) therefore likely represents a sizeable 
proportion of Pacific salmon in the Fraser River when fishing pressure is high, and these fish are overlooked by fisheries managers. Because fisheries escape and its consequences are not considered by fisheries managers, current escapement estimates may be overinflated due to potential unaccounted en-route and pre-spawn mortality of fish that volitionally escape gear (Baker and Schindler, 2009).

For fisheries managers to accurately account for gear escape, the consequences of escape need to be well understood. In Chapter 2, I investigated what consequences gear escape might have for sockeye salmon. Supporting my initial hypotheses, I found that following gear escape simulations fish showed increased migration duration to Gates Creek and demonstrated behavioural thermoregulation in Seton Lake (choosing to migrate at cooler temperatures through the lake hypolimnion). Migration delay and behavioural thermoregulation can be indications of stress and need for recovery from exhaustion or injury for Pacific salmon (Lee et al., 2003; Newell and Quinn, 2005; Bass, 2018). Behavioural thermoregulation following fisheries interactions is a novel finding but is similar to that of Bass (2018) who observed fish with more severe gillnet injuries to migrate at cooler temperatures through lake systems. It is important to note that the lower Fraser River has very limited opportunities for thermal refuge (Donaldson et al., 2009), and survival might be reduced following gear escape (or any other gear interactions) if fish do not have access to thermal refuges. Future work investigating the benefits thermal refuge may have for improving survival of non-retention fish would be valuable, especially in an era of climate change and increasing water temperatures. Contrary to my hypotheses, I did not find any evidence of decreased survival to spawning grounds or decreased spawning success following gear escape (Chapter 2). However, it is known that survival of non-retention fish varies with salmon population (Donaldson et al., 2012) and location of capture (and thus maturation status of 
the fish; Bass et al., 2018b). As fish mature their skin thickens (Robertson and Wexler, 1960), scales reabsorb (Kacem et al., 1998), and blood cortisol levels increase (Baker and Vynne, 2014), which likely makes them more resilient to fisheries interactions, and thus survival of more mature non-retention fish is higher (Bass et al., 2018b). Because Gates Creek sockeye have completed approximately $88 \%$ of their total freshwater migration upon entering the Seton River, their advanced maturation status likely increases their resilience to fisheries interactions, and thus survival following gear escape simulations is expected to be higher than for sockeye salmon in the lower Fraser River. I recommend that investigations into the effects of gear escape be repeated at different locations in the lower Fraser River, and I predict that survival following escape would be lower in these locations.

Fisheries interactions have the potential to leave non-retention fish more vulnerable to opportunistic infectious agents and disease through either injury or stress-induced compromised immune function allowing invasion of infectious agents (Pickering and Pottinger, 1989; Svendsen and Bøgwald, 1997; Tort, 2011; Mateus et al., 2017). To study the potential interactive effects of fisheries interactions on infectious agents following escape, I examined changes in infectious agent prevalence and loads between Seton fish fence and Gates Creek spawning channel for fish that experienced gear escape simulations compared with control fish (Chapter 3). The Seton System is unique in that two fish fences can be constructed (the first on the Seton River and the second on spawning grounds at Gates Creek) and I was able to recapture and resample tagged fish at the Gates Creek fish fence. I hypothesized that gear escape would alter infectious agent profiles compared with fish that did not interact with any fishing gear, and specifically the escapees would show increased prevalence and burden of certain infectious agents. However, I found no evidence to support this hypothesis. I also hypothesized that gear 
escape simulations would result in differential biomarker expression compared with control fish, but again I found no evidence to support this. However, I did find that both biomarker expression and infectious agent profiles changed for all fish as they migrated from the Seton River to Gates Creek spawning grounds. Specifically, thermal biomarker expression decreased between Seton River and Gates Creek, likely due to Seton and Anderson Lakes providing thermal refuge for the majority of the migration between these two sites. Viral disease development (VDD) biomarkers increased in expression between Seton River and Gates Creek. Further research is needed to determine why VDD biomarker expression changes, but as I detected no known viruses in any fish in that year, these biomarkers expression changes may be a result of altered immune function and increased maturation and senescence as fish approach spawning grounds (Dolan et al., 2016).

\subsection{High water temperature is a critical environmental factor during Pacific salmon spawning migrations}

This thesis provides further evidence demonstrating the critical role of temperature on the survival of Pacific salmon during spawning migrations (Fry, 1971; Cooke et al., 2004; Martins et al., 2011, 2012; Hinch et al., 2012; Eliason et al., 2013). Furthering our knowledge on the consequences of high water temperature, I observed differences in biomarker expression and infectious agent profiles in years of varying temperatures. This highlights the effects of water temperature directly on both Pacific salmon survival and gene expression, and indirectly through effects on infectious agent prevalence and load. Attempts to investigate the consequences of gillnet entanglement duration in 2018 were unsuccessful due to exceptionally high mortality. In 2018, survival to spawning grounds of Gates Creek sockeye for control-tagged fish was as low as 
$26 \%$, and I found no difference in survival between control fish and fish that experienced gillnet entanglement. I hypothesized that longer entanglement durations would result in decreased survival to spawning grounds, supported by previous research demonstrating the severe consequences of longer entanglement duration on survival (Teffer et al., 2017). In this study, some fish experienced $20-32$ minutes of gillnet entanglement, yet there were still no differences in survival between these treatment fish and control fish, and survival of all fish was extraordinarily low. This result indicates that high water temperatures can confound the impacts of even severe fisheries interactions, and temperature can be considered a 'master' factor in determining the survival of wild Pacific salmon (Brett, 1971).

My finding of $26 \%$ survival to spawning grounds in 2018 is incredibly low compared to previous years of research on the Seton River; survival of control-tagged fish was $73-86 \%$ between 2014-2017 (Casselman et al., 2016; Harrower et al., 2019; Chapter 2). Large-scale mortality events have previously been attributed to high water temperatures (Cooke et al., 2004; Hinch et al, 2012), and characterization of 2018 thermal experience in the Fraser River migration corridor revealed high temperatures that exceed the thermal optima range of Gates Creek sockeye $\left(>20^{\circ} \mathrm{C}\right.$; Chapter 4; Eliason et al., 2013). The high mortality observed in 2018 is therefore likely a function of high water temperature. Characterization of thermal experience of fish tagged in 2017 revealed average temperatures in the lower Fraser River to be below $19^{\circ} \mathrm{C}$, and thus within the thermal optima window for Gates Creek sockeye (Eliason et al., 2013). I was therefore able to make interesting comparisons between biomarker expression and infectious agent profiles between two years with differences in thermal profiles that were ecologically relevant. In a year of warm water temperatures, fish had elevated expression of thermal biomarkers, thus confirming thermal stress (Akbarzadeh et al., 2018; Houde et al., 2019). Water 
temperature is also a critical environmental factor for infectious agents as their virulence, replication rates, and development are all temperature-dependent (Marcogliese, 2008; Ray et al., 2012; Chiaramonte, 2013). I therefore hypothesized that infectious agent profiles would differ between years of varying water temperature. My results from Chapter 3 supported this hypothesis, as various infectious agents differed in either prevalence or load in the warmer vs cooler year. The consequences of high water temperature on Pacific salmon are complex, and both direct effects of temperature on fish physiology and indirect effects of temperature on fish through altering infectious agent development and virulence must be considered. High water temperature has many severe, negative impacts on Pacific salmon, and affects fish from multiple angles, with sometimes devasting impacts of mortality (Cooke et al., 2004; Martins et al., 2011, 2012; Hinch et al., 2012; Chapter 4).

\subsection{Infectious agents contributing to en-route mortality of Pacific salmon}

Infectious agents have been identified as a potential factor contributing to Pacific salmon en-route mortality and population declines, however this is often difficult to investigate and thus less is known (Altizer et al., 2011; Cohen, 2012; Miller et al., 2014). In this thesis I report that infectious agent profiles differed between live fish and those that died en-route below Seton Dam (Chapter 5), thus supporting my initial hypothesis. I also observed interannual variation in infectious agent profiles, likely as a consequence of water temperature (Chapters 4 and 5). Kent (2011) reviewed infectious diseases and their potential to impact survival of Fraser River sockeye, and in this report certain infectious agents were deemed high- or moderate risk to these fish. When comparing live fish to those that died en-route at Seton Dam, two infectious agents deemed as high risk, Aeromonas salmonicida and Parvicapsula minibicornis, were present in 
higher prevalence and loads, respectively, in dead fish compared with live fish (Chapter 5).

Flavobacterium psychrophilum, a bacterium deemed to be of moderate risk by Kent (2011), was also present in higher loads in dead fish compared with live fish (Chapter 5). Results from this chapter support the potential risk of these infectious agents in contributing to en-route mortality of Pacific salmon, however further research is needed to confirm this, and to determine the exact effects of these infectious agents on their host that might contribute to mortality (e.g. if fish are in active disease states resulting from these infections).

Research in this thesis also demonstrates interannual variation in infectious agent profiles (Chapters 4 and 5). In both Chapters 4 and 5, Ceratomyxa shasta was present in higher loads in warmer years compared with cooler years, a result that complements previous research showing that this myxozoan parasite replicates faster at warmer temperatures (Chiaramonte, 2013). I found no evidence that this parasite was contributing to mortality of sockeye salmon in this thesis, however previous work has suggested that $C$. shasta can impact survival of Pacific salmon in certain locations (Fujiwara et al., 2011; Ray et al., 2012). Flavobacterium psychrophilum, a bacterium associated with Coldwater Disease (Starliper, 2011; Robert, 2012), shows greater virulence at temperatures below $16{ }^{\circ} \mathrm{C}$ (Starliper, 2011). Supporting this, $F$. psychrophilum was detected in lower prevalence in cooler years of Fraser River water temperatures compared with warmer years (Chapters 4 and 5). Other infectious agents such as Paranucleospora theridion, Ichthyophthirius multifiliis, Candidatus Branchiomonas cysticola, and Parvicapsula minibicornis also demonstrated interannual variation in either prevalence or load. I speculate that these interannual differences in infectious agent profiles are largely a function of water temperature, however this is not confirmed and there are likely other factors that are also affecting infectious agent prevalence and loads in a given year. 
Behavioural thermoregulation may be important for improving survival of fish with high infectious agent burdens (Chapter 3). I found that fish with higher relative infection burdens (RIB) migrated at cooler temperatures through both Seton and Anderson lakes compared to fish with lower RIB, a behavioural adaptation likely to reduce temperature-mediated effects on infectious agent development and replication. Previous work has reported increased survival of Weaver Creek sockeye salmon that migrated at cooler temperatures in Harrison Lake, and the authors speculated that this increased survival was likely due to slowed development of Parvicapsula minibicornis at cooler temperatures (Mathes et al., 2009). In Chapter 3, I found that cooler migration was not associated with the prevalence or load of any singular infectious agent, but instead was associated with overall RIB, a calculated metric that sums all of the infectious agents and their loads in a given fish. In Chapter 5, I observed higher RIB in a warmer water temperature year, and in this warm year dead fish had higher RIB compared to live fish. Temperature is known to impact all infectious agents, and for a majority of Pacific salmon infectious agents, higher water temperatures are usually associated with faster development and replication to a certain extent (Noe and Dickerson, 1995; Crossin et al., 2008; Marcogliese, 2008; Bettge et al., 2009; Ray et al., 2012; Chiaramonte, 2013). Warming water temperature may therefore be increasing RIB in fish (Chapter 5), and thermal refuges might be increasingly important for improving survival or recovery for fish with high infectious agent burden (Chapter 2), in addition to providing refuge from certain infectious agents (Chiaramonte et al., 2016). 


\subsection{Recommendations for future research}

Before fisheries managers can accurately account for fishing gear escape in escapement estimates, further research is needed. I investigated the frequency of sockeye salmon escape from gillnets and observed nearly half of all fish that interacted with the net were capable of volitional escape. Similar experiments are now needed to determine the frequency of sockeye escape from different gear types (tangle nets, seine nets, etc.), and to determine the frequency of escape of other salmon species from these gear types. Gillnets can vary in their mesh sizing depending on the target species (i.e. Chinook gillnets typically require a larger mesh size compared to sockeye gillnets). Mesh sizing is likely an important factor in determining the frequency of escape for different salmon species (i.e. smaller-bodied sockeye or coho salmon may be more likely to escape from a larger mesh Chinook gillnet), and it is therefore important for future research to consider escape under varying mesh sizes on a species-specific basis. If future research can provide escape estimates on a species-, gear type-, and mesh-type basis, escapement estimates would be more accurate.

The consequences of gear escape also need to be further studied as fisheries escape has rarely been considered for Pacific salmon. First, gear escape needs to be studied in different locations, and with different salmon populations. Although I did not find an effect of gear escape on survival or spawning success, other studies found that sockeye salmon with gillnet markings (thus assumed escapees) showed reduced survival or spawning success (Baker and Schindler, 2009; Bass et al., 2018a; Kanigan et al., 2019). Upon entering the Seton River, Gates Creek sockeye salmon are of more advanced maturation and have opportunities for thermal refuge following gear interactions, which likely improves their resilience and survival to these gear interactions. I therefore recommend that similar experiments on the effects of gear escape for 
survival and spawning success to be repeated in sections of the lower Fraser River, and I would expect to see more severe consequences of escape. Second, gear escape should also be considered for non-target salmon species. In this thesis I focused on escape of target species from common fishing gears. However, non-target species are also capable of escape (and due to sizeselective fisheries may even be more capable of volitional escape). The consequences and occurrence of fisheries interactions for non-target species has been well researched in the context of by-catch (Raby et al., 2015; Patterson et al., 2017a), however they have not been considered in the context of escape. Third, the consequences of entanglement duration before escape need to be researched. In Chapter 2, I attempted to investigate this, however high water temperature confounded my results from this study and thus I was unable to make any conclusions. Overall, this thesis presents novel and early research into the consequences of gear escape; however, this is a large subject area with many variables and contributing factors that need to be investigated and considered in future research. Gear escape is likely an underappreciated occurrence in fisheries worldwide, and fisheries management would benefit from increased research efforts across the globe.

This thesis also reports the novel findings of behavioural thermoregulation in response to fisheries interactions and high relative infection burden (RIB). Behavioural thermoregulation is being increasingly recognised for its benefits to salmonid survival (Newell and Quinn, 2005; Mathes et al., 2009; Keefer and Caudill, 2015), spawning success (Minke-Martin et al., 2018), injury and stress recovery (Bass, 2018; Chapter 2), and mitigating infection (Mathes et al., 2009; Chiaramonte, 2013; Chiaramonte et al., 2016; Chapter 3). As climate change persists, thermal refuges may be increasingly important for improving survival of salmon population. I therefore highlight the importance of further understanding the benefits of behavioural thermoregulation, 
and specifically investigating the extent to which behavioural thermoregulation might improve survival following fisheries stressors or infection compared with fish that can not thermoregulate. Climate change is warming waters across the planet, and researchers across the globe should also research and consider the benefits behavioural thermoregulation may have for all fish species.

Finally, in Chapter 5 I reported three infectious agents to be present in higher prevalence or loads in sockeye that died en-route to spawning grounds compared with live fish. Aeromonas salmonicida and Parvicapsula minibicornis have been determined high-risk to Fraser River sockeye, and Flavobacterium psychrophilum has been recognised as a moderate risk (Kent, 2011). Based on these findings, further investigation into potential effects that compromise the fitness of Pacific salmon, and their contribution to en-route mortality (and potentially to overall population declines) is warranted. I recommend that future research include challenge studies of these three infectious agents to assess the consequences of infection and to confirm if these agents compromise the host at higher prevalence/load, or if fish are merely in carrier states. Infectious agents have been suggested to impact animal migrations (Altizer et al., 2011), however they are difficult to study and thus less is known (Miller et al., 2014). The Seton system provided a rare opportunity to consistently collect and sample migrant mortalities in the wild, and this allowed me to find potentially important differences in infectious agent prevalence and loads between live fish and those that perish en-route to spawning grounds. 


\subsection{Management implications}

Pacific salmon are capable of escaping from fishing gears, and I found nearly half of all sockeye salmon in an experimental gillnet simulation were capable of volitional escape. This supports previous studies that estimated gillnet escapement from observations of gillnet markings (Baker and Schindler, 2009; Bass et al., 2018a; Kanigan et al., 2019), and suggests that gear escape is a frequent event that is currently not considered in escapement estimate models. The frequency and consequences of escape from various fishing gears needs to be incorporated into escapement estimates on a location- and population-specific basis. Currently, escapement estimates are likely an over-estimation because they do not consider gear escape. From this thesis I cannot provide an estimation as to how over-inflated current escapement estimates might be, however Baker and Schindler (2009) suggest that escapement counts may be overestimated by $5-15 \%$ in Bristol Bay, Alaska. Such overestimation may have negative repercussions for the accuracy of stock-recruitment analyses and overall population trends of Pacific salmon.

Temperature is a master ecological factor that can confound the results of fisheries interaction simulations (Brett, 1971; Gale et al., 2013; Chapter 2) and result in massive mortality events (Cooke et al., 2004; Chapter 4). In years of high water temperatures, fish are likely suffering with the physiological impacts of warm water, as well as reductions in aerobic scope, and higher prevalence and loads of certain infectious agents. High temperatures can cause a suite of negative impacts for Pacific salmon with sometimes devastating consequences when high temperatures are sustained for longer periods. Climate change is causing more unpredictable weather and water temperatures continue to rise. Managers should therefore further consider water temperature during in-season management adjustments. In periods of high water temperature $\left(>20^{\circ} \mathrm{C}\right.$ or even $\left.>19^{\circ} \mathrm{C}\right)$ may be necessary, such as in-season fisheries closures. 
Because of the severe consequences of high water temperature (Chapter 4; Cooke et al., 2004; Martins et al., 2011, 2012), as well as novel evidence that Gates Creek sockeye salmon exhibit behavioural thermoregulation following fisheries gear escape (Chapter 2) and in response to higher RIB (Chapter 3), this thesis emphasizes the importance of thermal refuges for the survival of adult Pacific salmon during spawning migrations. Previous work has also found thermal refuges have improved survival of Pacific salmon (Newell and Quinn, 2005; Mathes et al., 2009; Keefer and Caudill, 2015). In an era of climate change and increasing water temperatures, thermal refuges may become increasingly important and should be protected to improve survival of salmon in freshwater. Recently, Oregon Department of Fish \& Wildlife recognized the importance of thermal refuges for wild salmon and steelhead and will establish 'Thermal Angling Sanctuaries' on the Columbia River and associated Oregon tributaries. These sanctuaries will prohibit angling in important thermal refuges during the warmest summer months, allowing fish to hold in these cold water refuges and hopefully improve survival and spawning success for Columbia River salmonids. Fisheries managers in Canada should also consider protecting important thermal refuges (for example by establishing no-angling sanctuaries at these locations) or preventing high fishing efforts in locations without thermal refuges in years of higher water temperatures. 


\subsection{Conclusions}

Animal migrations are threatened by overexploitation, barriers to migration routes, and climate change (Wilcove and Wikelski, 2008), and these disturbances to migratory patterns may subsequently impact migrant-infectious agent dynamics (Altizer et al., 2011). If we are to protect declining migrant populations across the globe, we must fully understand the consequences of these stressors to improve conservation and management efforts. Fisheries interactions, warm water temperatures, dams, and infectious agents are all important stressors faced by Pacific salmon during spawning migrations. The intensity of these stressors can fluctuate from year-toyear, and importantly these factors have varying interactive and cumulative effects for fish in the wild. Research from this thesis not only confirms many of the negative impacts that fisheries interactions, water temperature, and infectious agents can have during Pacific salmon spawning migrations, but also reports novel findings concerning fisheries escape, behavioural thermoregulation, genomic and infectious agent changes during migration, and variations in infectious agent profiles in different years and salmon en-route mortalities. This thesis provides the first direct studies on the consequences and occurrence of gear escape for Pacific salmon spawning migrations, a stressor that needs to be further researched and considered in fisheries management. Fisheries by-catch has been well researched in many contexts and scenarios, and hopefully following from my preliminary investigations, fisheries escape will also receive similar research attention. High water temperature appears to be a 'master' factor impacting survival of Pacific salmon, and warm water temperatures confound the effects of even severe fisheries interactions. Novel evidence of behavioural thermoregulation in response to fisheries interactions and high infection burden, in addition to a suite of previous research highlighting the positive impacts thermal refuge can have for salmon survival, emphasizes the importance of cool 
water refuges in an era of climate change and warming water temperatures. I also investigated the interactive impacts fisheries interactions, warm water temperatures, and en-route mortality can have for infectious agent profiles for Pacific salmon, and I found important differences in infectious agent prevalence and loads following these stressors. Finally, I discussed important future research directions and management implications arising from this research which I believe will greatly benefit Pacific salmon populations and be applicable to the conservation of animal migrations across the globe. 


\section{Bibliography}

Akbarzadeh A, Gunther OP, Houde AL, Li SR, Ming TJ, Jeffries KM, Hinch SG, Miller KM (2018) Developing specific molecular biomarkers for thermal stress in salmonids. BMC Genomics, 19. doi:10.1186/s12864-018-5108-9.

Allen RL, Meekin TK, Pauley GB, Fujihara MP (1968) Mortality among Chinook salmon associated with the fungus Dermocystidium. Journal of the Fisheries Board of Canada, $25: 2467-2475$.

Altizer S, Bartel R, Han BA (2011) Animal migration and infectious disease risk. Science, 33:296-302.

Alvarez-Pellitero P (2008) Fish immunity and parasite infections: from innate immunity to immunoprophylactic prospects. Veterinary Immunology and Immunopathology, 126:171198.

Ashbrook CE, Dixon JF, Hassel KW, Schwartz EA, Skalski JR (2008) Estimating bycatch survival in a mark-selective fishery. American Fisheries Society Symposium, 49:677.

Baker MR, Schindler DE (2009) Unaccounted mortality in salmon fisheries: non-retention in gillnets and effects on estimates of spawners. Journal of Applied Ecology, 46:752-761.

Baker MR, Vynne C (2014) Cortisol profiles in sockeye salmon: sample bias and baseline values at migration, maturation, spawning, and senescence. Fisheries Research, 154:38-43.

Baker MR, Swanson P, Young G (2013) Injuries from non-retention in gillnet fisheries suppress reproductive maturation in escaped fish. PloS ONE, 8: e69615. doi:

10.1371/journal.pone.0069615.

Baker MR, Schindler DE, Essington TE, Hilborn R (2014) Accounting for escape mortality in fisheries: implications for stock productivity and optimal management. Ecological Applications, 24:55-70. 
Bartholomew JL, Whipple MJ, Stevens DG, Fryer JL (1997) The life cycle of Ceratomyxa shasta, a myxosporean parasite of salmonids, requires a freshwater polychaete as an alternate host. The Journal of Parasitology, 83:859-868.

Bartholomew JL, Atkinson SD, Hallett SL (2006) Involvement of Manayunkia speciosa (Annelida: Polychaeta: Sabellidae) in the life cycle of Parvicapsula minibicornis, a myxozoan parasite of Pacific salmon. Journal of Parasitology, 92:742-748.

Barton BA (2002) Stress in fishes: a diversity of responses with particular reference to changes in circulating corticosteroids. Integrative and Comparative Biology, 42:517-525.

Barton BA, Iwama GK (1991) Physiological changes in fish from stress in aquaculture with emphasis on the response and effects of corticosteroids. Annual Review of Fish Diseases, 1:3-26.

Bass AL (2018) Fisheries gear and biological context drive fishing-related incidental mortality in Pacific salmon spawning migrations. PhD Thesis. University of British Columbia, Vancouver, BC, Canada.

Bass AL, Hinch SG, Teffer AK, Patterson DA, Miller KM (2017) A survey of microparasites present in adult migrating Chinook salmon (Oncorhynchus tshawytscha) in south-western British Columbia determined by high-throughput quantitative polymerase chain reaction. Journal of Fish Diseases, 40:453-477.

Bass AR, Hinch SG, Casselman MT, Bett NN, Burnett NJ, Middleton CT, Patterson DA (2018a) Visible gillnet injuries predict migration and spawning failure in adult sockeye salmon. Transactions of the American Fisheries Society, 147:1085-1099.

Bass AL, Hinch SG, Patterson DA, Cooke SJ, Farrell AP (2018b) Location-specific consequences of beach seine and gillnet capture on upriver-migrating sockeye salmon migration behavior and fate. Canadian Journal of Fisheries and Aquatic Sciences, 75:2011-2023.

Bass AL, Hinch SG, Teffer AK, Patterson DA, Miller KM (2019) Fisheries capture and infectious agents are associated with travel rate and survival of Chinook salmon during spawning migration. Fisheries Research, 209:156-166. 
Bates D, Machler M, Bolker BM, Walker SC (2015) Fitting linear mixed-effects models using lme4. Journal of Statistical Software, 67:1-48.

Bergmann S, Kempter J (2011) Detection of koi herpesvirus (khv) after re-activation in persistently infected common carp (Cyprinus carpio 1.) using non-lethal sampling methods. Bulletin of the European Association of Fish Pathology, 31:92-100.

Bernardet JF, Bowman JP (2006) The genus Flavobacterium. In: M Dworkin et al., eds. The Prokaryotes, Vol. 7. Springer-Verlag, New York, NY, pp 481-531.

Bett NB, Hinch SG, Bass AL, Braun DC, Burnett NJ, Casselman MT, Cooke SJ, Drenner SM, Gelchu A, Harrower WL, Ledoux R, Lotto AG, Middleton CT, Minke-Martin V, Patterson DA, Zhang W, Zhu DZ (2020) Using an integrative research approach to improve fish migrations in regulated rivers: a case study on Pacific salmon in the Fraser River, Canada. Hydrobiologia. In Press.

Bettge K, Wahli T, Segner H, Schmidt-Posthaus H (2009) Proliferative kidney disease in rainbow trout: time- and temperature-related renal pathology and parasite distribution. Diseases of Aquatic Organisms, 83:67-76.

Bradford MJ, Irvine JR (2000) Land use, fishing, climate change, and the decline of Thompson River, British Columbia, coho salmon. Canadian Journal of Fisheries and Aquatic Sciences, 57:13-16.

Bradford MJ, Lovy J, Patterson DA, Speare DJ, Bennett WR, Stobbart AR, Tovey CP (2010) Parvicapsula minibicornis infections in gill and kidney and the premature mortality of adult sockeye salmon (Oncorhynchus nerka) from Cultus Lake, British Columbia. Canadian Journal of Fisheries and Aquatic Sciences, 67:673-683.

Brannon EL (1987) Mechanisms stabilizing salmonid fry emergence timing. In: L Smith, L Margolis, and CC Wood, eds. Sockeye Salmon (Oncorhynchus nerka) Population Biology and Future Management. Canadian Special Publications of Fisheries and Aquatic Sciences, 96, pp. 120-124 
Brett JR (1971) Energetic responses of salmon to temperature. a study of some thermal relations in the physiology and freshwater ecology of sockeye salmon (Oncorhynchus nerka). American Zoologist, 11:99-113.

Brett JR (1995) Energetics. In: C Groot, L Margolis, and WC Clarke, eds. Physiological Ecology of Pacific Salmon. University of British Columbia Press, Vancouver, BC, pp. 1-68.

Broadhurst MK, Suuronen P, Hulme A (2006) Estimating collateral mortality from towed fishing gear. Fish and Fisheries, 7:180-218.

Broadhurst MK, Uhlmann SS, Millar RB (2008) Reducing discard mortality in an estuarine trawl fishery. Journal of Experimental Marine Biology and Ecology, 364:54-61.

Bruno DW, Wood BP (1999) Saprolegnia and other Oomycetes. In: PTK Woo, and DW Bruno, eds. Fish Diseases and Disorders, Vol 3. Viral, Bacterial and Fungal Infections. CABI International, UK, pp. 599-659.

Buchanan S, Farrell AP, Fraser J, Gallaugher P, Joy R, Routledge R (2002) Reducing gillnet mortality of incidentally caught coho salmon. North American Journal of Fisheries Management, 22:1270-1275.

Burgner RL (1991) Life history of sockeye salmon. In: C Groot, and L Margolis, eds. Pacific Salmon Life Histories. University of British Columbia Press, Vancouver, pp. 3-117.

Burnett NJ, Hinch SG, Braun DC, Casselman MT, Middleton CT, Wilson SM, Cooke SJ (2014) Burst swimming in areas of high flow: delayed consequences of anaerobiosis in wild adult sockeye salmon. Physiological and Biochemical Zoology, 87:587-598.

Casselman MT, Middleton CT, Minke-Martin V, Drenner SM, Bett NN, Burnett NJ, Braun DC, Hinch SG (2016) BRGMON-14 Effectiveness of Cayoosh Flow Dilution, Dam Operation, and Fishway Passage on Delay and Survival of Upstream Migration of Salmon in the Seton-Anderson Watershed. Annual Report - 2015. Report prepared for St'á t'imc Eco-Resources Ltd. and BC Hydro., The University of British Columbia, Vancouver, BC.

Caudill CC, Daigle WR, Keefer ML, Boggs CT, Jepson MA, Burke BJ, Zabel RW, Bjornn TC, Peery CA (2007) Slow dam passage in adult Columbia River salmonids associated with 
unsuccessful migration: delayed negative effects of passage obstacles or conditiondependent mortality? Canadian Journal of Fisheries and Aquatic Sciences, 64:979-995.

Chiaramonte LV (2013) Climate warming effects on the life cycle of the parasite Ceratomyxa shasta in salmon in the Pacific Northwest. Oregon State University, Corvallis, OR, USA. MSc thesis.

Chiaramonte LV, Ray RA, Corum RA, Soto T, Hallett SL, Bartholomew JL (2016) Klamath River thermal refuge provides juvenile salmon reduced exposure to the parasite Ceratonova shasta. Transactions of the American Fisheries Society, 145:810-820.

Chopin FS, Arimoto T (1995) The condition of fish escaping from fishing gears: a review. Fisheries Research, 21:315-327.

Clark TD, Jeffries KM, Hinch SG, Farrell AP (2011) Exceptional aerobic scope and cardiovascular performance of pink salmon (Oncorhynchus gorbuscha) may underlie resilience in a warming climate. Journal of Experimental Biology, 214:3074-3081.

Clarke WC, Hinch SG, Lapointe M, Williams IV, Bradford M (1994) Report of the en route mortality team, 1994 Fraser River investigation. Report prepared for the Fraser River Sockeye Public Review Board, Nanaimo, British Columbia.

Cohen B (2012) The uncertain future of Fraser River sockeye' in Final Report, Cohen Commission of Inquiry Into the Decline of Sockeye Salmon in the Fraser River (Canada). DFO Overview: Organization, Science, Policies.

Cooke SJ, Hinch SG, Farrell AP, Lapointe MF, Jones SRM, Macdonald JS, Patterson DA, Healey MC, Van der Kraak G (2004) Abnormal migration timing and high en route mortality of sockeye salmon in the Fraser River, British Columbia. Fisheries, 29:22-33.

Cooke SJ, Crossin GT, Patterson DA, English K, Hinch SG, Young JL, Alexander R, Healey MC, Van Der Kraak G, Farrell AP (2005) Coupling non-invasive physiological and energetic assessments with telemetry to understand inter-individual variation in behaviour and survivorship of sockeye salmon: development and validation of a technique. Journal of Fish Biology, 67:1342-1358. 
Cooke SJ, Hinch SG, Crossin GT, Patterson DA, English KK, Healey MC, Shrimpton JM, Van Der Kraak G, Farrell AP (2006) Mechanistic basis of individual mortality in Pacific salmon during spawning migrations. Ecology, 87:1575-1586.

Cooke SJ, Donaldson MR, O’Connor CM, Raby GD, Arlinghaus R, Danylchuk AJ, Hanson KC, Hinch SG, Clark TD, Patterson DA, Suski CD (2013) The physiological consequences of catch-and-release angling: perspectives on experimental design, interpretation, extrapolation, and relevance to stakeholders. Fisheries Management and Ecology, 20:268-287.

Corbeil S, McColl KA, Crane MSJ (2003) Development of a TaqMan quantitative PCR assay for the identification of Piscirickettsia salmonis. Bulletin of the European Association of Fish Pathologists, 23:95-101.

Crossin GT, Hinch SG, Cooke SJ, Welch DW, Patterson DA, Jones SRM, Lotto AG, Leggatt RA, Mathes MT, Shrimpton JM, Van der Kraak G, Farrell AP (2008) Exposure to high temperature influences the behaviour, physiology, and survival of sockeye salmon during spawning migration. Canadian Journal of Zoology, 86:127-140.

Crossin GT, Hinch SG, Cooke SJ, Cooperman MS, Patterson DA, Welch DW, Hanson KC, Olsson I, English KK, Farrell AP (2009) Mechanisms influencing the timing and success of reproductive migration in a capital breeding semelparous fish species, the sockeye salmon. Physiological and Biochemical Zoology, 82:635-652.

Davies RWD, Cripps SJ, Nickson A, Porter G (2009) Defining and estimating global marine fisheries bycatch. Marine Policy, 33:661-672.

Davis HS (1947) Studies of the protozoan parasites of freshwater fishes. Fishery Bulletin of the Fish and Wildlife Service, vol. 41, pp. 1-29.

Davis MW (2002) Key principles for understanding fish bycatch discard mortality. Canadian Journal of Fisheries and Aquatic Sciences, 59:1834-1843.

Deinet S, Scott-Gatty K, Rotton H, Twardek WM, Marconi V, McRae L, Baumgartner LJ, Brink K, Claussen JE, Cooke SJ, Darwall W, Eriksson BK, Garcia de Leaniz C, Hogan Z, Royte J, Silva LGM, Thieme ML, Tickner D, Waldman J, Wanningen H, Weyl OLF 
(2020) The Living Planet Index (LPI) for freshwater migratory fish - Technical Report. World Fish Migration Foundation, The Netherlands.

DFO (2019) Pacific Region Integrated Fisheries Management Plan, Salmon, Southern BC. Technical report.

Di Cicco E, Ferguson HW, Kaukinen KH, Schulze AD, Li SR, Tabata A, Gunther OP, Mordecai G, Suttle CA, Miller KM (2018) The same strain of Piscine orthoreovirus (PRV-1) is involved in the development of different, but related, diseases in Atlantic and Pacific Salmon in British Columbia. Facets, 3:599-641.

Dickerson B, Brinck K, Willson M, Bentzen P, Quinn T (2005) Relative importance of salmon body size and arrival time at breeding grounds to reproductive success. Ecology, 86:347352.

Dingle H (1996) Migration: The Biology of Life on the Move. New York, Oxford University Press.

Dingle H (2006) Animal migration: is there a common migratory syndrome? Journal of Ornithology, 147:212-220.

Dingle H, Drake VA (2007) What is migration? BioScience, 57:113-121.

Dittmar J, Janssen H, Kuske A, Kurtz J, Scharsack JP (2014) Heat and immunity: an experimental heat wave alters immune functions in three-spined sticklebacks (Gasterosteus aculeatus). Journal of Animal Ecology, 83:744-757.

Dolan BP, Fisher KM, Colvin ME, Benda SE, Peterson JT, Kent ML, Schreck CB (2016) Innate and adaptive immune responses in migrating spring-run adult Chinook salmon, Oncorhynchus tshawytscha. Fish and Shellfish Immunology, 48:136-144.

Dominguez M, Takemura A, Tsuchiya M, Nakamura S (2004) Impact of different environmental factors on the circulating immunoglobulin levels in the Nile tilapia, Oreochromis niloticus. Aquaculture, 241:491-500.

Donaldson MR, Cooke SJ, Patterson DA, Hinch SG, Robichaud D, Hanson KC, Olsson I, Crossin GT, English KK, Farrell AP (2009) Limited behavioural thermoregulation by 
adult upriver-migrating sockeye salmon (Oncorhynchus nerka) in the Lower Fraser River, British Columbia. Canadian Journal of Zoology, 87:480-490.

Donaldson MR, Hinch SG, Patterson DA, Farrell AP, Shrimpton JM, Miller KM, Robichaud D, Hills J, Hruska KA, Hanson KC, English KK, Van Der Kraak G, Cooke SJ (2010) Physiological condition differentially affects the behavior and survival of two populations of sockeye salmon during their freshwater spawning migration. Physiological and Biochemical Zoology, 83:446-458.

Donaldson MR, Hinch SG, Patterson DA, Hills J, Thomas JO, Cooke SJ, Raby GD, Thompson LA, Robichaud D, English KK, Farrell AP (2011) The consequences of angling, beach seining, and confinement on the physiology, post-release behaviour and survival of adult sockeye salmon during upriver migration. Fisheries Research, 108:133-141.

Donaldson MR, Hinch SG, Raby GD, Patterson DA, Farrell AP, Cooke SJ (2012) Populationspecific consequences of fisheries-related stressors on adult sockeye salmon. Physiological and Biochemical Zoology, 85:729-739.

Donaldson MR, Hinch SG, Jeffries KM, Patterson DA, Cooke SJ, Farrell AP, Miller KM (2014) Species- and sex-specific responses and recovery of wild, mature Pacific salmon to an exhaustive exercise and air exposure stressor. Comparative Biochemistry and Physiology - A Molecular and Integrative Physiology, 173:7-16.

Drenner SM, Hinch SG, Furey NB, Clark TD, Li SR, Ming TB, Jeffries KM, Patterson DA, Cooke SJ, Robichaud D, Welch DW, Farrell AP, Miller KM (2018) Transcriptome patterns and blood physiology associated with homing success of sockeye salmon during their final stage of marine migration. Canadian Journal of Fisheries and Aquatic Sciences, 75:1511-1524.

Duesund H, Nylund S, Watanabe K, Ottem KF, Nylund A (2010) Characterization of a VHS virus genotype III isolated from rainbow trout (Oncorhychus mykiss) at a marine site on the west coast of Norway. Virology Journal, 7:19.

Eiler JH, Masuda MM, Spencer TR, DriscollRJ, Schreck CB (2014) Distribution, stock composition and timing, and tagging response of wild Chinook salmon returning to a 
large, free-flowing river basin. Transactions of the American Fisheries Society, 143:1476-1507.

Eliason EJ, Clark TD, Hague MJ, Hanson LM, Gallagher ZS, Jeffries KM, Gale MK, Patterson DA, Hinch SG, Farrell AP (2011) Differences in thermal tolerance among sockeye salmon populations. Science, 332:109-112.

Eliason EJ, Clark TD, Hinch SG, Farrell AP (2013) Cardiorespiratory collapse at high temperature in swimming adult sockeye salmon. Conservation Physiology, 1:1-19.

Ellegren H, Sheldon BC (2008) Genetic basis of fitness differences in natural populations. Nature, 452:169-175.

Evans TG, Hammill E, Kaukinen K, Schulze AD, Patterson DA, English KK, Curtis JMR, Miller KM (2011) Transcriptomics of environmental acclimatization and survival in wild adult Pacific sockeye salmon (Oncorhynchus nerka) during spawning migration. Molecular Ecology, 20:4472-4489.

Evelyn TPT, Kent ML, Poppe TT (1998) Bacterial diseases. In: ML Kent, and TT Poppe, eds. Diseases of seawater netpen-reared salmonid fishes. Pacific Biological Station, Fisheries and Oceans Canada, Nanaimo, British Columbia, pp. 17-34.

Ewing MS, Lynn ME, Ewing SA (1986) Critical periods in development of Ichthyophthiriusmultifiliis (ciliophora) populations. Journal of Protozoology, 33:388-391.

Farrell AP, Hinch SG, Cooke SJ, Patterson DA, Crossin GT, Lapointe MF, Mathes MT (2008) Pacific salmon in hot water: applying aerobic scope models and biotelemetry to predict the success of spawning migrations. Physiological and Biochemical Zoology, 81:697708.

Fenkes M, Shiels HA, Fitzpatrick JL, Nudds RL (2016) The potential impacts of migratory difficulty, including warmer waters and altered flow conditions, on the reproductive success of salmonid fishes. Comparative Biochemistry and Physiology Part A: Molecular \& Integrative Physiology, 193:11-21.

Flores AM, Shrimpton JM, Patterson DA, Hills JA, Cooke SJ, Yada T, Moriyama S, Hinch SG, Farrell AP (2012) Physiological and molecular endocrine changes in maturing wild 
sockeye salmon, Oncorhynchus nerka, during ocean and river migration. Journal of Comparative Physiology B-Biochemical Systems and Environmental Physiology, 182:7790.

Folt CL, Chen CY, Moore MV, Burnaford J (1999) Synergism and antagonism among multiple stressors. Limnology and Oceanography, 44:864-877.

Frank HJ, Mather ME, Smith JM, Muth RM, Finn JT, McCormick SD (2009) What is "fallback"?: metrics needed to assess telemetry tag effects on anadromous fish behavior. Hydrobiologia, 635:237-249.

Freeman MA, Sommerville C (2011) Original observations of Desmozoon lepeophtherii, a microsporidian hyperparasite infecting the salmon louse Lepeophtheirus salmonis, and its subsequent detection by other researchers. Parasites \& Vectors, 4: 231. doi:10.1186/1756-3305-4-231.

Fringuelli E, Gordon AW, Rodger H, Welsh MD, Graham DA (2012) Detection of Neoparamoeba perurans by duplex quantitative taqman real-time PCR in formalin-fixed, paraffin-embedded atlantic salmonid gill tissues. Journal of Fish Diseases, 35:711-724.

Fry FEJ (1947) Effects of the environment on animal activity. Publications of the Ontario Fisheries Research Laboratory, 68:1-63.

Fry FEJ (1971) The effect of environmental factors on the physiology of fish. In: W Hoar, and D Randall, eds. Fish Physiology: Environmental Relations and Behaviour. Academic Press, New York, USA, pp. 1-98.

Funk VA, Raap M, Sojonky K, Jones S, Robinson J, Falkenberg C, Miller KM (2007) Development and validation of an RNA- and DNA-based quantitative PCR assay for determination of Kudoa thyrsites infection levels in Atlantic salmon Salmo salar. Diseases of Aquatic Organisms, 75:239-249.

Gale MK, Hinch SG, Eliason EJ, Cooke SJ, Patterson DA (2011) Physiological impairment of adult sockeye salmon in fresh water after simulated capture-and-release across a range of temperatures. Fisheries Research, 112:85-95. 
Gale MK, Hinch SG, Donaldson MR (2013) The role of temperature in the capture and release of fish. Fish and Fisheries, 14:1-33.

Gale MK, Hinch SG, Cooke SJ, Donaldson MR, Eliason EJ, Jeffries KM, Martins EG, Patterson DA (2014) Observable impairments predict mortality of captured and released sockeye salmon at various temperatures. Conservation Physiology, 2: cou029. doi:10.1093/conphys/cou029

Gilhousen P (1990) Prespawning mortalities of sockeye salmon in the Fraser River system and possible causal factors. IPFSC Bulletin, 26, $58 \mathrm{pp}$.

Gislason GS, Lam E, Knapp G, Guettabi M (2017). Economic impacts of Pacific salmon fisheries. Report prepared for Pacific Salmon Commission, 92 pp.

Goniea TM, Keefer ML, Bjornn TC, Peery CA, Bennett DH, Stuehrenberg LC (2006) Behavioral thermoregulation and slowed migration by adult fall Chinook salmon in response to high Columbia River water temperatures. Transactions of the American Fisheries Society, 135:408-419.

Grant SCH, Michielsens CGJ, MacDonald B (2016) Fraser River sockeye: abundance and productivity trends. In: PC Chandler, SA King, and RI Perry, eds. State of the Physical, Biological and Selected Fishery Resource Pacific Canadian Marine Ecosystems in 2014. Canadian Technical Report of Fisheries Aquatic Science, 3131. Fisheries and Oceans Canada, Ottawa, Ontario, pp. 172-176.

Grant SCH, MacDonald BL, Winston ML (2019) State of Canadian Pacific salmon: responses to changing climate and habitats. Canadian Technical Report of Fisheries and Aquatic Sciences. 3332. ix +50 pp.

Gratzek J (1993) Parasites associated with freshwater tropical fishes. In: M Stoskopf, eds. Fish Medicine. WB Saunders Company, New York, New York, pp. 573-601.

Groot C, Margolis L (1991) Pacific Salmon Life Histories. University of British Columbia Press, Vancouver, BC, Canada. 
Gunnarsson G, Karlsbakk E, Blindheim S, Plarre H, Imsland A, Handeland S, Sveierf H, Nylund A (2017) Temporal changes in infections with some pathogens associated with gill disease in farmed Atlantic salmon (Salmo salar). Aquaculture, 468:126-134.

Haldane JBS (1937) The effect of variation of fitness. The American Naturalist, 71:337-349.

Hallett SL, Bartholomew JL (2006) Application of a real-time PCR assay to detect and quantify the myxozoan parasite Ceratomyxa shasta in river water samples. Diseases of Aquatic Organisms, 71:109-118.

Hanson KC, Cooke SJ, Hinch SG, Crossin GT, Patterson DA, English KK, Donaldson MR, Shrimpton JM, Van der Kraak G, Farrell AP (2008) Individual variation in migration speed of upriver-migrating sockeye salmon in the Fraser River in relation to their physiological and energetic status at marine approach. Physiological and Biochemical Zoology, 81:255-268.

Harrower WL, Bett NN, Hinch SG (2019) BRGMON-14: Effectiveness of Cayoosh flow dilution, dam operation, and fishway passage on delay and survival of upstream migration of salmon in the Seton-Anderson watershed. Prepared for St'át'imc EcoResources Ltd. and BC Hydro. The University of British Columbia, Vancouver, BC. 154 pp. - 1 App.

Healy TM, Tymchuk WE, Osborne EJ, Schulte PM (2010) Heat shock response of killifish (Fundulus heteroclitus): candidate gene and heterologous microarray approaches. Physiological Genomics, 41:171-184.

Hebblewhite M, Merrill EH (2009) Trade-offs between predation risk and forage differ between migrant strategies in a migratory ungulate. Ecology, 90:3445-3454.

Hesami S, Metcalf DS, Lumsden JS, Macinnes JI (2011) Identification of cold-temperatureregulated genes in Flavobacterium psychrophilum. Applied and Environmental Microbiology,77:1593-1600.

Hinch SG, Rand PS (1998) Swim speeds and energy use of upriver-migrating sockeye salmon (Oncorhynchus nerka): role of local environment and fish characteristics. Canadian Journal of Fisheries and Aquatic Sciences, 55:1821-1831. 
Hinch SG, Cooke SJ, Healey MC, Farrell AP (2006) Behavioural Physiology of Fish Migrations: salmon as a model approach. In: K Sloman, S Balshine, R Wilson, eds. Behaviour and Physiology of Fish. Academic Press, New York, USA, pp. 239-295.

Hinch SG, Cooke SJ, Farrell AP, Miller KM, Lapointe MF, Patterson DA (2012) Dead fish swimming: a review of research on the early migration and high premature mortality in adult Fraser River sockeye salmon Oncorhynchus nerka. Journal of Fish Biology, 81:576-599.

Hiney M, Olivier G (1999) Furunculosis (Aeromonas salmonicida). In: PTK Woo, DW Bruno, eds. Fish Diseases and Disorders, Volume 3: Viral, bacterial and fungal infections. CAB International, pp. 427-454.

Holland MCH, Lambris JD (2002) The complement system in teleosts. Fish and Shellfish Immunology, 12:399-420.

Hoskins G, Bell GR, Evelyn T (1976) The occurence, distribution and significance of infectious diseases and of neoplasms observed in fish in the Pacific region up to the end of 1974. Technical report, Fisheries and Marine Service Canada, Pacific Biological Station.

Houde ALS, Akbarzadeh A, Günther OP, Li S, Patterson DA, Farrell AP, Hinch SG, Miller KM (2019) Salmonid gene expression biomarkers indicative of physiological responses to changes in salinity and temperature, but not dissolved oxygen. Journal of Experimental Biology, 222: jeb198036. doi:10.1242/jeb.198036.

Houde ALS, Günther AP, Strohm J, Ming TJ, Li S, Kaukinen KH, Patterson DA, Farrell AP, Hinch SG, Miller KM (2020) Discovery and validation of candidate smoltification gene expression biomarkers across multiple species and ecotypes of Pacific salmonids, Conservation Physiology, 7: coz051. doi:10.1093/conphys/coz051.

Hruska KA, Hinch SG, Healey MC, Patterson DA, Larsson S, Farrell AP (2010) Influences of sex and activity level on physiological changes in individual adult sockeye salmon during rapid senescence. Physiological and Biochemical Zoology, 83:663-676.

Irvine JR, Fukuwaka M (2011) Pacific salmon abundance trends and climate change. ICES Journal of Marine Science, 68:1122-1130. 
Jeffries KM, Hinch SG, Sierocinski T, Clark TD, Eliason EJ, Donaldson MR, Li S, Pavlidis P, Miller KM (2012) Consequences of high temperatures and premature mortality on the transcriptome and blood physiology of wild adult sockeye salmon (Oncorhynchus nerka). Ecology and Evolution, 2:1747-1764.

Jeffries KM, Hinch SG, Sierocinski T, Pavlidis P, Miller KM (2014) Transcriptomic responses to high water temperature in two species of Pacific salmon. Evolutionary Applications, 7:286-300.

Jensen LB, Wahli T, Mcgurk C, Eriksen TB, Obach A, Waagbø R, Handler A, Tafalla C (2015) Effect of temperature and diet on wound healing in Atlantic salmon (Salmo salar L.). Fish physiology and biochemistry, 41:1527-1543.

Johnson JE, Patterson DA, Martins EG, Cooke SJ, Hinch SG (2012) Quantitative methods for analysing cumulative effects on fish migration success: a review. Journal of Fish Biology, 81:600-631.

Jones SRM, Prosperi-Porta G, Dawe SC, Barnes DP (2003) Distribution, prevalence and severity of Parvicapsula minibicornis infections among anadromous salmonids in the Fraser River, British Columbia, Canada. Diseases of Aquatic Organisms, 54:49-54.

Jones SRM, Prosperi-Porta G, Kim E (2012) The diversity of microsporidia in parasitic copepods (Caligidae: Siphonostomatoida) in the Northeast Pacific Ocean with description of Facilispora margolising, n. g., n. sp. and a new Family Facilisporidae n. fam. Journal of Eukaryotic Microbiology, 59:206-217.

Jonstrup SP, Kahns S, Skall HF, Boutrup TS, Olesen NJ (2013) Development and validation of a novel Taqman-based real-time RT-PCR assay suitable for demonstrating freedom from viral haemorrhagic septicaemia virus. Journal of Fish Diseases, 36:9-23.

Jørgensen A, Nylund A, Nikolaisen V, Alexandersen S, Karlsbakk E (2011) Real-time PCR detection of Parvicapsula pseudobranchicola (Myxozoa: Myxosporea) in wild salmonids in Norway. Journal of Fish Diseases, 34:365-371. 
Kacem A, Meunier F, Bagliniere J (1998) A quantitative study of morphological and histological changes in the skeleton of Salmo salar during its anadromous migration. Journal of Fish Biology, 53:1096-1109.

Kanigan AM, Hinch SG, Bass AL, Harrower WL (2019) Gillnet fishing effort predicts physical injuries on sockeye salmon captured near spawning grounds. North American Journal of Fisheries Management, 39:441-451.

Kassahn KS, Crozier RH, Portner HO, Caley MJ (2009) Animal performance and stress: responses and tolerance limits at different levels of biological organisation. Biological Reviews, 84:277-292.

Keefer ML, Peery CA, Jepson MA, Tolotti KR, Bjornn TC, Stuehrenberg LC (2004) Stockspecific migration timing of adult spring-summer Chinook salmon in the Columbia River basin. North American Journal of Fisheries Management, 24:1145-1162.

Keefer ML, Peery C, Heinrich MJ (2008) Temperature-mediated en route migration mortality and travel rates of endangered Snake River sockeye salmon. Ecology of Freshwater Fish, $17: 136-145$.

Keefer ML, Caudill CC (2015) Estimating thermal exposure of adult summer steelhead and fall Chinook salmon migrating in a warm impounded river. Ecology of Freshwater Fish, 25:599-611.

Keeling SE, Johnston C, Wallis R, Brosnahan CL, Gudkovs N, McDonald WL (2012) Development and validation of real-time PCR for the detection of Yersinia ruckeri. Journal of Fish Diseases, 35:119-125.

Keeling SE, Brosnahan CL, Johnston C, Wallis R, Gudkovs N, McDonald WL (2013)

Development and validation of a real-time PCR assay for the detection of Aeromonas salmonicida. Journal of Fish Diseases, 36:495-503.

Kent ML (2011) Infectious Diseases and Potential Impacts on Survival of Fraser River Sockeye Salmon. Cohen Commission Technical Report 1-58pp. Vancouver, BC. 
Kiessling A, Lindahl-kiessling K, Kiessling K (2004) Energy utilization and metabolism in spawning migrating Early Stuart sockeye salmon (Oncorhynchus nerka): the migratory paradox. Canadian Journal of Fisheries and Aquatic Sciences, 61:452-465.

Kojima T, Ishii M, Kobayashi M, Shimizu M (2004) Blood parameters and electrocardiogram in squeezed fish simulating the effect of net damage and recovery. Fisheries Science, 70:860-866.

Korkmaz S, Goksuluk D, Zararsiz G (2014) MVN: An R Package for Assessing Multivariate Normality. R Journal, 6:151-162.

Korsnes K, Devold M, Nerland AH, Nylund A (2005) Viral encephalopathy and retinopathy (VER) in Atlantic salmon Salmo salar after intraperitoneal challenge with a nodavirus from Atlantic halibut Hippoglossus hippoglossus. Diseases of Aquatic Organisms, 68:715.

Lee CG, Farrell AP, Lotto A, MacNutt MJ, Hinch SG, Healy MC (2003) The effect of temperature on swimming performance and oxygen consumption in adult sockeye (Oncorhynchus nerka) and coho (O. kisutch) salmon stocks. Journal of Experimental Biology, 206:3239-3251.

Lenth R (2018) emmeans: Estimated Marginal Means, aka Least-Squares Means. R package version 1.1.3. https://CRAN.R-project.org/package=emmeans. 2018.

Lewis JM, Hori TS, Rise ML, Walsh PJ, Currie S (2010) Transcriptome responses to heat stress in the nucleated red blood cells of the rainbow trout (Oncorhynchus mykiss). Physiological Genomics, 42:361-373.

Lichatowich J (1999) Salmon Without Rivers: A History of the Pacific Salmon Crisis. Island Press, Washington D.C.

Lichatowich J (2013) Salmon, People, and Place: A Biologist's Search for Salmon Recovery. Oregon State University Press.

Lloyd SJ, LaPatra SE, Snekvik KR, Cain KD, Call DR (2011) Quantitative PCR demonstrates a positive correlation between a Rickettsia-like organism and severity of strawberry disease 
lesions in rainbow trout, Oncorhynchus mykiss (Walbaum). Journal of Fish Diseases, 34:701-709.

Macdonald JS, Foreman MGG, Farrell T, Williams IV, Grout J, Cass A, Woodey JC, Enzenhofer H, Clarke WC, Houtman R, Donaldson EM, Barnes D (2000) The influence of extreme water temperatures on migrating Fraser River sockeye salmon (Oncorhynchus nerka) during the 1998 spawning season. Canadian Technical Report of Fisheries and Aquatic Sciences, 2326, 117 pp.

Magnadottir B, Jonsdottir H, Helgason S, Bjornsson B, Jorgensen TO (1999) Pilstrom L. Humoral immune parameters in Atlantic cod (Gadus morhua L.) I. The effects of environmental temperature. Comparative Biochemistry and Physiology B - Biochemistry and Molecular Biology, 122:173-180.

Mäkinen TS, Niemelä E, Moen K, Lindström R (2000) Behaviour of gill-net and rod-captured Atlantic salmon (Salmo salar L.) during upstream migration and following radio tagging. Fisheries Research, 45:117-127.

Marcogliese DJ (2008) The impact of climate change on the parasites and infectious diseases of aquatic animals. Revue Scientifique et Technique (International Office of Epizootics), 27:467-484.

Martins EG, Hinch SG, Patterson DA, Hague MJ, Cooke SJ, Miller KM, Lapointe MF, English KK, Farrell AP (2011) Effects of river temperature and climate warming on stockspecific survival of adult migrating Fraser River sockeye salmon (Oncorhynchus nerka). Global Change Biology, 17:99-114.

Martins EG, Hinch SG, Patterson DA, Hague MJ, Cooke SJ, Miller KM, Robichaud D, English KK, Farrell AP (2012) High river temperature reduces survival of sockeye salmon (Oncorhynchus nerka) approaching spawning grounds and exacerbates female mortality. Canadian Journal of Fisheries and Aquatic Sciences, 69:330-342.

Mateus AP, Anjos L, Cardoso JR, Power DM (2017) Chronic stress impairs the local immune response during cutaneous repair in gilthead sea bream (Sparus aurata, L.). Molecular Immunology, 87:267-283. 
Mathes MT, Hinch SG, Cooke SJ, Crossin GT, Patterson DA, Lotto AG, Farrell AP (2009) Effect of water temperature, timing, physiological condition, and lake thermal refugia on migrating adult Weaver Creek sockeye salmon (Oncorhynchus nerka). Canadian Journal of Fisheries and Aquatic Sciences, 67:70-84.

Miller KM, Schulze AD, Ginther N, Li SR, Patterson DA, Farrell AP, Hinch SG (2009) Salmon spawning migration: Metabolic shifts and environmental triggers. Comparative Biochemistry and Physiology D - Genomics \& Proteomics, 4:75-89.

Miller KM, Li SR, Kaukinen KH, Ginther N, Hammill E, Curtis JMR, Patterson DA, Sierocinski T, Donnison L, Pavlidis P, Hinch SG, Hruska KA, Cooke SJ, English KK, Farrell AP (2011) Genomic Signatures Predict Migration and Spawning Failure in Wild Canadian Salmon. Science, 331:214-217.

Miller KM, Teffer AK, Tucker S, Li S, Schulze AD, Trudel M, Juanes F, Tabata A, Kaukinen KH, Ginther NG, Ming TJ, Cooke SJ, Hipfner JM, Patterson DA, Hinch SG (2014) Infectious disease, shifting climates, and opportunistic predators: cumulative factors potentially impacting wild salmon declines. Evolutionary Applications, 7:812-855.

Miller KM, Gardner IA, Vanderstichel R, Burnley T, Angela D, Li S, Tabata A, Kaukinen KH, Ming TJ, Ginther NG (2016) Report on the Performance Evaluation of the Fluidigm BioMark Platform for High-Throughput Microbe Monitoring in Salmon. DFO Canadian Science Advisory Secretariat Research Document 2016/038. Ottawa, ON, Canada.

Miller KM, Gunther OP, Li SR, Kaukinen KH, Ming TJ (2017) Molecular indices of viral disease development in wild migrating salmon. Conservation Physiology, 5: cox036. doi:10.1093/conphys/cox036.

Mitchell SO, Steinum TM, Toenshoff ER, Kvellestad A, Falk K, Horn M, Colquhoun DJ (2013) Candidatus Branchiomonas cysticola is a common agent of epitheliocysts in seawaterfarmed Atlantic salmon Salmo salar in Norway and Ireland. Diseases of Aquatic Organisms, 103:35-43. 
Minke-Martin V, Hinch SG, Braun DC, Burnett NJ, Casselman MT, Eliason EJ, Middleton CT (2018) Physiological condition and migratory experience affect fitness-related outcomes in adult female sockeye salmon. Ecology of Freshwater Fish, 27:296-309.

Mokili JL, Rohwer F, Dutilh BE (2012) Metagenomics and future perspectives in virus discovery. Current Opinion in Virology, 2:63-77.

Mordecai GJ, Miller KM, Di Cicco E, Schulze AD, Kaukinen KH, Ming TJ, Li S, Tabata A, Teffer AK, Patterson DA, Ferguson HW, Suttle CA (2019) Endangered wild salmon infected by newly discovered viruses. eLife, 8: e47615. doi:10.7554/eLife.47615.

Mordecai GJ, Di Cicco E, Günther OP, Schulze AD, Kaukinen KH, Li S, Tabata A, Ming TJ, Ferguson HW, Suttle CA, Miller KM (2020) Emerging viruses in British Columbia salmon discovered via a viral immune response biomarker panel and metatranscriptomic sequencing. BioRxiv, 948026. doi: 10.1101/2020.02.13.948026.

Muoneke MI, Childress WM (1994) Hooking mortality: a review for recreational fisheries. Reviews in Fisheries Science, 2:123-156.

Naiman RJ, Bilby RE, Schindler DE, Helfield JM (2002) Pacific salmon, nutrients, and the dynamics of freshwater and riparian ecosystems. Ecosystems, 5:399-417.

Neilson JD, Waiwood KG, Smith SJ (1989) Survival of Atlantic halibut (Hippoglossus hippoglossus) caught by longline and otter trawl gear. Canadian Journal of Fisheries and Aquatic Sciences, 46:887-897.

Nekouei O, Vanderstichel R, Kaukinen KH, Thakur K, Ming T, Patterson DA, Trudel M, Neville C, Miller KM (2019) Comparison of infectious agents detected from hatchery and wild juvenile Coho salmon in British Columbia, 2008-2018. Plos One, 14: 0221956. doi: 10.1371/journal.pone.0221956.

Newell JC, Quinn TP (2005) Behavioral thermoregulation by maturing adult sockeye salmon (Oncorhynchus nerka) in a stratified lake prior to spawning. Canadian Journal of Zoology, 83:1232-1239.

Noe JG, Dickerson HW (1995) Sustained growth of Ichthyophthirius multifiliis at low temperature in the laboratory. The Journal of Parasitology, 81:1022-1024. 
Nguyen VM, Martins EG, Robichaud D, Raby GD, Donaldson MR, Lotto AG, Willmore WG, Patterson DA, Farrell AP, Hinch SG, Cooke SJ (2014) Disentangling the roles of air exposure, gill net injury, and facilitated recovery on the postcapture and release mortality and behavior of adult migratory sockeye salmon (Oncorhynchus nerka) in Freshwater. Physiological and Biochemical Zoology, 87:125-135.

Nylund A, Watanabe K, Nylund S, Karlsen M, Sæther PA, Arnesen CE, Karlsbakk E (2008) Morphogenesis of salmonid gill poxvirus associated with proliferative gill disease in farmed Atlantic salmon (Salmo salar) in Norway. Archives of Virology, 153:1299-1309.

Nylund S, Nylund A, Watanabe K, Arnesen CE, Karlsbakk E (2010) Paranucleospora theridion (Microsporidia, Enterocytozoonidae) with a life cycle in the salmon louse (Lepeophtheirus salmonis, Copepoda) and Atlantic salmon (Salmo salar). Journal of Eukaryotic Microbiology, 57:95-114.

Nylund S, Andersen L, Sævareid I, Plarre H, Watanabe K, Arnesen CE, Karlsbakk E, Nylund A (2011) Diseases of farmed Atlantic salmon Salmo salar associated with infections by the microsporidian Paranucleospora theridion. Diseases of aquatic organisms, 94:41-57.

Oksanen JF, Blanchet G, Friendly M, Kindt R, Legendre P, McGlinn D, Minchin PR, O'Hara RB, Simpson GL, Solymos P, Henry M, Stevens H, Szoecs E, Wagner H (2019) vegan: community ecology package, $\mathrm{R}$ package version $2.4-0$.

Olsen RE, Oppedal F, Tenningen M, Vold A (2012) Physiological response and mortality caused by scale loss in Atlantic herring. Fisheries Research, 129:21-27.

Olson R, Dungan C, Holt R (1991) Water-borne transmission of Dermocystidium salmonis in the laboratory. Diseases of Aquatic Organisms, 12:41-48.

Olson R, Holt R (1995) The gill pathogen Dermocystidium salmonis in Oregon salmonids. Journal of Aquatic Animal Health, 7:111-117.

Orr HA (2009) Fitness and its role in evolutionary genetics. Nature Reviews Genetics, 10:531539.

Pankhurst NW, King HR (2010) Temperature and salmonid reproduction: implications for aquaculture. Journal of Fish Biology, 76:69-85. 
Patterson DA, Macdonald JS, Skibo KM, Barnes DP, Guthrie I, Hills J (2007) Reconstructing the summer thermal history for the lower Fraser River, 1941 to 2006, and implications for adult sockeye salmon (Oncorhynchus nerka) spawning migration. Canadian Technical Report of Fisheries and Aquatic Sciences 2724. Burnaby, BC, Canada.

Patterson DA, Robinson KA, Lennox RJ, Nettles TL, Donaldson LA, Eliason EJ, Raby GD, Chapman JM, Cook KV., Donaldson MR, Bass AL, Drenner SM, Reid AJ, Cooke SJ, Hinch SG (2017a) Review and Evaluation of Fishing-Related Incidental Mortality for Pacific Salmon. DFO Canadian Science Advisory Secretariat Research Document 2017/010. Ix + 155p. Ottawa, ON, Canada.

Patterson DA, Robinson KA, Raby GD, Bass AL, Houtman R, Hinch SG, Cooke SJ (2017b) Guidance to Derive and Update Fishing-Related Incidental Mortality Rates for Pacific Salmon. DFO Can. Sci. Advis. Sec. Res. Doc. 2017/011. vii + 56 p.

Pauley GB (1967) Prespawning adult salmon mortality associated with a fungus of the genus Dermocystidium. Journal of the Fisheries Board of Canada, 24:843-848.

Paull SH, Johnson PTJ (2014) Experimental warming drives a seasonal shift in the timing of host-parasite dynamics with consequences for disease risk. Ecology Letters, 17:445-453.

Pauly D, Zeller D (2016) Catch reconstructions reveal that global marine fisheries catches are higher than reported and declining. Nature communications, 7: ncomms10244. doi: 10.1038/ncomms 10244 .

Peterman RM, Dorner B (2012) A widespread decrease in productivity of sockeye salmon (Oncorhynchus nerka) populations in western North America. Canadian Journal of Fisheries and Aquatic Sciences, 69:1255-1260.

Petersen JH, Kitchell JF (2001) Climate regimes and water temperature changes in the Columbia River: bioenergetic implications for predators of juvenile salmon. Canadian Journal of Fisheries and Aquatic Sciences, 58:1831-1841.

Pickering A, Pottinger T (1989) Stress responses and disease resistance in salmonid fish: effects of chronic elevation of plasma cortisol. Fish Physiology and Biochemistry, 7:253-258. 
Pike GC (1962) Migration and Feeding of the Gray Whale (Eschrichtius gibbosus). Journal of the Fisheries Research Board of Canada, 19:815-838.

Portner HO (2002) Climate variations and the physiological basis of temperature dependent biogeography: systemic to molecular hierarchy of thermal tolerance in animals. Comparative Biochemistry and Physiology A - Molecular and Integrative Physiology, 132:739-761.

Powell M, Overturf K, Hogge C, Johnson K (2005) Detection of Renibacterium salmoninarum in Chinook salmon, Oncorhynchus tshawytscha (Walbaum), using quantitative PCR. Journal of Fish Diseases, 28:615-622.

Prosser CL (1955) Physiological variation in animals. Biological Reviews, 30:229-261.

Prystay TS, Eliason EJ, Lawrence MJ, Dick M, Brownscombe JW, Patterson DA, Crossin GT, Hinch SG, Cooke SJ (2017) The influence of water temperature on sockeye salmon heart rate recovery following simulated fisheries interactions. Conservation Physiology, 5: cox050. doi:10.1093/conphys/cox050.

Purcell MK, Thompson RL, Garver KA, Hawley LM, Batts WN, Sprague L, Sampson C, Winton JR (2013) Universal reverse-transcriptase real-time PCR for infectious hematopoietic necrosis virus (IHNV). Diseases of Aquatic Organisms, 106:103-115.

Purcell MK, Pearman-Gillman S, Thompson RL, Gregg JL, Hart LM, Winton JR, Emmenegger EJ, Hershberger PK (2016) Identification of the major capsid protein of erythrocytic necrosis virus (ENV) and development of quantitative real-time PCR assays for quantification of ENV DNA. Journal of Veterinary Diagnostic Investigation, 28:382-391.

Quinn TP, Eggers DM, Clark JH, Rich HB (2007) Density, climate, and the processes of prespawning mortality and egg retention in Pacific salmon (Oncorhynchus spp.). Canadian Journal of Fisheries and Aquatic Sciences, 64:574-582.

Quinn NL, McGowan CR, Cooper GA, Koop BF, Davidson WS (2011) Identification of genes associated with heat tolerance in Arctic charr exposed to acute thermal stress. Physiological Genomics, 43:685-696. 
R Core Team (2015) R: A language and environment for statistical computing. R Foundation for Statistical Computing, Vienna, Austria.

Raby GD, Colotelo AH, Blouin-Demers G, Cooke SJ (2011) Freshwater commercial bycatch: an understated conservation problem. BioScience, 61:271-280.

Raby GD, Donaldson MR, Hinch SG, Patterson DA, Lotto AG, Robichaud D, English KK, Willmore WG, Farrell AP, Davis MW, Cooke SJ (2012) Validation of reflex indicators for measuring vitality and predicting the delayed mortality of wild coho salmon bycatch released from fishing gears. Journal of Applied Ecology, 49:90-98.

Raby GD, Cooke SJ, Cook KV, McConnachie SH, Donaldson MR, Hinch SG, Whitney CK, Drenner SM, Patterson DA, Clark TC, Farrell AP (2013) Resilience of pink salmon and chum salmon to simulated fisheries capture stress incurred upon arrival at spawning grounds. Transactions of the American Fisheries Society, 142:524-539.

Raby GD, Donaldson MR, Nguyen VM, Taylor MK, Sopinka NM, Cook KV, Patterson DA, Robichaud D, Hinch SG, Cooke SJ (2014a). Bycatch mortality of endangered coho salmon: impacts, solutions, and aboriginal perspectives. Ecological Applications, 24:1803-1819.

Raby GD, Packer JR, Danylchuk AJ, Cooke SJ (2014b) The understudied and underappreciated role of predation in the mortality of fish released from fishing gears. Fish and Fisheries, $15: 489-505$.

Raby GD, Donaldson MR, Hinch SG, Clark TD, Eliason EJ, Jeffries KM, Cook KV, Teffer AK, Bass AL, Miller KM, Patterson DA, Farrell AP, Cooke SJ (2015) Fishing for effective conservation: context and biotic variation are keys to understanding the survival of Pacific salmon after catch-and-release. Integrative and Comparative Biology, 55:554576.

Rand PS, Hinch SG (1998) Swim speeds and energy use of upriver-migrating sockeye salmon (Oncorhynchus nerka): simulating metabolic power and assessing risk of energy depletion. Canadian Journal of Fisheries and Aquatic Sciences, 55:1832-1841. 
Rand PS, Hinch SG, Morrison J, Foreman MGG, MacNutt MJ, Macdonald JS, Healey MC, Farrell AP, Higgs DA (2006) Effects of river discharge, temperature, and future climates on energetics and mortality of adult migrating Fraser River sockeye salmon. Transactions of the American Fisheries Society, 135:655-667.

Ray RA, Holt RA, Bartholomew JL (2012) Relationship between temperature and Ceratomyxa shasta-induced mortality in Klamath River salmonids. The Journal of Parasitology, 98:520-526.

Reid S, Bernier N, Perry S (1998) The adrenergic stress response in fish: control of catecholamine storage and release. Comparative Biochemistry and Physiology, 120:1-27.

Richard A, Bernatchez L, Valiquette E, Dionne M, Jonsson B (2014) Telemetry reveals how catch and release affects prespawning migration in Atlantic salmon (Salmo salar). Canadian Journal of Fisheries and Aquatic Sciences, 71:1730-1739.

Ricker WE (1976) Review of the rate of growth and mortality of Pacific salmon in salt water, and non-catch mortality caused by fishing. Journal of the Fisheries Research Board of Canada, 33:1483-1524.

Roberts RJ (2012) Fish pathology. John Wiley \& Sons, West Sussex, UK, fourth edition.

Robertson OH, Wexler BC (1960) Histological changes in the organs and tissues of migrating and spawning Pacific salmon (genus Oncorhynchus). Endocrinology, 66: 222-239.

Robinson KA, Hinch SG, Raby GD, Donaldson MR, Robichaud D, Patterson DA, Cooke SJ (2015) Influence of post-capture ventilation assistance on migration success of adult sockeye salmon following capture and release. Transactions of the American Fisheries Society, 144:693-704.

Roscoe DW, Hinch SG, Cooke SJ, Patterson DA (2010) Behaviour and thermal experience of adult sockeye salmon migrating through stratified lakes near spawning grounds: the roles of reproductive and energetic states. Ecology of Freshwater Fish, 19:51-62.

Roscoe DW, Hinch SG, Cooke SJ, Patterson DA (2011) Fishway passage and post-passage mortality of up-river migrating sockeye salmon in the Seton River, British Columbia. River Research and Applications, 27:693-705. 
Ryer CH (2002) Trawl stress and escapee vulnerability to predation in juvenile walleye pollock:

Is there an unobserved bycatch of behaviorally impaired escapees? Marine Ecology Progress Series, 232:269-279.

Riddell B, Bradford MJ, Carmichael R, Hankin D, Peterman R, Wertheimer A (2013) Assessment for the status and factors for decline of southern B.C. Chinook salmon: Independent panel's report. Prepared with the assistance of D.R. Marmorek and A.W. Hall, ESSA Technologies Ltd., Vancouver, B.C. for Fisheries and Oceans Canada (Vancouver, BC) and Fraser River Aboriginal Fisheries Secretariat (Merritt, BC). xxix + 165 pp. + Appendices.

Roberts RJ (2012) Fish pathology. John Wiley \& Sons, West Sussex, UK, fourth edition.

Robertson L, Thomas P, Arnold C, Trant J (1987) Plasma cortisol and secondary stress responses of red drum to handling, transport, rearing density, and a disease outbreak. The Progressive Fish-Culturist, 49:1-12.

Schouten J, Clister T, Bruce A, Epp L, Zwollo R (2013) Sockeye salmon retain immunoglobulinsecreting plasma cells throughout their spawning journey and post-spawning. Immunology, 40:202-209.

Shrimpton JM, Patterson DA, Richards JG, Cooke SJ, Schulte PM, Hinch SG, Farrell AP (2005) Ionoregulatory changes in different populations of maturing sockeye salmon Oncorhynchus nerka during ocean and river migration. The Journal of Experimental Biology, 208:4069-4078.

Smith NC, Rise ML, Christian SL (2019) A comparison of the innate and adaptive immune systems in cartilaginous fish, ray-finned fish, and lobe-finned fish. Frontiers in Immunology, 10: 2292. doi:10.3389/fimmu.2019.02292.

Southwood TRE (1962) Migration of terrestrial arthropods in relation to habitat. Biological Reviews, 37:171-214.

Southwood TRE (1977) Habitat, the templet for ecological strategies? Journal of Animal Ecology, 46:337-365. 
Speare DJ, Lovy J (2012) Loma salmonae and related species. In: PTK Woo and K Buchmann, eds. Fish Parasites: Pathobiology and Protection. CABI, Wallingford, pp 109.

Spicer J, Gaston K (2009) Physiological diversity: ecological implications. John Wiley \& Sons. New York, NY.

St-Hilaire S, Boichuk M, Barnes D, Higgins M, Devlin R, Withler R, Khattra J, Jones S, Kieser D (2002) Epizootiology of Parvicapsula minibicornis in Fraser River sockeye salmon, Oncorhynchus nerka (Walbaum). Journal of Fish Diseases, 25:107-120.

Starliper CE (2011) Bacterial coldwater disease of fishes caused by Flavobacterium psychrophilum. Journal of Advanced Research, 2:97-108.

Stocking RW, Holt RA, Foott JS, Bartholomew JL (2006) Spatial and temporal occurrence of the salmonid parasite Ceratomyxa shasta in the Oregon-California Klamath River basin. Journal of Aquatic Animal Health, 18:194-202

Suski C, Killen S, Kieffer J, Tufts B (2006) The influence of environmental temperature and oxygen concentration on the recovery of largemouth bass from exercise: implications for live-release angling tournaments. Journal of Fish Biology, 68:120-136.

Svendsen YS, Bøgwald J (1997) Influence of artificial wound and non-intact mucus layer on mortality of Atlantic salmon (Salmo salar L) following a bath challenge with Vibrio anguillarum and Aeromonas salmonicida. Fish \& Shellfish Immunology, 7:317-325.

Taguchi Y, Oono Y (2005) Relational patterns of gene expression via non-metric multidimensional scaling analysis. Bioinformatics, 21:730-740.

Taksdal T, Ramstad A, Stangeland K, Dannevig B (1998) Induction of infectious pancreatic necrosis (IPN) in covertly infected Atlantic salmon, Salmo salar L., post-smolts by stress exposure, by injection of IPN virus (IPNV) and by cohabitation. Journal of Fish Diseases, 21:193-204.

Teffer AK (2018) Impacts of cumulative thermal and fishery stressors and infection development on the health and survival of adult Pacific salmon during freshwater residence. Ph.D. Thesis, University of Victoria, Victoria, British Columbia. 
Teffer AK, Hinch SG, Miller KM, Patterson DA, Farrell AP, Cooke SJ, Bass AL, Szekeres P, Juanes F (2017) Capture severity, infectious disease processes and sex influence postrelease mortality of sockeye salmon bycatch. Conservation Physiology, 5: cox017. doi: 10.1093/conphys/cox017.

Teffer AK, Bass AL, Miller KM, Patterson DA, Juanes F, Hinch SG (2018) Infections, fisheries capture, temperature, and host responses: multistressor influences on survival and behaviour of adult Chinook salmon. Canadian Journal of Fisheries and Aquatic Sciences, 75:2069-2083.

Teffer AK, Hinch SG, Miller KM, Jeffries KM, Patterson DA, Cooke SJ, Farrell AP, Kaukinen, KH, Li S, Juanes F (2019) Cumulative effects of thermal and fisheries stressors reveal sex-specific effects on infection development and early mortality of adult coho salmon (Oncorhynchus kisutch). Physiological and Biochemical Zoology, 92:505-529.

Thakur KK, Vanderstichel R, Kaukinen K, Nekouei O, Laurin E, Miller KM (2019) Infectious agent detections in archived Sockeye salmon (Oncorhynchus nerka) samples from British Columbia, Canada (1985-94). Journal of Fish Diseases, 42:533-547.

Thompson R, Hunter C (1971) Viability of adult sockeye salmon that disentangle from gillnets. International North Pacific Fisheries Commission Annual Report, pp. 107-109.

Thompson R, Hunter C, Patten B (1971) Studies of live and dead salmon that unmesh from gillnets. International North Pacific Fisheries Commission Annual Report 1969, pp. 108112.

Tort L (2011) Stress and immune modulation in fish. Developmental and Comparative Immunology 35:1366-1375.

Traxler GS, Richard J, McDonald TE (1998) Ichthyophthirius multifiliis (Ich) epizootics in spawning sockeye salmon in British Columbia, Canada. Journal of Aquatic Animal Health, 10:143-151.

Uhlmann SS, Broadhurst MK (2015) Mitigating unaccounted fishing mortality from gillnets and traps. Fish and Fisheries, 16:183-229. 
Urquhart FA, Urquhart NR (1978) Autumnal migration routes of the eastern population of the monarch butterfly (Danaus p. plexippus L.; Danaidae; Lepidoptera) in North America to the overwintering site in the Neovolcanic Plateau of Mexico. Canadian Journal of Zoology, 56:1759-1764.

Vander Haegen GE, Ashbrook CE, Yi KW, Dixon JF (2004) Survival of spring Chinook salmon captured and released in a selective commercial fishery using gill nets and tangle nets. Fisheries Research, 68:123-133.

Wagner GN, Hinch SG, Kuchel LJ, Lotto AG, Jones SRM, Patterson DA, Macdonald JS, Kraak G Van Der, Shrimpton M, English KK, Larsson S, Cooke SJ, Healey MC, Farrell AP (2005) Metabolic rates and swimming performance of adult Fraser River sockeye salmon (Oncorhynchus nerka) after a controlled infection with Parvicapsula minibicornis. Canadian Journal of Fisheries and Aquatic Sciences, 62:2124-2133.

Wedemeyer GA, Barton BA, McLeay DJ (1990) Stress and acclimation. In: CB Schreck, and PB Moyle, eds. Methods for fish biology. American Fisheries Society, Bethesda, Maryland, pp. $451-489$.

Wendelaar Bonga SE (1997) The Stress Response in Fish. Physiological Reviews, 77:591-625.

West CJ, Mason JC (1987) Evaluation of sockeye salmon Oncorhynchus nerka production from the Babine Lake Development Project. In: HD Smith HD, and DS Wilcove eds. Animal Migration: An Endangered Phenomenon? (2008) Issues in Science and Technology, 24:71-78.

White VC, Morado JF, Crosson LM, Vadopalas B, Friedman CS (2013) Development and validation of a quantitative PCR assay for Ichthyophonus spp. Diseases of Aquatic Organism, 104:69-81.

Wiik-Nielsen CR, Ski PMR, Aunsmo A, Løvoll M (2012) Prevalence of viral RNA from piscine reovirus and piscine myocarditis virus in Atlantic salmon, Salmo salar L., broodfish and progeny. Journal of Fish Diseases, 35:169-171.

Wilcove DS, Wikelski M (2008) Going, Going, Gone: Is Animal Migration Disappearing. PLoS Biol., 6: e188. doi:10.1371/journal.pbio.0060188. 
Woo PT, Leatherland JF, Bruno DW (2011) Fish diseases and disorders, vol. 3. CABI, Wallingford, Oxfordshire, UK.

Zampatti BP, Bice CM, Jennings PR (2010) Temporal variability in fish assemblage structure and recruitment in a freshwater-deprived estuary: The Coorong, Australia. Marine and Freshwater Research, 61:1298-1312.

Zeller D, Cashion T, Palomares M, Pauly D (2018) Global marine fisheries discards: a synthesis of reconstructed data. Fish and Fisheries, 19:30-39.

Zwollo P (2017) The humoral immune system of anadromous fish. Developmental and Comparative Immunology, 80: 008. doi:10.1016/j.dci.2016.12.008. 